\section{Pacific Northwest}

National Laboratory

Operated by Battelle for the

U.S. Department of Energy

\title{
Investigation of $\mathrm{T}_{\mathrm{c}}$ Migration Mechanism During Bulk Vitrification Process Using Re Surrogate
}

\author{
D-S. Kim \\ L. M. Bagaasen \\ J. V. Crum \\ A. Fluegel \\ A. Gallegos \\ B. Martinez \\ J. Matyáš
}
P. A. Meyer
D. R. Paulsen
B. J. Riley
M. J. Schweiger
C. W. Stewart
R. G. Swoboda
J. D. Yeager

December 2006

Prepared for the U.S. Department of Energy under Contract DE-AC05-76RL01830 


\title{
DISCLAIMER
}

This report was prepared as an account of work sponsored by an agency of the United States Government. Neither the United States Government nor any agency thereof, nor Battelle Memorial Institute, nor any of their employees, makes any warranty, express or implied, or assumes any legal liability or responsibility for the accuracy, completeness, or usefulness of any information, apparatus, product, or process disclosed, or represents that its use would not infringe privately owned rights. Reference herein to any specific commercial product, process, or service by trade name, trademark, manufacturer, or otherwise does not necessarily constitute or imply its endorsement, recommendation, or favoring by the United States Government or any agency thereof, or Battelle Memorial Institute. The views and opinions of authors expressed herein do not necessarily state or reflect those of the United States Government or any agency thereof.

\author{
PACIFIC NORTHWEST NATIONAL LABORATORY \\ operated by \\ BATTELLE \\ for the \\ UNITED STATES DEPARTMENT OF ENERGY \\ under Contract DE-ACO5-76RL01830
}

Printed in the United States of America
Available to DOE and DOE contractors from the
Office of Scientific and Technical Information,
P.O. Box 62, Oak Ridge, TN 37831-0062;
ph: (865) 576-8401
fax: (865) 5765728
email: reports@adonis.osti.gov

\author{
Available to the public from the National Technical Information Service, \\ U.S. Department of Commerce, 5285 Port Royal Rd., Springfield, VA 22161 \\ ph: (800) 553-6847 \\ fax: (703) 605-6900 \\ email: orders@nits.fedworld.gov \\ online ordering: http://www.ntis.gov/ordering.htm
}




\section{Investigation of Te Migration Mechanism During Bulk Vitrification Process Using Re Surrogate}

D-S. Kim

L. M. Bagaasen

J. V. Crum

A. Fluegel

A. Gallegos

B. Martinez

J. Matyáš
P. A. Meyer

D. R. Paulsen

B. J. Riley

M. J. Schweiger

C. W. Stewart

R. G. Swoboda

J. D. Yeager

December 2006

Prepared for the U.S. Department of Energy under Contract DE-AC05-76RL01830

Pacific Northwest National Laboratory

Richland, WA 99352 


\section{Summary}

As a part of bulk vitrification (BV) performance enhancement tasks, laboratory scoping tests were performed in FY 2004-2005 to explore possible ways to reduce the amount of soluble Tc in the BV waste package. Theses scoping tests helped identify which mechanisms play an important role in the migration of Tc in the BV process (Hrma et al. 2005; Kim et al. 2005). Based on the results from these scoping tests, additional tests were identified that will improve the understanding of Tc migration and clearly identify the dominant mechanisms.

The additional activities identified from previous studies were evaluated and prioritized for planning for Tasks 29 and 30 conducted in FY 2006. Task 29 focused on the improved understanding of Tc migration mechanisms, and Task 30 focused on identifying the potential process changes that might reduce Tc/Re migration into the castable refractory block (CRB). This report summarizes the results from the laboratory- and crucible-scale tests in the laboratory for improved understanding of the Tc migration mechanism using Re as a surrogate performed in Task 29. Other tests performed in Task 30, which specifically aimed at testing changes to the BV process that might reduce Tc/Re migration into the CRB, will be reported in a separate report. The FY 2004-2005 work also showed that Re is an excellent surrogate for Tc. Therefore, Re was used for all the tests performed in this study because a broader set of non-radioactive Re tests could be conducted for less cost than radioactive Tc tests.

The water and molten ionic salt (MIS) capillary experiments suggested that the capillary force is a dominant mechanism for MIS penetration in the CRB, which was also supported by the preliminary modeling results.

Hot-stage microscopy observations of the feed-melting and liquid-formation processes showed that the behavior of a dry blended feed and a feed prepared from liquid simulant was significantly different. A dry blended feed seemed to form a higher fraction of liquid than a feed prepared from liquid simulant, which could cause an increase in MIS migration into CRB. This may suggest that the information obtained in the full-scale tests conducted with dry blended feed may need to be verified with drier prepared feed in future operations.

Thin-section MIS/Re profile measurements with FS-38B CRB samples provided new information on how the MIS and Re penetrate as the melt progresses.

- For the CRB above the melt line, Re penetrates into the CRB by a vapor disposition mechanism, i.e., Re deposits when the CRB is cold, becomes molten as the temperature increases, and then penetrates further into the CRB by capillary action. The extent of penetration and the concentration of Re above the melt line is small.

- For the CRB at the melt line, Re penetrates into the CRB through both the vapor deposition at the early stages of processing and then liquid MIS formation and penetration at later processing stages. The CRB at the melt line close to the glass interface exhibited the highest soluble Re concentration.

- For the CRB below the melt line, regions of the CRB that experience Re penetration through MIS migration early in the process and then are subsequently covered by the progressing melt do not incorporate the Re in an insoluble melt phase. Instead, they push the Re salt outward through evaporation and/or melting and flow of molten salt. This results in a relatively low concentration of 
soluble Re on the surface layer and a higher concentration of soluble Re in the outer layer close to the $\mathrm{CRB} /$ sand interface

The new experimental setup developed in this study to investigate Re migration during feed processing and glass melting successfully achieved a high mass balance closure. The new setup was designed to capture all the volatiles by condensing them inside a stainless tube or dissolving them in a pair of scrub solutions. The tests with pre-melted glass showed that $\mathrm{Re}$ is more volatile than $\mathrm{S}$ and $\mathrm{Cl}$ with an estimated volatilization rate, $r=20.4 \mathrm{wt} \% / \mathrm{h}$ at $1200^{\circ} \mathrm{C}$. The volatilization rate of Re showed a strong dependence on temperature with an activation energy of $258 \mathrm{~J} / \mathrm{mole}$.

The results of dried feed Cases 2-4 in relation to the baseline feed (Case 1) are summarized below:

- The feed with high $\mathrm{Cl}$ and $\mathrm{F}$ (Case 2) resulted in higher volatilization of Re during melting and consequently lower Re retention in glass. The high $\mathrm{Cl}$ and $\mathrm{F}$ concentrations in the feed resulted in more separated salt, which is likely responsible for higher Re volatilization.

- The addition of $\mathrm{CaO}$ and $\mathrm{MgO}$ (Case 3) resulted in comparable Re retention in glass. As expected, the $\mathrm{CaO}$ and $\mathrm{MgO}$ increased $\mathrm{S}$ retention in the melt, but this did not lead to the desired increase in $\mathrm{Re}$ retention.

- The feed with crushed soil (Case 4) resulted in a comparable Re retention in the glass. The crushed soil accelerated the formation of the glass-forming melt to a lower temperature, but that did not improve the Re retention in glass.

From the study of Re incorporation, it was found that the Re becomes incorporated into the glass-forming melt at approximately $700^{\circ} \mathrm{C}$, and the incorporation of Re in the glass-forming melt reaches a maximum at $\sim 800^{\circ} \mathrm{C}$ and then decreases as the temperature increases up to $1000^{\circ} \mathrm{C}$. The results suggest that $\operatorname{Re}$ loss is not solely from volatilization from glass-forming melt but may be partly caused by partitioning to small salt inclusions that coalesce to form a separated salt phase at higher temperatures.

The present study based on thin-section MIS/Re profile measurements with FS-38B CRB samples and the investigation of Re migration during feed processing and glass melting has focused on two routes of $\operatorname{Re}$ (used as a surrogate for Tc) transport to the outside of the bulk glass: 1) to the offgas stream through volatilization and 2) to the CRB through MIS penetration by capillary action. The Re is a highly volatile component, and its volatilization will be enhanced by the presence of other volatile components, such as $\mathrm{Cl}$ and F. Due to its inherent nature of high volatility, it seems that there is no simple effective solution except for the application of a cold cap that condenses the volatiles and brings them back to the feed to maximize their retention in glass. The thicker cold cap and lower plenum temperature would help to incorporate more Re into glass.

Using clean glass feed would help to capture the Re volatilized from melting the waste-containing feed and incorporate it into glass at the end of the bulk vitrification process. However, once the clean glass becomes melted and mixed into the main body of the melt, the Re-containing melt will become exposed to the surface. The volatilization of Re also proceeds at a relatively high rate from a melt that has already incorporated the Re. The Re can escape relatively easily from the surface as the temperature increases at the end of the process. Therefore, it is important to find the optimal heating condition at the end of the process to fully melt the clean glass feed to a reasonably durable glassy phase (because the partially 
melted feed may contain the volatilized Re that is soluble) but not to overheat to expose the hot glass surface for volatilization.

The main mechanism of Tc transport to the CRB is penetration of MIS. The contribution of volatilization and condensation of Re to the total Re migration into CRB seems to be very small compared to MIS penetration. The use of a cold cap, although very critical to control Re volatilization, is likely to promote MIS penetration into the CRB by providing the condition to increase the MIS formation: the cold cap helps to keep the feed at the temperatures favored for MIS formation (e.g., 350 to $550^{\circ} \mathrm{C}$ ) for a longer time. A few promising methods to reduce the MIS migration have been identified and are being tested in crucible scale under Task 30, which will be reported in a separate report. Depending on the effectiveness of the methods developed under Task 30, the balance between the transport of Re to offgas and to the $\mathrm{CRB}$ can be made by controlling the formation of the cold cap during the bulk vitrification process.

\section{References}

Hrma P, J Matyas, LM Bagaasen, KBC Minister, AE Beck, MJ Schweiger, TM Brouns, DM Strachan, DD Caldwell, BP Tinsley, ML Elliott, and GW Hollenberg. 2005. Bulk Vitrification Castable Refractory Block Protection Study. PNNL-15193, Pacific Northwest National Laboratory, Richland, WA.

Kim D-S, CZ Soderquist, JP Icenhower, BP McGrail, RD Scheele, BK McNamara, LM Bagaasen, MJ Schweiger, JV Crum, JD Yeager, J Matyáš, LP Darnell, HT Schaef, AT Owen, AE Kozelisky, LA Snow, and MJ Steele. 2005. Tc Reductant Chemistry and Crucible Melting Studies with Simulated Hanford Low-Activity Waste. PNNL-15131, Pacific Northwest National Laboratory, Richland, WA. 



\section{Abbreviations and Acronyms}

\begin{tabular}{|c|c|}
\hline AES & atomic emission spectroscopy \\
\hline AMEC & AMEC Earth and Environmental, Inc. \\
\hline $\mathrm{BV}$ & bulk vitrification \\
\hline CH2M HILL & CH2M HILL Hanford Group, Inc. \\
\hline CRB & castable refractory block \\
\hline DIW & deionized water \\
\hline DOE & U.S. Department of Energy \\
\hline EDS & energy dispersive spectroscopy \\
\hline ES & engineering-scale \\
\hline FS & full-scale \\
\hline GBM & glass batching and melting \\
\hline GDL & Glass Development Laboratory \\
\hline HASQARD & Hanford Analytical Services Quality Assurance Requirements Document \\
\hline HRTS & Horn Rapids Test Site \\
\hline HT & heat treated \\
\hline IC & ion chromatography \\
\hline $\mathrm{ICP}$ & inductively coupled plasma \\
\hline ILAW & immobilized low-activity waste \\
\hline LAW & low-activity waste \\
\hline LCR & inductance, capacitance, and resistance \\
\hline LOI & loss on ignition \\
\hline LRB & laboratory record book \\
\hline MIS & molten ionic salt \\
\hline MS & mass spectrometry \\
\hline PMG & pre-melted glass \\
\hline PNNL & Pacific Northwest National Laboratory \\
\hline QA & quality assurance \\
\hline RPD & relative percent difference \\
\hline SBMS & Standards Based Management System \\
\hline SEM & scanning electron microscopy \\
\hline SwRI & Southwest Research Institute \\
\hline WTP & Waste Treatment and Immobilization Plant \\
\hline
\end{tabular}





\section{Contents}

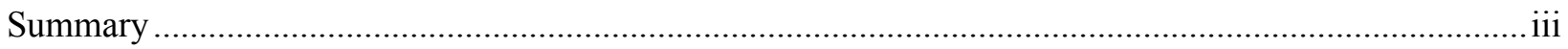

Abbreviations and Acronyms ……………………………........................................................... vii

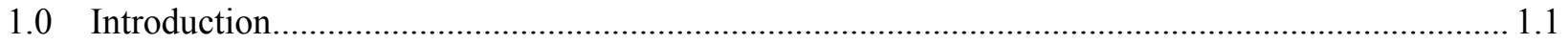

2.0 Quality Assurance ......................................................................................................... 2.1

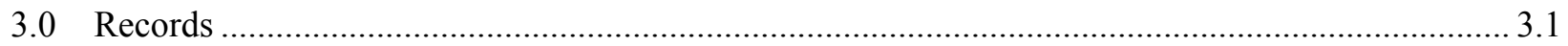

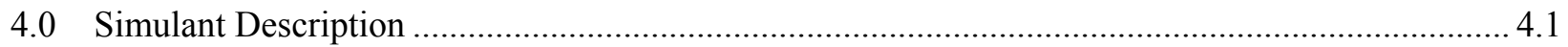

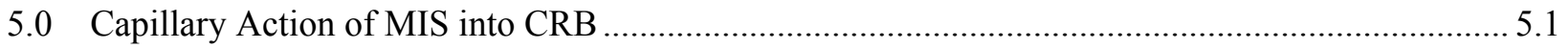

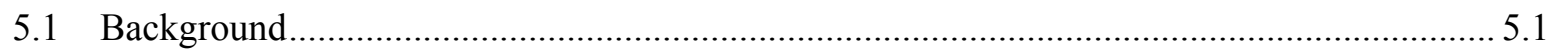

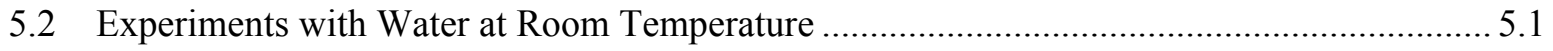

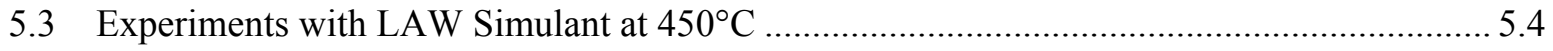

5.4 Summary

6.0 Hot-Stage Microscopy Feed Melting Study ……………................................................................ 6.1

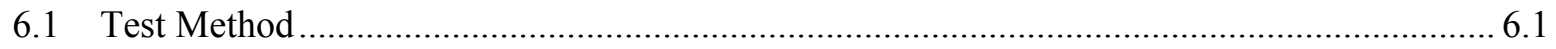

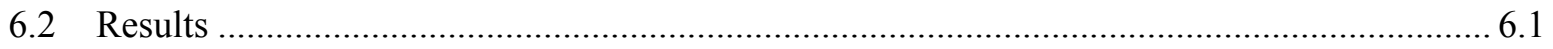

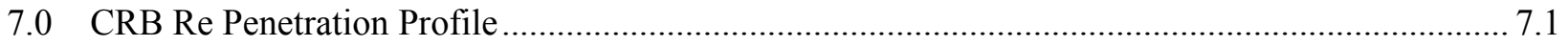

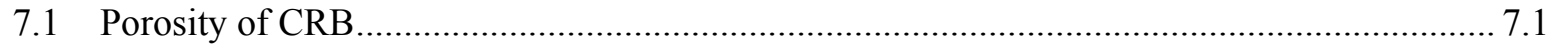

7.2 CRB Sample Descriptions ……………………………………………………………... 7.2

7.3 SEM-EDS Analysis of CRB for MIS Profile …………………………………………….... 7.4

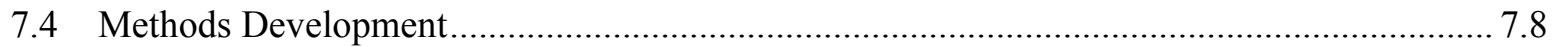

7.4.1 CRB Powder Preparation................................................................................. 7.9

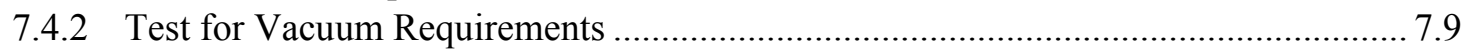

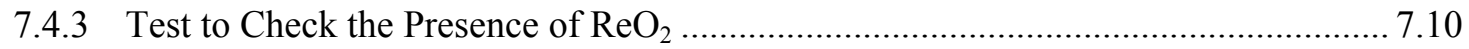

7.5 Re and MIS Profile Analyses in FS-38B CRB …………….......................................... 7.12

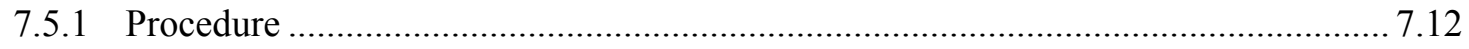

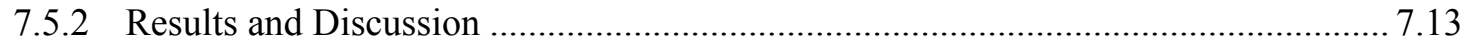

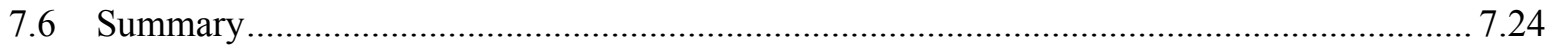




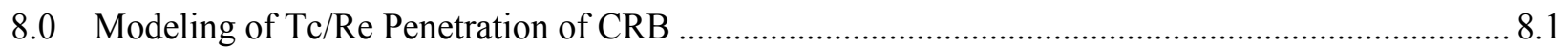

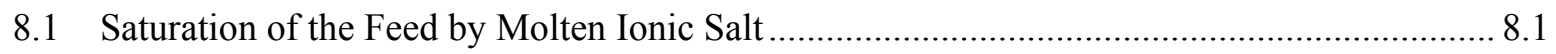

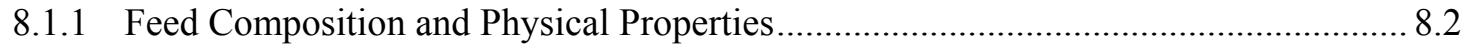

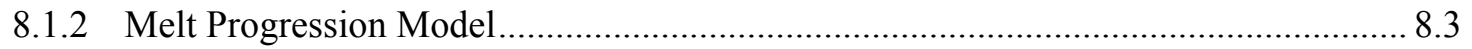

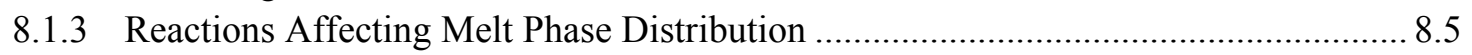

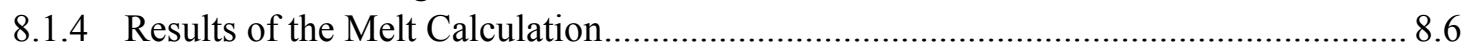

8.2 Maximum Theoretical Concentration of MIS in the CRB................................................ 8.8

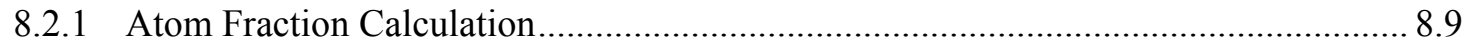

8.2.2 Results of Sodium Atom Fraction Analysis........................................................ 8.10

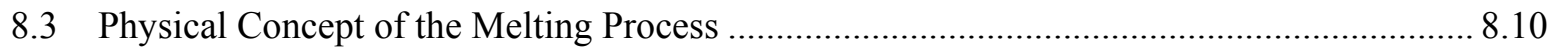

8.4 Mathematical Model for Molten Salt Migration into the CRB ........................................ 8.14

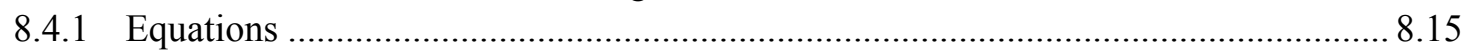

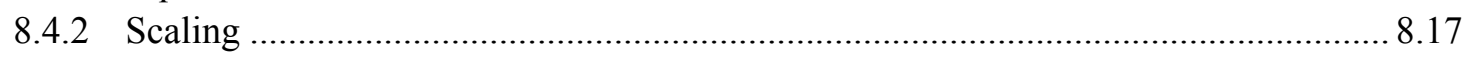

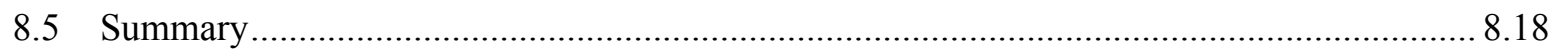

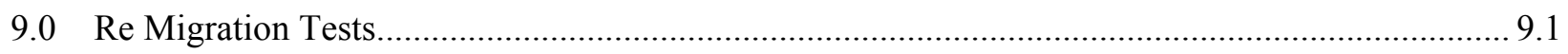

9.1 Feeds and Pre-Melted Glass Preparation ...................................................................... 9.1

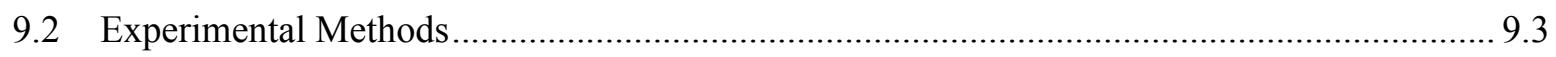

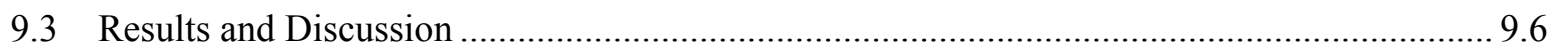

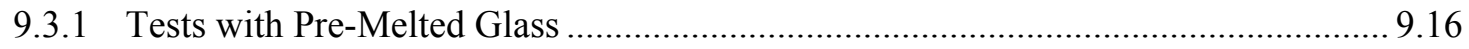

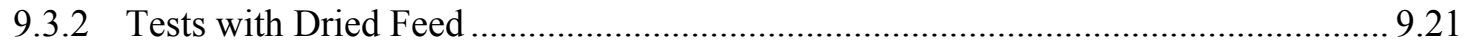

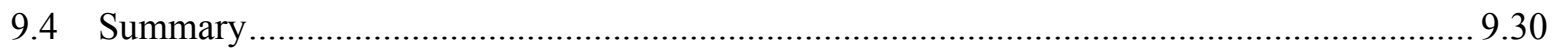

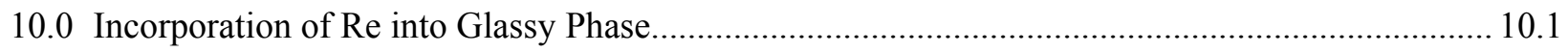

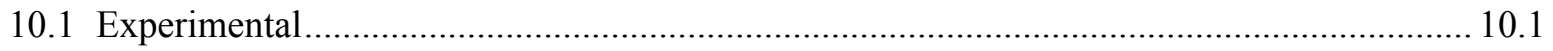

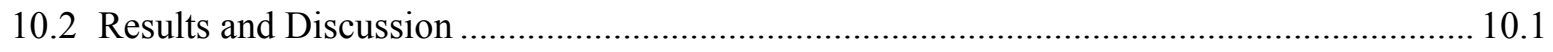

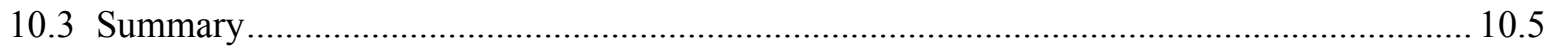

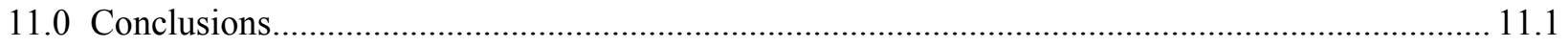

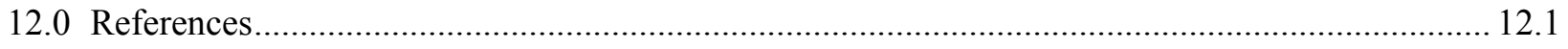

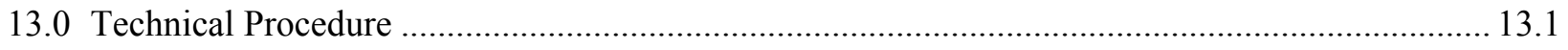




\section{Figures}

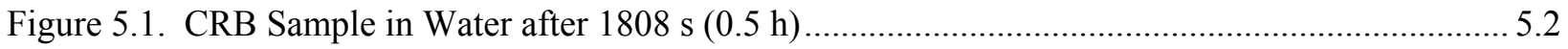

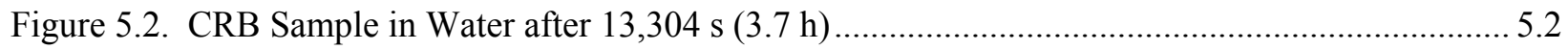

Figure 5.3. Capillary Rise of Water in the CRB at Room Temperature ............................................. 5.3

Figure 5.4. Experimental Setup for Measuring LAW Salt Melt Capillary Rise in CRB ....................... 5.5

Figure 5.5. Typical Capillary Rise Result of LAW Simulant Melt at $450^{\circ} \mathrm{C}$ in CRB .......................... 5.6

Figure 5.6. Typical Capillary Rise Result of LAW Simulant Melt at $450^{\circ} \mathrm{C}$ in CRB, Fractured Surface (exaggerated color contrast for better visibility) ..................................................................... 5.7

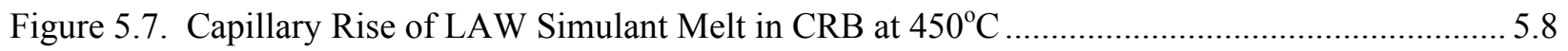

Figure 6.1. Hot-Stage Microscopy Images of Dry LAW (6-Tank Composite) Simulant ....................... 6.2

Figure 6.2. Hot-Stage Microscopy Images of 38B (Left) and Baseline (Right) Feeds .......................... 6.3

Figure 7.1. Porosity of As-Received and Heat-Treated CRB Samples.................................................... 7.2

Figure 7.2. Picture of East Wall from Test FS-38B Showing the Locations for CRB Sampling ............. 7.3

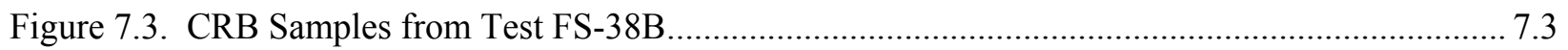

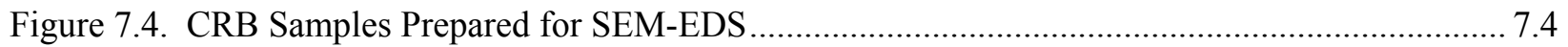

Figure 7.5. SEM Images of CRB Surface Showing Pores and Inhomogeneous Microstructure ............. 7.5

Figure 7.6. SEM Image of CRB Showing Small Pores .................................................................... 7.5

Figure 7.7. $\mathrm{Na}, \mathrm{S}$, and $\mathrm{Cl}$ Concentrations in $\mathrm{CRB}$ Sample from $38.1 \mathrm{~cm}$ Above the Melt Line.............7.7

Figure 7.8. $\mathrm{Na}, \mathrm{S}$, and $\mathrm{Cl}$ Concentrations in CRB Sample from at the Melt Line ................................. 7.7

Figure 7.9. $\mathrm{Na}, \mathrm{S}$, and $\mathrm{Cl}$ Concentrations in CRB Sample from $\sim 15.2 \mathrm{~cm}$ Below the Melt Line............ 7.8

Figure 7.10. CRB Pieces Taken from $\sim 15.2 \mathrm{~cm}$ Below the Melt Line (lined up from glass/CRB interface

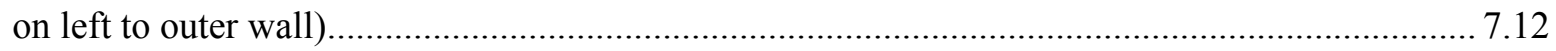

Figure 7.11. Concentration of Soluble Re, $\mathrm{Na}$, and $\mathrm{S}$ in the $\mathrm{CRB} \sim 38.1 \mathrm{~cm}$ Above the Melt Line........ 7.19

Figure 7.12. Concentration of Insoluble $\mathrm{Re}, \mathrm{Na}$, and $\mathrm{S}$ in the $\mathrm{CRB} \sim 38.1 \mathrm{~cm}$ Above the Melt Line ..... 7.20

Figure 7.13. Concentration of Soluble Re, $\mathrm{Na}$, and $\mathrm{S}$ in the $\mathrm{CRB}$ at the Melt Line ............................. 7.20

Figure 7.14. Concentration of Insoluble $\mathrm{Re}, \mathrm{Na}$, and $\mathrm{S}$ in the $\mathrm{CRB}$ at the Melt Line........................... 7.21

Figure 7.15. Concentration of Soluble Re, $\mathrm{Na}$, and $\mathrm{S}$ in the $\mathrm{CRB} \sim 15.2 \mathrm{~cm}$ Below the Melt Line........7.21 
Figure 7.16. Concentration of Insoluble $\mathrm{Re}, \mathrm{Na}$, and $\mathrm{S}$ in the $\mathrm{CRB} \sim 15.2 \mathrm{~cm}$ Below the Melt Line ..... 7.22

Figure 7.17. Concentration of Re in the CRB Samples from Different Locations ............................... 7.22

Figure 7.18. Concentration of $\mathrm{Na}$ in the CRB Samples from Different Locations ............................... 7.23

Figure 7.19. Concentration of $\mathrm{S}$ in the CRB Samples from Different Locations ................................ 7.23

Figure 8.1. Solid Matrix Unsaturated (left) and Effectively Saturated (right) with Liquid .................... 8.1

Figure 8.2. Melting Model: Melting Solid (left) Reduces Feed Volume (right) (solids were labeled A through I so that migrating solids can be easily tracked) ............................................................. 8.2

Figure 8.3. Phase Volume Fractions Versus Temperature ............................................................ 8.7

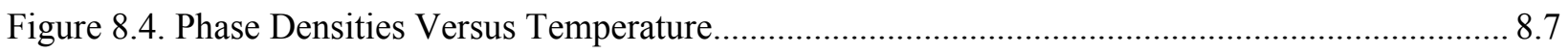

Figure 8.5. Atomic Concentrations in CRB after ES-31B Test [Figure 5.16 from Hrma et al. (2005)] ... 8.8

Figure 8.6. Melt Process Concept—Vertical Progression ............................................................. 8.11

Figure 8.7. Temperature Contours from Simulation of Test 38A ................................................... 8.12

Figure 8.8. Melt Process Concept—Lateral Progression .............................................................. 8.13

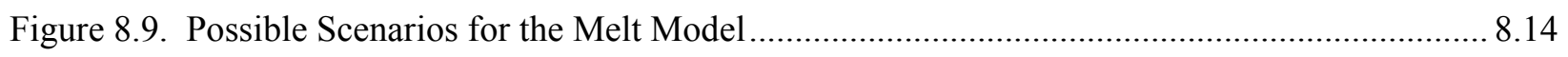

Figure 8.10. Illustrating the MIS Layer and Transport into CRB .................................................. 8.15

Figure 9.1. Schematic of Experimental Setup for Cold Finger Crucible Tests Used in the Previous Study

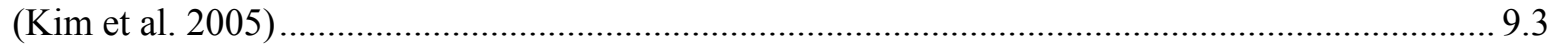

Figure 9.2. Schematic of New Experimental Setup Proposed for Re Migration Tests .......................... 9.4

Figure 9.3. Wt\% of Total Analyzed in Condensate Solutions from the Tests with Pre-melted Glass.... 9.18

Figure 9.4. Wt\% of Total Retained in Glass from the Tests with Pre-melted Glass............................ 9.18

Figure 9.5. Wt $\%$ of Total Re Retained in Glass and Analyzed in Condensate Solutions from the Tests

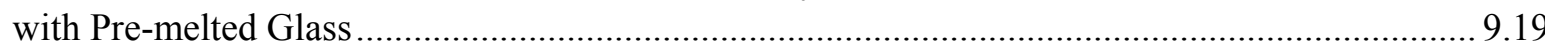

Figure 9.6. $\mathrm{Wt} \%$ of Total S Retained in Glass and Analyzed in Condensate Solutions from the Tests with

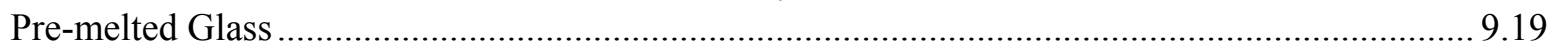

Figure 9.7. Average Volatilization Rate of $\mathrm{Re}, \mathrm{S}$, and $\mathrm{Cl}$ from Pre-melted Glass............................. 9.20

Figure 9.8. Natural Log of Average Volatilization Rate of Re, S, and Cl from Pre-melted Glass ........ 9.20

Figure 9.9. Measured Versus Calculated Accumulated Re wt $\%$ Volatilized....................................... 9.21

Figure 9.10. $\mathrm{Wt} \%$ of Total Analyzed in Crucible Rinse from Case 1 (Baseline Feed) ....................... 9.23 
Figure 9.11. Wt\% of Total Analyzed in Condensate Solutions from Case 1 (Baseline Feed).

Figure 9.12. Wt\% of Total Analyzed in Crucible Rinse from Case 2 (High $\mathrm{Cl} / \mathrm{F} \mathrm{Feed})$.

Figure 9.13. Wt\% of Total Analyzed in Condensate Solutions from Case 2 (High Cl/F Feed)...... 9.25

Figure 9.14. $\mathrm{Wt} \%$ of Total Analyzed in Crucible Rinse from Case 3 (High $\mathrm{CaO} / \mathrm{MgO}$ Feed) 9.25

Figure 9.15. $\mathrm{Wt} \%$ of Total Analyzed in Condensate Solutions from Case 3 (High $\mathrm{CaO} / \mathrm{MgO}$ Feed) ... 9.26

Figure 9.16. Wt\% of Total Analyzed in Crucible Rinse from Case 4 (Crushed Soil Feed) ...... 9.26

Figure 9.17. Wt $\%$ of Total Analyzed in Condensate Solutions from Case 4 (Crushed Soil Feed)........ 9.27

Figure 9.18. Wt\% of Total Re Analyzed in All Crucible Rinses and Condensate Solutions........ 9.27

Figure 9.19. Wt\% of Total S Analyzed in All Crucible Rinses and Condensate Solutions..... 9.28

Figure 9.20. Wt\% of Total Cl Analyzed in All Crucible Rinses and Condensate Solutions 9.28

Figure 9.21. Wt $\%$ of Total Re and S Retained in Glass Tested at $1200^{\circ} \mathrm{C}$ 9.29

Figure 9.22. Wt\% of Total Re Retained in Glass and Analyzed in Crucible Rinse and Condensate Tested at $1200^{\circ} \mathrm{C}$

Figure 9.23. Wt\% of Total S Retained in Glass and Analyzed in Crucible Rinse and Condensate Tested at $1200^{\circ} \mathrm{C}$ 9.30

Figure 10.1. Wt\% of Total Batched Re, $\mathrm{Na}$, and $\mathrm{S}$ Analyzed in Crucible Rinse 10.3

Figure 10.2. Wt\% of Total Batched Re, $\mathrm{Na}$, and $\mathrm{S}$ Analyzed in Solid . 10.4

Figure 10.3. Sum of $\mathrm{Wt} \%$ of Total Batched $\mathrm{Re}, \mathrm{Na}$, and $\mathrm{S}$ Recovered in Crucible Rinse and Solid 10.4 


\section{Tables}

Table 4.1. Composition of 1 Liter of 5 M Sodium "6 Tank Composite" Simulant (Rassat et al. 2003) .. 4.1

Table 4.2. Compositions of Simulant, HRTS Soil, and Resulting Glass in Mass Fraction of Oxides and Halogens .....

Table 5.1. Capillary Rise of Water in CRB at Room Temperature .................................................... 5.3

Table 5.2. Dry LAW Simulant Composition Used in Capillary Test .................................................... 5.4

Table 5.3. Surface Tension of Sodium Nitrate Melt (Gale and Totemeier 2004)................................. 5.4

Table 5.4. Viscosity of Sodium Nitrate Melt (Gale and Totemeier 2004) ........................................... 5.5

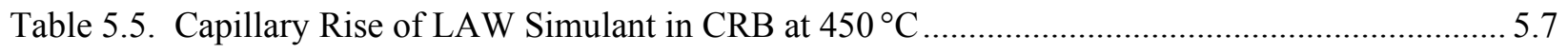

Table 7.1. Density and Porosity of As-Received and Heat-Treated CRB Samples.............................. 7.2

Table 7.2. Soluble and Insoluble Re Concentrations from CRB (in $\mu \mathrm{g} / \mathrm{kg})$................................. 7.11

Table 7.3. Summary of Duplicate Analytical Results ................................................................. 7.15

Table 7.4. Concentrations of $\mathrm{Re}, \mathrm{Na}$, and $\mathrm{S}$ in Leach Solutions (soluble) and in Remaining CRB Particles (insoluble) (in $\mu \mathrm{g}$ or $\mathrm{mg}$ of element per $\mathrm{kg}$ of $\mathrm{CRB}$ ) ............................................................... 7.16

Table 7.5. Soluble Re Concentration in CRB Blanks Determined by Centrifugal Extraction Method

(Cooley et al. 2006)

Table 7.6. Comparison of Soluble Re Concentrations by Two Different Methods for the FS-38B CRB

Samples Taken from Similar Locations (in $\mu \mathrm{g} \mathrm{Re} / \mathrm{kg} \mathrm{CRB}$ ) ..................................................... 7.17

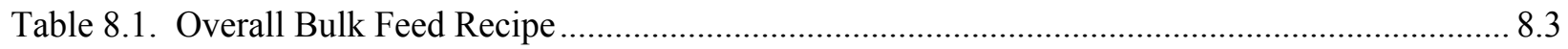

Table 8.2. Mixed Feed Composition By Melting Point ......................................................................... 8.3

Table 8.3. Composition of Castable Refractory Solids in Terms of Metal Oxides................................ 8.9

Table 8.4. Values Used for Evaluating MIS Penetration Model....................................................... 8.17

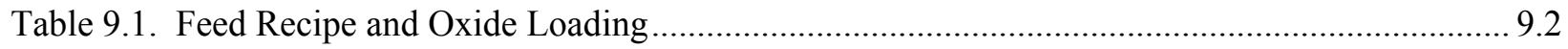

Table 9.2. Target Glass Compositions (in mass fraction except for Re metal in $\mathrm{mg} / \mathrm{kg}$ ) .................... 9.2

Table 9.3. Summary of Chemical Analyses To Be Performed for Various Samples ........................... 9.6

Table 9.4. Summary of Re Mass Balance Closure from Preliminary Tests......................................... 9.6

Table 9.5. Analyzed Composition of 6-Tank Composite Simulant Compared to Target ........................ 9.7 
Table 9.6 Analyzed Composition of Dried Feeds Compared to Target Compositions (in mass fraction for oxides/halogens and $\mathrm{mg} / \mathrm{kg}$ for Re metal)

Table 9.7. Relative Percent Difference ${ }^{1)}$ between Target and Analyzed Compositions in Dried Feeds... 9.9

Table 9.8. Re, Na, and S Concentration in Pre-melted Glass Samples (in mg/kg) 9.9

Table 9.9. Analyzed Composition of Pre-melted Glass Compared with Target Composition (in mass fraction) 9.10

Table 9.10 Analyzed Concentrations in Crucible Rinse and Condensate Solutions (in mg/L) 9.11

Table 9.11. Wt\% of Total Analyzed in Crucible Rinse or Condensate Solution....... 9.13

Table 9.12. Analyzed Concentration and $\mathrm{Wt} \%$ of Total Retained in Glass for $\mathrm{Re}, \mathrm{Na}$, and $\mathrm{S}$........ 9.14

Table 9.13. Summary of Duplicate Analytical Results..... 9.15

Table 9.14. Comparison of Results from Duplicate Tests 9.15

Table 9.15. Calculated Re Volatilization Rate...... 9.17

Table 10.1. Analyzed Concentration of $\mathrm{Re}, \mathrm{Na}$, and $\mathrm{S}$ in Crucible Rinse and Solids........ 10.1

Table 10.2. Mass of Re, Na, and S in Crucible Rinse and Solids and Total Batched 10.2

Table 10.3. Wt\% of Total Analyzed in Crucible Rinse and in Solids and Total Recovered 10.2 


\subsection{Introduction}

The Hanford Site has the largest volume of high-level radioactive tank waste in the United States stored in 177 underground tanks containing 53 million gallons of waste and 200 million Curies of radioactivity. The life-cycle cost for cleanup has been estimated at nearly $\$ 50$ billion over 50 years. The Waste Treatment and Immobilization Plant (WTP) is under construction and will immobilize both high-level waste for disposal at a national repository and low activity waste (LAW) for onsite disposal at Hanford. However, vitrification of the high volume of LAW is the rate-limiting step in the WTP and results in the 50-year project duration. The U.S. Department of Energy (DOE) accelerated cleanup mission for the Hanford Site is a strategic initiative to accelerate tank waste treatment by increasing the capacity of the WTP and using supplemental technologies for waste treatment and immobilization for as much as $70 \%$ of the LAW. Bulk vitrification (BV) was selected for further evaluation as a potential supplemental treatment technology for treating LAW at Hanford (Raymond et al. 2004). The use of this supplemental waste form would help DOE meet the long-term groundwater protection criteria for disposing of waste in a shallow land burial facility.

The FY 2003 risk assessment (Mann et al. 2003) of BV waste packages used $0.3 \mathrm{wt} \%$ of the technetium $(\mathrm{Tc})^{(\mathrm{a})}$ inventory as a leachable salt and found it sufficient to create a significant peak in the groundwater concentration in a 100-meter down-gradient well in approximately 1500 years after facility closure. Although this peak met regulatory limits, the CH2M HILL Hanford Group, Inc. (CH2M HILL) has requested that the soluble fraction of Tc in the BV waste package be significantly reduced; the ideal goal (not a requirement) is to reduce the amount of soluble salt in the BV waste package to the point that peak concentrations in the 100-meter down-gradient well do not exceed the highest levels seen for WTP glass. Early attempts to include a castable refractory block (CRB) in place of the refractory sand layer and to use a bottom-up melting technique have eliminated the two main areas where soluble Tc was depositing in the previous process design. However, the refractory block is still quite porous, and early analyses have shown that larger-than-desired quantities of rhenium (Re, a chemical surrogate for $\mathrm{Tc}$ ) are depositing in the pores of the CRB.

As a part of the BV performance enhancement efforts to explore possible ways to reduce the amount of soluble Tc in the BV waste package, laboratory scoping tests, Tasks 14 and 15, were conducted in FY 2004-2005. Tasks 14 and 15 helped identify which mechanisms play an important role in the migration of Tc in the BV process. Task 14 focused on the volatilization of Tc from the melting feed and molten glass (Kim et al. 2005), and Task 15 focused on the migration of Tc into the CRB (Hrma et al. 2005). Based on the results from these scoping tests, additional tests were identified that will improve the understanding of Tc migration and clearly identify the dominant mechanisms.

The additional activities identified from Tasks 14 and 15 were evaluated and prioritized for planning for Tasks 29 and 30 conducted in FY 2006. Task 29 focused on the improved understanding of Tc migration mechanisms, and Task 30 focused on identifying the potential process changes that might reduce $\mathrm{Tc} / \mathrm{Re}$ migration into the CRB. This report summarizes the results from the laboratory- and crucible-scale tests in the laboratory under Task 29 to improve our understanding of the mechanism for Tc migration. Other

(a) Technetium used in this study was all ${ }^{99} \mathrm{Tc}$. The symbol "Tc" is used for "999 $\mathrm{Tc}$ " throughout this report. 
tests performed in Task 30, which specifically aimed at testing changes to the BV process that might reduce $\mathrm{Tc} / \mathrm{Re}$ migration into the $\mathrm{CRB}$, will be reported in a separate report.

The FY 2004-2005 work also showed that Re is an excellent surrogate for Tc. The engineering-scale tests ES-32A and 32B used both Re and Tc and found an overall good correlation between Re and Tc except for CRB migration: the CRB extraction measurements resulted in a significantly lower Tc concentration than $\operatorname{Re}$ (Pierce et al. 2005), indicating that Re is a conservative CRB migration surrogate in engineering-scale tests. The crucible tests performed in a previous study on the $\mathrm{Re} / \mathrm{Tc}$ volatilization (Kim et al. 2005) also used both Re and Tc and obtained a very good agreement between Re and Tc. Therefore, Re was used for all the tests performed in this study because a broader set of non-radioactive Re tests could be conducted for less cost than radioactive Tc tests. 


\subsection{Quality Assurance}

All the tests in this report were proof-of-principle ${ }^{(a)}$ in nature and were performed in accordance with Pacific Northwest National Laboratory's (PNNL's) Standards-Based Management System (SBMS) as specified in the Supplemental Technologies Support Project Tank Waste Support Quality Assurance Plan, Rev. 7 (QAP 46029, January 2006). The SBMS Quality Assurance Program meets DOE Order 414.1C and 10 CFR 830, Subpart A. Staff training is documented and test plans, procedures, and instructions are approved and in project records.

(a) Proof-of-principle testing indicates that the tests performed in this study are not intended to supply data for major project decisions without further verification through testing that complies with the Hanford Analytical Services Quality Assurance Requirements Document (HASQARD). 


\subsection{Records}

Records for this report are the data sheets from the test instructions, applicable procedures, and any laboratory record book (LRB) pages used to record data and test information. These include instrument calibrations, test setup and standards, data logging, calculations, and review comments and signatures. Copies of all test records are provided to the project records custodian for storage in accordance with the quality assurance (QA) plan. 


\subsection{Simulant Description}

The simulant used in this study was the same as used in a previous study (Kim et al. 2005), $5 \mathrm{M}$ sodium "6 tank composite" simulated Hanford LAW developed by Rassat et al. (2003). Table 4.1 shows the reagent masses used to prepare $1 \mathrm{~L}$ of liquid simulant. The simulant was spiked with $0.0090 \mathrm{~g} / \mathrm{L} \mathrm{Re}_{2} \mathrm{O}_{7}$ to provide a target concentration of $8.1 \mathrm{ppm} \operatorname{Re}$ (metal basis) in glass based on the baseline glass formulation (Kim et al. 2003) at $20 \mathrm{wt} \% \mathrm{Na}_{2} \mathrm{O}$ with $12 \mathrm{wt} \%$ total additive and using Horn Rapids Test Site (HRTS) soil. The measured density of the simulant was $1.23 \mathrm{~g} / \mathrm{cm}^{3}$, which is very close to the calculated value of $1.24 \mathrm{~g} / \mathrm{cm}^{3}$ (Rassat et al. 2003). Table 4.1 also shows the $\mathrm{wt} \%$ of each chemical for a mixture of dry chemicals, which was used in some subtasks instead of liquid simulant.

Table 4.2 shows the composition of the simulant in terms of oxides and halogens that will remain in glass (assuming 100\% retention). Table 4.2 also shows the compositions of HRTS soil and the resulting glass from the baseline formation. The soil composition given in Table 4.2 (designated as HRTS05) has been updated since the last study (Kim et al. 2005), resulting in a slightly different target glass composition.

Table 4.1. Composition of 1 Liter of 5 M Sodium "6 Tank Composite" Simulant (Rassat et al. 2003)

\begin{tabular}{||l|c|c||}
\hline \multicolumn{1}{|c|}{ Reagent } & Mass (g) & Dry Wt\% \\
\hline $\mathrm{H}_{2} \mathrm{O}$ & 860 & \\
\hline $\mathrm{Na}_{2} \mathrm{C}_{2} \mathrm{O}_{4}$ & 1.58 & 0.416 \\
\hline $\mathrm{CH}_{3} \mathrm{COONa}_{2}$ & 10.79 & 2.84 \\
\hline $\mathrm{NaNO}_{3}$ & 196.11 & 51.63 \\
\hline $\mathrm{KNO}_{3}$ & 1.25 & 0.329 \\
\hline $\mathrm{NaOH}$ & 29.58 & 7.79 \\
\hline $\mathrm{Al}\left(\mathrm{NO}_{3}\right)_{3} \cdot 9 \mathrm{H}_{2} \mathrm{O}$ & 23.90 & 6.292 \\
\hline $\mathrm{Na}_{2} \mathrm{CO}_{3}$ & 50.35 & 13.25 \\
\hline $\mathrm{Na}_{2} \mathrm{SO}_{4}$ & 12.78 & 3.364 \\
\hline $\mathrm{Na}_{2} \mathrm{CrO}_{4}$ & 1.68 & 0.442 \\
\hline $\mathrm{Na}_{3} \mathrm{PO}_{4} \cdot 12 \mathrm{H}_{2} \mathrm{O}$ & 18.70 & 4.923 \\
\hline $\mathrm{NaCl}^{\mathrm{NaF}}$ & 2.56 & 0.674 \\
\hline $\mathrm{NaNO}$ & 1.33 & 0.350 \\
\hline $\mathrm{NaNO}$ & 29.26 & 7.702 \\
\hline
\end{tabular}


Table 4.2. Compositions of Simulant, HRTS Soil, and Resulting Glass in Mass Fraction of Oxides and Halogens

\begin{tabular}{||c|c|c|c||}
\hline Component & Simulant & HRTS05 soil & Glass \\
\hline $\mathrm{Al}_{2} \mathrm{O}_{3}$ & 0.0188 & 0.1239 & 0.0878 \\
\hline $\mathrm{B}_{2} \mathrm{O}_{3}$ & - & - & 0.0500 \\
\hline $\mathrm{BaO}$ & - & 0.0008 & 0.0005 \\
\hline $\mathrm{CaO}$ & - & 0.0436 & 0.0295 \\
\hline $\mathrm{Cl}$ & 0.0090 & - & 0.0018 \\
\hline $\mathrm{Cr}_{2} \mathrm{O}_{3}$ & 0.0046 & 0.0001 & 0.0010 \\
\hline $\mathrm{F}$ & 0.0035 & - & 0.0007 \\
\hline $\mathrm{Fe}_{2} \mathrm{O}_{3}$ & - & 0.0682 & 0.0462 \\
\hline $\mathrm{K}_{2} \mathrm{O}$ & 0.0034 & 0.0318 & 0.0223 \\
\hline $\mathrm{MgO}$ & - & 0.0213 & 0.0144 \\
\hline $\mathrm{MnO}_{\mathrm{Na}} \mathrm{O}$ & - & 0.0011 & 0.0007 \\
\hline $\mathrm{P}_{2} \mathrm{O}_{5}$ & 0.8987 & 0.0268 & 0.2000 \\
\hline $\mathrm{SiO}_{2}$ & - & 0.0023 & 0.0057 \\
\hline $\mathrm{SO}_{3}$ & 0.0418 & 0.6687 & 0.4531 \\
\hline $\mathrm{SrO}_{\mathrm{TiO}}$ & - & - & 0.0085 \\
\hline $\mathrm{ZrO}_{2}$ & - & 0.0004 & 0.0003 \\
\hline $\mathrm{SUM}$ & 1.0000 & 1.0000 & 0.0074 \\
\hline \hline
\end{tabular}




\subsection{Capillary Action of MIS into CRB}

This subtask determines the degree to which capillary action influences Re/molten ionic salt (MIS) penetration into the CRB. One of the proposed mechanisms suggested by Hrma et al. (2005) is that MIS penetrates into the CRB by capillary force through small open pores present in the CRB. To evaluate the proposed mechanism, a test setup was designed to demonstrate capillary action drawing MIS into the CRB.

\subsection{Background}

In capillaries with a small radius, the capillary action follows the law (Washburn 1921; Whitehead and Greenfield 1932)

$$
h=K t^{1 / 2}
$$

where $h$ is the capillary rise height, $t$ is the time, and $K$ is a constant that depends on the viscosity and surface tension of the liquid as well as the wetting angle between the liquid and the solid in which the capillary action takes place. The gravity force is neglected in Equation (5.1) because it is very small compared to the capillary force in fine capillaries. Washburn (1921) showed that the influence of the contact angle between liquid and solid on $K$ also can be neglected (as long as the liquid wets the solid) if the capillary radius is small. Hence, $K$ can be determined using Equation (5.2)

$$
K=\left(\frac{r \sigma}{2 \eta}\right)^{1 / 2}
$$

where $\sigma$ is the surface tension of the liquid, $\eta$ is its viscosity, and $r$ is the capillary radius.

\subsection{Experiments with Water at Room Temperature}

The cylindrical CRB bars of $\sim 4 \mathrm{~cm}$ diameter and $\sim 20 \mathrm{~cm}$ height used in this study were supplied by the same supplier of the CRB for engineering-scale and full-scale tests. Initial tests were conducted with water because it has viscosities and surface tensions similar to molten salt and would allow long tests at room temperature to be conducted.

The capillary rise of water in the castable refractory was monitored as a function of time. The measurement started from the water surface level. Figure 5.1 and Figure 5.2 show the observations of capillary rise of water in the CRB after 1,808 (0.5) and 13,304 (3.7) seconds (hrs) of reaction time, respectively. Table 5.1 shows the results, and Figure 5.3 depicts the results graphically. 


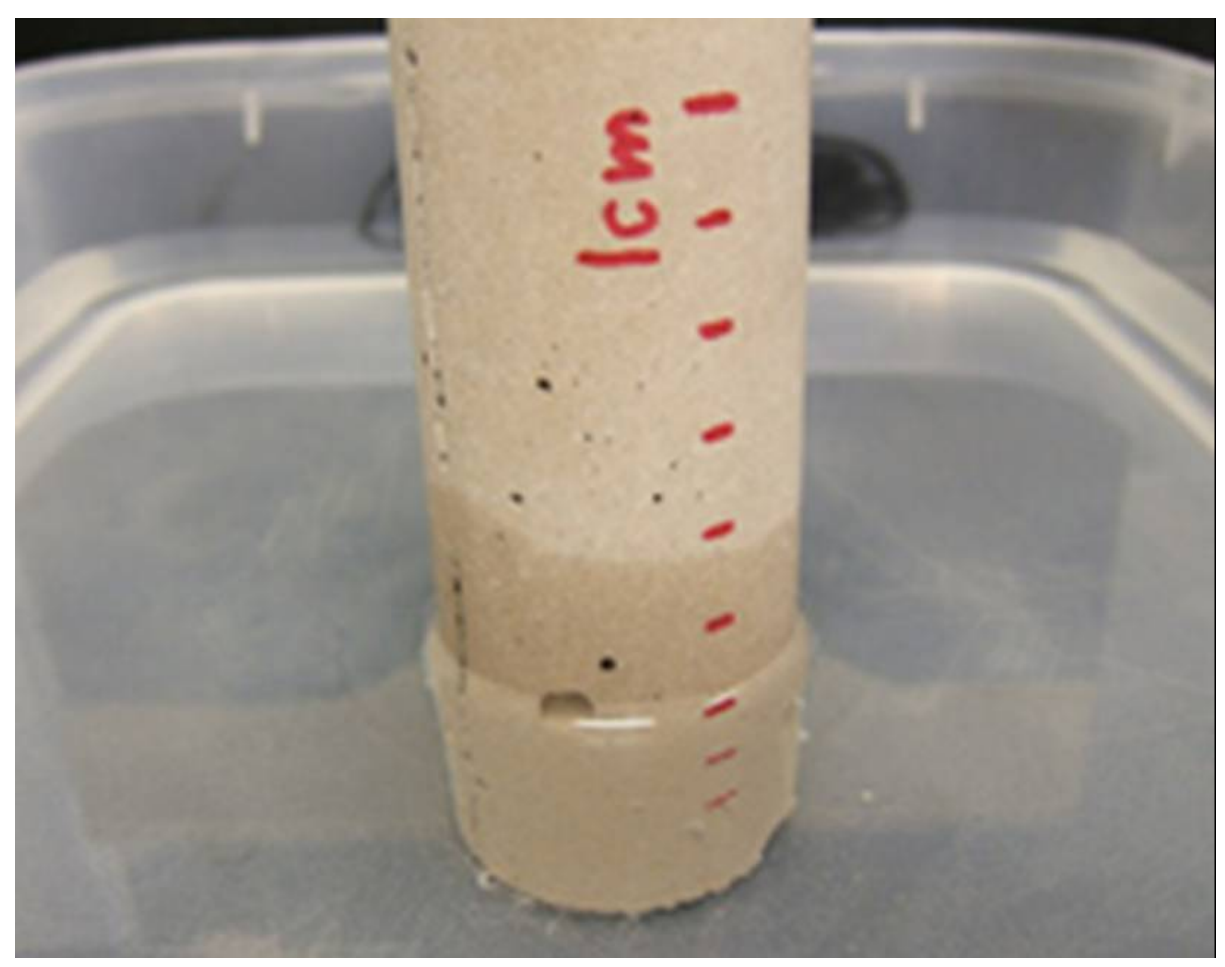

Figure 5.1. CRB Sample in Water after $1808 \mathrm{~s}(0.5 \mathrm{~h})$

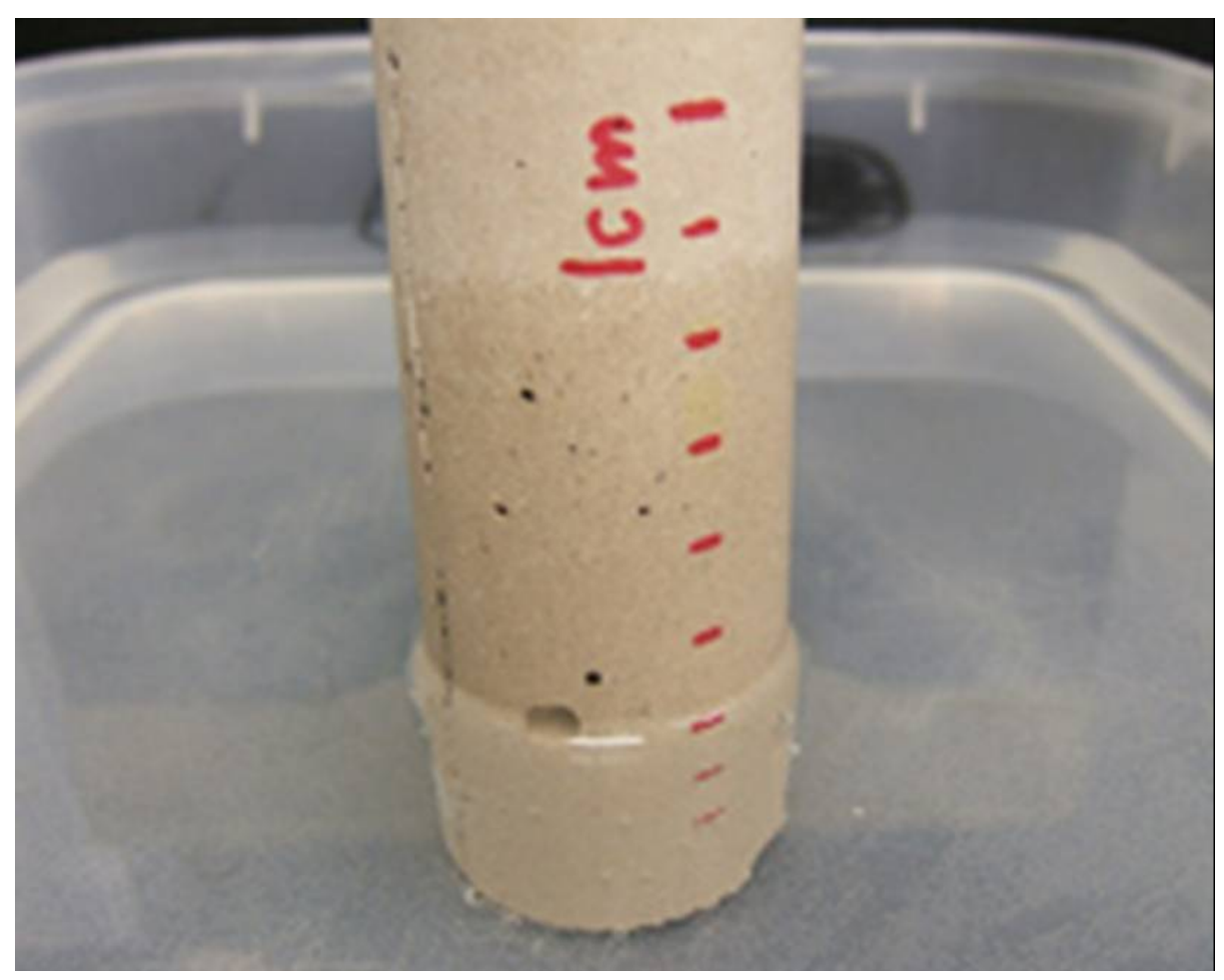

Figure 5.2. CRB Sample in Water after 13,304 s (3.7 h) 
Table 5.1. Capillary Rise of Water in CRB at Room Temperature

\begin{tabular}{|c|c|}
\hline Time, $\mathbf{s}$ & $\boldsymbol{h}, \mathbf{m m}$ \\
\hline 0 & 0 \\
\hline 29 & 1.6 \\
\hline 79 & 2.4 \\
\hline 119 & 3.2 \\
\hline 259 & 4.8 \\
\hline 354 & 6.4 \\
\hline 592 & 8.4 \\
\hline 1808 & 15.6 \\
\hline 2398 & 18.4 \\
\hline 3700 & 24.2 \\
\hline 5512 & 30.8 \\
\hline 6824 & 33.7 \\
\hline 13304 & 45.3 \\
\hline 55716 & 66.9 \\
\hline
\end{tabular}

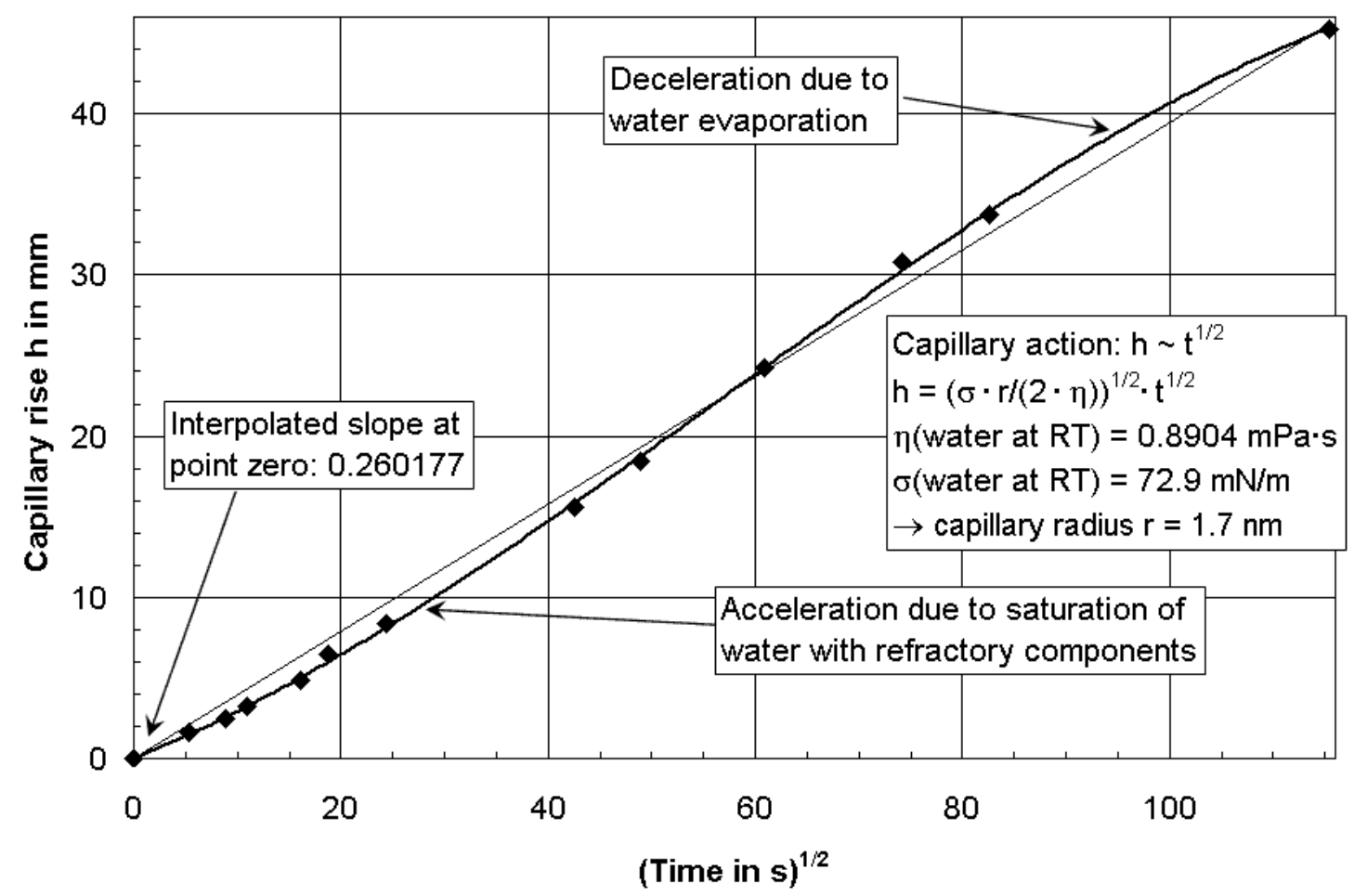

Figure 5.3. Capillary Rise of Water in the CRB at Room Temperature

From the experiment with water, an effective capillary radius of $1.7 \mathrm{~nm}$ can be calculated, using the interpolated slope at time zero of 0.2602 , a viscosity of $0.8904 \mathrm{mPa} \cdot \mathrm{s}$, and a surface tension of $72.9 \mathrm{mN} / \mathrm{m}$ of water at room temperature. The effective radius is equivalent to the radius of a single capillary tube and is likely represented by the size of small channels (necks) that connect the open pores. 
Figure 5.3 also demonstrates that the capillary rise of water in the castable refractory did not take place under ideal conditions. The water properties changed because the refractory components dissolved, and water evaporated during the experiment. Therefore, the interpolated slope at the time zero was used in the calculations.

\subsection{Experiments with LAW Simulant at $450^{\circ} \mathrm{C}$}

The dry LAW simulant was mixed in a ball mill as listed in Table 5.2, which is the same as in Table 4.1 except that the sodium chromate was added in threefold excess as a coloring agent. The main component of the dried LAW simulant is sodium nitrate.

Table 5.2. Dry LAW Simulant Composition Used in Capillary Test

\begin{tabular}{|l|r|}
\hline Component & wt\% \\
\hline $\mathrm{NaOH}$ & 7.72 \\
\hline $\mathrm{Al}\left(\mathrm{NO}_{3}\right)_{3} * 9 \mathrm{H}_{2} \mathrm{O}$ & 6.24 \\
\hline $\mathrm{Na}_{2} \mathrm{CrO}_{4}$ & 1.32 \\
\hline $\mathrm{Na}_{2} \mathrm{C}_{2} \mathrm{O}_{4}$ & 0.41 \\
\hline $\mathrm{CH}_{3} \mathrm{COONa}$ & 2.82 \\
\hline $\mathrm{NaNO}_{3}$ & 51.17 \\
\hline $\mathrm{KNO}_{3}$ & 0.33 \\
\hline $\mathrm{Na}_{2} \mathrm{CO}_{3}$ & 13.14 \\
\hline $\mathrm{Na}_{2} \mathrm{SO}_{4}$ & 3.33 \\
\hline $\mathrm{Na}_{3} \mathrm{PO}_{4} * 12 \mathrm{H}_{2} \mathrm{O}$ & 4.88 \\
\hline $\mathrm{NaCl}$ & 0.67 \\
\hline $\mathrm{NaF}$ & 0.35 \\
\hline $\mathrm{NaNO}$ & 7.64 \\
\hline \hline
\end{tabular}

Table 5.3 and Table 5.4 list the surface tension and viscosity of sodium nitrate, the main component in dry LAW. These values were used as approximate values to help estimate the capillary action of the LAW salt melt in the refractory according to Equations (5.1) and (5.2).

Table 5.3. Surface Tension of Sodium Nitrate Melt (Gale and Totemeier 2004)

\begin{tabular}{|c|c|}
\hline \hline Temperature, ${ }^{\circ} \mathbf{C}$ & $\boldsymbol{\sigma}, \mathbf{N} / \mathbf{m}$ \\
\hline 310 & 0.11621 \\
\hline 400 & 0.11270 \\
\hline 450 & 0.11075 \\
\hline 500 & 0.10880 \\
\hline 600 & 0.10490 \\
\hline
\end{tabular}


Table 5.4. Viscosity of Sodium Nitrate Melt (Gale and Totemeier 2004)

\begin{tabular}{|c|c|}
\hline \hline Temperature, ${ }^{\circ} \mathbf{C}$ & $\boldsymbol{\eta}, \mathbf{m P a} \cdot \mathbf{s}$ \\
\hline 300 & 3.156 \\
\hline 400 & 1.901 \\
\hline 450 & 1.521 \\
\hline 500 & 1.305 \\
\hline
\end{tabular}

Figure 5.4 shows that the LAW simulant mix melted at $450^{\circ} \mathrm{C}$ in a platinum crucible. At $450^{\circ} \mathrm{C}$, most of the LAW simulant melts with vigorous gas evolution; unmelted material such as $\mathrm{Al}_{2} \mathrm{O}_{3}$, which forms from Al-nitrate, settles to the bottom of the crucible. The refractory sample with Inconel wire wrapped around the bottom end was lowered into the crucible until contact with the melt was established; that is, the resistivity dropped to zero. Then the refractory was lowered another $\sim 5 \mathrm{~mm}$ into the melt, causing the melt level to rise proportionally. Samples were held at temperature for a specified period of time and then removed and allowed to cool. After cooling, the samples were fractured to measure the height of the capillary rise. Multiple samples were used to obtain heights at different times.

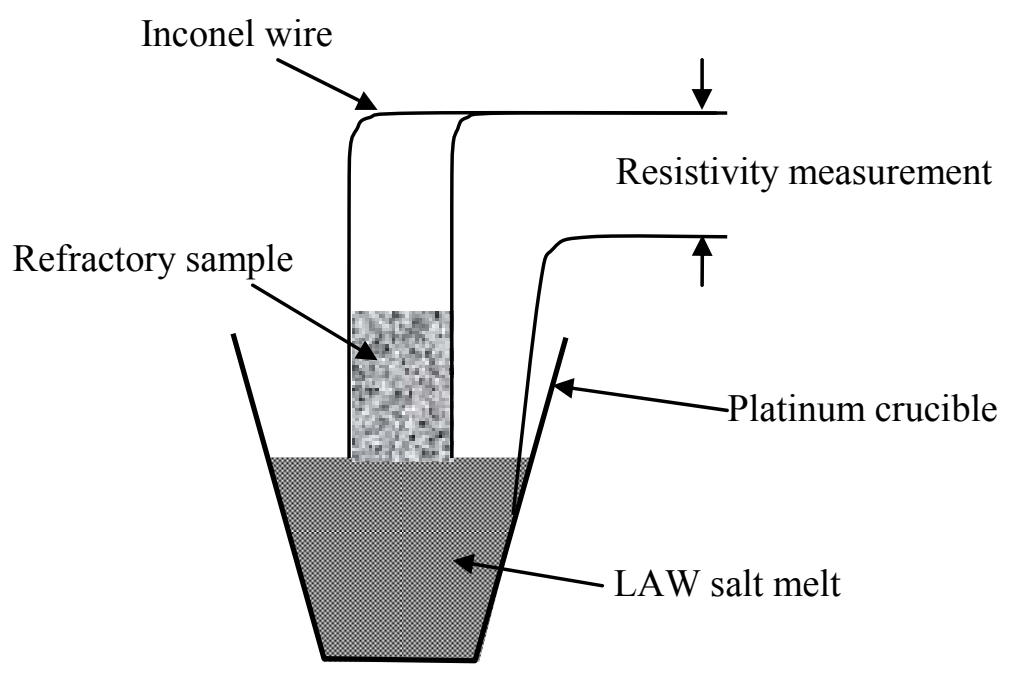

Figure 5.4. Experimental Setup for Measuring LAW Salt Melt Capillary Rise in CRB

Figure 5.5 shows a typical experimental result. The capillary action fronts are clearly visible. Figure 5.6 displays a CRB cross-section with exaggerated colors for better contrast. The chromate coloring agent appears to interact with the refractory in such a way that it penetrates to a limited depth, in contrast to the remainder of the LAW simulant melt. It appeared that the chromate capillary action stopped completely, but more tests would be needed to confirm this preliminary observation.

Table 5.5 and Figure 5.7 display the capillary action results in the castable refractory using LAW simulant salt melt at $450^{\circ} \mathrm{C}$. The force of gravity and the liquid pressure from the salt above the CRB bottom were neglected, allowing the capillary rise height to be estimated as the distance from the bottom of the castable refractory to the capillary action front. 


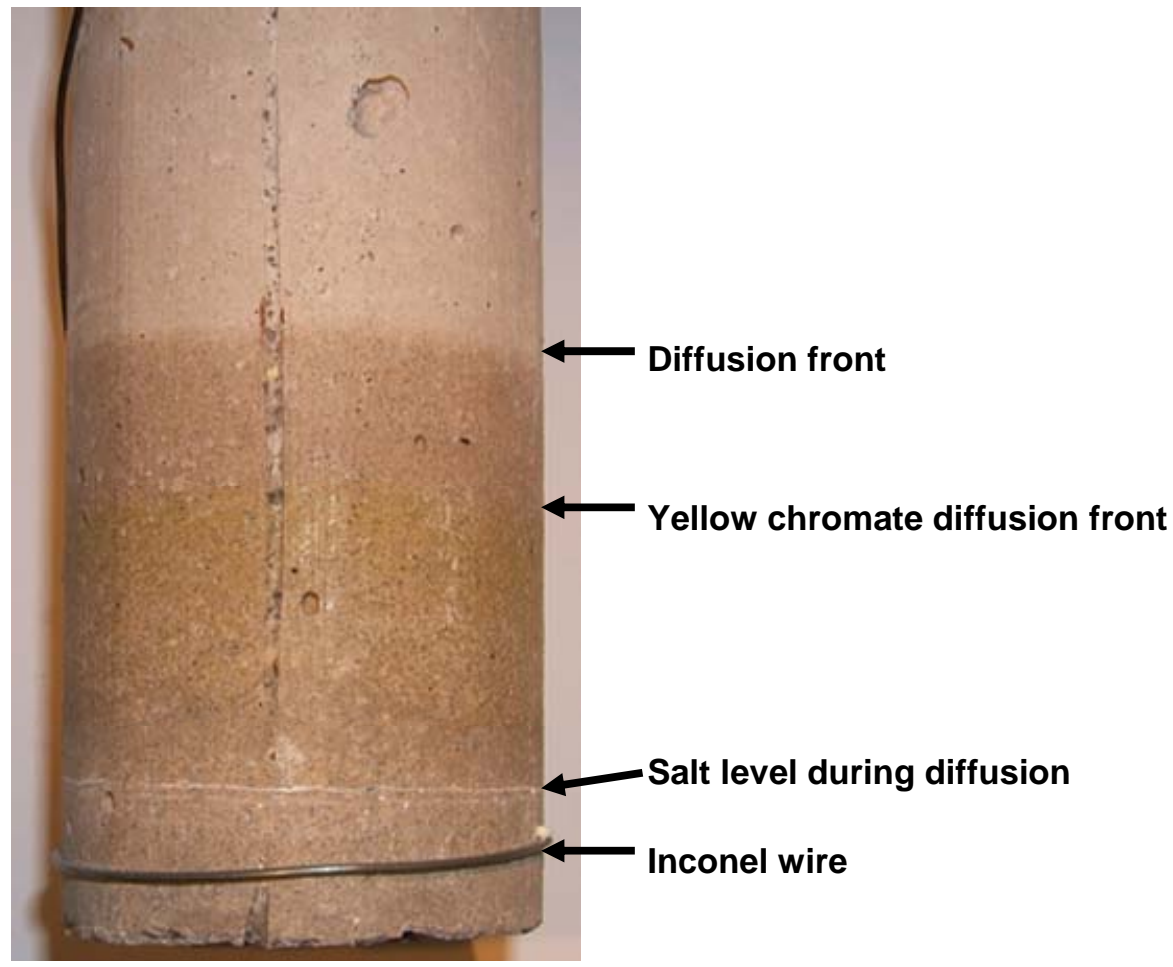

Figure 5.5. Typical Capillary Rise Result of LAW Simulant Melt at $450^{\circ} \mathrm{C}$ in CRB 


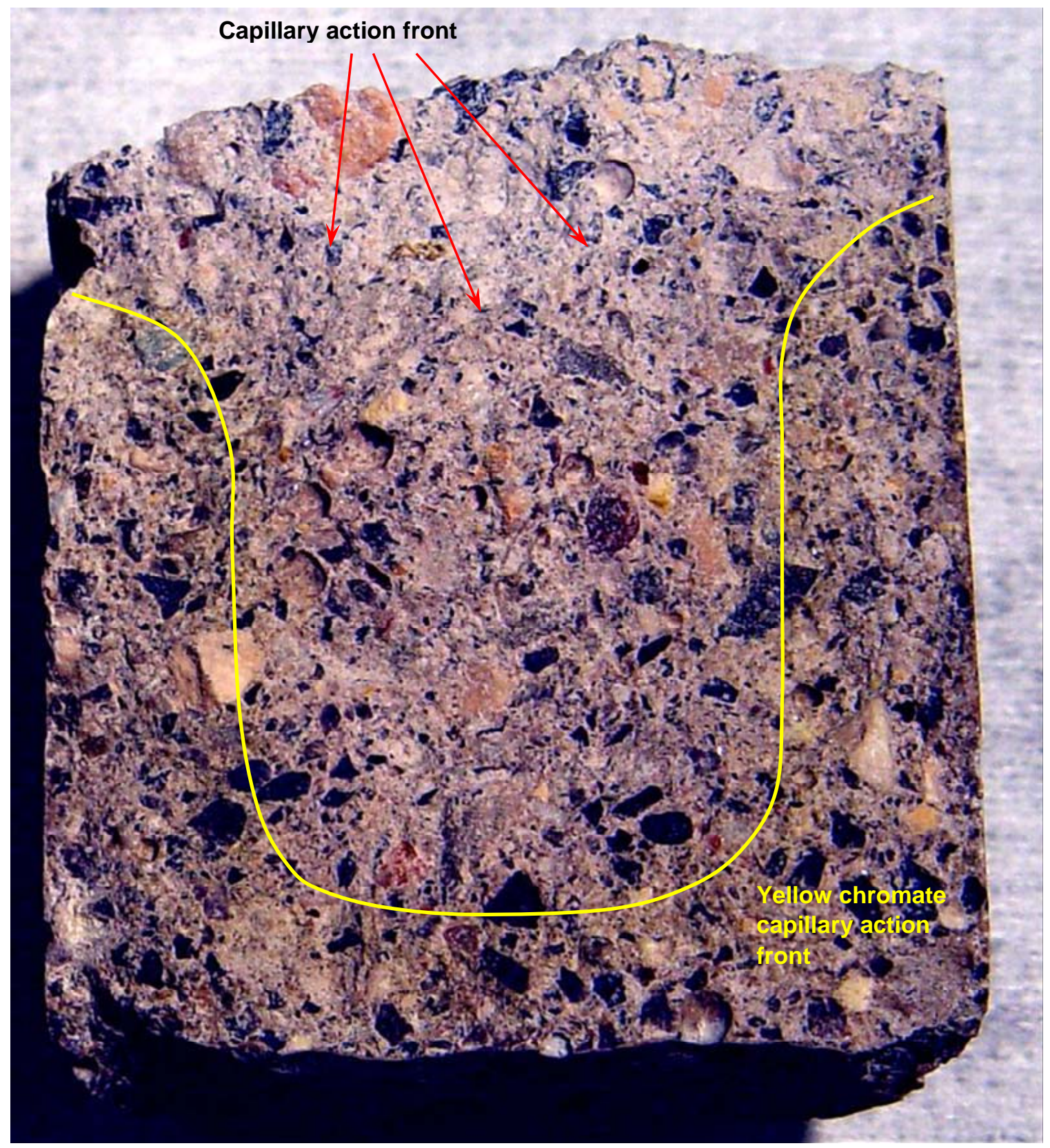

Figure 5.6. Typical Capillary Rise Result of LAW Simulant Melt at $450^{\circ} \mathrm{C}$ in CRB, Fractured Surface (exaggerated color contrast for better visibility)

Table 5.5. Capillary Rise of LAW Simulant in CRB at $450{ }^{\circ} \mathrm{C}$

\begin{tabular}{||c|c||}
\hline Time, $\mathbf{s}$ & $\boldsymbol{h}, \mathbf{m m}$ \\
\hline 0 & 0 \\
\hline 1800 & 5 \\
\hline 5400 & 15 \\
\hline 10800 & 21 \\
\hline
\end{tabular}




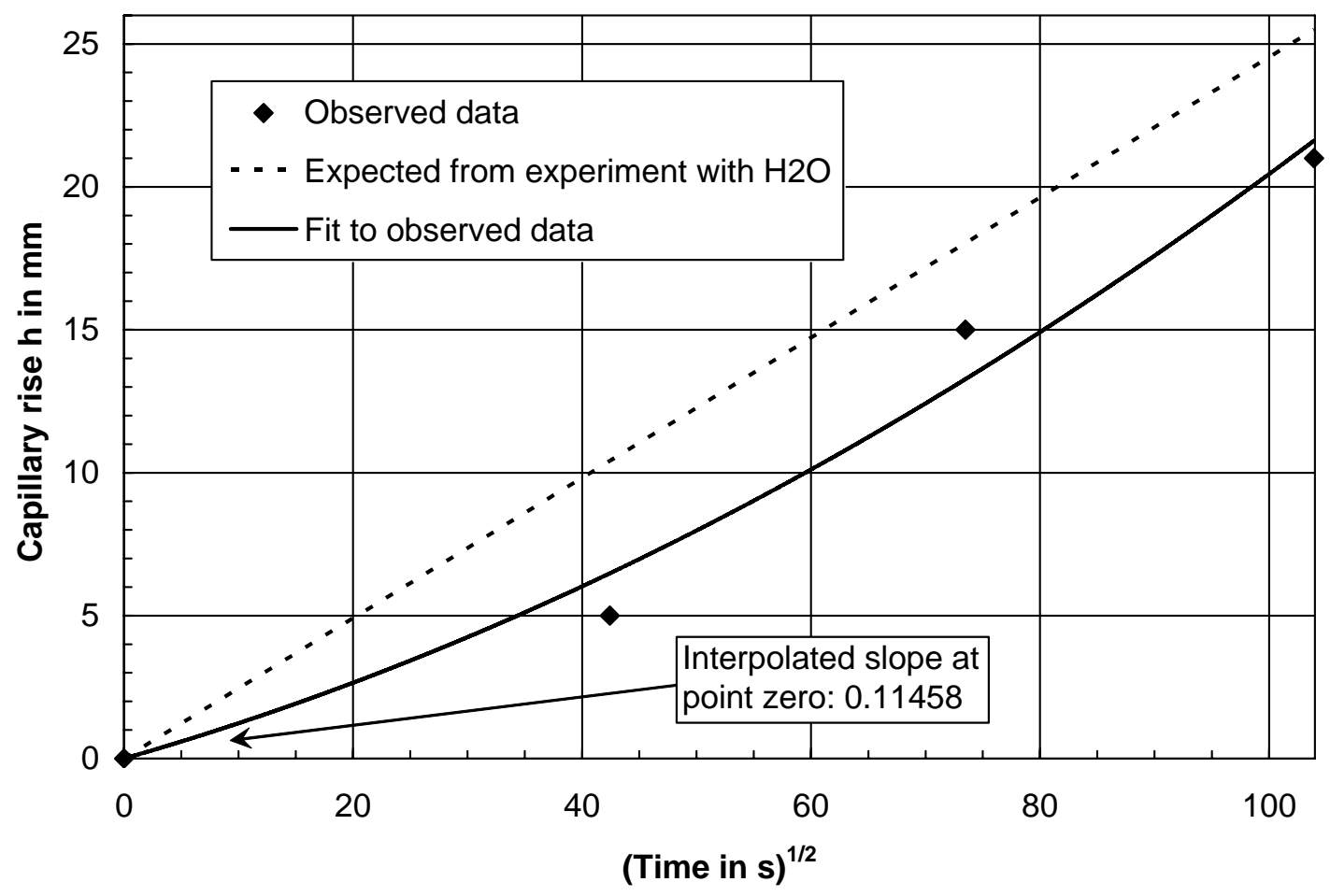

Figure 5.7. Capillary Rise of LAW Simulant Melt in CRB at $450^{\circ} \mathrm{C}$

Using the viscosity and surface tension data of $\mathrm{NaNO}_{3}$ in Table 5.3 and Table 5.4, the "effective" capillary radius in the refractory would be $0.4 \mathrm{~nm}$ compared to $1.7 \mathrm{~nm}$ determined from the experiment with water. The capillary rise curve based on the "effective" capillary radius obtained from the water penetration test is also shown in Figure 5.7 for comparison. Figure 5.7 shows that there is a reasonable agreement between the water and LAW simulant tests. The difference in the expected and observed data is likely from the assumption that the viscosity and surface tension of the LAW simulant melt at $450^{\circ} \mathrm{C}$ is the same as the pure $\mathrm{NaNO}_{3}$. If the capillary radius of $1.7 \mathrm{~nm}$ determined from the experiment with water is assumed to be accurate, the ratio of surface tension in $\mathrm{N} / \mathrm{m}$ to viscosity in Pa.s of the LAW melt at $450^{\circ} \mathrm{C}$ would be 15.9 , as opposed to 72.8 for pure $\mathrm{NaNO}_{3}$. In other words, if the viscosity of the MIS is slightly higher or the surface tension slightly lower than pure $\mathrm{NaNO}_{3}$, the expected and observed data would match better. Also, more scatter in the data is expected in the experiments with the LAW melt compared to the water experiments because a new refractory rod was used for each time period, and the capillary radius in different refractory rods may be somewhat variable.

\subsection{Summary}

The experiments in this report confirmed that the penetration of LAW simulant salt melt into a CRB through capillary force is the dominant force for Tc transport. The effective capillary radius in the castable refractory was estimated as $1.7 \mathrm{~nm}$ from the experiment with water. At $450^{\circ} \mathrm{C}$, the ratio of surface tension in $\mathrm{N} / \mathrm{m}$ to viscosity in Pa.s of the LAW melt was predicted as 15.9. 


\subsection{Hot-Stage Microscopy Feed Melting Study}

This section documents the result of a small-scale, hot-stage melting study on the simulated BV feeds. The purpose of this subtask was to investigate the feasibility of applying hot-stage melting studies to the fast verification of BV melting mechanisms and to the screening of alternate additive materials that mitigate MIS penetration into CRB.

\subsection{Test Method}

Approximately $100 \mathrm{mg}$ of feed was loaded into a small cylindrical platinum (Pt) crucible 6 to $7 \mathrm{~mm}$ in diameter and $4 \mathrm{~mm}$ in height, heated in a hot-stage furnace, and viewed microscopically. The crucible was covered with a 1.6-mm-thick fused quartz window through which the feed melting was observed. The feed was heated stepwise from room temperature at 10 to $25^{\circ} \mathrm{C}$ increments to keep a rough average heating rate of $5^{\circ} \mathrm{C} / \mathrm{min}$. The heating was stopped when all the feed melted and became a clear liquid. Because the hot-stage furnace was not equipped with an automatic temperature controller, the heating had to be adjusted manually, resulting in unavoidable variations in the heating rate between different samples.

The dry simulant mix (as shown in Table 4.1) and two feed variations were tested: 1) 38B feed: a mixture of all dry chemicals as used in a recent FS-38B test, and 2) baseline feed: a full-scale design feed prepared from liquid simulant that was mixed with all additives to have the same composition as the $38 \mathrm{~B}$ feed.

\subsection{Results}

Figure 6.1 displays the change of morphology of a dry 6-tank composite simulant with temperature. At $330^{\circ} \mathrm{C}$, local melting was apparent; at $450^{\circ} \mathrm{C}$, the simulant was mainly liquid with some undissolved particles and bubbles; at $550^{\circ} \mathrm{C}$, it was almost clear liquid; between 700 and $760^{\circ} \mathrm{C}$, the liquid started to generate foam, likely from decomposing chemicals (likely $\mathrm{NaNO}_{3}$ ); at $850^{\circ} \mathrm{C}$, bubbles started disappearing; and by $940^{\circ} \mathrm{C}$, the bubbles were gone, and solids were shown to have precipitated at the lower-right corner of the crucible.

Figure 6.2 displays hot-stage microscopy images of two feeds as a function of temperature: 1) left: $38 \mathrm{~B}$ feed and 2) right: baseline feed. At $700^{\circ} \mathrm{C}$, some chemical particles at the top and bottom of the pan melted for the 38B feed while most of the soil particles remained in the same place. The baseline feed at $675^{\circ} \mathrm{C}$ showed little evidence of liquid formation. At $875^{\circ} \mathrm{C}$ for the $38 \mathrm{~B}$ feed and at $850^{\circ} \mathrm{C}$ for the baseline feed, there was a clear indication of liquid-phase formation. At 900 and $1100^{\circ} \mathrm{C}$ for $38 \mathrm{~B}$ feed and at 950 and $1075^{\circ} \mathrm{C}$ for the baseline feed, the progress of liquid formation was obvious for both feeds, but a higher fraction of liquid seemed to have formed for the 38B feed than the baseline feed. The 38B feed also seemed to have a greater degree of segregation of the different particles than the baseline feed.

These observations show that the behavior of a dry blended feed and a feed prepared from liquid simulant is significantly different. Although there was important information obtained in the full-scale tests conducted with dry blended feed, it is important to verify results with drier prepared feed in future operations. 


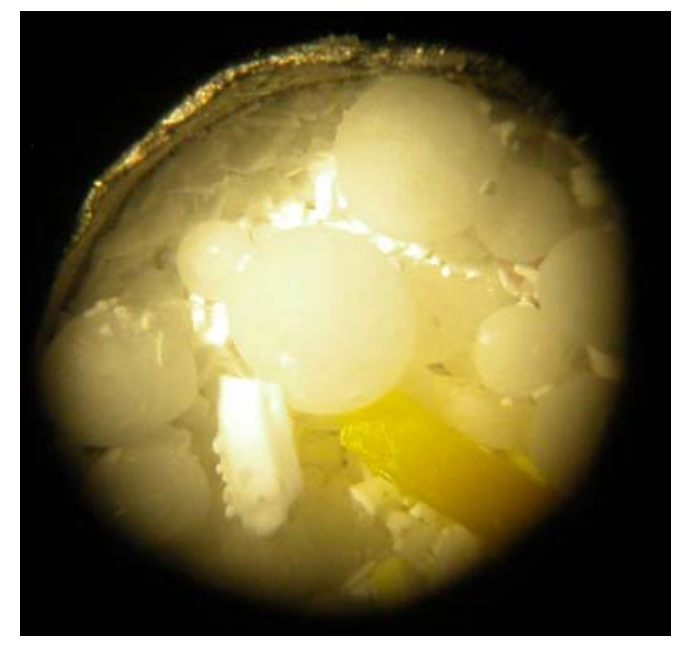

Room temperature

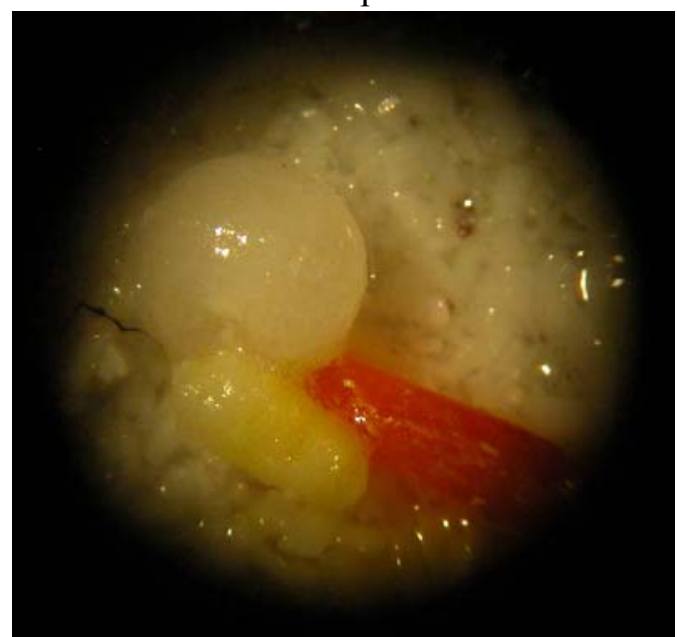

$330^{\circ} \mathrm{C}$

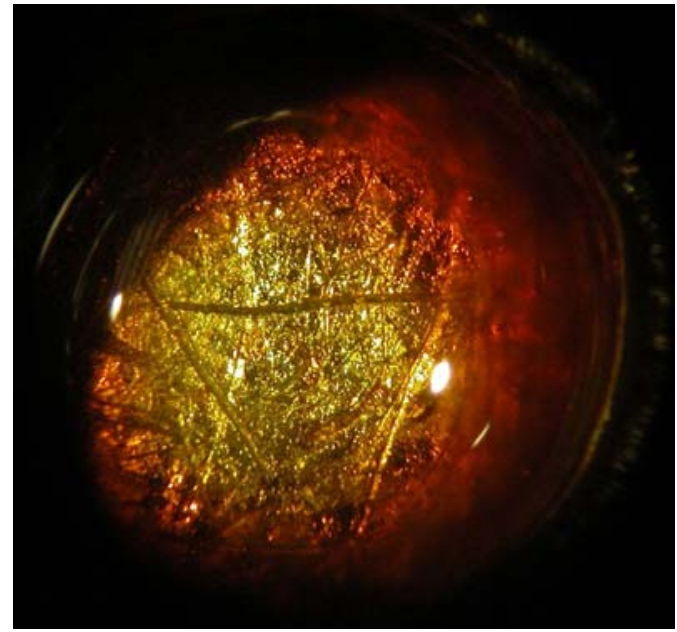

$550^{\circ} \mathrm{C}$

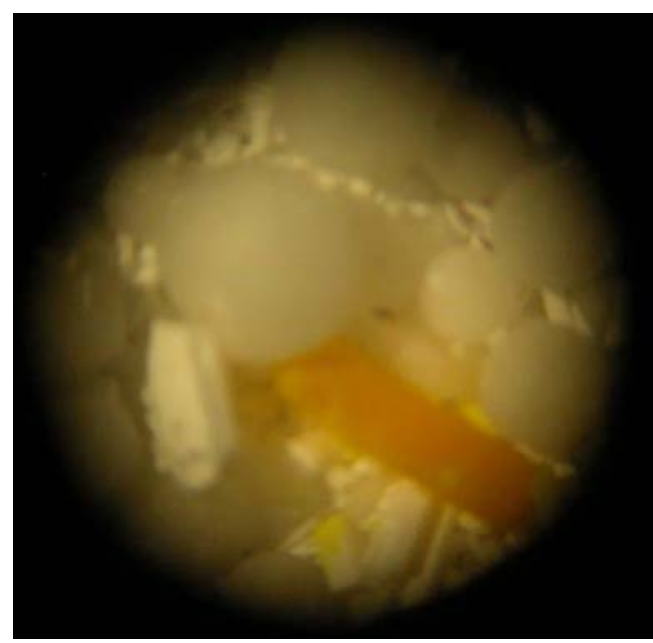

$250^{\circ} \mathrm{C}$

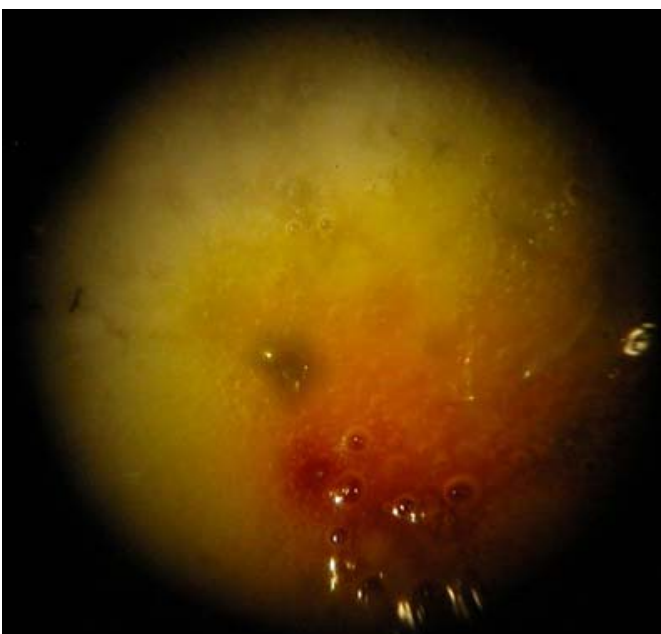

$450^{\circ} \mathrm{C}$

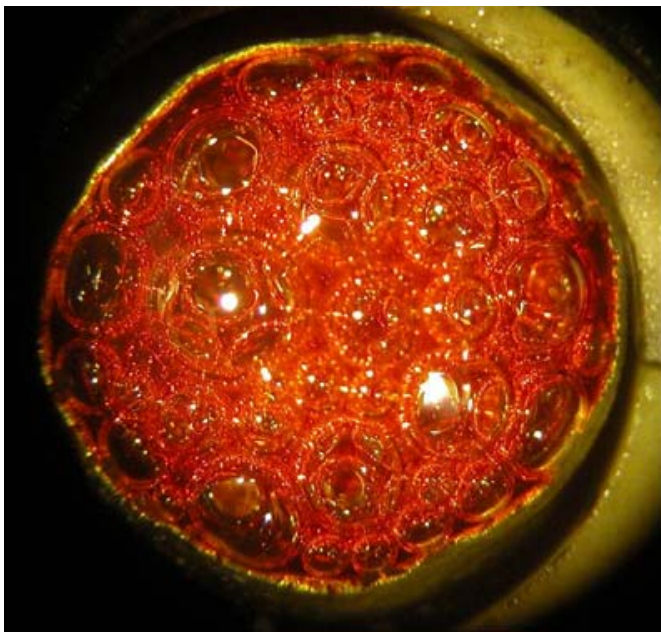

$760^{\circ} \mathrm{C}$

Figure 6.1. Hot-Stage Microscopy Images of Dry LAW (6-Tank Composite) Simulant 


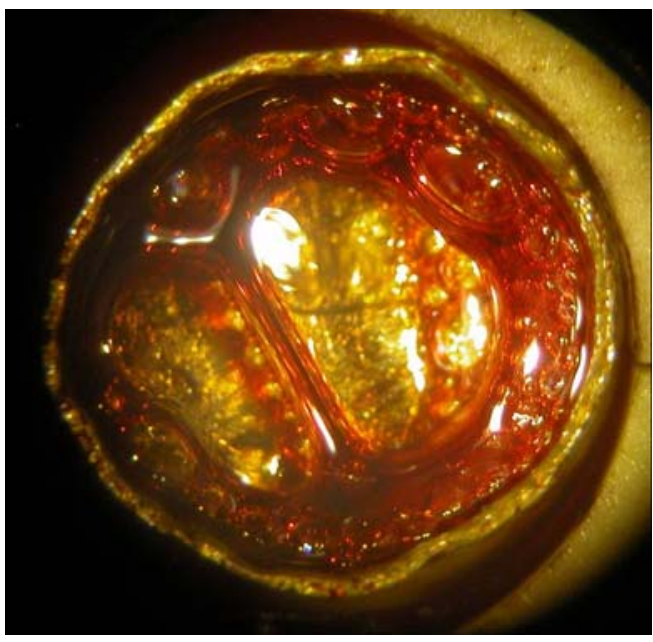

$850^{\circ} \mathrm{C}$

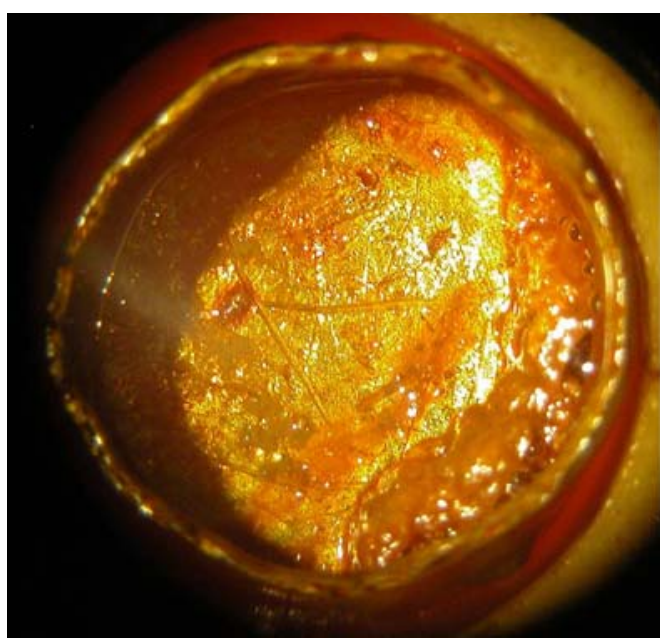

$940^{\circ} \mathrm{C}$

Figure 6.1 (Contd)

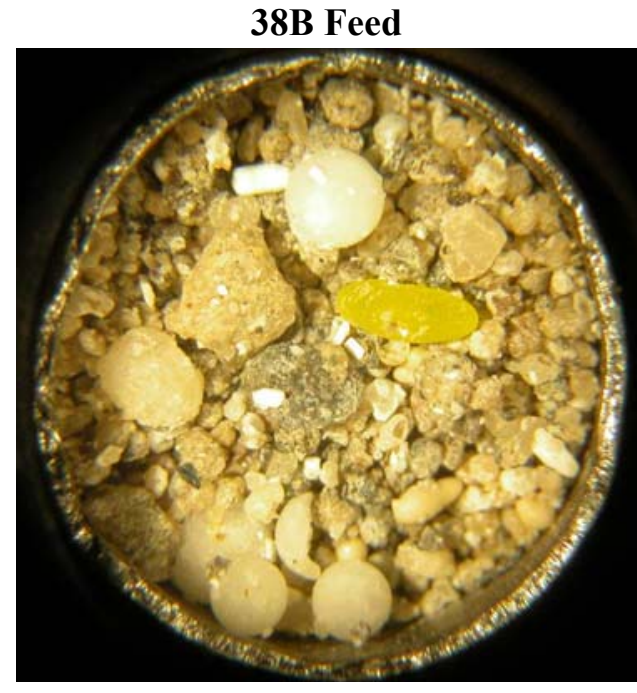

Room temperature

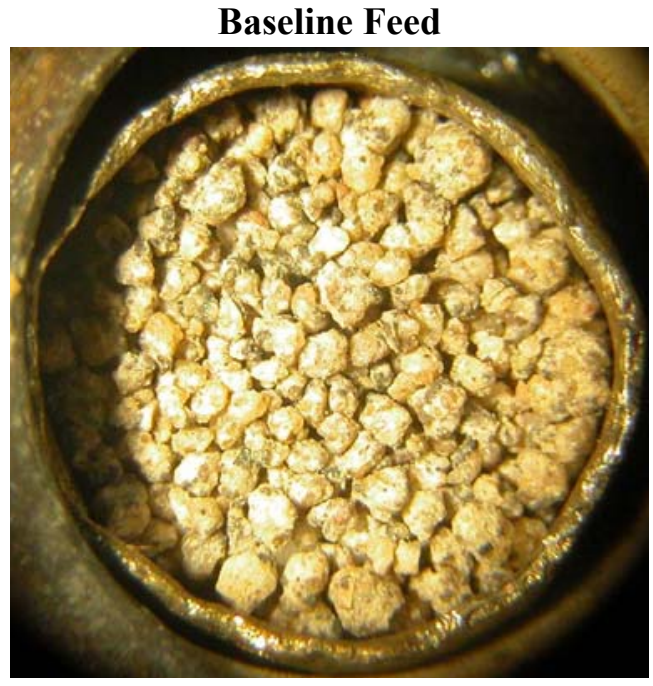

Room temperature

Figure 6.2. Hot-Stage Microscopy Images of 38B (Left) and Baseline (Right) Feeds 


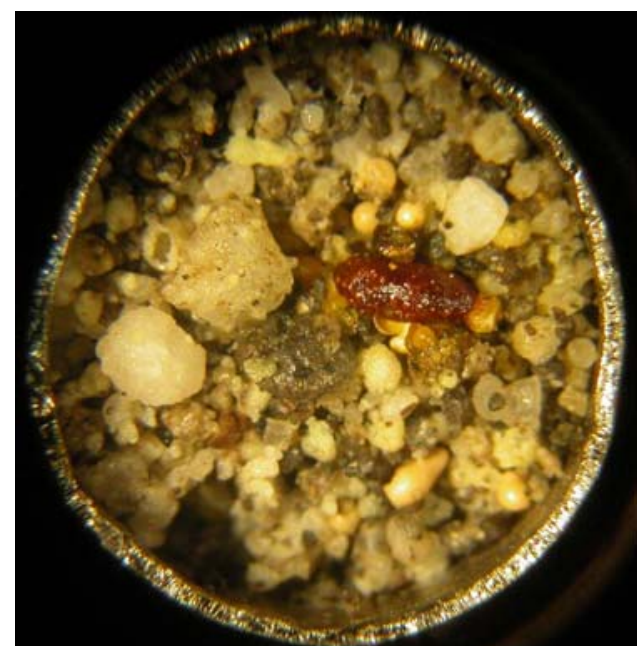

$700^{\circ} \mathrm{C}$

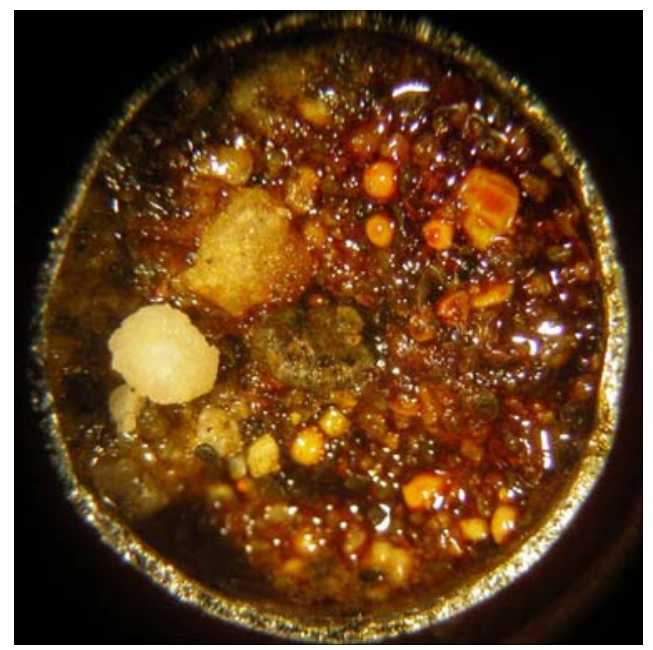

875

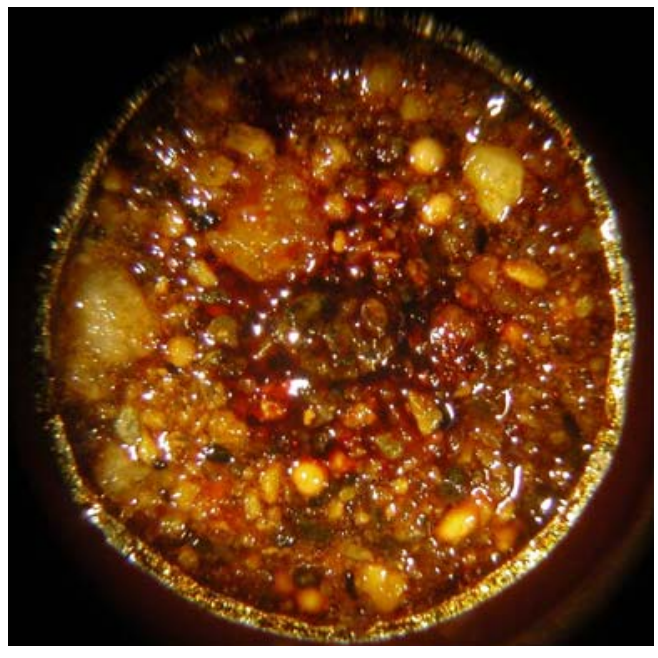

$900^{\circ} \mathrm{C}$

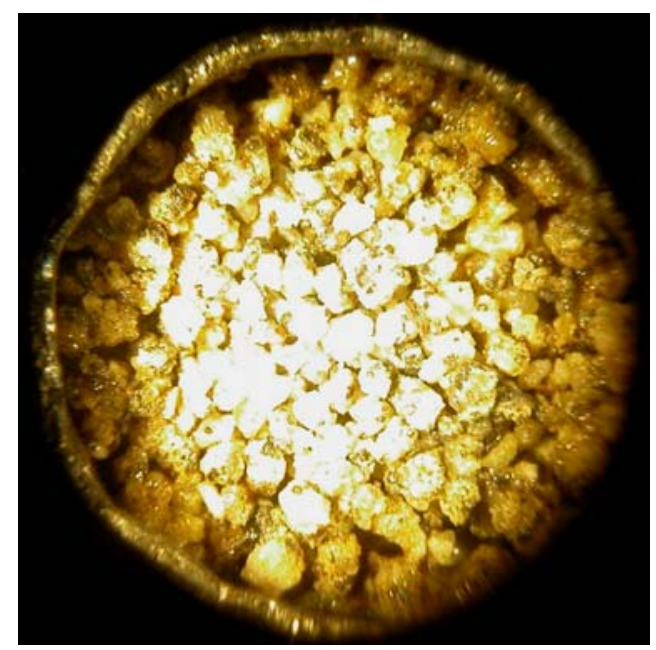

$675^{\circ} \mathrm{C}$

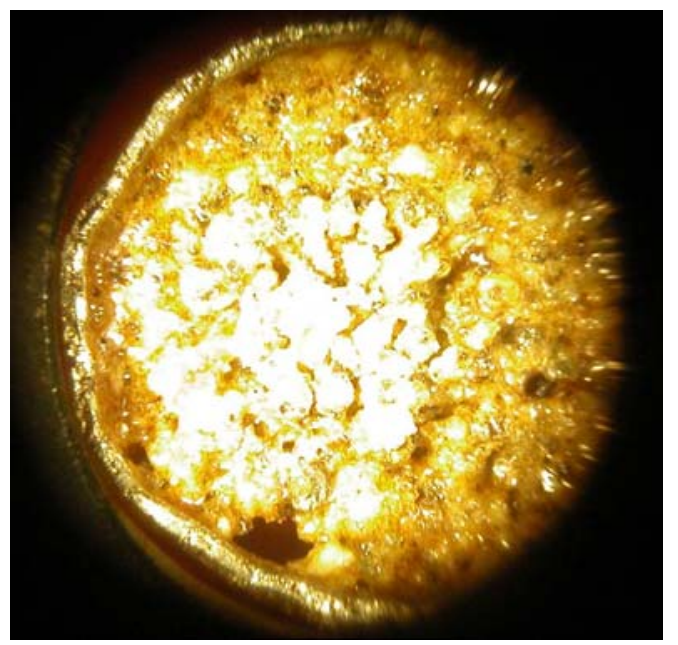

850

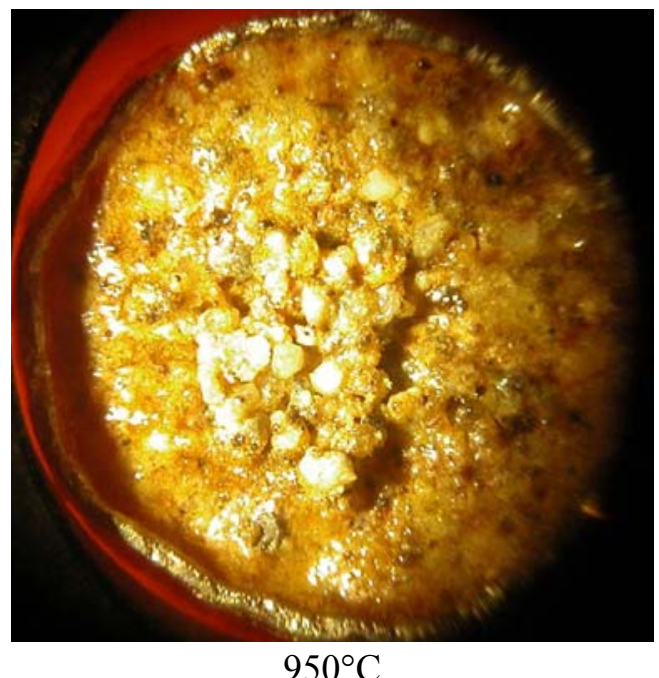

Figure 6.2 (Contd) 


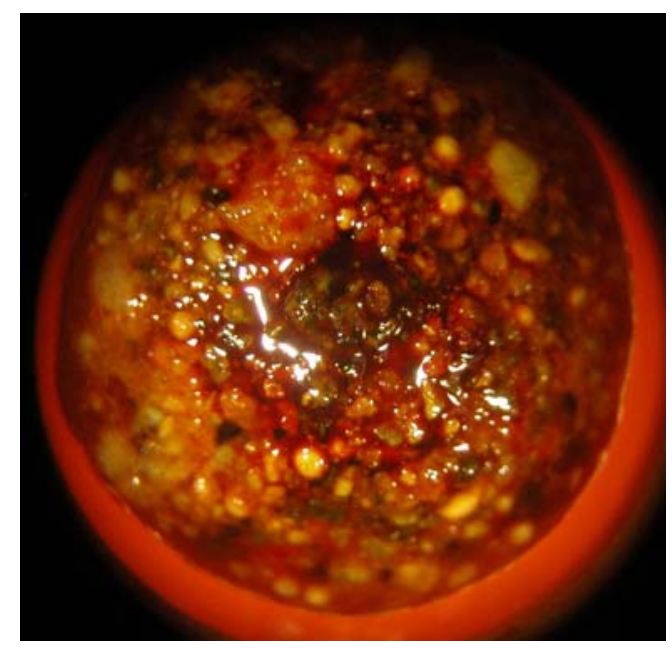

$1100^{\circ} \mathrm{C}$

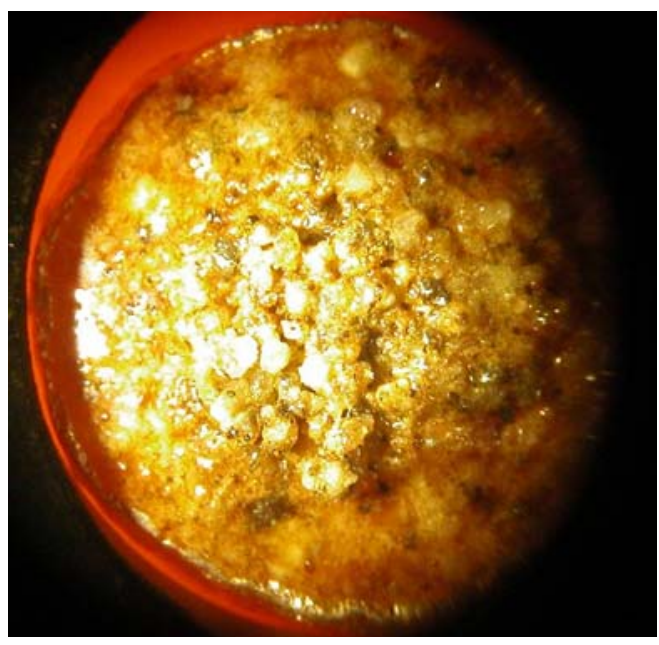

$1075^{\circ} \mathrm{C}$

Figure 6.2 (Contd) 


\subsection{CRB Re Penetration Profile}

This section documents the results of MIS penetration profile analyses of CRB samples from the FS-38B test. The purpose of this subtask was to provide important information of the mechanism for Re and Tc penetration/deposition and investigate mechanistic differences between the top and bottom portions of the CRB.

\subsection{Porosity of CRB}

The porosity of the CRB was measured to estimate the maximum amount of MIS that would be present in a fully saturated CRB. The open and total porosity were measured for both as-received and heat-treated CRB cylinder samples.

Six samples of approximately equal size were cut from the $\sim 4$-cm-diameter cylinder using a large cutoff saw. Each sample was $2.4 \mathrm{~cm}$ tall. After drying overnight in a $90^{\circ} \mathrm{C}$ oven, three of the samples were heat treated at $1200^{\circ} \mathrm{C}$ for $1 \mathrm{~h}$. The heat-treated samples were labeled $\mathrm{H} 1, \mathrm{H} 2$, and $\mathrm{H} 3$, while the nonheat-treated samples were labeled A1, A2, and A3 for "as-received." The bulk density was measured from the mass and volume of each CRB sample. The sample volume was determined from multiple height and diameter readings for each sample.

For measuring open porosity, each weighed sample was immersed into deionized water (DIW) in a container that was evacuated using the building vacuum system. After holding the sample under a vacuum for $2 \mathrm{~h}$, each sample was re-weighed. The total mass gain was attributed to water absorption into the open pores, which was then converted to a volume of open pores by assuming a water density of 1 $\mathrm{g} / \mathrm{cm}^{3}$. The volume-fraction open porosity is the volume of open pores divided by the total sample volume.

For measuring the density of CRB material, $\sim 1 \mathrm{~g}$ was removed from each sample and ground in a tungsten carbide mill for 4 min. The density of fine CRB particles was measured using a calibrated gas pycnometer. The total porosity was then obtained from (total porosity) $=1-$ (bulk density) $/($ particle density). The closed porosity is obtained by subtracting the open porosity from the total porosity.

Table 7.1 summarizes the result of measuring density and porosity on the as-received and heat-treated CRB samples. Figure 7.1 shows that heat treatment increased the closed porosity slightly but without noticeable change in the open porosity. The total porosity of $22 \%$ measured in this study was higher than the $17 \%$ reported by the CRB manufacturer. 
Table 7.1. Density and Porosity of As-Received and Heat-Treated CRB Samples

\begin{tabular}{|c|c|c|c|c|c|c|}
\hline CRB & Sample & $\begin{array}{c}\text { Bulk } \\
\text { density } \\
\left(\mathrm{g} / \mathrm{cm}^{3}\right)\end{array}$ & $\begin{array}{c}\text { Material } \\
\text { density } \\
\left(\mathrm{g} / \mathrm{cm}^{3}\right)\end{array}$ & $\begin{array}{c}\text { Open } \\
\text { porosity } \\
(\%)\end{array}$ & $\begin{array}{c}\text { Closed } \\
\text { porosity } \\
(\%)\end{array}$ & $\begin{array}{c}\text { Total } \\
\text { porosity } \\
(\%)\end{array}$ \\
\hline \multirow{5}{*}{$\begin{array}{c}\text { As- } \\
\text { received }\end{array}$} & A1 & 2.480 & 3.154 & 15.8 & 5.6 & 21.4 \\
\hline & $\mathrm{A} 2$ & 2.450 & 3.135 & 16.1 & 5.7 & 21.9 \\
\hline & A3 & 2.440 & 3.119 & 15.4 & 6.4 & 21.8 \\
\hline & Average & 2.456 & 3.136 & 15.8 & 5.9 & 21.7 \\
\hline & STD & 0.021 & 0.018 & 0.38 & 0.44 & 0.25 \\
\hline \multirow{5}{*}{$\begin{array}{l}\text { Heat- } \\
\text { treated }\end{array}$} & $\mathrm{H} 1$ & 2.437 & 3.155 & 15.2 & 7.5 & 22.7 \\
\hline & $\mathrm{H} 2$ & 2.448 & 3.175 & 14.9 & 8.0 & 22.9 \\
\hline & $\mathrm{H} 3$ & 2.444 & 3.132 & 15.0 & 6.9 & 21.9 \\
\hline & Average & 2.443 & 3.154 & 15.1 & 7.5 & 22.5 \\
\hline & STD & 0.006 & 0.022 & 0.16 & 0.52 & 0.51 \\
\hline
\end{tabular}
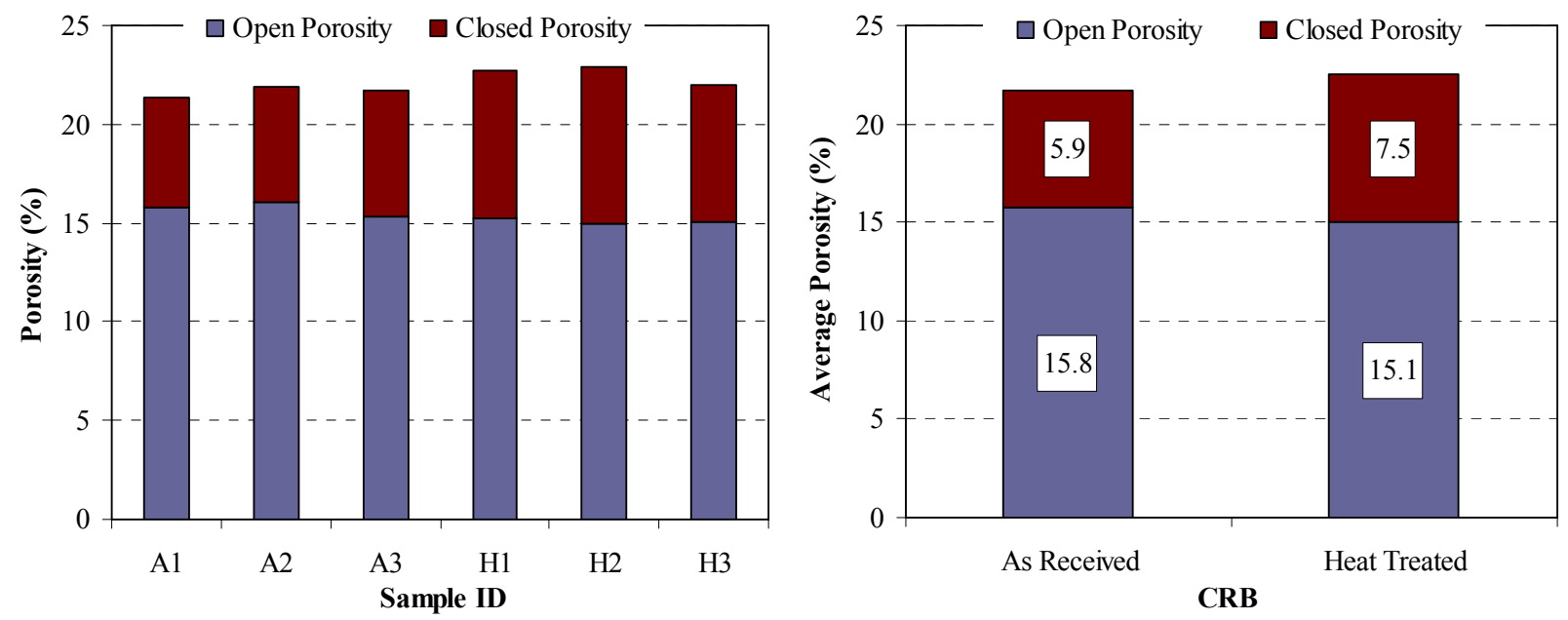

Figure 7.1. Porosity of As-Received and Heat-Treated CRB Samples

\subsection{CRB Sample Descriptions}

Figure 7.2 displays the east wall of Test FS-38B showing the locations for CRB samples taken for this study. Figure 7.3 shows the sample blocks after they were removed from the CRB panel: \#1 was from $\sim 38.1 \mathrm{~cm}$ above the melt line, $\# 2$ just above the melt line, $\# 3$ at the melt line, and $\# 4 \sim 15.2 \mathrm{~cm}$ below the melt line. CRB samples \#1,\#3, and \#4 were used to study the Re penetration profile. Tests included a semi-quantitative scanning electron microscopy-energy dispersive spectroscopy (SEM-EDS) analysis, a preliminary method development study, and a quantitative thin section study. These sample locations represent different areas of the $\mathrm{CRB}$ and were also in the same locations as the CRB samples taken for the Re Extraction Study (Cooley et al. 2006) so that direct comparisons can be made. The \#4 sample block was used for the preliminary method development study. 


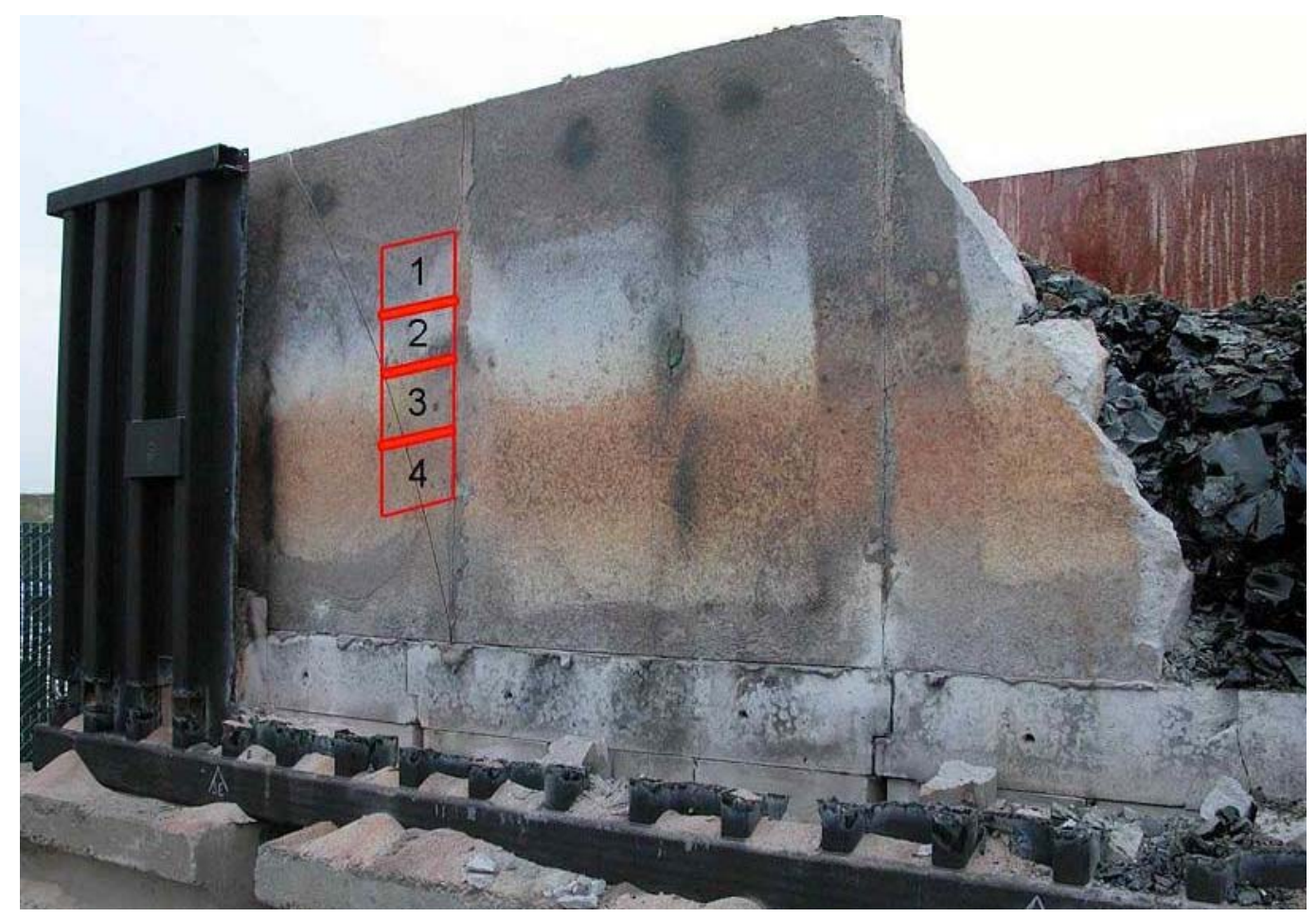

Figure 7.2. Picture of East Wall from Test FS-38B Showing the Locations for CRB Sampling

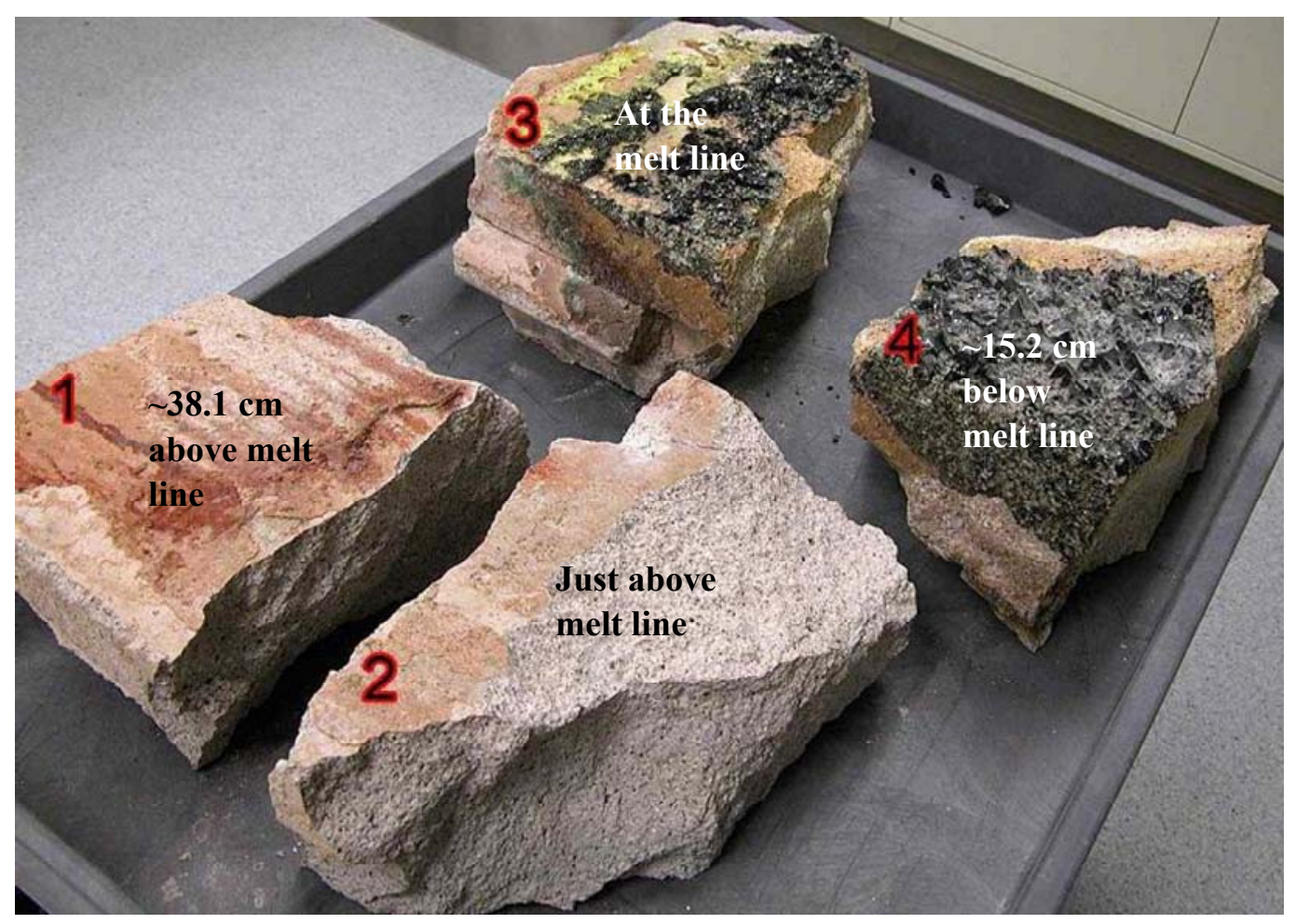

Figure 7.3. CRB Samples from Test FS-38B 


\subsection{SEM-EDS Analysis of CRB for MIS Profile}

The CRB samples from three locations were used to determine the preliminary MIS profile using sodium (Na) as an indication of MIS penetration. The samples for the SEM-EDS study were taken right next to the samples that were taken to analyze the thin-section profiles. To facilitate loading into the SEM, the CRB blocks were split into three pieces of $\sim 5$ to $8 \mathrm{~cm}$ wide and $\sim 5 \mathrm{~cm}$ depth using a jackhammer.

Figure 7.4 shows the CRB samples used for SEM-EDS. The samples labeled as I are from the glass/refractory interface (inside wall), and samples labeled as III are from the sand/refractory interface (outside wall). For the CRB from $\sim 38.1 \mathrm{~cm}$ above the melt line (CRB block 1), piece I was $5.1 \mathrm{~cm}$, piece II was $4.3 \mathrm{~cm}$, and piece III was $4.2 \mathrm{~cm}$ long with $\sim 0.6 \mathrm{~cm}$ of piece II and $\sim 0.8 \mathrm{~cm}$ of piece III lost during the sample preparation. For the CRB at the melt line (CRB block 3), piece I was $6.7 \mathrm{~cm}$, piece II was $3.6 \mathrm{~cm}$, and piece III was $4.7 \mathrm{~cm}$ long with minimal sample loss. For the CRB from $\sim 15.2 \mathrm{~cm}$ below the melt line (CRB block 43), piece I was $5 \mathrm{~cm}$, piece II was $3 \mathrm{~cm}$, and piece III was $4 \mathrm{~cm}$ long. Red-crossed areas for the CRB from $\sim 15.2 \mathrm{~cm}$ below the melt line in Figure 7.4 were lost during sample preparation.

Each CRB piece was coated with carbon under high vacuum $\left(\sim 10^{-7}\right.$ torr $)$ and analyzed using SEM-EDS. The distribution of $\mathrm{Na}$, sulfur $(\mathrm{S})$, and chlorine $(\mathrm{Cl})$ was measured at depth intervals of 1 to $3 \mathrm{~mm}$ using a measurement area of $\sim 0.5 \times 0.5 \mathrm{~mm}$ at each interval.

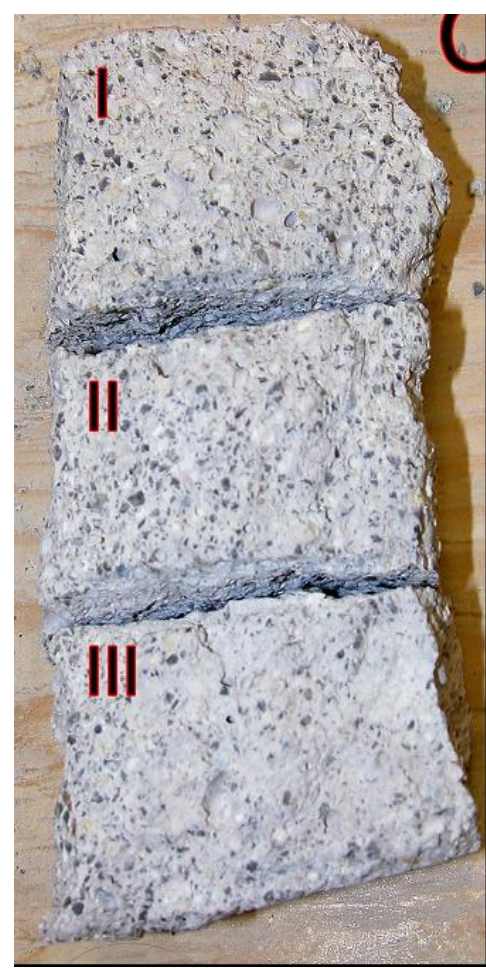

$\# 1$ ( $38.1 \mathrm{~cm}$ above the melt line)

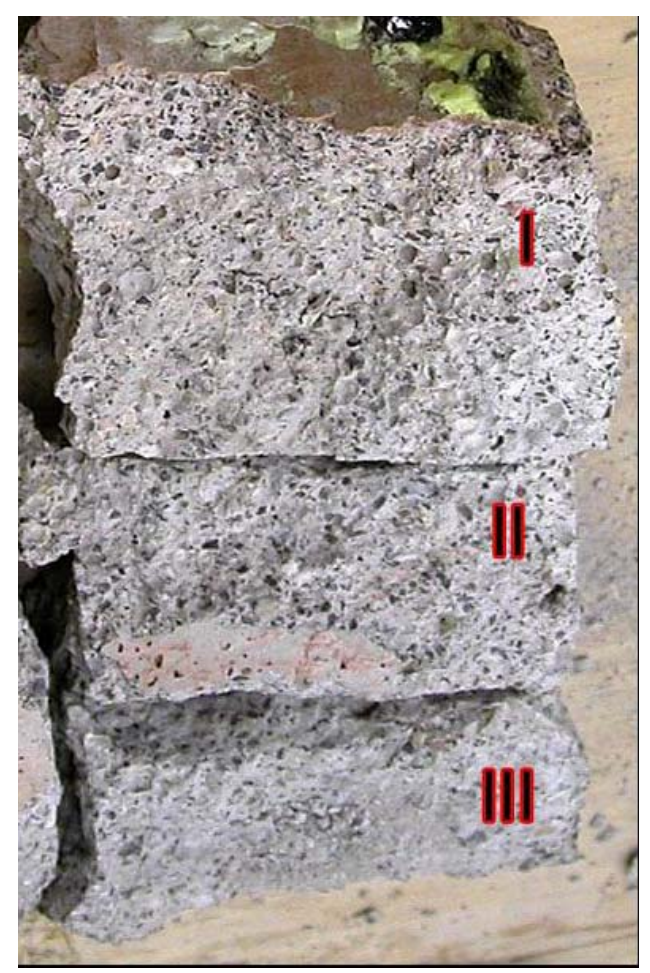

\#3 (at the melt line)

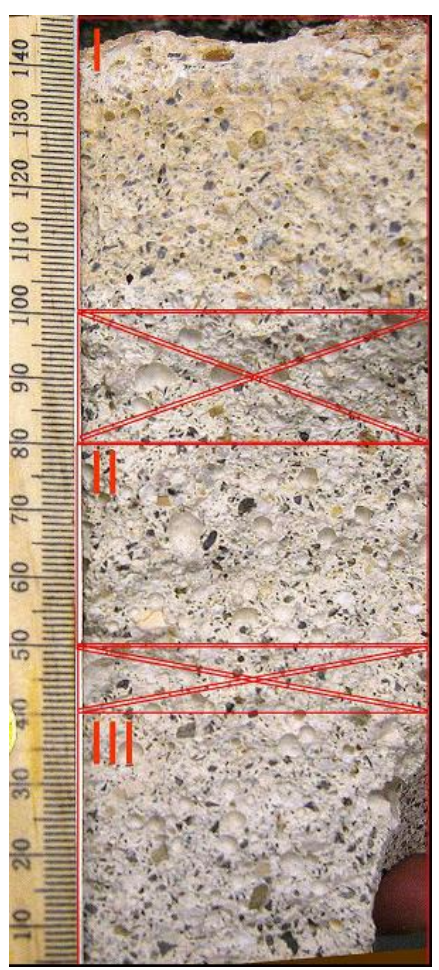

\#4 ( 15.2 cm below the melt line)

Figure 7.4. CRB Samples Prepared for SEM-EDS

The EDS analysis detected a low and somewhat variable concentration of $\mathrm{Na}$ in the CRB blank sample not exposed to MIS. For five randomly chosen areas, three contained sodium below the detection limit, one contained about 0.21 atomic $\%$, and the other 0.37 atomic $\%$ of $\mathrm{Na}$. 
The CRB is composed of large grains and fine particles embedded in binding material. There are regions with high concentrations of binding material with high porosity and regions with high concentrations of large particles having minimal porosity. Figure 7.5 shows the inhomogeneous microstructure of the CRB and the highly porous regions available for MIS penetration. Figure 7.6 is a high-magnification picture of the CRB showing small pores between small particles.
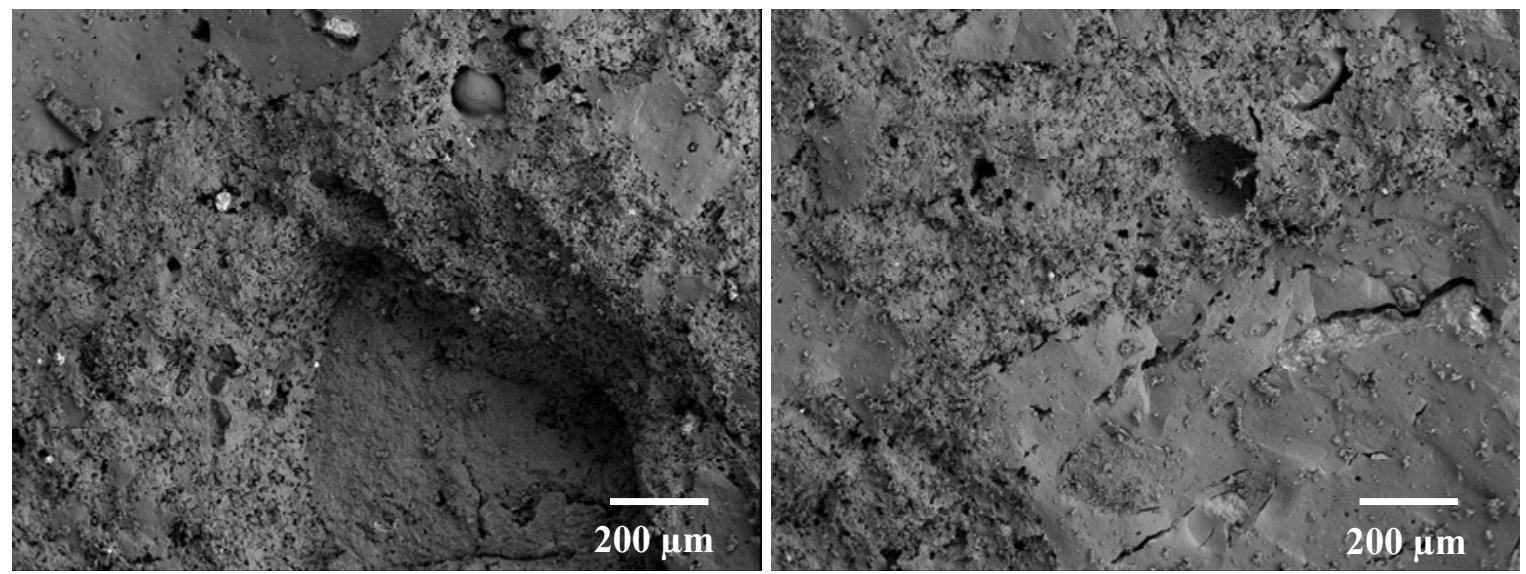

Figure 7.5. SEM Images of CRB Surface Showing Pores and Inhomogeneous Microstructure

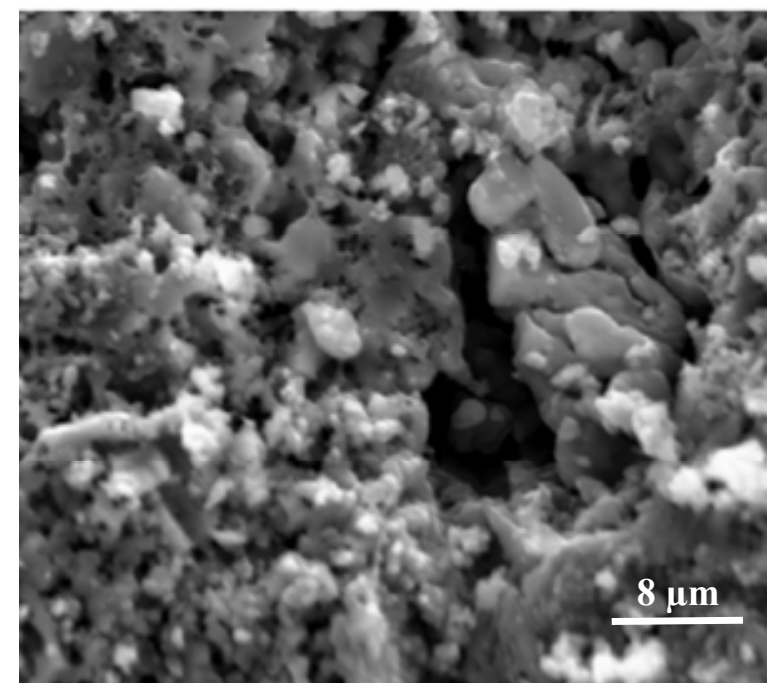

Figure 7.6. SEM Image of CRB Showing Small Pores

Figure 7.7 through Figure 7.9 display the concentration profile of $\mathrm{Na}, \mathrm{S}$, and $\mathrm{Cl}$ (in atomic \%) determined by SEM-EDS as a function of distance from the glass/CRB interface (inside CRB wall) for the CRB samples from $\sim 38.1 \mathrm{~cm}$ above the melt line (Figure 7.7), at the melt line (Figure 7.8), and $\sim 15.2 \mathrm{~cm}$ below the melt line (Figure 7.9). The EDS was not calibrated with the standard samples, and thus the results are semi-quantitative, and only relative comparisons are valid. Based on Na concentration, the MIS penetrated $\sim 1 \mathrm{~cm}$ or less into the CRB $\sim 38.1 \mathrm{~cm}$ above the melt line, $\sim 2.5 \mathrm{~cm}$ into the $\mathrm{CRB}$ at the melt line, and $\sim 10 \mathrm{~cm}$ into the $\mathrm{CRB} \sim 15.2 \mathrm{~cm}$ below the melt line, assuming that the $\sim 0.3$ atomic $\% \mathrm{Na}$ is background, and the minor jump at the $\mathrm{CRB} /$ sand interface is not a result of MIS penetration. 
For the $\mathrm{CRB} \sim 15.2 \mathrm{~cm}$ below the melt line, the Na concentration dropped to background at $\sim 5 \mathrm{~cm}$ and had another peak between 7 and $10 \mathrm{~cm}$ depth (the sample was lost between 5 and $7 \mathrm{~cm}$ ), whereas for the CRB samples from $\sim 38.1 \mathrm{~cm}$ above the melt line and at the melt line, the $\mathrm{Na}$ concentration sharply decreased from the glass/CRB interface to the background level. It is interesting to note that there are only a couple of points with high $\mathrm{S}$ ( $\sim 8.5 \mathrm{~cm}$ and close to the CRB/sand interface) in the CRB from $\sim 38.1 \mathrm{~cm}$ above the melt line. The $\mathrm{S}$ concentration in the $\mathrm{CRB}$ at the melt line dropped to background much earlier than $\mathrm{Na}$ $(1 \mathrm{~cm}$ compared to $2.5 \mathrm{~cm}$ ) and increased again between 5 and $7 \mathrm{~cm}$. If the MIS penetration depth at the melt line were based on $\mathrm{S}$, it would be $\sim 7 \mathrm{~cm}$. For the area between 5 and $7 \mathrm{~cm}$, there is an indication of a slight increase of $\mathrm{Na}$, but it is unclear if this is a result of MIS penetration or just variation in the $\mathrm{Na}$ background. For the CRB sample from $\sim 15.2 \mathrm{~cm}$ below the melt line, the $\mathrm{S}$ concentration starts to increase above the background level only after $7 \mathrm{~cm}$ where the $\mathrm{Na}$ peak reappears and extends to a depth of $12 \mathrm{~cm}$. If $\mathrm{S}$ concentration is used for MIS penetration, it would be $12 \mathrm{~cm}$ compared to $10 \mathrm{~cm}$.

For $\mathrm{Cl}$, the $\mathrm{CRB}$ from $\sim 38.1 \mathrm{~cm}$ above the melt line had only two points of high $\mathrm{Cl}$ above the background ( $\sim 11 \mathrm{~cm}$ and close to the $\mathrm{CRB} /$ sand interface). The $\mathrm{Cl}$ concentration in the $\mathrm{CRB}$ at the melt line had high and low fluctuation throughout the sample, whereas the CRB sample from $\sim 15.2 \mathrm{~cm}$ below the melt line had high fluctuation only in the 8 to $9 \mathrm{~cm}$ depth, which is within the area with high $\mathrm{S}$ and $\mathrm{Na}$.

Assuming that $\mathrm{Cl}$ is a result of volatilization, not MIS penetration, the MIS penetration depth was estimated as $1 \mathrm{~cm}$ or less, $\sim 7 \mathrm{~cm}$, and $12 \mathrm{~cm}$ based on $\mathrm{Na}$ and $\mathrm{S}$ concentrations, for the sample above, at, and below the melt line, respectively. Based on this information, the depth of Re profile measurement for each sample was determined. The above melt line sample was analyzed to depths of $4 \mathrm{~cm}$, the at melt line sample to $8 \mathrm{~cm}$, and the below melt line sample to $15 \mathrm{~cm}$. 


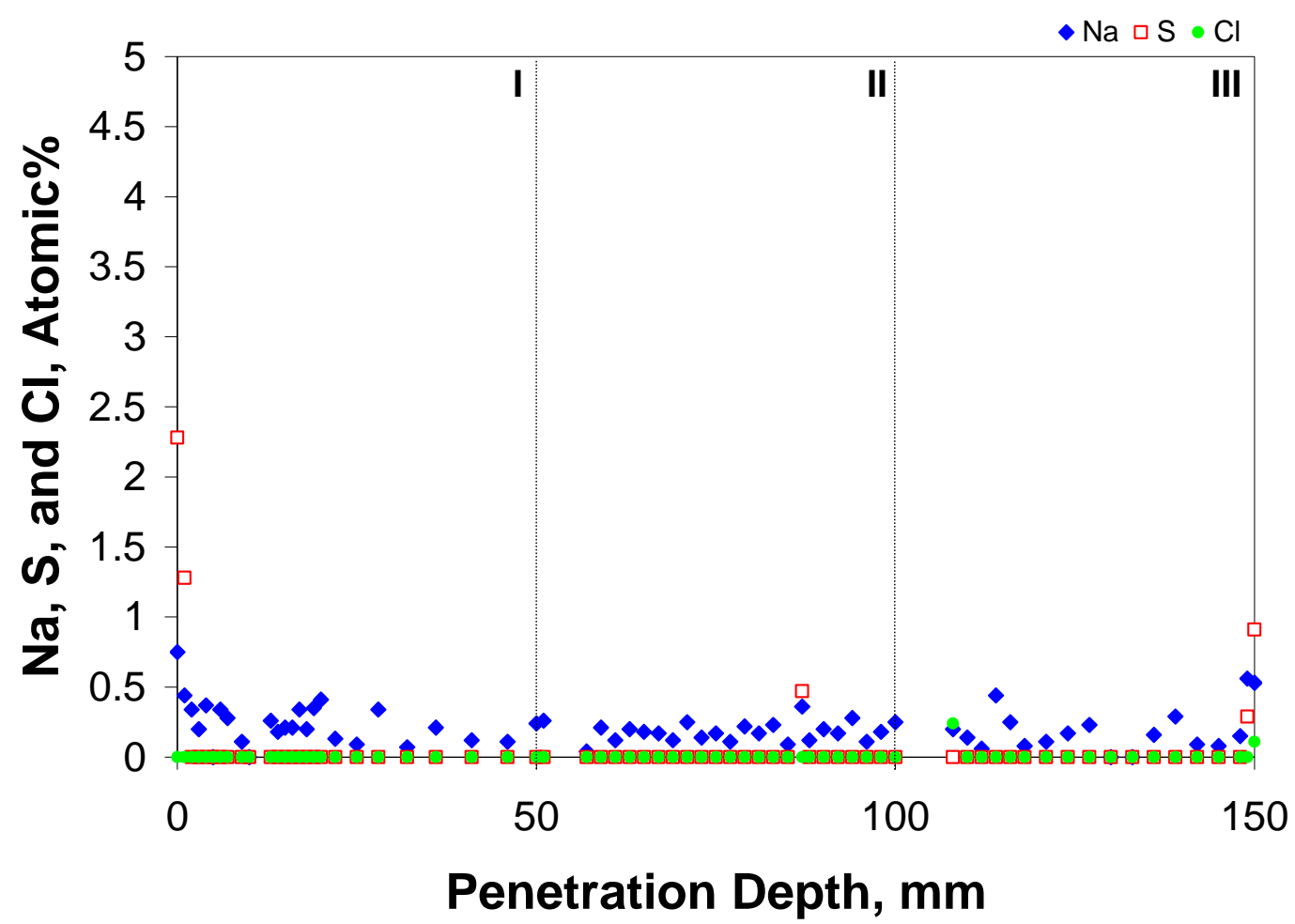

Figure 7.7. Na, $\mathrm{S}$, and CI Concentrations in CRB Sample from $\sim 38.1 \mathrm{~cm}$ Above the Melt Line

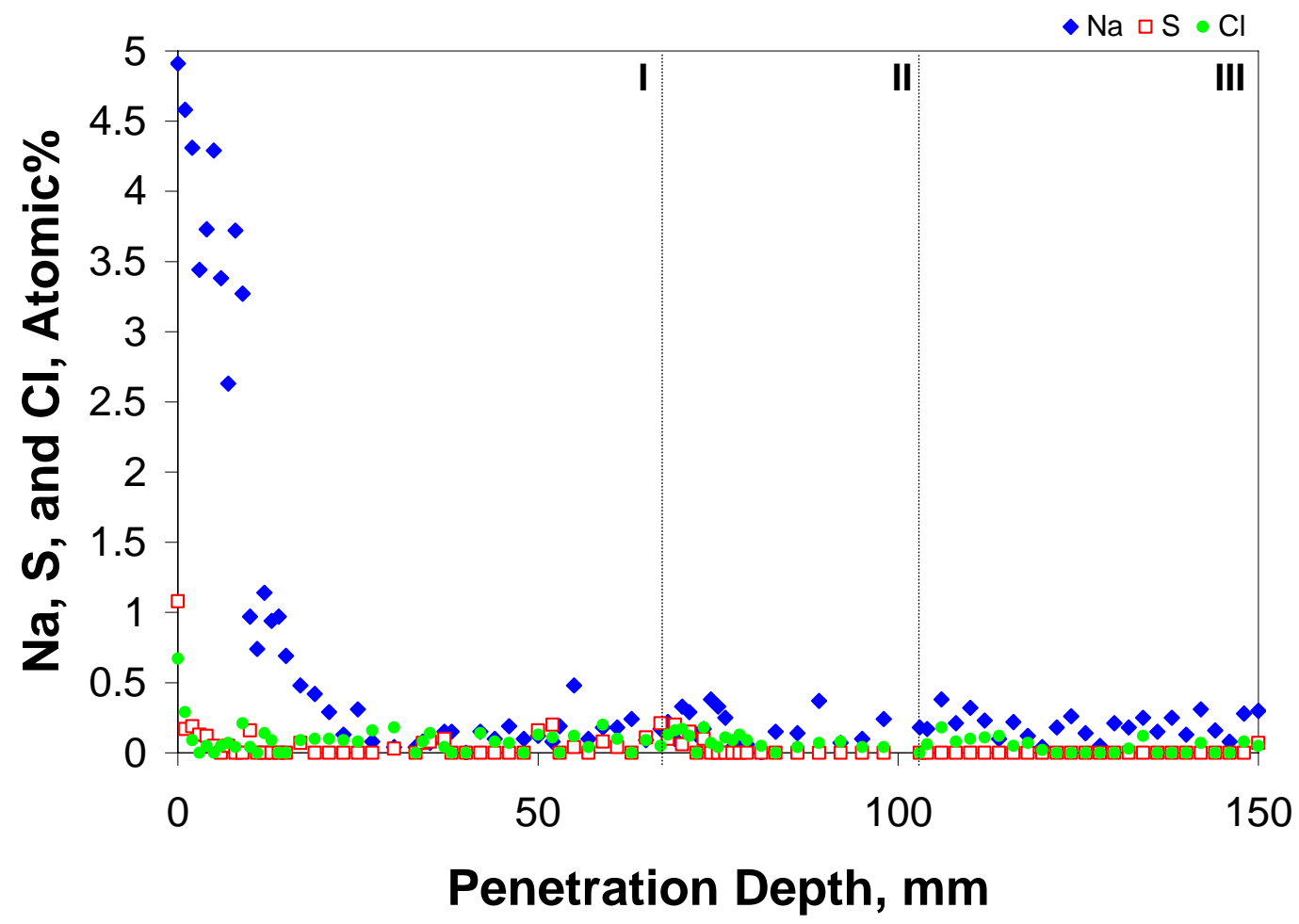

Figure 7.8. Na, S, and Cl Concentrations in CRB Sample from at the Melt Line 


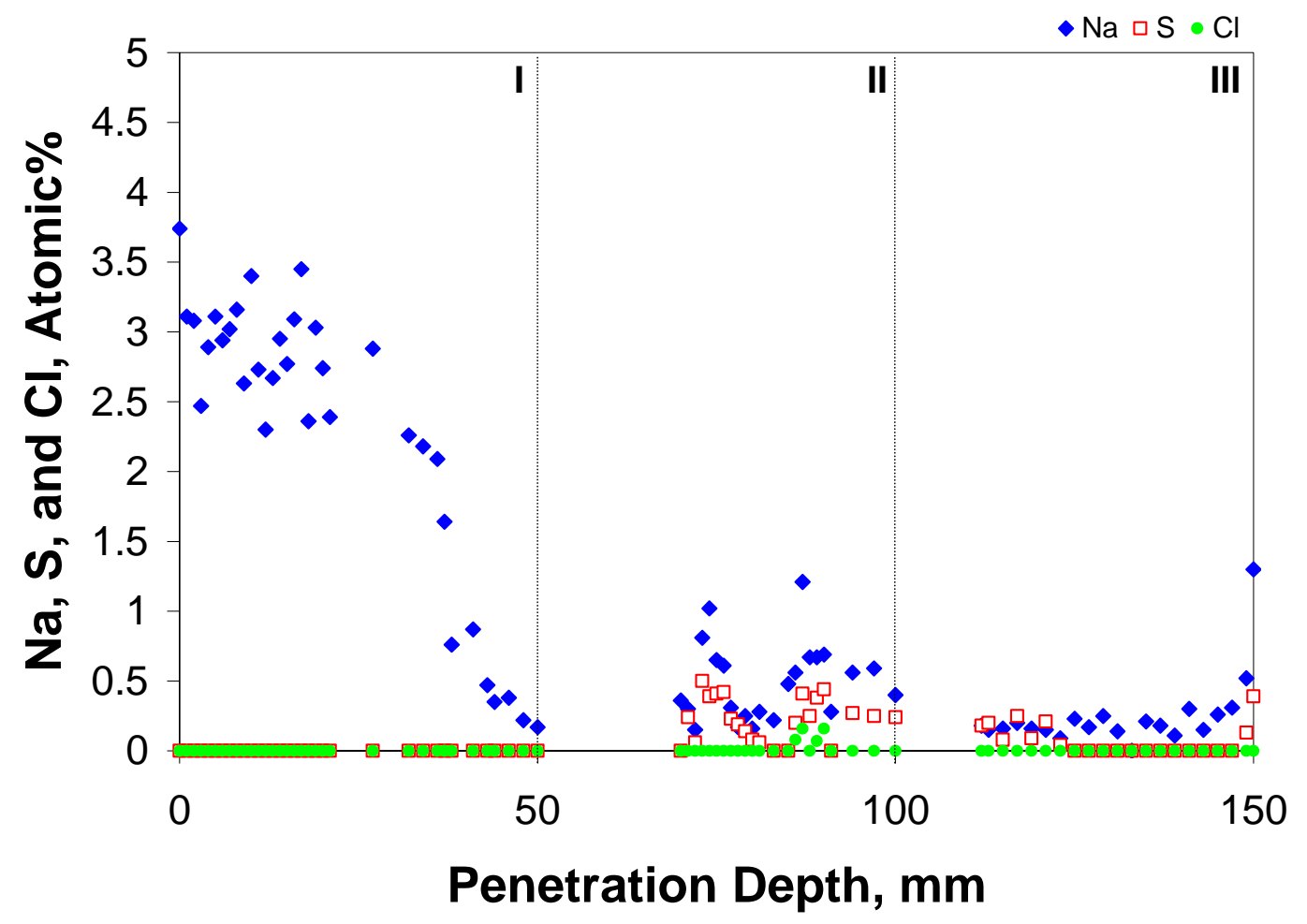

Figure 7.9. Na, S, and Cl Concentrations in CRB Sample from $\sim 15.2 \mathrm{~cm}$ Below the Melt Line

\subsection{Methods Development}

In a previous study (Hrma et al. 2005), the CRB taken from ES-31B was ground into powder layer by layer in 1-mm intervals starting at the glass refractory interface and moving into the refractory block. The resulting refractory powder was washed and analyzed for soluble Re, and the remaining solids were dried and analyzed for Re. The penetration of salt components ( $\mathrm{Na}, \mathrm{S}, \mathrm{Cl}$ ) was analyzed by SEM/EDS. These preliminary methods supplied good scoping results, but did not result in a clear understanding of Re penetration depths. The concentration profiles for both soluble and insoluble forms of Re were relatively flat over the measured 10-mm depth, and the depth where Re concentrations dropped off was not determined. The MIS penetration profile determined by SEM/EDS (e.g., Na, S, Cl penetration) showed that MIS penetrated up to $15 \mathrm{~mm}$, indicating that greater penetration depths needed to be examined for Re.

The following modified method was used to obtain a better understanding of the Re penetration profiles in the CRB:

1. The FS-38B CRB block for thin section analysis was first examined by SEM/EDS to get a rough measurement of the penetration depth of MIS components as discussed in Section 7.3.

2. The CRB was cut into planar sections of roughly constant thickness that were oriented perpendicular to the movement of the MIS. The sections were dry cut with a diamond saw without using water lubricant. The thin slice of CRB was broken into smaller pieces and then ground into powder with a tungsten carbide mill. 
3. The resulting ground CRB powder was washed with a dilute $(0.001 \mathrm{M})$ nitric acid $\left(\mathrm{HNO}_{3}\right)$ solution. ${ }^{\text {(a) }}$ The resulting solutions were analyzed for $\mathrm{Re}, \mathrm{Na}$, and $\mathrm{S}$.

4. The CRB powder was dried and then prepared with the fusion method to completely dissolve all the materials into solution, and the fusion solutions were analyzed for $\mathrm{Re}, \mathrm{Na}$, and $\mathrm{S}$.

The final experimental procedure is described in the following sections.

\subsubsection{CRB Powder Preparation}

A sample out of the CRB block that was $\sim 15.2 \mathrm{~cm}$ below the melt line was used for preliminary tests. The CRB section was extracted using a high-speed diamond-bladed concrete saw and a power hammer. An $\sim 5-\mathrm{cm}$ piece was cut into four rough cubes of 1-cm depth. The sample was cut with a low-speed diamond saw without water or other type of lubricant to prevent any MIS component from dissolving that may have been in the CRB. Each 1-cm cube was then crushed separately in a tungsten carbide mill for $3 \mathrm{~s}$ to reduce the cube into granular/powder form. The crushing time of $3 \mathrm{~s}$ was determined from preliminary crushing tests varying crushing times. The resulting particle size of roughly $500 \mu \mathrm{m}$ or smaller was deemed to be small enough to provide a short distance for DIW penetration into the CRB pores and solute diffusion into solution, but large enough to avoid producing fine particles that might release the otherwise insoluble $\mathrm{Na} / \mathrm{Re} / \mathrm{S}$. The granular/powder samples made from all four cubes were then mixed by shaking and rolling for several minutes in a vial to obtain a homogeneous mix of grains. The mix was divided into five equivalent portions that were used for the preliminary method-development tests as described below. The same cutting/crushing sample preparation steps were used for the thinsection profile tests.

\subsubsection{Test for Vacuum Requirements}

There was a potential concern that the extraction solution would not penetrate deep enough into the very small pores in the CRB powder to extract all of the soluble Re present. Therefore, the first set of methoddevelopment extraction tests was performed with and without vacuum to determine whether vacuum extraction was necessary. Extraction solutions were evaluated using electrical resistance as an indication of relative extraction efficiency.

Teflon extraction vessels were cleansed by washing in hot, soapy water and then in boiling DIW for $1 \mathrm{~h}$ with a DIW rinse after each washing step. This cleaning process was used for all extraction tests performed in this study. Two clean Teflon vessels with $15 \mathrm{~mL}$ of DIW and $2.8 \mathrm{~g}$ ground CRB were prepared for the extraction tests. One vessel was placed at room temperature for $24 \mathrm{~h}$, while the other vessel was placed in a vacuum chamber for $1 \mathrm{~h}$ before a 23 -h room-temperature extraction. The extraction solutions were decanted into smaller clean vials, and their electrical resistances were measured using an inductance, capacitance, and resistance (LCR) meter and Pt probe at a probe depth of $12.5 \mathrm{~cm}$. The measured electrical resistance was $9.0 \mathrm{k} \Omega$ for the solution with a 1-h vacuum exposure and $9.2 \mathrm{k} \Omega$

(a) Dilute nitric acid was used to promote the dissolution of all the soluble phases because some phases may have a slow dissolution rate in DIW. The same solution was used in the extraction of soluble Re from CRB that was performed in support of the 2005 Integrated Disposal Facility Performance Assessment (Pierce et al. 2005). 
for the solution without the vacuum exposure, indicating that there is no significant difference. ${ }^{\text {(a) }}$ It appears that water can penetrate into pores to extract the soluble MIS components without the assistance of vacuum. Based on this result, it was determined that vacuum application was not necessary for acceptable extraction, so all subsequent tests were performed without vacuum.

\subsubsection{Test to Check the Presence of $\mathrm{ReO}_{2}$}

As discussed in Section 7.4, the Re profile test planned to use dilute nitric acid. It was assumed that MIS penetrates the CRB pores and forms a glassy phase that contains an insoluble Re based on the results of a previous study (Hrma et al. 2005). It was suggested that the insoluble fraction of Re (assumed to be bound within a glassy layer inside the pore surface) may include $\mathrm{ReO}_{2}$ that was not incorporated in a glass phase. $\mathrm{ReO}_{2}$ is not readily soluble in dilute nitric acid solution but may be oxidized to higher valence states over time and released into the environment in a short time relative to the time frame of a performance assessment. Therefore, other method development tests were conducted to determine if the $\mathrm{ReO}_{2}$ phase was present. An ammonium hydroxide $\left(\mathrm{NH}_{4} \mathrm{OH}\right)$-hydrogen peroxide $\left(\mathrm{H}_{2} \mathrm{O}_{2}\right)$ solution should dissolve $\mathrm{ReO}_{2}$ at room temperature if present in a crystalline form on pore surfaces. The $\mathrm{ReO}_{2}$ encapsulated in a glassy layer will not be released by this method. It was also decided to compare the DIW wash and dilute nitric acid wash. Below is a summary of comparison tests:

- Test 1: (1) first DIW wash, (2) second DIW wash, and (3) fusion of dried CRB powder

- Test 2: (1) first dilute nitric acid solution wash, (2) second dilute nitric acid solution wash, and (3) fusion of dried CRB powder

- Test 3: (1) dilute nitric acid solution wash, (2) ammonium hydroxide solution wash, and (3) fusion of dried CRB powder.

For Tests 1 and 2, $15 \mathrm{~mL}$ of DIW (Test 1) or dilute nitric acid (Test 2) was added to a Teflon vessel with one 2.8-g portion of the ground CRB. The samples were kept at room temperature for $24 \mathrm{~h}$, and then the liquid leachate was decanted and filtered for chemical analysis. The treated CRB powder samples were then rinsed with $\sim 50 \mathrm{~mL}$ DIW for $1 \mathrm{~h}$ to remove residuals of the first leach solution. The rinsed solution was archived for potential analysis later if necessary. This CRB powder was then combined with $15 \mathrm{~mL}$ of DIW (Test 1) or dilute nitric acid (Test 2) and held for $24 \mathrm{~h}$, and then the liquid leachate was decanted and filtered for chemical analysis. The resulting CRB powder samples were again rinsed with $\sim 50 \mathrm{~mL}$ DIW for $1 \mathrm{~h}$ to remove residual leach solution. The CRB powder samples were then placed in a drying oven at $105^{\circ} \mathrm{C}$ overnight to evaporate any remaining water. The dried powder samples were ground to fine powder in a tungsten carbide mill and sent to the Southwest Research Institute (SwRI) for Re analysis by $\mathrm{KOH}$ fusion/inductively coupled plasma-mass spectrometry (ICP-MS).

For Test 3, the first leach with dilute nitric acid was performed exactly the same as Test 2 up to the DIW rinse. The second extraction used the following procedure: a 50:50 solution of ammonium hydroxide $(\sim 30 \mathrm{~mL})$ and DIW $(\sim 30 \mathrm{~mL})$ was mixed with the CRB in a beaker along with $8 \mathrm{~mL}$ of $30 \%$ hydrogen peroxide (referred to as the $\mathrm{NH}_{4} \mathrm{OH}$ leach). The mixture was then stirred for an hour to allow the solution to dissolve the $\mathrm{ReO}_{2}$ if present in the CRB. After stirring, the fluid contents were vacuum-filtered and

(a) Based on the $\mathrm{KCl}$ solution resistance data as a function of concentration, it is calculated that the $9 \mathrm{k} \Omega$ corresponds to roughly $5.2 \mathrm{mg} / \mathrm{L}$ for $\mathrm{K}$ (this was the same range as $\mathrm{Na}$ concentration in the leach solution). The increase of $\mathrm{K}$ concentration by $50 \%$ to $7.8 \mathrm{mg} / \mathrm{L}$ would result in the decrease of electrical resistance to $6.6 \mathrm{k} \Omega$. 
rinsed into another beaker. The solution was then evaporated at moderate temperatures on a hot plate to 1.5 to $2 \mathrm{~mL}$ of condensed solution. The condensed solution was poured into a vial and diluted with DIW to exactly $10 \mathrm{~mL}$, which was sent for Re analysis. Similar to Tests 1 and 2, the CRB powder samples were dried in a drying oven at $105^{\circ} \mathrm{C}$ overnight, ground to fine powder in a tungsten carbide mill, and sent to SwRI for Re analysis by $\mathrm{KOH}$ fusion/inductively coupled plasma-mass spectrometry (ICP-MS).

Table 7.2 summarizes the Re analysis results from the comparison tests. The soluble Re from the first leach was lower when DIW was used (Test 1) compared to dilute nitric acid (Tests 2 and 3). The agreement between the two dilute nitric acid leaches is good, indicating that the CRB powder was well homogenized. These results indicate that dilute nitric acid leach provides a little more aggressive leach condition than DIW. The soluble Re from the second leach was the same for all three tests. The DIW leach was comparable to two other tests, likely because the first leach left more soluble Re. There was no difference between a second leach with dilute nitric acid or a second leach with $\mathrm{NH}_{4} \mathrm{OH}$, indicating that there was not a significant amount of $\mathrm{ReO}_{2}$ present in the CRB pores.

For Tests 2 and 3, the second leach resulted in 33\% of the Re from the first leach on average, which suggests that, if the same rate is assumed for further leaches, about $99 \%$ of all potential soluble Re will leach out after four repeated leach and wash steps. The same calculation indicates that the present twostep leach would result in $67 \%$ of total Re in the first leach and $89 \%$ of the total after the second leach. After reviewing the results, it was decided to use a one-step leach process with a larger volume of dilute nitric acid ( $45 \mathrm{~mL}$ versus $15 \mathrm{~mL}$ ), longer leach times ( $48 \mathrm{~h}$ versus $24 \mathrm{~h}$ ), and added stirring. The one-step leach is preferred to save time and reduce analytical costs.

Table 7.2 shows that the soluble Re is less than $10 \%$ of the insoluble Re for all tests. This could indicate that the Re formed "insoluble" glassy phases in the CRB, or Re could be an impurity in the CRB materials. The average of insoluble Re was $391 \mu \mathrm{g} / \mathrm{kg}$ with a relative percent standard deviation of $17.3 \%$.

Table 7.2. Soluble and Insoluble Re Concentrations from CRB (in $\mu \mathrm{g} / \mathrm{kg}$ )

\begin{tabular}{|c|c|c|c|c|}
\hline \multirow[b]{2}{*}{ Test } & \multicolumn{3}{|c|}{ Soluble Re, $\mu \mathrm{gg} / \mathrm{kg}$} & \multirow{2}{*}{$\begin{array}{c}\text { Insoluble Re, } \\
\mu \mathrm{g} / \mathrm{kg}\end{array}$} \\
\hline & $1^{\text {st }}$ leach & $2^{\text {nd }}$ leach & Total & \\
\hline Test 1 (DIW - DIW) & 15.5 & 7.6 & 23.1 & 468 \\
\hline Test 2 (Dilute $\mathrm{HNO}_{3}$ - Dilute $\mathrm{HNO}_{3}$ ) & 22.4 & 7.4 & 29.8 & 366 \\
\hline Test 3 (Dilute $\mathrm{HNO}_{3}-\mathrm{NH}_{4} \mathrm{OH}$ ) & 23.4 & 7.5 & 30.9 & 340 \\
\hline Blank CRB* & - & - & - & $<239$ \\
\hline
\end{tabular}

(e) D Kim, MJ Schweiger, JV Crum, BP Tinsley, PR Hrma, and ML Elliott. 2005. Letter report (Unpublished), Estimation of $\mathrm{ZrO}_{2}$ Dissolved in Engineering-Scale- $\mathrm{ZrO}_{2}$ Test Products, Pacific Northwest National Laboratory, Richland, WA. 


\subsection{Re and MIS Profile Analyses in FS-38B CRB}

\subsubsection{Procedure}

The CRB sample sections were cut into increments $\sim 1 \mathrm{~cm}$ deep starting at the glass/CRB interface (or inner surface in the case of Section 1) up to the depth determined based on SEM-EDS results discussed in Section 7.3.

- $\quad \sim 4 \mathrm{~cm}$ for the CRB taken from $\sim 38.1 \mathrm{~cm}$ above the melt line (Sample \#1 in Figure 7.3)

- $\quad \sim 8 \mathrm{~cm}$ for the CRB taken at the melt line (Section \#3)

- $\sim 15 \mathrm{~cm}$ (entire depth), for the CRB taken from $\sim 15.2 \mathrm{~cm}$ below the melt line (Section \#4).

Each CRB sample piece was an $\sim 1$-cm cube, with allowances for material losses during the cutting process. The cutting process was done by low-speed diamond-chip-bladed saws without using any form of lubricant as discussed earlier.

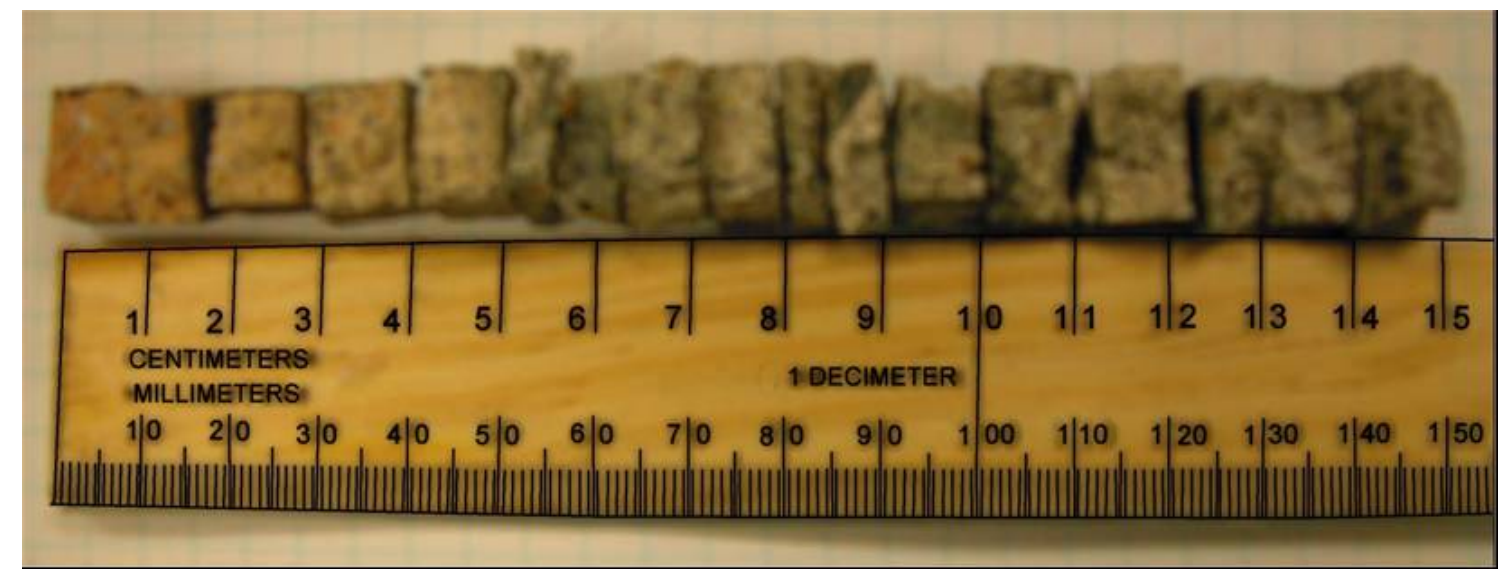

Figure 7.10. CRB Pieces Taken from $\sim 15.2 \mathrm{~cm}$ Below the Melt Line (lined up from glass/CRB interface on left to outer wall)

Figure 7.10 displays the $15 \mathrm{CRB}$ cut pieces taken from $\sim 15.2 \mathrm{~cm}$ below the melt line. As illustrated in Figure 7.10, the CRB pieces are not exactly cube shaped or the same size because of the difficulty in cutting hard materials without using water. Each sample was crushed in the tungsten carbide mill for $3 \mathrm{~s}$. The grinding time was not adjusted for sample size. Overall, the mass of ground CRB ranged from $2.72 \mathrm{~g}$ to $5.08 \mathrm{~g}$. The tungsten carbide mill was thoroughly cleaned after each grinding to prevent possible cross contamination.

For the extraction test, $45 \mathrm{~mL}$ of $0.001 \mathrm{M} \mathrm{HNO}_{3}$ and the ground CRB samples were added to a clean Teflon vessel. The test assembly was mixed for $48 \mathrm{~h}$ at room temperature by rotating the Teflon vessel at $45 \mathrm{rpm}$ in a ball mill roller. After the 48-h test, the extraction solution was decanted and filtered using a clean 10 -mL syringe and a $0.45-\mu \mathrm{m}$ filter. A solution sample of $\sim 20 \mathrm{~mL}$ was sent out for Re analysis by ICP-MS and Na, and S analysis by ICP-atomic emission spectroscopy (AES). The ground CRB sample was rinsed with DIW to remove the residual extraction solution. 
For the two samples taken from $\sim 15.2 \mathrm{~cm}$ below the melt line (the sample from 2 to $3 \mathrm{~cm}$ and the sample from 11 to $12 \mathrm{~cm}$ ), another extraction with $45 \mathrm{~mL}$ of $0.001 \mathrm{M} \mathrm{HNO}_{3}$ was performed after completing the first extraction and DIW rinse to check how much additional soluble Re remained after the first extraction. After the second $0.001 \mathrm{M} \mathrm{HNO}_{3}$ extraction was complete, the ground $\mathrm{CRB}$ sample was prepared and rinsed as described in the previous paragraph.

The ground CRB samples were dried overnight in a $90^{\circ} \mathrm{C}$ drying oven, finely ground for 2 min in the tungsten carbide mill, and sent to SwRI for analyses. The tungsten carbide mill was thoroughly cleaned after each grinding to prevent possible cross contamination.

\subsubsection{Results and Discussion}

Table 7.3 displays the analytical results of $\mathrm{Re}, \mathrm{Na}$, and $\mathrm{S}$ concentrations for those samples with duplicate analyses. Table 7.3 shows that the reproducibility of analyses is good with a relative percent difference (RPD) of $10 \%$ or smaller except for the Re concentration in one blank sample, which may be explained by a low Re concentration close to the equipment detection limit.

Table 7.4 summarizes the concentrations of $\mathrm{Re}, \mathrm{Na}$, and $\mathrm{S}$ in the leach solutions (soluble) and in the ground CRB samples after leaching (insoluble). The concentrations of soluble components are given in units of $\mu \mathrm{g}$ (for $\mathrm{Re}$ ) or $\mathrm{mg}$ (for $\mathrm{Na}$ and $\mathrm{S}$ ) of each element per $\mathrm{kg}$ of CRB so that direct comparison with the concentrations in the ground CRB can be made. The average is given for duplicate analyses.

As seen in Table 7.4, the blank CRB contained a significant concentration of soluble Re in addition to soluble $\mathrm{Na}$ and S. Similar high concentrations of soluble Re in CRB blanks were also observed from the CRB centrifugal extraction study (Cooley et al. 2006) as summarized in Table 7.5. ${ }^{(\mathrm{f})}$ The "Heat Treated Manufactured Blank" samples were prepared from the same manufacturer's lot number as used in this study, but different pieces of cylinder were used. The two "Heat Treated Manufactured Blank" samples had essentially the same soluble Re concentration. However, the FS-38A blank samples had highly variable Re concentrations that ranged from 0.58 to $18.9 \mu \mathrm{g} / \mathrm{kg}$ with an average of $6.7 \mu \mathrm{g} / \mathrm{kg}$. This confirms that the material itself had non-negligible background levels of soluble Re with high variations. The heat-treated CRB blank tested in this study had a comparable level of soluble Re to those from FS-38A. The untreated blank in this study had higher soluble Re than any blanks tested by Cooley et al. (2006).

The CRB centrifugal extraction method uses a larger sample size, $\sim 500 \mathrm{~g}^{(\mathrm{g})}$ compared to $\sim 4 \mathrm{~g}$ for the thinsection method, but it still had substantial variations, which may signify that the distribution of Re within the CRB is extremely inhomogeneous.

The heat-treated CRB in this study had lower concentrations of all three elements than the untreated CRB. This could possibly be the result of the soluble species that were present on the inside surface of the open pores escaping during heat treatment. However, based on the variations found in the CRB samples in the

(f) Engineering-scale (ES) results are not included because the high Re results were suspected to result from potential contamination from previous Re spiked tests.

(g) Based on a typically sized CRB of $2 \times 2 \times 3$ in. $(5.1 \times 5.1 \times 7.6 \mathrm{~cm})$ with a bulk density of $2.5 \mathrm{~g} / \mathrm{cm}^{3}$. 
study of the centrifugal extraction method, the difference between heat-treated and untreated samples could be within the range of variation of the samples.

The blank CRB contained $0.67 \mathrm{mg} / \mathrm{kg}$ total $\mathrm{Re}$ (soluble plus insoluble) on average compared to 3.1 and $6.3 \mathrm{mg} / \mathrm{kg}$ Re measured in FS-38B and 38C glasses (average from six samples taken from different locations; $8.1 \mathrm{mg} / \mathrm{kg}$ Re target for FS-38B and 38C glasses), which signifies that CRB contains roughly $10 \%$ of the Re in full-scale test glasses. The background level of Re in soda-lime glass frit and Hanford soil measured within the study of FS-38C was 0.45 and $0.76 \mathrm{mg} / \mathrm{kg}$, respectively, which is comparable to the present CRB blank results. This may suggest that the $0.67 \mathrm{mg} / \mathrm{kg}$ Re level is the typical background concentration found in these materials.

The concentration of insoluble $\mathrm{Na}$ and $\mathrm{S}$ in the blank CRBs given in Table $7.4(153 \mathrm{mg} / \mathrm{kg} \mathrm{Na}$ and $21 \mathrm{mg} / \mathrm{kg} \mathrm{S}$ on average) corresponds to oxide concentrations of $0.13 \mathrm{wt} \% \mathrm{Na}_{2} \mathrm{O}$ and $0.03 \mathrm{wt} \% \mathrm{SO}_{3}$.

The average values from the two blank samples measured in this set of tests were used as a basis for background soluble and insoluble $\mathrm{Re}, \mathrm{Na}$, and $\mathrm{S}$ concentrations for the interpretation of test results. The $\mathrm{Na}$ concentration in the heat-treated blank CRB was less than the reporting limit of $69.4 \mathrm{mg} / \mathrm{kg}$. Half of this reporting limit was used as the assumed value for this sample in calculating the average.

As mentioned earlier, the CRB samples used in this study were collected from the same CRB pieces that were used in the centrifugal extraction study (Cooley et al. 2006) so that direct comparisons can be made. Table 7.6 compares the concentration of soluble Re obtained by two different methods for the FS-38B samples collected from similar locations (from the same piece in Figure 7.3). Sample \#2 was not measured in this study, but the data by Cooley et al. (2006) are included in Table 7.6 for reference. The results from each cube were averaged to obtain the inner and outer $\sim 7.5-\mathrm{cm}$ results. The data from the thin-section method for the above the melt line sample (measured up to $4 \mathrm{~cm}$ depth only) were calculated assuming that the rest of samples not analyzed had the same soluble Re concentration as the averaged blank. For outer half results for Samples \#1 and \#3, the blank results are included as a reference. Table 7.6 shows that there is a reasonable agreement in the general trend of the Re distribution for the CRB samples taken at and below the melt line, although there are large differences in value-to-value comparisons. 
Table 7.3. Summary of Duplicate Analytical Results

\begin{tabular}{|c|c|c|c|c|c|c|c|}
\hline \multicolumn{8}{|c|}{ In leach solutions (soluble) } \\
\hline \multirow{2}{*}{ Sample ID } & \multirow{2}{*}{$\begin{array}{c}\text { Sample } \\
\text { Description }\end{array}$} & \multicolumn{3}{|c|}{ Analyzed concentration } & \multicolumn{3}{|c|}{ RPD, \% } \\
\hline & & $\operatorname{Re}(\mu \mathrm{g} / \mathrm{L})$ & $\mathrm{Na}(\mathrm{mg} / \mathrm{L})$ & $\mathrm{S}(\mathrm{mg} / \mathrm{L})$ & $\operatorname{Re}$ & $\mathrm{Na}$ & $\mathbf{S}$ \\
\hline CRBASHT & \multirow{2}{*}{ Blank } & 0.681 & $<5.00$ & 0.619 & \multirow{2}{*}{$30.3 \%$} & \multirow{2}{*}{ - } & \multirow{2}{*}{$3.6 \%$} \\
\hline Duplicate & & 0.924 & $<5.00$ & 0.597 & & & \\
\hline S1CRB01 & \multirow{2}{*}{$\begin{array}{l}\sim 38.1 \mathrm{~cm} \text { above } \\
\text { ML, } 0-1 \mathrm{~cm}\end{array}$} & 38.4 & 9.18 & - & \multirow{2}{*}{$0.0 \%$} & \multirow{2}{*}{$1.1 \%$} & \multirow{2}{*}{ - } \\
\hline Duplicate & & 38.4 & 9.08 & - & & & \\
\hline S4CRB12 & \multirow{2}{*}{$\begin{array}{c}\sim 15.2 \mathrm{~cm} \text { below } \\
\mathrm{ML}, 1-2 \mathrm{~cm}\end{array}$} & - & - & 0.583 & \multirow{2}{*}{ - } & \multirow{2}{*}{ - } & \multirow{2}{*}{$1.2 \%$} \\
\hline Duplicate & & - & - & 0.576 & & & \\
\hline S4CRB1314 & \multirow{2}{*}{$\begin{array}{l}\sim 15.2 \mathrm{~cm} \text { below } \\
\mathrm{ML}, 13-14 \mathrm{~cm}\end{array}$} & - & - & 48.6 & \multirow{2}{*}{ - } & & \multirow{2}{*}{$0.6 \%$} \\
\hline Duplicate & & - & - & 48.9 & & & \\
\hline \multicolumn{8}{|c|}{ In remaining CRB particles (insoluble) } \\
\hline \multirow[b]{2}{*}{ Sample ID } & \multirow{2}{*}{$\begin{array}{c}\text { Sample } \\
\text { Description }\end{array}$} & \multicolumn{3}{|c|}{ Analyzed concentration } & \multicolumn{3}{|c|}{ RPD, \% } \\
\hline & & $\begin{array}{c}\operatorname{Re} \\
(\mu \mathrm{g} / \mathrm{Kg})\end{array}$ & $\begin{array}{c}\mathrm{Na} \\
(\mathrm{mg} / \mathrm{Kg})\end{array}$ & $\mathrm{S}(\mathrm{mg} / \mathrm{Kg})$ & $\operatorname{Re}$ & $\mathbf{N a}$ & $\mathbf{S}$ \\
\hline S1CRB23G & \multirow{2}{*}{$\begin{array}{c}\sim 38.1 \mathrm{~cm} \text { above } \\
\mathrm{ML}, 2-3 \mathrm{~cm}\end{array}$} & $<481$ & 1260 & 106 & \multirow{2}{*}{-} & \multirow{2}{*}{$3.9 \%$} & \multirow{2}{*}{$1.9 \%$} \\
\hline Duplicate & & $<483$ & 1310 & 104 & & & \\
\hline S4CRB1415G & \multirow{2}{*}{$\begin{array}{l}\sim 15.2 \mathrm{~cm} \text { below } \\
\mathrm{ML}, 14-15 \mathrm{~cm}\end{array}$} & 480 & 1490 & 97 & \multirow{2}{*}{$10.1 \%$} & \multirow{2}{*}{$0.0 \%$} & \multirow{2}{*}{$3.0 \%$} \\
\hline Duplicate & & 531 & 1490 & 100 & & & \\
\hline
\end{tabular}


Table 7.4. Concentrations of Re, Na, and $S$ in Leach Solutions (soluble) and in Remaining CRB Particles (insoluble) (in $\mu \mathrm{g}$ or $\mathrm{mg}$ of element per $\mathrm{kg}$ of CRB)

\begin{tabular}{|c|c|c|c|c|c|c|}
\hline \multirow[b]{2}{*}{$\begin{array}{c}\text { Distance }^{(a)} \\
(\mathrm{cm})\end{array}$} & \multicolumn{3}{|c|}{ Soluble } & \multicolumn{3}{|c|}{ Insoluble } \\
\hline & $\begin{array}{c}\text { Re } \\
(\mu \mathrm{g} / \mathrm{kg})\end{array}$ & $\begin{array}{c}\mathrm{Na} \\
(\mathrm{mg} / \mathrm{kg})\end{array}$ & $\begin{array}{c}\mathrm{S} \\
(\mathrm{mg} / \mathrm{kg})\end{array}$ & $\begin{array}{c}\mathrm{Re} \\
(\mu \mathrm{g} / \mathrm{kg})\end{array}$ & $\begin{array}{c}\mathrm{Na} \\
(\mathrm{mg} / \mathrm{kg})\end{array}$ & $\begin{array}{c}\mathrm{S} \\
(\mathrm{mg} / \mathrm{kg})\end{array}$ \\
\hline \multicolumn{7}{|c|}{ FS-38B CRB $\sim 38.1 \mathrm{~cm}$ above the melt line } \\
\hline 0.5 & 340 & 912 & 409 & 707 & 4110 & 156 \\
\hline 1.5 & 27.5 & 240 & 105 & 571 & 2240 & 112 \\
\hline 2.5 & 21.6 & 86.5 & 172 & $<481$ & 1285 & 105 \\
\hline 3.5 & 15.5 & 59.5 & 185 & 565 & 956 & 111 \\
\hline \multicolumn{7}{|c|}{ FS-38B CRB at the melt line } \\
\hline 0.5 & 5243 & 1104 & 376 & 4530 & 9240 & 271 \\
\hline 1.5 & 52.9 & 160 & 76.4 & 719 & 1900 & 92.6 \\
\hline 2.5 & 28.3 & $<56.5$ & 87.6 & 523 & 1040 & 88.2 \\
\hline 3.5 & 14.2 & $<58.5$ & 131 & 721 & 879 & 94.2 \\
\hline 4.5 & 14.6 & 73.3 & 298 & $<465$ & 880 & 107 \\
\hline 5.5 & 18.6 & $<63.4$ & 254 & 531 & 912 & 149 \\
\hline 6.5 & 11.7 & $<77.0$ & 462 & 639 & 883 & 103 \\
\hline 7.5 & 12.9 & $<82.9$ & 262 & $<464$ & 837 & 98.2 \\
\hline \multicolumn{7}{|c|}{ FS-38B CRB $\sim 15.2 \mathrm{~cm}$ below the melt line } \\
\hline 0.5 & 43.7 & 117 & 17.8 & $<483$ & 21500 & 222 \\
\hline 1.5 & 20.0 & 59.8 & 7.29 & 647 & 18000 & 87.9 \\
\hline 2.5 & 21.2 & 62.7 & 10.5 & 589 & 15500 & 74.8 \\
\hline 3.5 & 25.3 & 47.6 & 9.90 & $<480$ & 13600 & 77.1 \\
\hline 4.5 & 52.7 & 32.2 & 783 & $<481$ & 9970 & 139 \\
\hline 5.5 & 4.17 & 6.59 & 8.09 & $<490$ & 1220 & $<49.7$ \\
\hline 6.5 & 6.83 & 6.40 & 16.2 & $<466$ & 974 & $<49.4$ \\
\hline 7.5 & 5.16 & 6.96 & 29.0 & $<458$ & 962 & $<49.0$ \\
\hline 8.5 & 6.09 & 6.47 & 86.3 & 525 & 927 & 57.6 \\
\hline 9.5 & 7.11 & 7.35 & 194 & $<493$ & 989 & 69.3 \\
\hline 10.5 & 10.6 & 6.28 & 333 & $<465$ & 1100 & 109 \\
\hline 11.5 & 24.4 & 7.97 & 605 & 482 & 805 & 85.3 \\
\hline 12.5 & 58.5 & 8.46 & 760 & 688 & 1020 & 83.4 \\
\hline 13.5 & 133.1 & 9.63 & 783 & 589 & 919 & 98.1 \\
\hline 14.5 & 130.2 & 21.6 & 180 & 506 & 1490 & 98.5 \\
\hline \multicolumn{7}{|c|}{ Blank CRB $^{\text {b) }}$} \\
\hline No HT & 34.3 & 271 & 33.3 & 569 & 735 & 179 \\
\hline $\mathrm{HT}^{\mathrm{c})}$ & 11.1 & $<69.4$ & 8.44 & 726 & 1260 & 85.8 \\
\hline $\begin{array}{l}\text { (a) Average } \\
\text { (b) The sam } \\
\text { manufa } \\
\text { (c) Heat tre }\end{array}$ & $\begin{array}{l}\text { listance fr } \\
\text { CRB as u } \\
\text { ured). } \\
\text { ed (HT) at }\end{array}$ & $\begin{array}{l}\text { the glass } / \mathrm{C} \\
\text { in capillar } \\
00^{\circ} \mathrm{C} \text { for } 8\end{array}$ & $\begin{array}{l}3 \text { interface } \\
\text { ests descri }\end{array}$ & $\begin{array}{l}\text { r each } \sim 1 \\
d \text { in Sectio }\end{array}$ & $\begin{array}{l}3 \text { cubes of } \\
.0 \text { (separat }\end{array}$ & \\
\hline
\end{tabular}


Table 7.5. Soluble Re Concentration in CRB Blanks Determined by Centrifugal Extraction Method (Cooley et al. 2006)

\begin{tabular}{||l|c|c||}
\hline \multicolumn{1}{|c|}{ Description } & Sample ID & Re $(\boldsymbol{\mu g} / \mathbf{k g})$ \\
\hline Untreated Refractory & Refractory Blank & 0.17 \\
\hline \multirow{3}{*}{$\begin{array}{l}\text { Heat-Treated } \\
\text { Manufactured Blanks }\end{array}$} & MF-BLK-01 & 1.04 \\
\cline { 2 - 3 } $\begin{array}{l}\text { FS-38A Full-Scale } \\
\text { Blanks }\end{array}$ & MF-BLK-02 & 0.98 \\
\cline { 2 - 3 } & FS_38A_01 Inner Segment & 18.79 \\
\cline { 2 - 3 } & FS_38A_01 Outer Segment & 5.72 \\
\cline { 2 - 3 } & FS_38A_01 Sample Average & 12.11 \\
\cline { 2 - 3 } & FS_38A_02 Inner Segment & 0.58 \\
\cline { 2 - 3 } & FS_38A_02 Outer Segment & 1.78 \\
\cline { 2 - 3 } & FS_38A_02 Sample Average & 1.08 \\
\hline
\end{tabular}

Table 7.6. Comparison of Soluble Re Concentrations by Two Different Methods for the FS-38B CRB Samples Taken from Similar Locations (in $\mu \mathrm{g} \mathrm{Re} / \mathrm{kg} \mathrm{CRB}$ )

\begin{tabular}{|c|c|c|c|c|c|}
\hline \multirow[b]{2}{*}{ CRB Location $^{(a)}$} & \multicolumn{3}{|c|}{$\begin{array}{l}\text { Extraction Method } \\
\text { (Cooley et al. 2006) }\end{array}$} & \multicolumn{2}{|c|}{$\begin{array}{c}\text { Thin Section Method } \\
\text { (this study) }\end{array}$} \\
\hline & Sample ID & $\begin{array}{c}\text { Inner } \\
\text { Sample }\end{array}$ & $\begin{array}{c}\text { Outer } \\
\text { Sample }\end{array}$ & $\begin{array}{c}\text { Inner } \sim 7.5 \\
\text { cm }\end{array}$ & $\begin{array}{c}\text { Outer } \sim 7.5 \\
\text { cm }\end{array}$ \\
\hline \multirow{2}{*}{$\begin{array}{l}\text { Above melt line } \\
\quad(\text { Sample } \# 1)\end{array}$} & FS-38B-01 & 5 & 21 & \multirow{2}{*}{65.0} & \multirow{2}{*}{$\sim 23^{(\mathrm{b})}$} \\
\hline & FS-38B-02 & 5 & 38 & & \\
\hline \multirow{2}{*}{$\begin{array}{l}\text { Above melt line } \\
\text { (Sample \#2) }\end{array}$} & FS-38B-03 & 24 & 54 & \multirow{2}{*}{ NA } & \multirow{2}{*}{ NA } \\
\hline & FS-38B-04 & 14 & 29 & & \\
\hline \multirow{2}{*}{$\begin{array}{l}\text { At melt line } \\
\text { (Sample \#3) }\end{array}$} & FS-38B-05 & 1197 & 14 & \multirow{2}{*}{674} & \multirow{2}{*}{$\sim 23^{(\mathrm{b})}$} \\
\hline & FS-38B-06 & 989 & 73 & & \\
\hline \multirow{2}{*}{$\begin{array}{l}\text { Below melt line } \\
\text { (Sample \#4) }\end{array}$} & FS-38B-07 & 49 & 516 & \multirow{2}{*}{22.4} & \multirow{2}{*}{46.9} \\
\hline & FS-38B-08 & 33 & 105 & & \\
\hline \multicolumn{6}{|c|}{$\begin{array}{l}\text { (a) Sample \# is as given in Figure } 7.3 \text {. } \\
\text { (b) Not analyzed by thin section method. Assumed to be similar to the blank CRB based } \\
\text { on SEM-EDS examination. } \\
\text { NA: not analyzed. }\end{array}$} \\
\hline
\end{tabular}

Figure 7.11 and Figure 7.12 display the concentration of soluble (Figure 7.11) and insoluble (Figure 7.12) $\mathrm{Re}, \mathrm{Na}$, and $\mathrm{S}$ as a function of distance from the inside wall in the CRB samples from $\sim 38.1 \mathrm{~cm}$ above the melt line. The soluble components penetrated up to $\sim 2 \mathrm{~cm}$ for $\mathrm{Na}$ and up to $\sim 1 \mathrm{~cm}$ for $\mathrm{Re}$, whereas $\mathrm{S}$ was higher than the blank level in all four samples tested up to $\sim 4 \mathrm{~cm}$. However, the change of all three soluble components had the same trend in that they were high in the first 1-cm layer and drop to the level of the blank or become relatively constant (this could be background level for the CRBs in this study). This observation suggests that Re penetrates through volatilization only to the thin surface layer, which seems to be the case for $\mathrm{Na}$ and $\mathrm{S}$ too. The concentrations of insoluble components were very close to the blank level for both Re and $\mathrm{S}$ for all four samples. However, the concentration of insoluble $\mathrm{Na}$ is higher than the blank level up to $\sim 2 \mathrm{~cm}$. It is possible that this high level of $\mathrm{Na}$ was due to volatilization from the clean glass feed that does not contain $\mathrm{Re}$ or $\mathrm{S}$ at the final stage of feed processing. This explanation suggests that $\mathrm{Na}$ that volatilized from the clean glass feed reacted with $\mathrm{CRB}$ materials to form insoluble 
phases (e.g., glass) at the pore surface but did not dissolve the soluble Re and $\mathrm{S}$ that were present (presumably in the salt form) at $340 \mu \mathrm{g} / \mathrm{kg}$ for Re and $409 \mathrm{mg} / \mathrm{kg}$ for S.

Figure 7.13 and Figure 7.14 show the concentration of soluble (Figure 7.13) and insoluble (Figure 7.14) $\mathrm{Re}, \mathrm{Na}$, and $\mathrm{S}$ as a function of distance from the glass interface in the CRB samples from at the melt line. The soluble components were detected above the CRB blank levels only at the surface layer to $\sim 1 \mathrm{~cm}$ for all three components. They were more than 10 times higher in concentration than the $\sim 38.1 \mathrm{~cm}$ above the melt line material for Re and had a similar concentration as the $\sim 38.1 \mathrm{~cm}$ above the melt line material for $\mathrm{Na}$ and $\mathrm{S}$. However the concentration of $\mathrm{S}$ initially decreased to nearly the blank level but tended to increase as the distance increased. The insoluble Re and $\mathrm{Na}$ were higher than the blank up to 1 or $2 \mathrm{~cm}$, and the insoluble $\mathrm{S}$ was close to the blank level for all samples. Overall, the trend is similar to the $\sim 38.1 \mathrm{~cm}$ above the melt line sample but with a much-higher concentration of soluble and insoluble Re. The soluble Re was comparable to the insoluble Re level. This high level of Re may suggest that the Re was soaked into CRB via liquid MIS (initially by vapor deposition), indicating that this final melt line was covered by the melting feed for part of the processing time. In addition, the separated salt layer (mainly sodium sulfate) that formed on the surface of the FS-38B melt was likely the reason for the high concentration of Re in the CRB at the glass surface. The operational challenges experienced in FS-38B resulted in the extensive formation of the salt layer concentrated with Re (Cooley et al. 2006).

Figure 7.15 and Figure 7.16 display the concentration of soluble (Figure 7.15) and insoluble (Figure 7.15) $\mathrm{Re}, \mathrm{Na}$, and $\mathrm{S}$ as a function of distance from the glass interface in the CRB samples from $\sim 15.2 \mathrm{~cm}$ below the melt line. The soluble Na was below the blank level for all 15 samples. The soluble Re and S showed similar trends in that both had a spike in concentration at the sample at 4 to $5 \mathrm{~cm}$ and a second increase to concentrations above the blank level at 8 to $9 \mathrm{~cm}$ for $\mathrm{S}$ and at 12 to $13 \mathrm{~cm}$ for $\mathrm{Re}$. Re was also higher than the blank level in the 0 - to $1-\mathrm{cm}$ sample. The insoluble components, Re and $\mathrm{S}$, were close to the blank level or lower for all 15 samples, whereas the concentration of $\mathrm{Na}$ was high at the glass interface and gradually decreased to the blank level at the 5- to 6-cm sample. The highest concentration of insoluble $\mathrm{Na}$ at the 0 - to $1-\mathrm{cm}$ sample $(21,500 \mathrm{mg} / \mathrm{kg})$ corresponds to $2.9 \mathrm{wt} \% \mathrm{Na}_{2} \mathrm{O}$ in the CRB.

If the $15 \%$ open porosity is completely filled with glass, the concentration in the CRB is $2.9 \mathrm{wt} \% \mathrm{Na}_{2} \mathrm{O}$, which is a good agreement with the highest $\mathrm{Na}$ concentration at the interface. This suggests that the observed trend of high concentration of $\mathrm{Na}$ at the glass interface and a gradual concentration decrease as the distance from the surface increases is the result of glass-forming melt penetrating into the CRB pores. CRB components dissolving in the glass will make the glass viscosity higher, slowing further penetration into the CRB.

If the Re peak at the 4- to 5-cm distance sample is excluded as an exception, it is speculated that, for the CRB below the melt line, the glass flows into open pores and pushes the soluble Re that was present close to the inside wall towards the outside wall; that is, the glass does not dissolve $\mathrm{S}$ or $\mathrm{Re}$ as it penetrates.

If the CRB that contains $648 \mu \mathrm{g} / \mathrm{kg}$ insoluble Re (measured in blank CRB) and has $15 \%$ open porosity is completely filled with glass that contains $3100 \mu \mathrm{g} / \mathrm{kg}$ Re (measured in $38 \mathrm{~B}$ glass), the resulting glassfilled CRB would have a Re concentration of $992 \mu \mathrm{g} / \mathrm{kg}$. However, the measured insoluble Re concentration in the entire sample of CRB from $\sim 15.2 \mathrm{~cm}$ below the melt line was $<700 \mu \mathrm{g} / \mathrm{kg}$, suggesting that it is unlikely that the glass within the CRB has a higher Re than the bulk of the $38 \mathrm{~B}$ glass. This result refutes earlier assumptions that MIS penetrates into open pores of the CRB and forms a glass layer that 
contains high a concentration of insoluble Re. The high concentration of insoluble Re is a more likely result due to a high insoluble Re blank level.

The observed high concentration of soluble Re towards the outside of the CRB suggests that some portion of Re may have passed through the CRB and deposited in the sand layer. However, the sand in 38B was not analyzed.

Figure 7.17 through Figure 7.19 display the concentrations of Re (Figure 7.17), Na (Figure 7.18), and S (Figure 7.19) as a function of distance from the glass interface in the CRB samples from different locations. Both soluble and insoluble forms are plotted in a logarithmic scale.

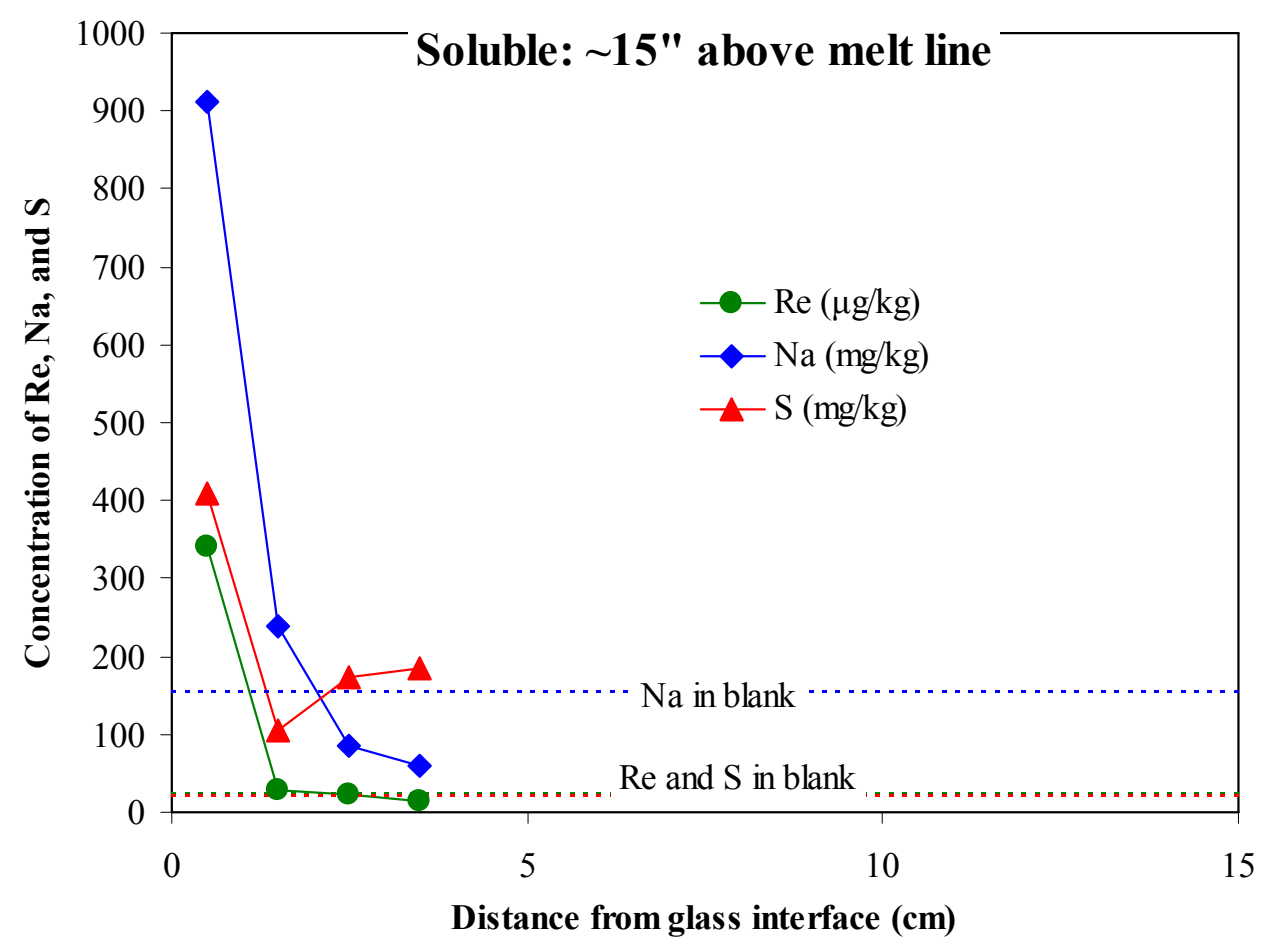

Figure 7.11. Concentration of Soluble Re, Na, and $S$ in the $C R B \sim 38.1 \mathrm{~cm}$ Above the Melt Line 


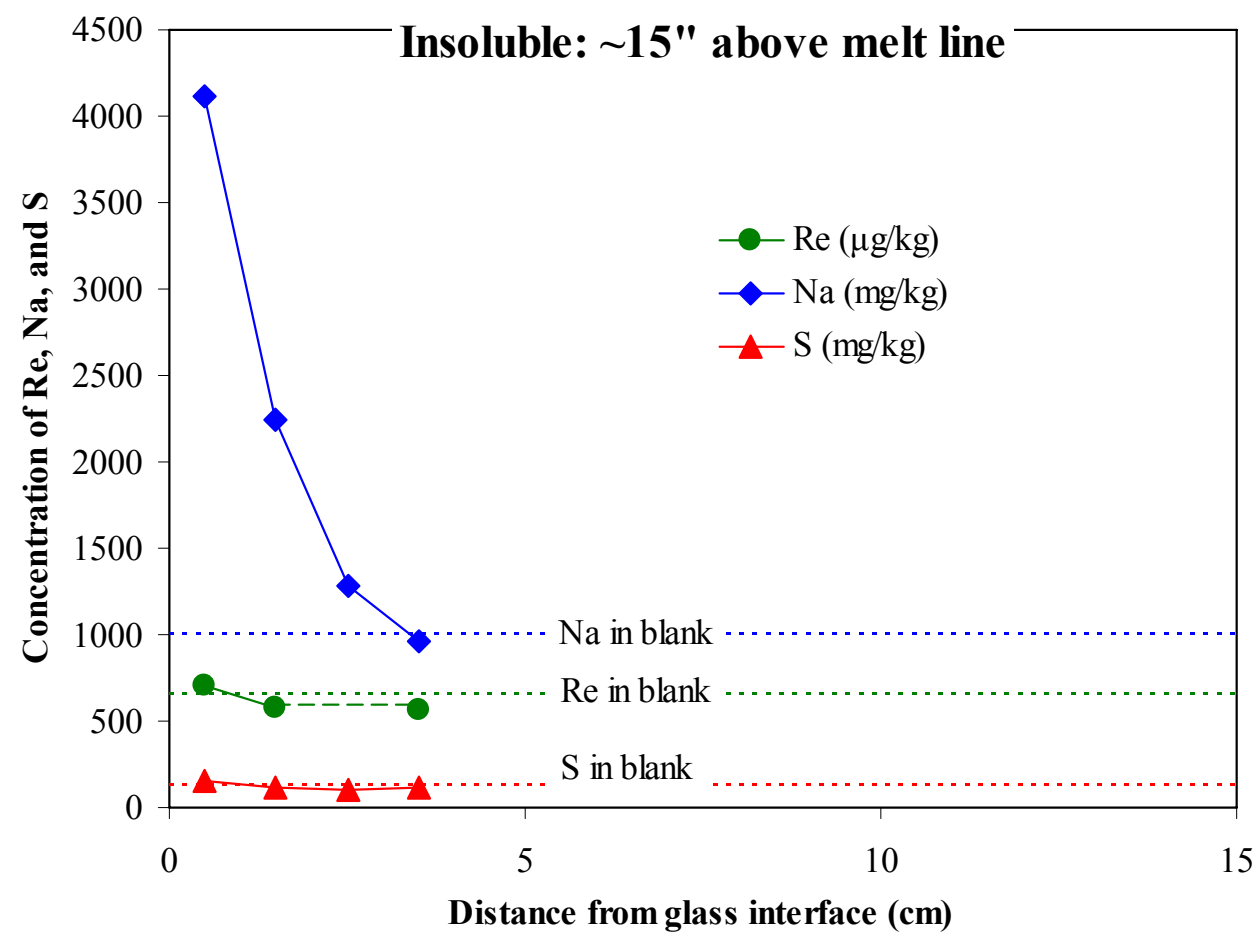

Figure 7.12. Concentration of Insoluble Re, $\mathrm{Na}$, and $\mathrm{S}$ in the $\mathrm{CRB} \sim 38.1 \mathrm{~cm}$ Above the Melt Line

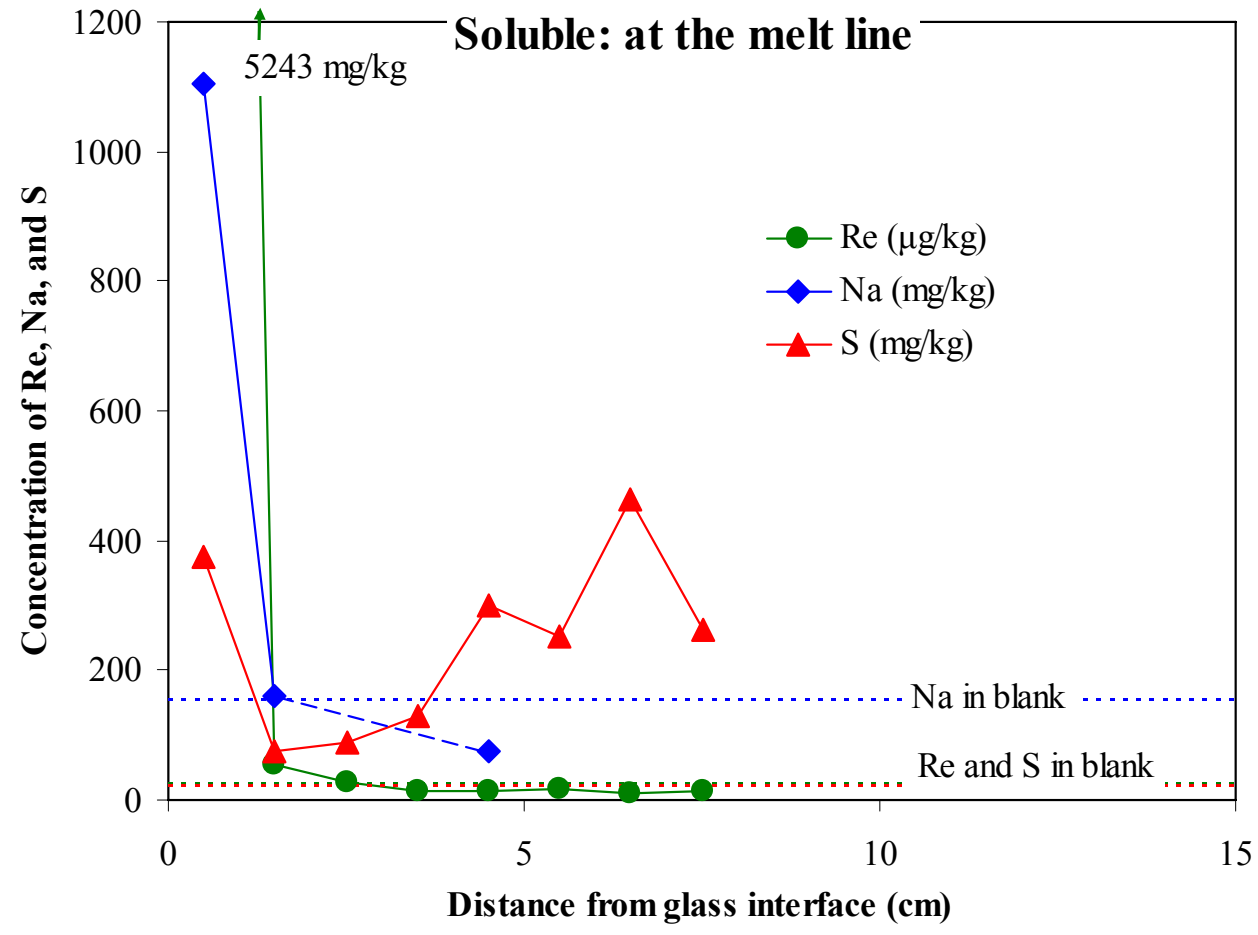

Figure 7.13. Concentration of Soluble Re, Na, and $\mathrm{S}$ in the CRB at the Melt Line 


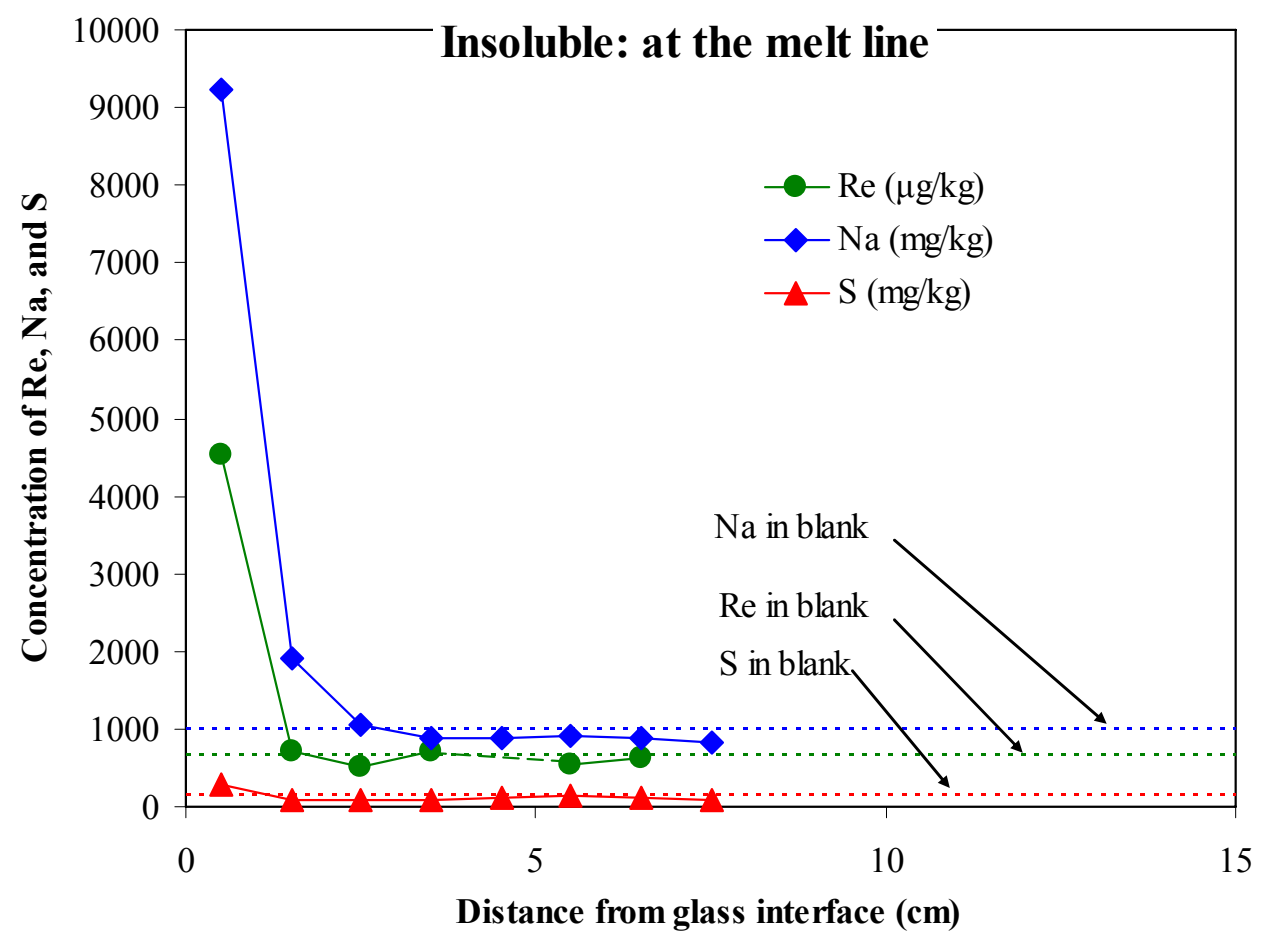

Figure 7.14. Concentration of Insoluble Re, $\mathrm{Na}$, and $\mathrm{S}$ in the CRB at the Melt Line

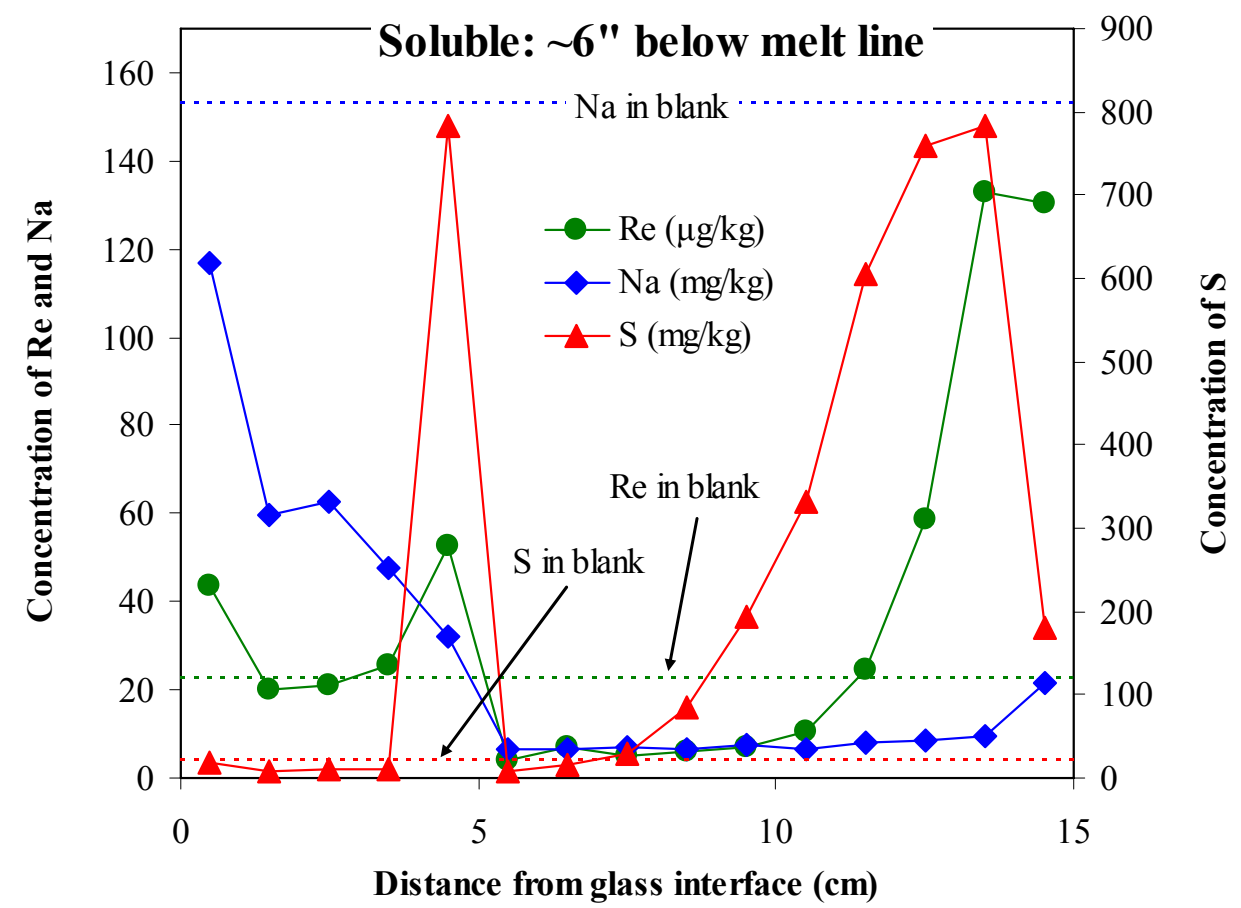

Figure 7.15. Concentration of Soluble Re, $\mathrm{Na}$, and $\mathrm{S}$ in the $\mathrm{CRB} \sim 15.2 \mathrm{~cm}$ Below the Melt Line 


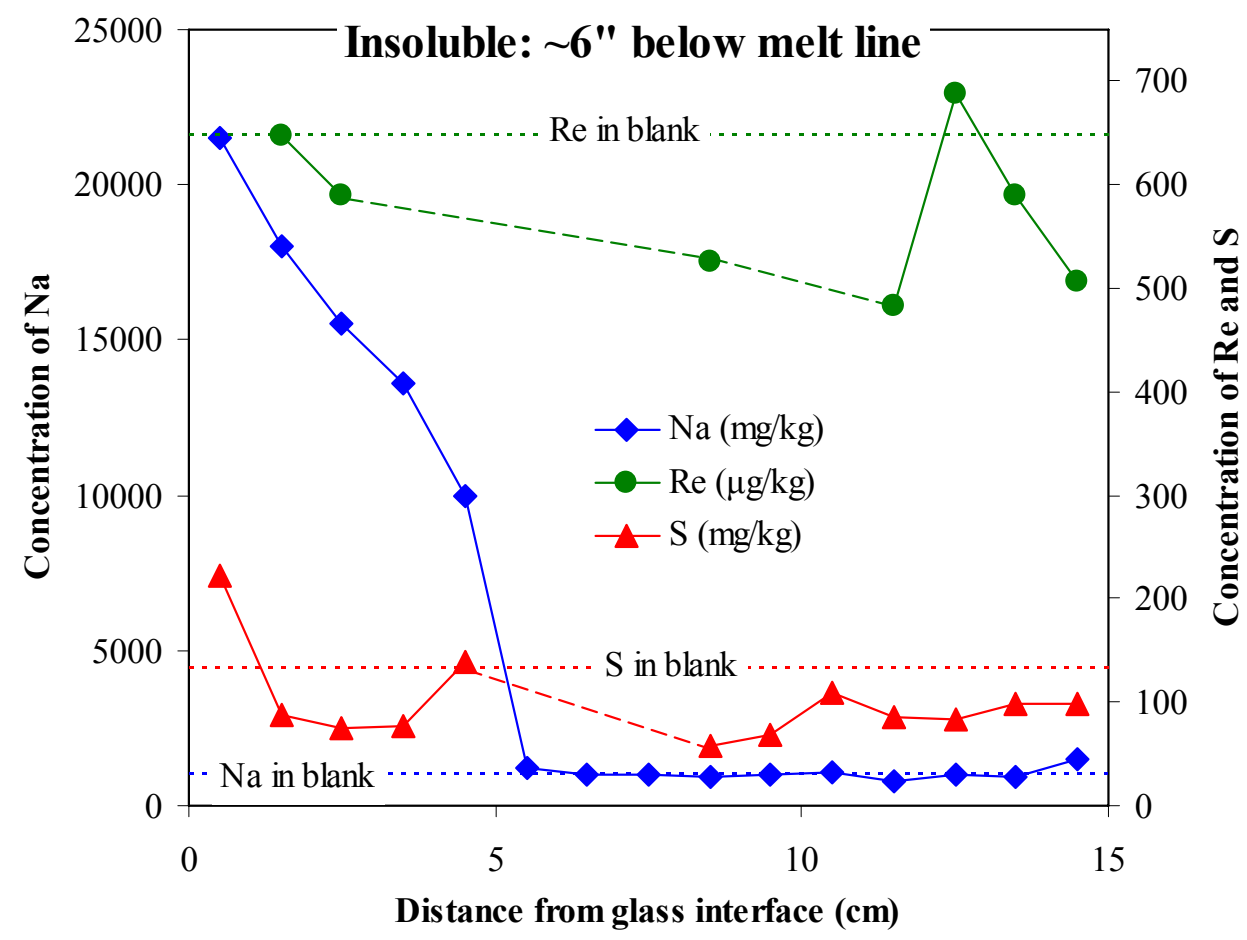

Figure 7.16. Concentration of Insoluble Re, $\mathrm{Na}$, and $\mathrm{S}$ in the $\mathrm{CRB} \sim 15.2 \mathrm{~cm}$ Below the Melt Line

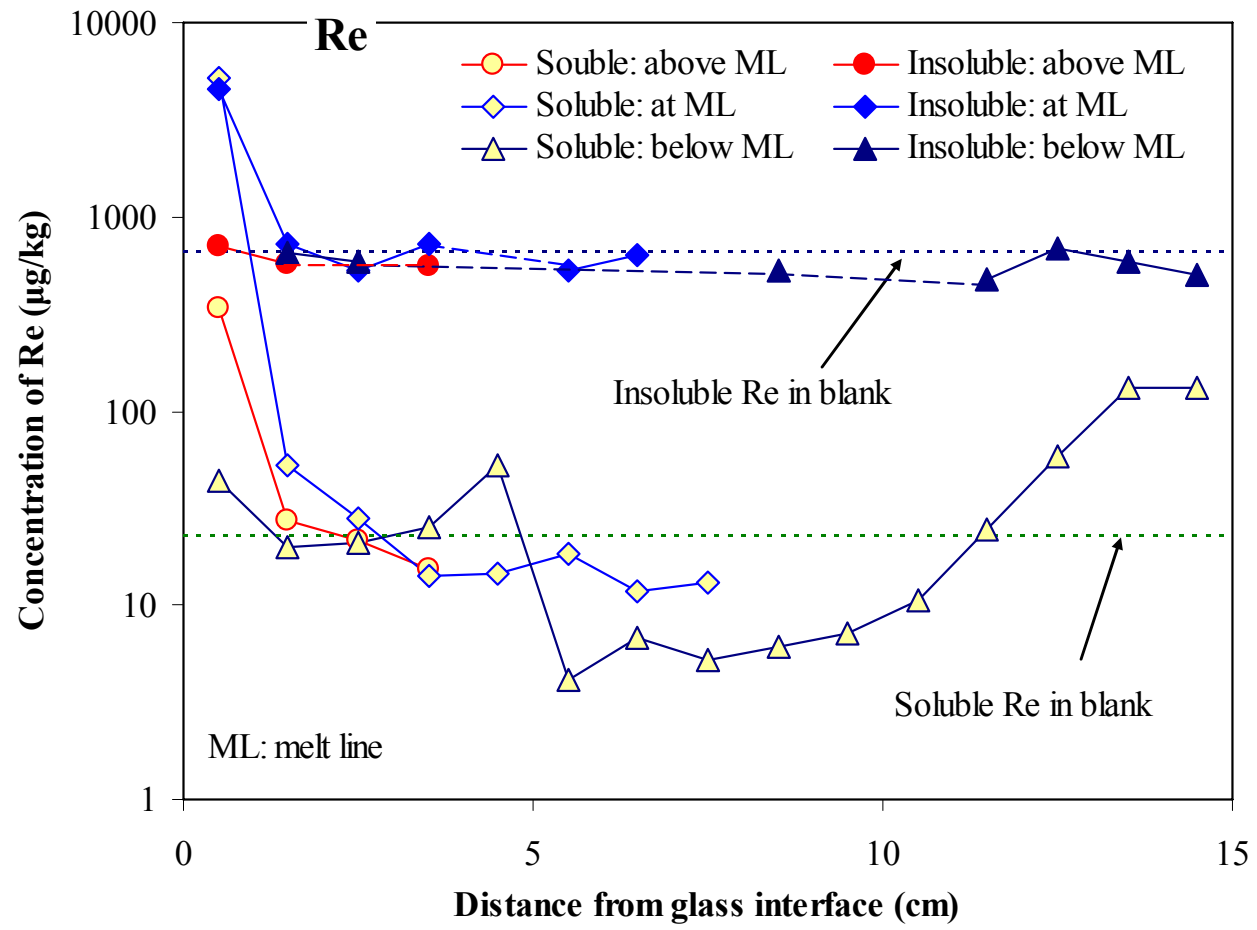

Figure 7.17. Concentration of Re in the CRB Samples from Different Locations 


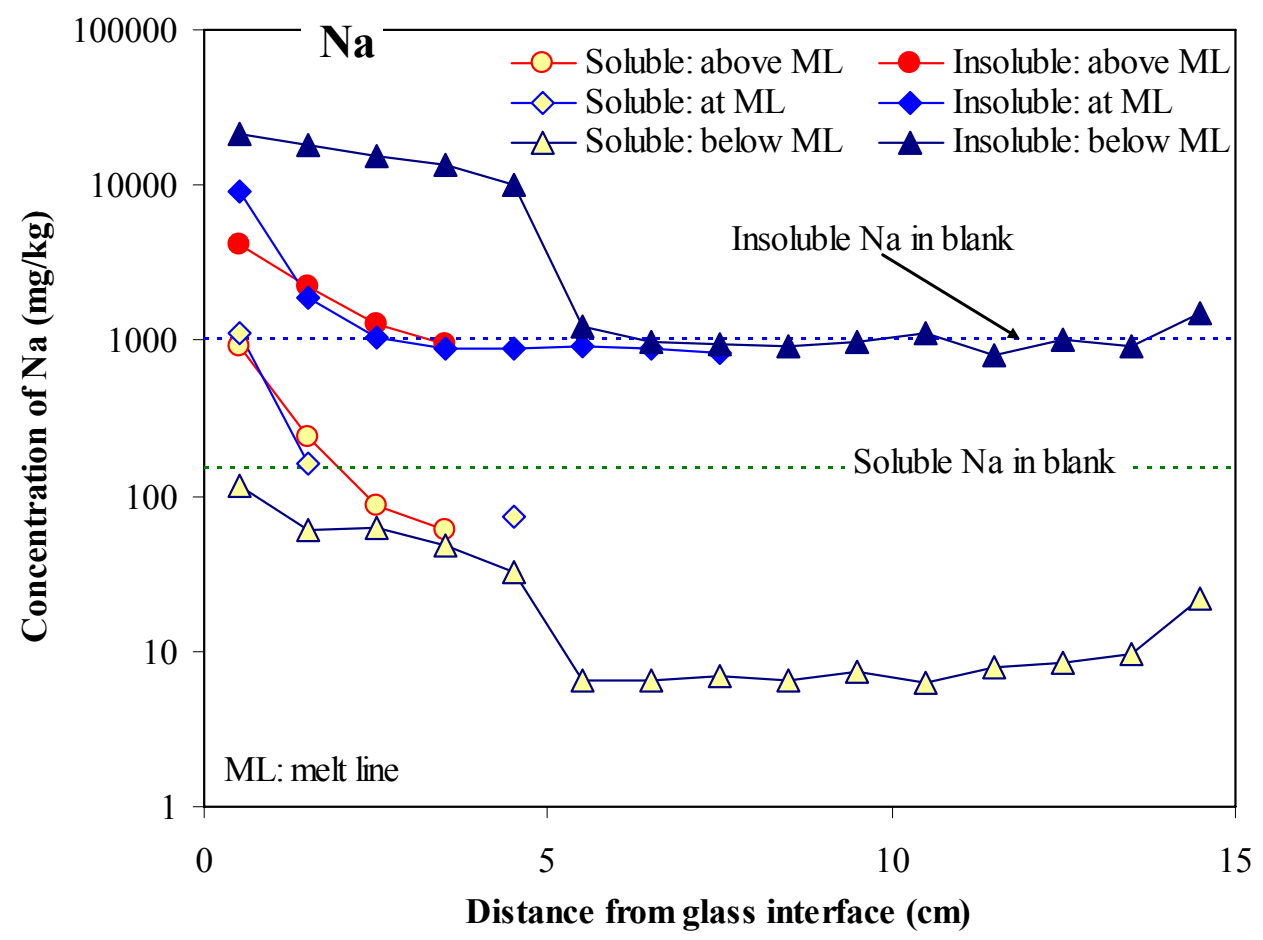

Figure 7.18. Concentration of $\mathrm{Na}$ in the CRB Samples from Different Locations

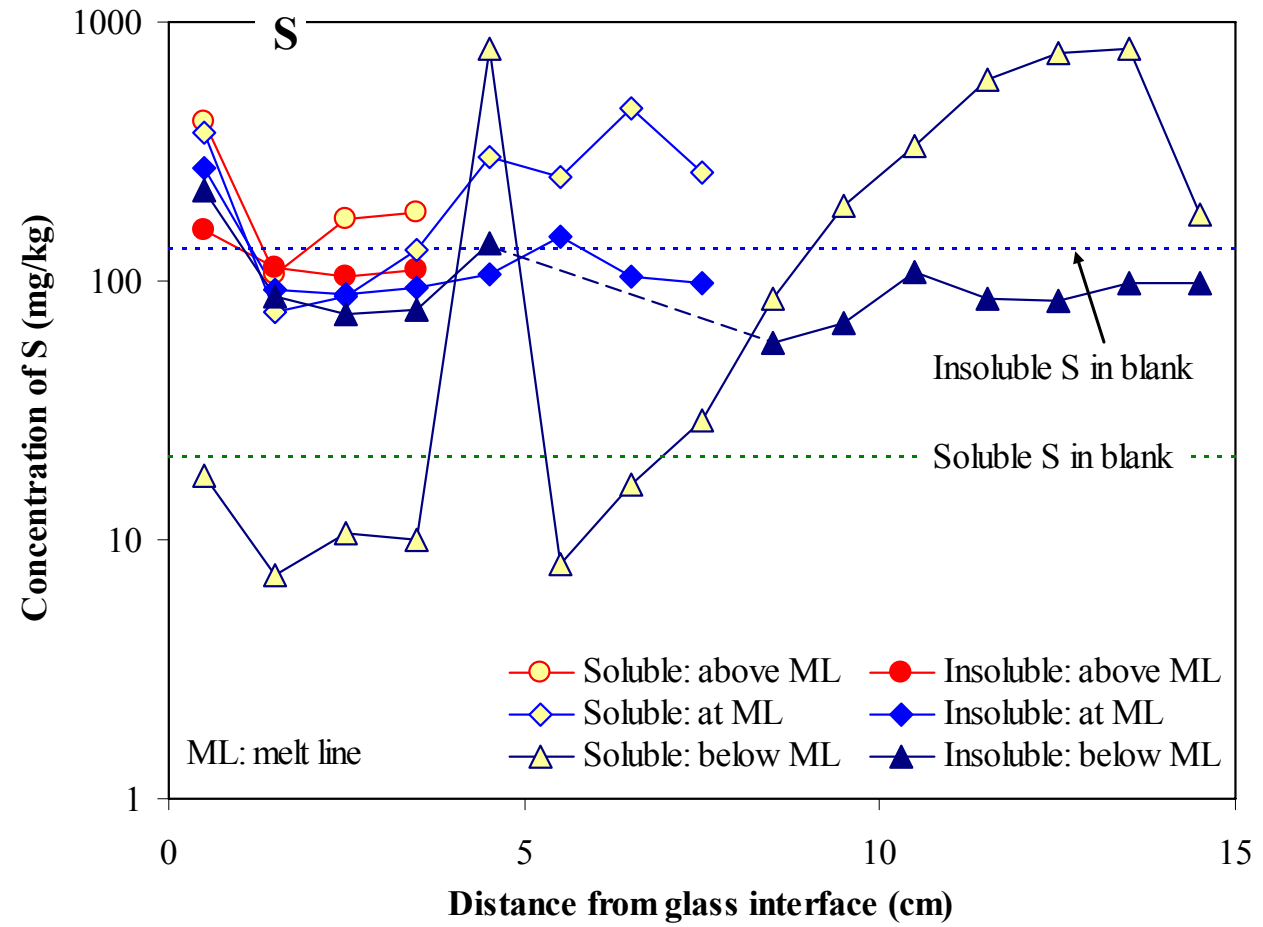

Figure 7.19. Concentration of $S$ in the CRB Samples from Different Locations 


\subsection{Summary}

In summary, for the CRB samples from above the melt line and at the melt line, soluble Re is present only up to $\sim 2 \mathrm{~cm}$ from the glass interface. For the CRB above the melt line, Re appears to penetrate into the CRB through a vapor disposition mechanism; that is, Re deposits when the CRB is cold, becomes molten as the temperature increases, and then penetrates further into the CRB by capillary action. The extent of penetration and the concentration of Re above the melt line is small. For the CRB at the melt line, Re penetrates into the CRB through both vapor deposition at the early stages of processing and then liquid MIS formation and penetration at later processing stages. The CRB at the melt line close to the glass interface had the highest soluble Re concentration. For the CRB below the melt line, a relatively low concentration of soluble $\mathrm{Re}$ is present on the surface layer while a higher concentration of soluble $\mathrm{Re}$ is observed in the outer layer close to the $\mathrm{CRB} /$ sand interface. Insoluble Re at a higher concentration than the blank level was observed only in the first 0 - to 1-cm layer of the CRB at the melt line. The below melt line results indicate that regions of the CRB that experience Re penetration through MIS migration early in the process that are subsequently covered by the progressing melt do not incorporate the Re in an insoluble melt phase but instead push the Re salt outward through evaporation and/or melting and flow of molten salt. 


\subsection{Modeling of Tc/Re Penetration of CRB}

This section documents a series of calculations and model-building efforts aimed at understanding the mechanisms by which Tc or Re might concentrate in the CRB during melting and the scaling principles that control the process. The primary effort has been directed toward the formation and flow of molten ionic salt.

\subsection{Saturation of the Feed by Molten Ionic Salt}

MIS cannot flow into the CRB in any volume unless it effectively saturates the particulate medium in which it forms. ${ }^{\text {(h) }}$ MIS is expected to form in the dry feed as the highly miscible salts melt and flow together. Until the MIS fills or saturates the pore space between the unmelted solid particles such that the liquid can develop a hydrostatic pressure, very little of it can flow into the CRB lining the melter. Effective liquid saturation, where not all the pores are liquid filled, but the liquid can develop hydrostatic pressure, should occur above a liquid volume fraction of $\sim 0.3$. ${ }^{(i)}$ Figure 8.1 illustrates effectively unsaturated and saturated conditions.
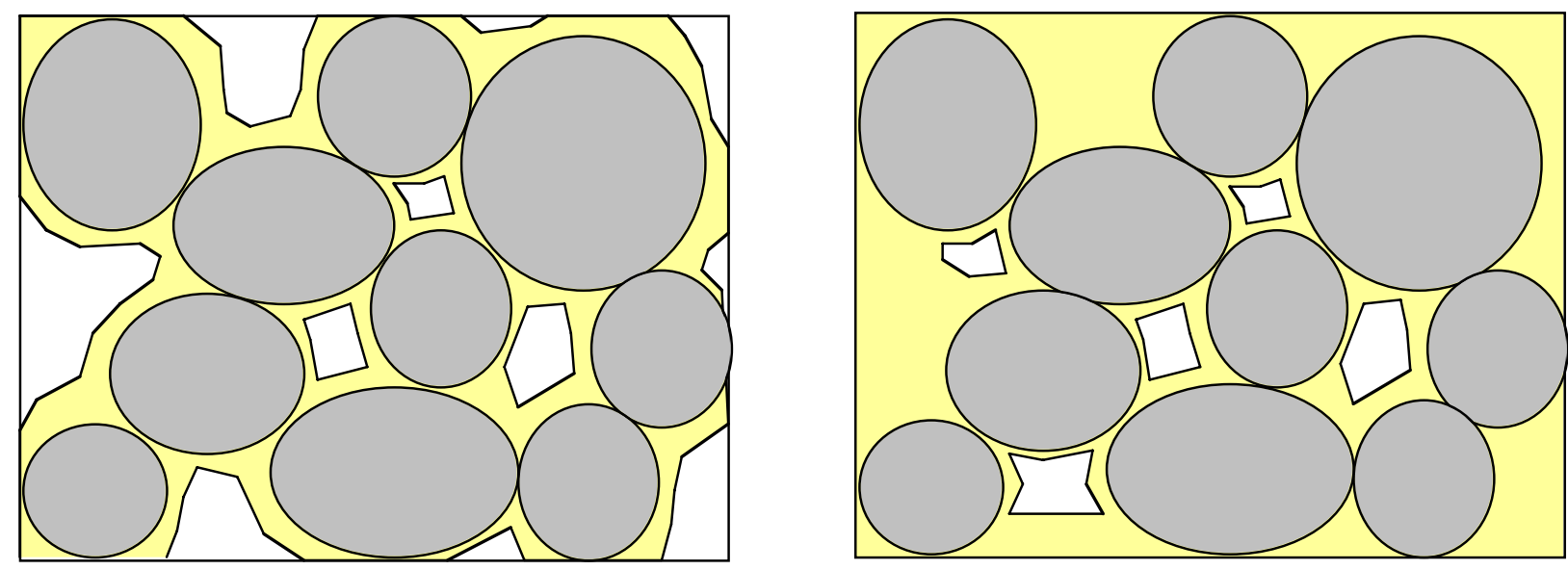

Figure 8.1. Solid Matrix Unsaturated (left) and Effectively Saturated (right) with Liquid

To determine whether MIS saturates the feed, a model of the melting process with a simple algorithm that tracked the mass and volume of solid and liquid and the void volume was constructed. Each solid species was assumed to become liquid at its melting-point, for the most part ignoring chemical reactions and eutectic liquid formation at lower temperatures (exceptions will be described later). This is conservative in that including these effects would increase the amount of liquid available, possibly indicating saturation at lower temperatures.

(h) Effective saturation is achieved when the liquid phase is sufficiently connected to establish a hydrostatic pressure gradient that can drive flow.

(i) A close-packed array of uniform spheres has a porosity of 0.26 and a square array of 0.476 . A randomly packed array of spheres averages a porosity of 0.36 . Non-uniform spheres pack more closely because small ones fill the space between the larger, but beds of non-spherical ground crystalline solids would have higher porosities. 
The algorithm assumed that the total mass of solid per unit initial mass of feed decreased by the mass fraction of the melting component, and the total mass of liquid per unit initial mass of feed increased by the same amount. The total volume of solid per unit initial mass of feed decreased by the melting component's mass fraction divided by its solid density and the total volume of liquid per unit initial mass of feed increased by the same amount, conservatively ignoring any volume change on melting. Assuming that each solid particle supported other particles, the melting of a particle causes the bed to contract, removing a void volume equal to the volume of the solid melted. This process has been observed experimentally ${ }^{(\mathrm{j})}$ and is illustrated in Figure 8.2.
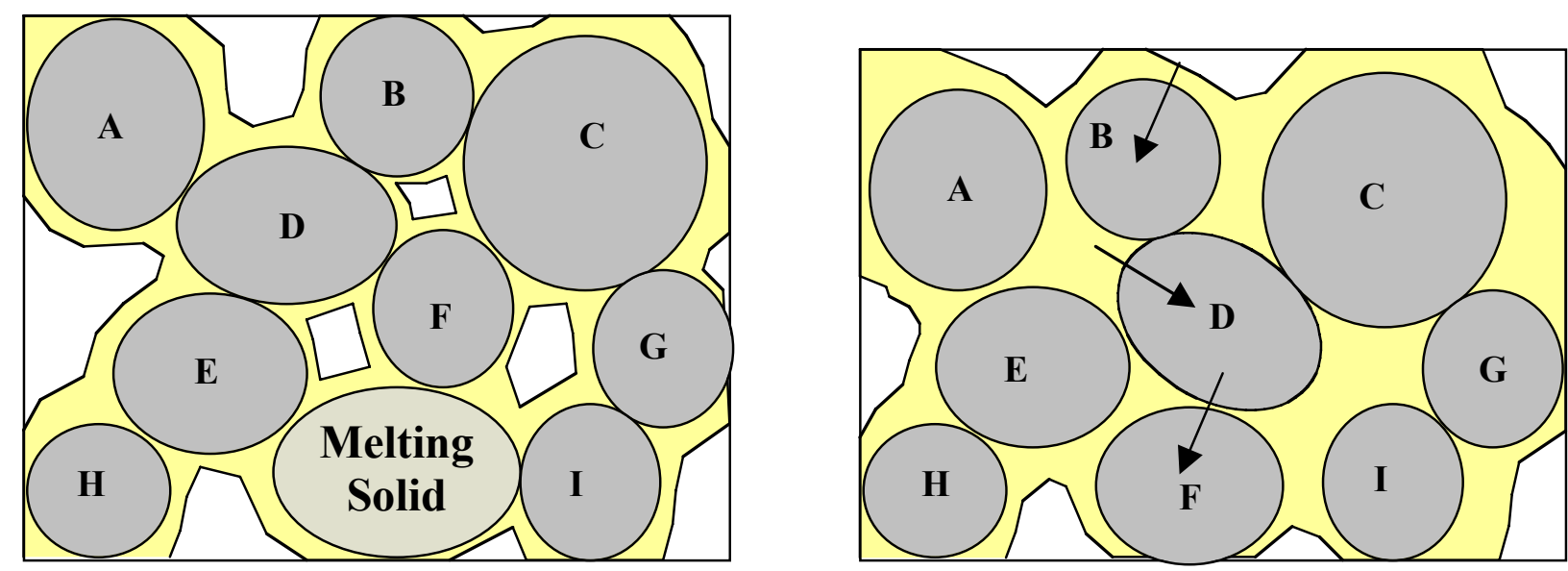

Figure 8.2. Melting Model: Melting Solid (left) Reduces Feed Volume (right) (solids were labeled A through I so that migrating solids can be easily tracked)

\subsubsection{Feed Composition and Physical Properties}

The feed in this study is a mixture of dry LAW simulant, Hanford soil, and other glass additives as given in Table 8.1. The composition of the LAW simulant was given in Table 4.1. The overall composition of the low-melting temperature $\left(<1000^{\circ} \mathrm{C}\right)$ components of initial feed is given in Table 8.2, arranged by melting point. The mass fraction of a component in the mixture (Table 8.2) is the product of the mass fraction of the component in the LAW simulant (Table 4.1) and the mass fraction of the submixture in the bulk feed (Table 8.1). The soil is assumed to be inert in the MIS temperature range. ${ }^{(\mathrm{k})}$ The volume per unit mass of initial feed of a component in Table 8.2 is the mass fraction divided by the solid density.

(j) Personal communication with Pavel Hrma, PNNL.

(k) Ibid. 
Table 8.1. Overall Bulk Feed Recipe

\begin{tabular}{||l|l|c||}
\hline \multicolumn{1}{|c|}{ Component } & \multicolumn{1}{c|}{ Name } & Mass Fraction \\
\hline $\mathrm{B}_{2} \mathrm{O}_{3}$ & Boron oxide & 0.043 \\
\hline Dry LAW simulant & LAW simulant (dry) & 0.347 \\
\hline $\mathrm{Re}_{2} \mathrm{O}_{7}$ & Rhenium oxide & 0.00009 \\
\hline Soil & Soil & 0.546 \\
\hline $\mathrm{ZrO}_{2}$ & Zirconium oxide & 0.062 \\
\hline
\end{tabular}

Table 8.2. Mixed Feed Composition By Melting Point

\begin{tabular}{|c|c|c|c|c|c|c|c|}
\hline No. & Component & Name & Source & $\begin{array}{c}\text { Molecular } \\
\text { Weight }\end{array}$ & $\begin{array}{c}\text { Melting } \\
\text { point } \\
\left({ }^{\circ} \mathrm{C}\right)^{(\text {a) }}\end{array}$ & $\begin{array}{l}\text { Density } \\
(\mathrm{g} / \mathrm{mL})^{(\mathrm{a})}\end{array}$ & $\begin{array}{c}\text { Mass } \\
\text { Fraction }\end{array}$ \\
\hline 1 & $\mathrm{Al}\left(\mathrm{NO}_{3}\right)_{3} \cdot 9 \mathrm{H}_{2} \mathrm{O}$ & $\begin{array}{l}\text { Aluminum nitrate } \\
\text { nonahydrate }\end{array}$ & $\begin{array}{l}\text { feed + LAW } \\
\text { sim }\end{array}$ & 375 & 73 & 1.72 & 0.0409 \\
\hline 2 & $\mathrm{Na}_{3} \mathrm{PO}_{4} \cdot 12 \mathrm{H}_{2} \mathrm{O}$ & $\begin{array}{l}\text { Sodium phosphate } \\
\text { dodecahydrate }\end{array}$ & LAW sim & 380 & 75 & 1.62 & 0.0148 \\
\hline 3 & $\mathrm{Na}_{2} \mathrm{C}_{2} \mathrm{O}_{4}$ & Sodium oxalate & LAW sim & 134 & 250 & 2.34 & 0.0012 \\
\hline 4 & $\mathrm{NaNO}_{2}$ & Sodium nitrite & LAW sim & 69 & 271 & 2.17 & 0.0231 \\
\hline 5 & $\mathrm{Re}_{2} \mathrm{O}_{7}$ & Rhenium oxide & feed & 484 & 297 & 6.10 & 0.0001 \\
\hline 6 & $\mathrm{NaNO}_{3}$ & Sodium nitrate & LAW sim & 85 & 307 & 2.26 & 0.1549 \\
\hline 7 & $\mathrm{NaOH}$ & Sodium hydroxide & $\begin{array}{l}\text { feed + LAW } \\
\text { sim }\end{array}$ & 40 & 323 & 2.13 & 0.0504 \\
\hline 8 & $\mathrm{KNO}_{3}$ & Potassium nitrate & LAW sim & 101 & 337 & 2.11 & 0.0010 \\
\hline 9 & $\mathrm{NaC}_{2} \mathrm{H}_{3} \mathrm{O}_{2}$ & Sodium acetate & LAW sim & 82 & 382 & 1.59 & 0.0085 \\
\hline 10 & $\mathrm{~B}_{2} \mathrm{O}_{3}$ & Boron oxide & feed & 70 & 450 & 2.55 & 0.0430 \\
\hline 11 & $\mathrm{Na}_{2} \mathrm{CrO}_{4}$ & Sodium chromate & LAW sim & 162 & 792 & 2.72 & 0.0013 \\
\hline 12 & $\mathrm{NaCl}$ & Sodium chloride & LAW sim & 58 & 801 & 2.17 & 0.0020 \\
\hline 13 & $\mathrm{Na}_{2} \mathrm{CO}_{3}$ & Sodium carbonate & LAW sim & 106 & 858 & 2.54 & 0.0398 \\
\hline 14 & $\mathrm{Na}_{2} \mathrm{SO}_{4}$ & Sodium sulfate & LAW sim & 142 & 884 & 2.70 & 0.0101 \\
\hline 15 & $\mathrm{NaF}$ & Sodium fluoride & LAW sim & 42 & 996 & 2.78 & 0.0011 \\
\hline
\end{tabular}

\subsubsection{Melt Progression Model}

The total initial volume of solids per unit initial mass of feed, $\mathrm{v}_{\mathrm{s}, \mathrm{f}}$, is the sum of the volumes for each component given by:

$$
\mathrm{v}_{\mathrm{s}, \mathrm{f}}=\sum_{\mathrm{i}=1}^{\mathrm{N}} \mathrm{v}_{\mathrm{s}, \mathrm{i}}=\sum_{\mathrm{i}=1}^{\mathrm{N}} \frac{\omega_{\mathrm{s}, \mathrm{i}}}{\rho_{\mathrm{s}, \mathrm{i}}}
$$

Using the values given in Table 8.2, the mixed-feed solid-specific volume calculated using Equation (8.1) is $0.3881 \mathrm{~mL} / \mathrm{g}$. 
The initial liquid mass and volume fractions are zero. The initial void volume fraction is determined from the bulk density and mass-averaged solids density by:

$$
\alpha_{\mathrm{f}}=1-\frac{\rho_{\mathrm{f}}}{\rho_{\mathrm{s}, \mathrm{f}}}=1-\rho_{\mathrm{f}} \mathrm{v}_{\mathrm{s}, \mathrm{f}}
$$

Measurements of the bulk density of the mixed feed samples for FS-38, which is represented by the recipes above, averaged $1.64 \mathrm{~g} / \mathrm{mL}^{(1)}$ The average solid density of the feed is simply the inverse of the feed-specific volume given by Equation (8.1) or $2.576 \mathrm{~g} / \mathrm{mL}$. Using Equation (8.2) with these densities gives an initial feed void fraction of 0.363 , making the initial solid volume fraction 0.637.

The melt progresses through each component, subtracting its mass from the total solid mass and adding it to the cumulative liquid mass at its melting point. Similarly, the component volume is subtracted from the total solid volume per unit initial feed mass, added to the cumulative liquid volume per unit feed mass and subtracted from the total void volume per unit initial feed mass. The masses, volumes, volume fractions, and phase densities are computed by the following equations:

At melting of feed component $i$ at temperature, $T_{i}$ after component $i-1$ has melted at $T_{i-1}$ :

$$
\begin{aligned}
\text { solid mass fraction: } & \omega_{\mathrm{s}, \mathrm{f}}\left(\mathrm{T}_{\mathrm{i}}\right)=\omega_{\mathrm{s}, \mathrm{f}}\left(\mathrm{T}_{\mathrm{i}-1}\right)-\omega_{\mathrm{s}, \mathrm{f}, \mathrm{i}} \\
\text { liquid mass fraction: } & \omega_{1, \mathrm{f}}\left(\mathrm{T}_{\mathrm{i}}\right)=\omega_{1, \mathrm{f}}\left(\mathrm{T}_{\mathrm{i}-1}\right)+\omega_{\mathrm{s}, \mathrm{f}, \mathrm{i}} \\
\text { total mass fraction: } & \omega_{\mathrm{f}}\left(\mathrm{T}_{\mathrm{i}}\right)=\omega_{\mathrm{s}, \mathrm{f}}\left(\mathrm{T}_{\mathrm{i}}\right)+\omega_{1, \mathrm{f}}\left(\mathrm{T}_{\mathrm{i}}\right) \\
\text { solid volume: } & \mathrm{v}_{\mathrm{s}, \mathrm{f}}\left(\mathrm{T}_{\mathrm{i}}\right)=\mathrm{v}_{\mathrm{s}, \mathrm{f}}\left(\mathrm{T}_{\mathrm{i}-1}\right)-\mathrm{v}_{\mathrm{s}, \mathrm{f}, \mathrm{i}} \\
\text { liquid volume: } & \mathrm{v}_{1, \mathrm{f}}\left(\mathrm{T}_{\mathrm{i}}\right)=\mathrm{v}_{\mathrm{l}, \mathrm{f}}\left(\mathrm{T}_{\mathrm{i}-1}\right)+\mathrm{v}_{\mathrm{s}, \mathrm{f}, \mathrm{i}} \\
\text { void volume: } & \mathrm{v}_{\mathrm{g}, \mathrm{f}}\left(\mathrm{T}_{\mathrm{i}}\right)=\mathrm{v}_{\mathrm{g}, \mathrm{f}}\left(\mathrm{T}_{\mathrm{i}-1}\right)-\mathrm{v}_{\mathrm{s}, \mathrm{f}, \mathrm{i}} \\
\text { total volume: } & \mathrm{v}_{\mathrm{f}}\left(\mathrm{T}_{\mathrm{i}}\right)=\mathrm{v}_{\mathrm{s}, \mathrm{f}}\left(\mathrm{T}_{\mathrm{i}}\right)+\mathrm{v}_{1, \mathrm{f}}\left(\mathrm{T}_{\mathrm{i}}\right)+\mathrm{v}_{\mathrm{g}, \mathrm{f}}\left(\mathrm{T}_{\mathrm{i}}\right) \\
\text { solid density: } & \rho_{\mathrm{s}, \mathrm{f}}\left(\mathrm{T}_{\mathrm{i}}\right)=\frac{\omega_{\mathrm{s}, \mathrm{f}}\left(\mathrm{T}_{\mathrm{i}}\right)}{\mathrm{v}_{\mathrm{s}, \mathrm{f}}\left(\mathrm{T}_{\mathrm{i}}\right)} \\
\text { liquid density: } & \rho_{1, \mathrm{f}}\left(\mathrm{T}_{\mathrm{i}}\right)=\frac{\omega_{1, \mathrm{f}}\left(\mathrm{T}_{\mathrm{i}}\right)}{\mathrm{v}_{1, \mathrm{f}}\left(\mathrm{T}_{\mathrm{i}}\right)} \\
\text { solid volume fraction: } & \alpha_{\mathrm{s}, \mathrm{f}}\left(\mathrm{T}_{\mathrm{i}}\right)=\frac{\mathrm{v}_{\mathrm{s}, \mathrm{f}}\left(\mathrm{T}_{\mathrm{i}}\right)}{\mathrm{v}_{\mathrm{f}}\left(\mathrm{T}_{\mathrm{i}}\right)} \\
\text { liquid volume fraction: } & \alpha_{1, \mathrm{f}}\left(\mathrm{T}_{\mathrm{i}}\right)=\frac{\mathrm{v}_{1, \mathrm{f}}\left(\mathrm{T}_{\mathrm{i}}\right)}{\mathrm{v}_{\mathrm{f}}\left(\mathrm{T}_{\mathrm{i}}\right)}
\end{aligned}
$$

(1) Memo from Renee Russell, PNNL, February 22, 2006, reporting measurements obtained under Test Instruction AMEC-TI-06-02. 


$$
\text { void volume fraction: } \alpha_{g, f}\left(T_{i}\right)=\frac{v_{g, f}\left(T_{i}\right)}{v_{f}\left(T_{i}\right)}(m)
$$

\subsubsection{Reactions Affecting Melt Phase Distribution}

Equations (8.3a) through (8.31) apply to each component at its melting temperature if there are no reactions that change the mass and volume of liquids and solids. However, several reactions have significant effects on masses and volumes and are accounted for in the calculation. As in the melting process, volumes of individual species formed and consumed are assumed to be conserved in the process. This assumption conservatively leads to a larger liquid volume than would actually occur.

Loss of water of hydration from aluminum nitrate and sodium phosphate: This reaction is assumed to occur between the melting temperatures of these components $\left(73\right.$ and $75^{\circ} \mathrm{C}$, respectively) and $200^{\circ} \mathrm{C}$. Aluminum nitrate loses 9 mole of water for each mole of hydrated aluminum nitrate, and sodium phosphate loses 12 moles per mole. The water released is assumed to leave as a vapor, reducing the liquid mass by the water mass lost and reducing the liquid volume by the value of water mass loss divided by the solid component density (density of mass lost assumed to be that of the original compound).

Sodium oxalate decomposition: Sodium oxalate decomposes or reacts with sodium nitrate/nitrite between 150 to $200^{\circ} \mathrm{C}$ (Hrma et al. 2005). We assume a direct decomposition of sodium oxalyate into sodium oxide and gas via the greatly simplified reaction:

$$
\mathrm{Na}_{2} \mathrm{C}_{2} \mathrm{O}_{4} \Rightarrow \mathrm{Na}_{2} \mathrm{O}+\mathrm{CO}_{2}+\mathrm{CO}
$$

Because there is relatively little oxalate in the feed (see Table 8.2), the exact reaction is not important. The sodium oxalate is assumed to have already melted, and the sodium oxide formed is assumed to exist as a liquid while the gas escapes without affecting the interstitial void fraction.

Reaction of sodium acetate with nitrate and nitrite: In the range of $\sim 300$ to $450^{\circ} \mathrm{C}$, the sodium acetate from the waste reacts with sodium nitrite, nitrate, and carbonate. It may also decompose into sodium carbonate. Many reactions and chains of reactions are possible, but the following nitrate reaction is assumed to dominate for the purpose of describing the phase distribution:

$$
\mathrm{NaC}_{2} \mathrm{H}_{3} \mathrm{O}_{2}+\mathrm{NaNO}_{3} \Rightarrow \mathrm{Na}_{2} \mathrm{O}+2 \mathrm{CO}+\frac{1}{2} \mathrm{~N}_{2} \mathrm{O}+\frac{3}{2} \mathrm{H}_{2} \mathrm{O}
$$

Though the reaction begins below its melting point, we assume that the sodium acetate is already liquid and the sodium oxide produced remains as a liquid. As above, the density of a liquid component, whether reactant or product, is assumed equal to the solid-phase density, and the evolving gas escapes without disturbing the remaining interstitial void volume.

(m) Because the total volume is the sum of the individual phase volumes, the three fractions automatically sum to 1.0 . 
Eutectic liquid includes salts with higher melting points: As temperatures approach $600^{\circ} \mathrm{C}$, where nitrate/nitrite decomposition begins, we assume that some sodium salts with higher melting points are incorporated in a eutectic liquid. These salts are sodium chromate, chloride, carbonate, sulfate, and fluoride. Because the exact temperatures at which these salts join the liquid are not known, all are included at once by repeated application of Equations (8.3a) through (8.31) for rows 11 to 15 of Table 8.2 at $600^{\circ} \mathrm{C} .^{(\mathrm{n})}$ The total mass and volume changes computed in this way (negative for solids and positive for liquid) are $0.054 \mathrm{~g} / \mathrm{g}$ of initial feed with a volume of $0.021 \mathrm{~mL} / \mathrm{g}$ of initial feed, respectively.

Decomposition of nitrates and nitrites: Beginning about $600^{\circ} \mathrm{C}$ and completing at about $750^{\circ} \mathrm{C}$, nitrate, nitrite, and carbonate salts decompose into oxides and gases. The non-gas products of these reactions are assumed to remain in the liquid. The large volume of gas escaping from the matrix is also assumed to create a large disturbance that releases all remaining interstitial gas so that the void volume within the solid matrix goes to zero (though bubbles may exist in the liquid). Sodium salts are by far the largest contributor, but aluminum nitrate is also included (the small concentration of potassium nitrate is ignored). The reactions are as follows:

$$
\begin{gathered}
\mathrm{NaNO}_{3} \Rightarrow \frac{1}{2} \mathrm{Na}_{2} \mathrm{O}+\mathrm{NO}+\frac{3}{4} \mathrm{O}_{2} \\
\mathrm{NaNO}_{2} \Rightarrow \frac{1}{2} \mathrm{Na}_{2} \mathrm{O}+\mathrm{NO}+\frac{1}{4} \mathrm{O}_{2} \\
\mathrm{Na}_{2} \mathrm{CO}_{3} \Rightarrow \mathrm{Na}_{2} \mathrm{O}+\mathrm{CO}_{2} \\
\mathrm{Al}\left(\mathrm{NO}_{3}\right)_{3} \Rightarrow \frac{1}{2} \mathrm{Al}_{2} \mathrm{O}_{3}+3 \mathrm{NO}+\frac{9}{4} \mathrm{O}_{2}
\end{gathered}
$$

\subsubsection{Results of the Melt Calculation}

Figure 8.3 plots the volume fractions of solids, liquids, and void as a function of temperature. The liquid volume fraction abruptly rises to 0.26 at $323^{\circ} \mathrm{C}$ when sodium nitrate $(15 \mathrm{wt} \%$ of the feed) and sodium hydroxide $(5 \mathrm{wt} \%)$ have melted. The volume fraction reaches 0.34 when boron oxide melts at $450^{\circ} \mathrm{C}$. Eutectic liquid forms from compounds with higher melting points, which increases the liquid fraction to 0.41 at $600^{\circ} \mathrm{C}$. At this point, nitrate decomposition begins to convert liquid to gas, and interstitial void escapes as the matrix is agitated by gas generation. There is probably enough molten salt available to effectively saturate the solid matrix at temperatures above $450^{\circ} \mathrm{C}$ and possibly as low as $350^{\circ} \mathrm{C}$, which matches experimental observations. ${ }^{(0)}$ Figure 8.4 shows the phase and bulk densities as a function of temperature. All densities continue to increase as more dense solids melt, and decomposition removes gases. The density of solids left after nitrate decomposition is almost $3.0 \mathrm{~g} / \mathrm{mL}$. The corresponding liquid density at $750^{\circ} \mathrm{C}$ is $2.3 \mathrm{~g} / \mathrm{mL}$.

(n) Per personal communication with Pavel Hrma, this temperature may be too high. Laboratory tests indicate that LAW is all melted at $450^{\circ} \mathrm{C}$. We do not know what compounds precipitate when liquid LAW is dried during preparation and what kinds of eutectics are formed when it is heated.

(o) Ibid. 


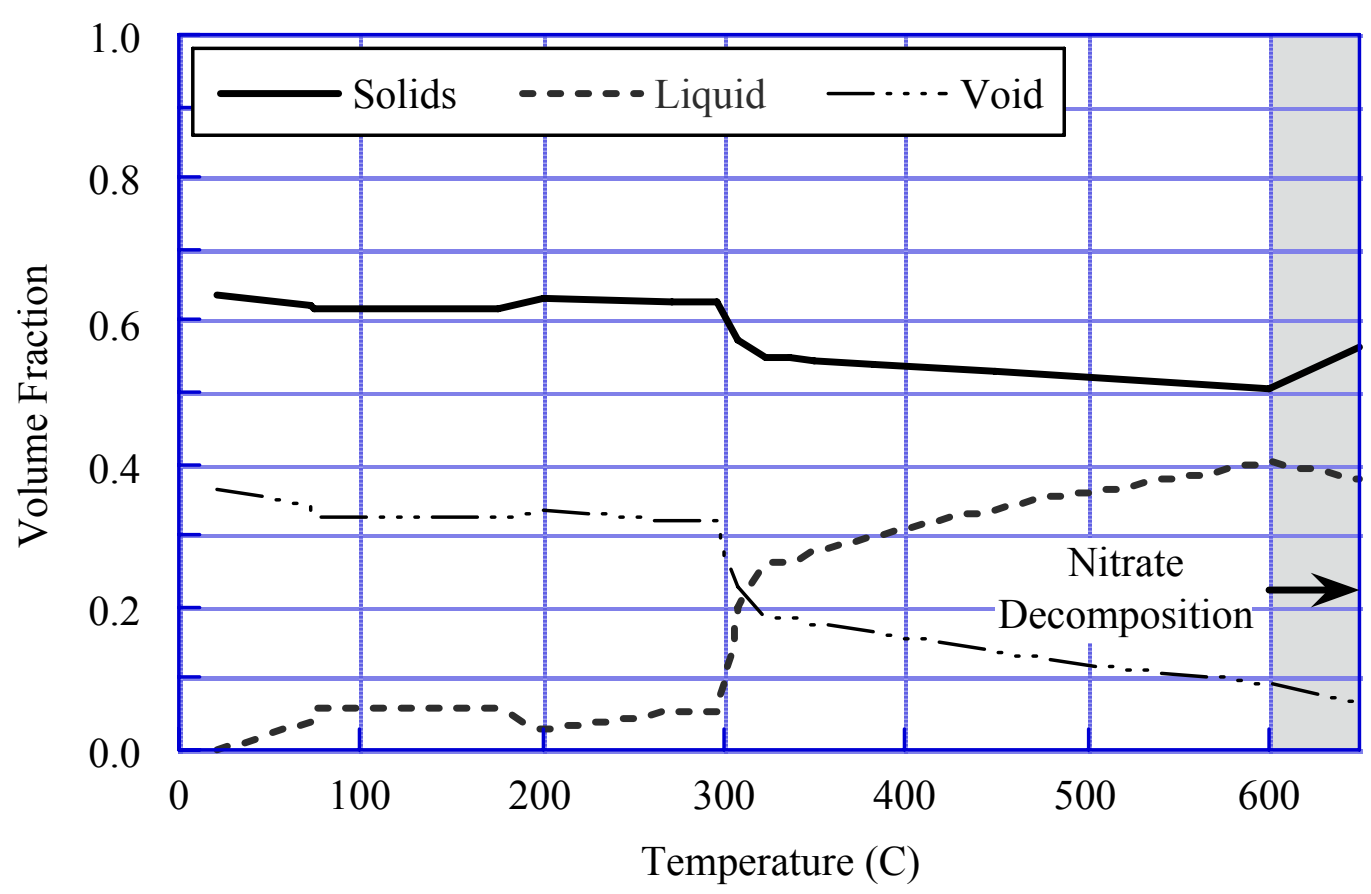

Figure 8.3. Phase Volume Fractions Versus Temperature

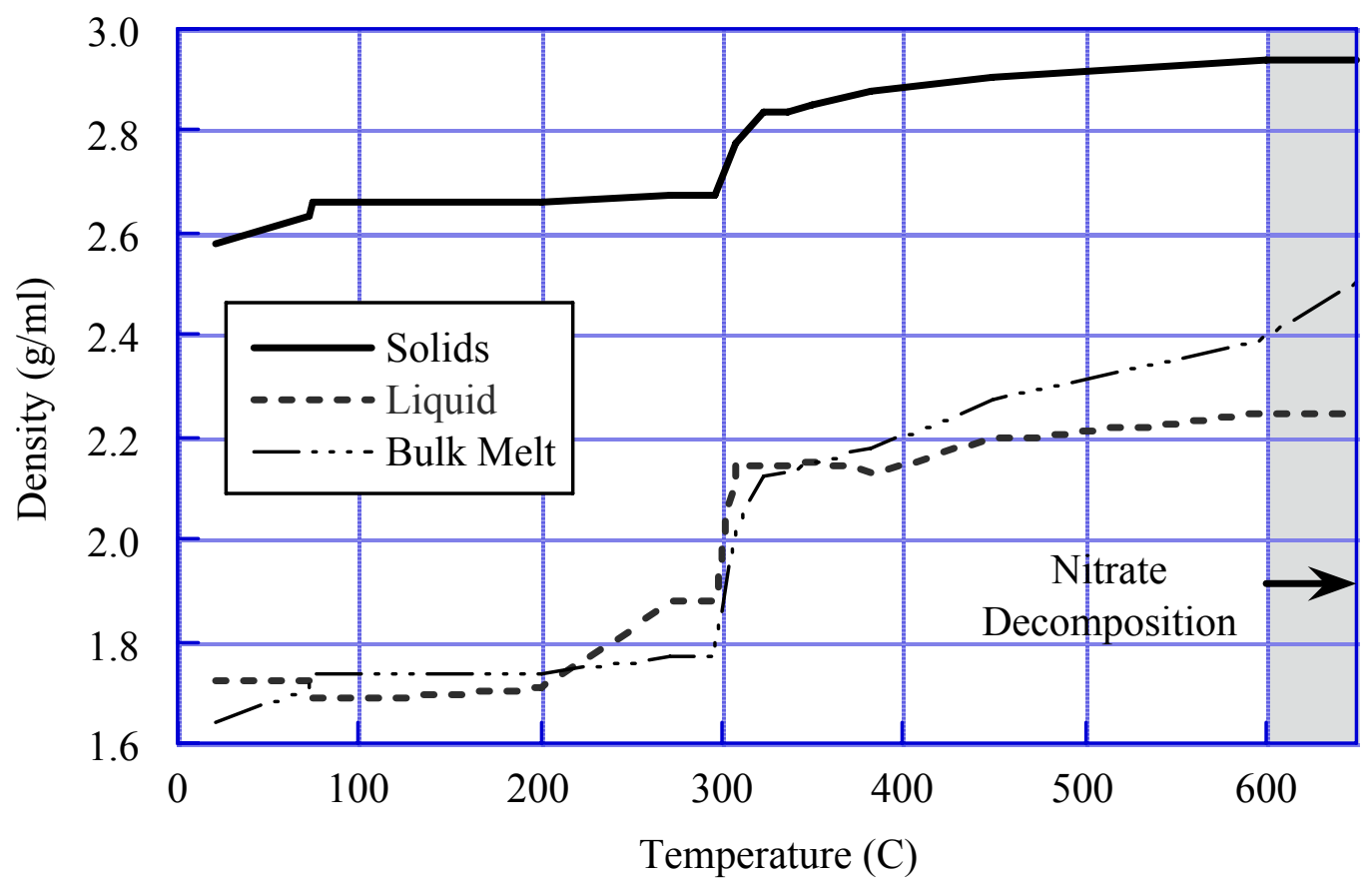

Figure 8.4. Phase Densities Versus Temperature 


\subsection{Maximum Theoretical Concentration of MIS in the CRB}

Figure 8.5 shows the distribution of sodium atoms in a sample of CRB from Engineering Scale Test 31B next to the inside surface exposed to glass (Hrma et al. 2005). The maximum sodium atomic concentration is $\sim 6$ atom $\%$. Similar data were obtained from a sample coupon of CRB material immersed in melting glass feed at various temperatures. Because there is little sodium in the CRB material, this indicates penetration of MIS into the CRB. A comparison to the maximum theoretical sodium concentration at different stages of the feed-melting and glass-forming processes gives some insight on which stage is represented and to what extent the molten feed filled the pores in the CRB. The objective of this calculation was to determine whether this amount of sodium represents complete saturation of the available pore space with MIS or some lesser, unsaturated volume.

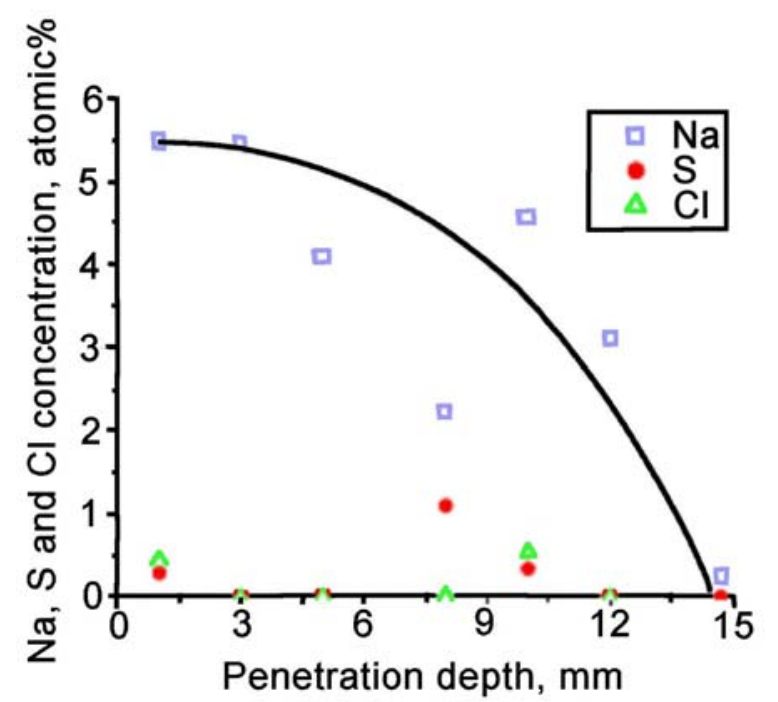

Figure 8.5. Atomic Concentrations in CRB after ES-31B Test [Figure 5.16 from Hrma et al. (2005)]

To confirm or refute this hypothesis, we need to calculate the theoretical atom\% sodium that would occur if all the pore space in the CRB were filled with MIS both before and after nitrate/nitrite decomposition, but before the transition to glass. This range of conditions includes compounds from 1 through 16 in Table 8.2 plus the sodium oxide formed during nitrate/nitrite decomposition. There are no sodium compounds in the CRB material, but the total number of atoms needs to be included. Table 8.3 gives the composition of the CRB solids in terms of metal oxides (Hrma et al. 2005). These oxides do not physically exist in the CRB. However, because the actual mineral content has not yet been determined, we use Table 8.3 as the only approximation available. The number of atoms computed from the oxides should be lower than in the actual mineral composition. 
Table 8.3. Composition of Castable Refractory Solids in Terms of Metal Oxides

\begin{tabular}{|c|l|l|c|c|c|c|}
\hline No. & \multicolumn{1}{|c|}{ Component } & \multicolumn{1}{c|}{ Name } & $\begin{array}{c}\text { Molecular } \\
\text { Weight }\end{array}$ & $\begin{array}{c}\text { Melting } \\
\text { Point (C) }^{(\mathbf{a})}\end{array}$ & $\begin{array}{c}\text { Density } \\
(\mathbf{g} / \mathbf{m L})^{(\mathbf{a})}\end{array}$ & $\begin{array}{c}\text { Mass } \\
\text { Fraction }^{(\mathbf{b})}\end{array}$ \\
\hline 1 & $\mathrm{Al}_{2} \mathrm{O}_{3}$ & Aluminum oxide & 102 & 2053 & 3.97 & 0.608 \\
\hline 2 & $\mathrm{SiO}_{2}$ & Silicon oxide & 60 & 1713 & 2.50 & 0.345 \\
\hline 3 & $\mathrm{Fe}_{2} \mathrm{O}_{3}$ & Iron oxide & 160 & 1565 & 5.25 & 0.001 \\
\hline 4 & $\mathrm{TiO}_{2}$ & Titanium oxide & 144 & 1777 & 4.49 & 0.018 \\
\hline 5 & $\mathrm{CaO}$ & Calcium oxide & 56 & 2898 & 3.34 & 0.016 \\
\hline
\end{tabular}

(a) CRC Handbook of Chemistry and Physics, $71^{\text {st }}$ Ed., 1990 to 1991.

(b) Mass fractions renormalized to a sum of 1.0 ignoring $0.3 \mathrm{wt} \%$ "other."

\subsubsection{Atom Fraction Calculation}

Given the porosity and solids density of the CRB, the atom fraction of sodium, $\mathrm{A}_{\mathrm{Na}}$, in the MIS-filled $\mathrm{CRB}$ is given by:

$$
\mathrm{A}_{\mathrm{Na}}=\frac{\mathrm{a}_{\mathrm{Na}, \mathrm{S}}}{\mathrm{a}_{\mathrm{S}}+\mathrm{a}_{\mathrm{CRB}} \frac{(1-\phi)}{\phi} \frac{\rho_{\mathrm{CRB}}}{\rho_{\mathrm{S}}}}
$$

where $\quad a_{\mathrm{Na}, \mathrm{S}}=$ atoms of sodium per unit mass of molten salt $(\# / g)$

$\mathrm{a}_{\mathrm{S}}=$ total number of atoms per unit mass of molten salt $(\# / \mathrm{g})$

$\mathrm{a}_{\mathrm{CRB}}=$ total number of atoms per unit mass of $\mathrm{CRB}$ material $(\# / \mathrm{g})$

$\phi=$ CRB porosity, given as 0.17 by Hrma et al. (2005)

$\rho_{\mathrm{S}}=$ bulk density of the molten salt $(\mathrm{g} / \mathrm{mL})$, Equation (8.3i) at the temperature corresponding to a specific condition (e.g., after initial melting, before nitrate decomposition, etc.)

$\rho_{\mathrm{CRB}}=$ density of the solid material in the CRB $(\mathrm{g} / \mathrm{mL})$. Applying Equation $(8.3 \mathrm{~h})$ to Table 8.3 gives $3.309 \mathrm{~g} / \mathrm{mL}$.

Because each mole of a compound contains the same number of molecules, the number of atoms of sodium per unit mass of molten salt is the mass fraction-weighted sum of the number of atoms of sodium per mole of compound over all compounds existing in the MIS. The number of atoms per unit mass of molten salt is the same mass-weighted sum of the total number of atoms per mole. The number of atoms per unit mass of CRB solids is the mass fraction-weighted sum of the number of atoms per mole of each compound over all compounds making up the CRB material. These sums are expressed in terms of mass fractions and molecular weights as follows:

$$
\mathrm{a}_{\mathrm{Na}, \mathrm{S}}=\sum_{\mathrm{i}=1}^{15} \frac{\omega_{\mathrm{i}}}{\mathrm{M}_{\mathrm{i}}} \mathrm{N}_{\mathrm{Na}, \mathrm{i}}+\left[\frac{\omega}{\mathrm{M}} \mathrm{N}_{\mathrm{Na}}\right]_{\mathrm{Na}_{2} \mathrm{O}}
$$




$$
\begin{gathered}
\mathrm{a}_{\mathrm{S}}=\sum_{\mathrm{i}=1}^{15} \frac{\omega_{\mathrm{i}}}{\mathrm{M}_{\mathrm{i}}} \mathrm{N}_{\mathrm{i}}+\left[\frac{\omega}{\mathrm{M}} \mathrm{N}\right]_{\mathrm{Na}_{2} \mathrm{O}} \\
\mathrm{a}_{\mathrm{CRB}}=\sum_{\mathrm{i}=1}^{5} \frac{\omega_{\mathrm{i}}}{\mathrm{M}_{\mathrm{i}}} \mathrm{N}_{\mathrm{i}}
\end{gathered}
$$

where $\mathrm{N}_{\mathrm{Na}, \mathrm{i}}$ is the number of sodium atoms in one molecule of $\mathrm{I}, \mathrm{N}_{\mathrm{i}}$ is the total number atoms in one molecule of $\mathrm{I}$, and $\omega_{\mathrm{i}}$ and $\mathrm{M}_{\mathrm{i}}$ in Equation (8.7a) and (8.7b) are taken from Table 8.2 and those in Equation (8.7c) from Table 8.3.

The various reactions (8.5a) through (8.5f) occurring as the feed temperature increases need to be included in the sodium atomic fraction calculation as they were in the melt progression analysis. The mass fractions of the compounds used in Equations (8.7a) and (8.7b) are adjusted to account for these reactions as described in the preceding section.

\subsubsection{Results of Sodium Atom Fraction Analysis}

The sodium atom concentrations in the CRB resulting from complete saturation of a liquid salt under several possible conditions are summarized below.

1. 2.6 atom $\%$ sodium at 300 to $320^{\circ} \mathrm{C}$ : molten salt consisting of the compounds through sodium nitrate before any decomposition reactions or loss of water of hydration. Molten salt alone has 19 atom\% sodium and a density of $2.15 \mathrm{~g} / \mathrm{mL}$.

2. 2.8 atom $\%$ sodium at 450 to $500^{\circ} \mathrm{C}$ : molten salt consisting of compounds through boron oxide after loss of water of hydration and sodium acetate decomposition but before other decomposition reactions. Molten salt alone has 19 atom\% sodium and a density of $2.20 \mathrm{~g} / \mathrm{mL}$.

3. 5.4 atom $\%$ sodium above $\sim 750^{\circ} \mathrm{C}$ : eutectic liquid consisting of compounds through sodium oxide after decomposition of nitrates, nitrites, and sodium oxalate. Molten salt alone has 47 atom $\%$ sodium and a density of $2.28 \mathrm{~g} / \mathrm{mL}$.

If the CRB porosity were increased to 0.20 , the sodium concentration would increase to 6.4 atom $\%$ after decomposition. We conclude that the 6 atom\% sodium measured in the CRB from the ES test must represent complete saturation of the pore space by molten salt. The gas generation accompanying nitrate/nitrate decomposition in the molten salt probably does not expel it from the CRB pore space to any measurable degree.

\subsection{Physical Concept of the Melting Process}

After the started batch has melted, melting should progress upward if feed is added at about the same rate it melts such that a cold cap of roughly constant thickness is maintained in the box. In this case, the dominant temperature gradient in the cold cap is vertical, and the thickness of the layers of feed in different stages of melting remains approximately constant. The time that a point on the CRB wall is exposed to each layer is therefore determined by the feed rate. Figure 8.6 is a sketch of this concept. 


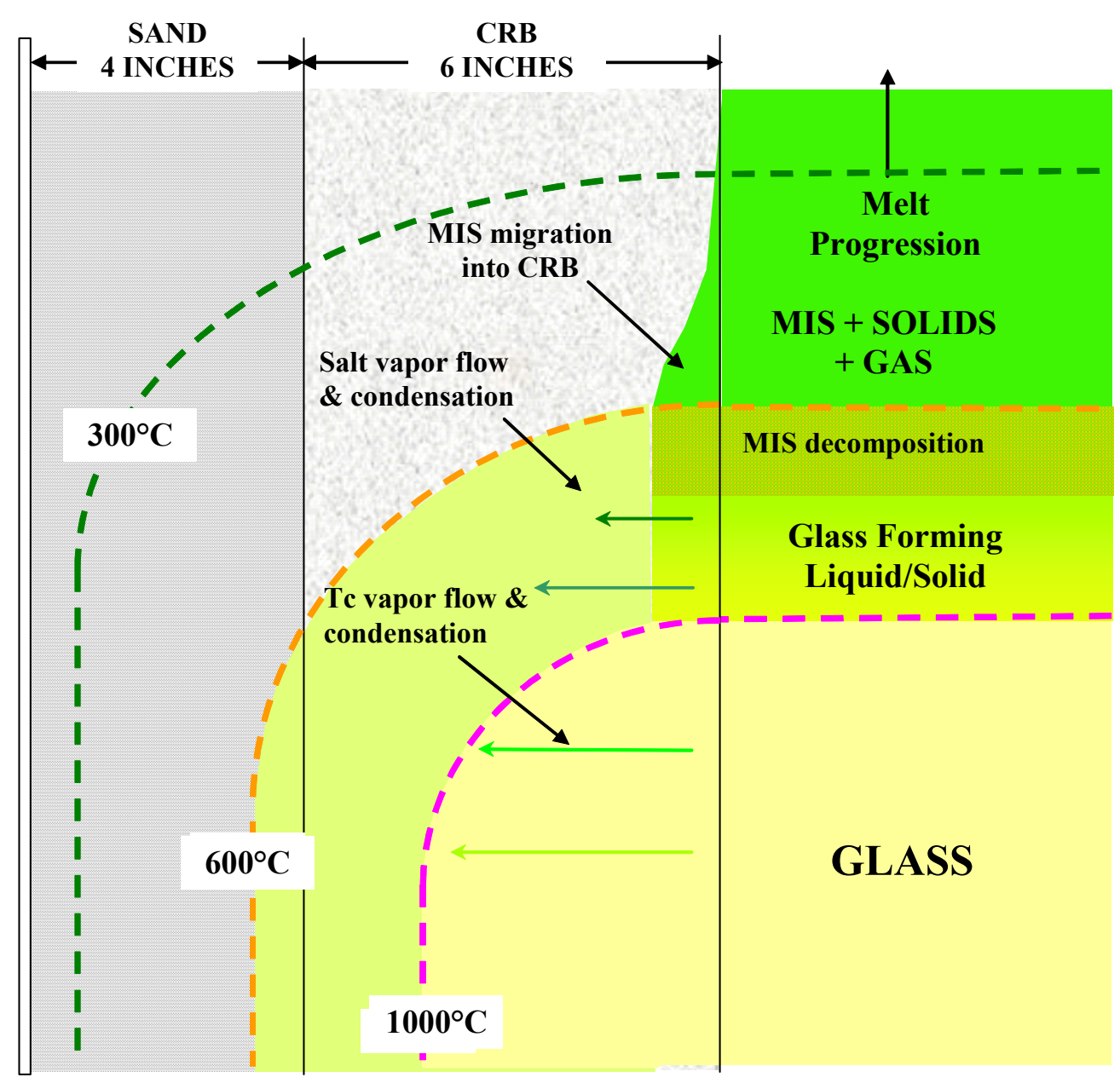

Figure 8.6. Melt Process Concept-Vertical Progression

While this concept is easy to model, it does not explain why the trace amounts of Re in the feed concentrate in the CRB. There is no clear mechanism for lateral transport of perrhenate salts or salt vapors in the vertical progression model to cause such concentration in the side walls. Also, the model does not easily accommodate the mixing effects of the large volume of gas generated during decomposition flowing up through the cold cap. Does this action tend to concentrate or disperse the MIS before decomposition?

An alternative melt progression model that is more lateral than vertical is suggested from the results from a simulation of FS-38A performed with the TEMPEST code. Figure 8.7 shows color contours of temperatures at 48,59 , and $72 \mathrm{~h}$ elapsed time on a section of the melter across the width of the melter box at the mid-section. The center line is on the right, and the melter box walls are shown by transparent gray shading. The darker blue oblong on top of the orange-red melt at 48 and $59 \mathrm{~h}$ represents feed batches added at 40 and $56 \mathrm{~h}$. 


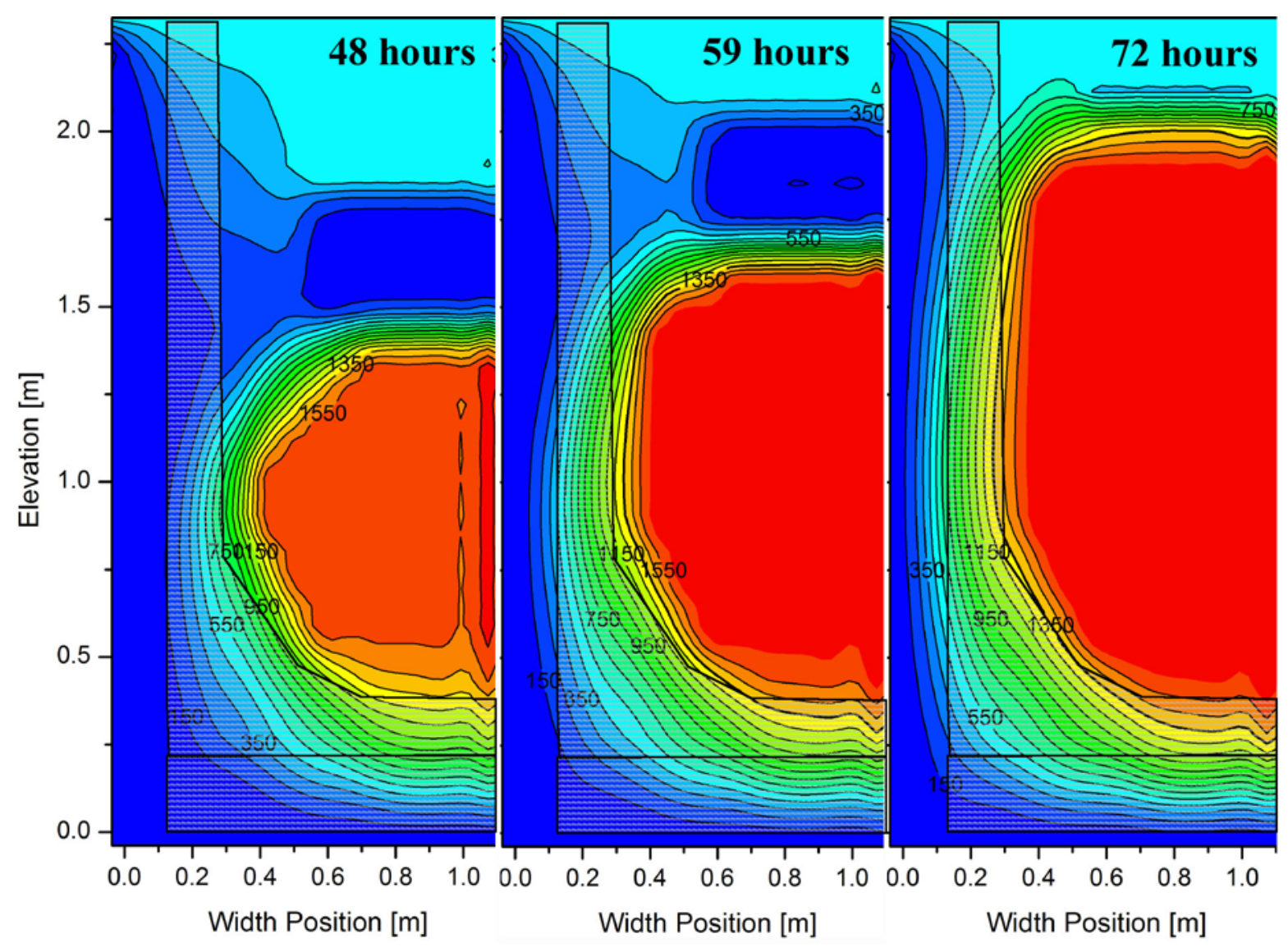

Figure 8.7. Temperature Contours from Simulation of Test 38A

The melt progression shown in Figure 8.7 is as much lateral as vertical most of the time, at least in the upper portion of the melt. This suggests the lateral melt model sketched in Figure 8.8. Rather than a relatively localized process moving up the wall as in the vertical model of Figure 8.6, the reactions may occur in series as the temperature raises more-or-less simultaneously over a large area of the CRB wall. The process might follow a sequence like this: 1) salts begin to melt and move into the $\mathrm{CRB}$ at $\sim 450^{\circ} \mathrm{C}$ when sufficient liquid becomes available and continues through the nitrate/nitrite/carbonate decomposition stage beginning at $\sim 600^{\circ} \mathrm{C}, 2$ ) post-decomposition liquid is replaced by heavier glassforming liquid/solids at 800 to $1000^{\circ} \mathrm{C}$, which halts penetration, and 3) molten salt that has penetrated the $\mathrm{CRB}$ reacts with CRB material, forming a durable glass at 1000 to $1200^{\circ} \mathrm{C}$. 


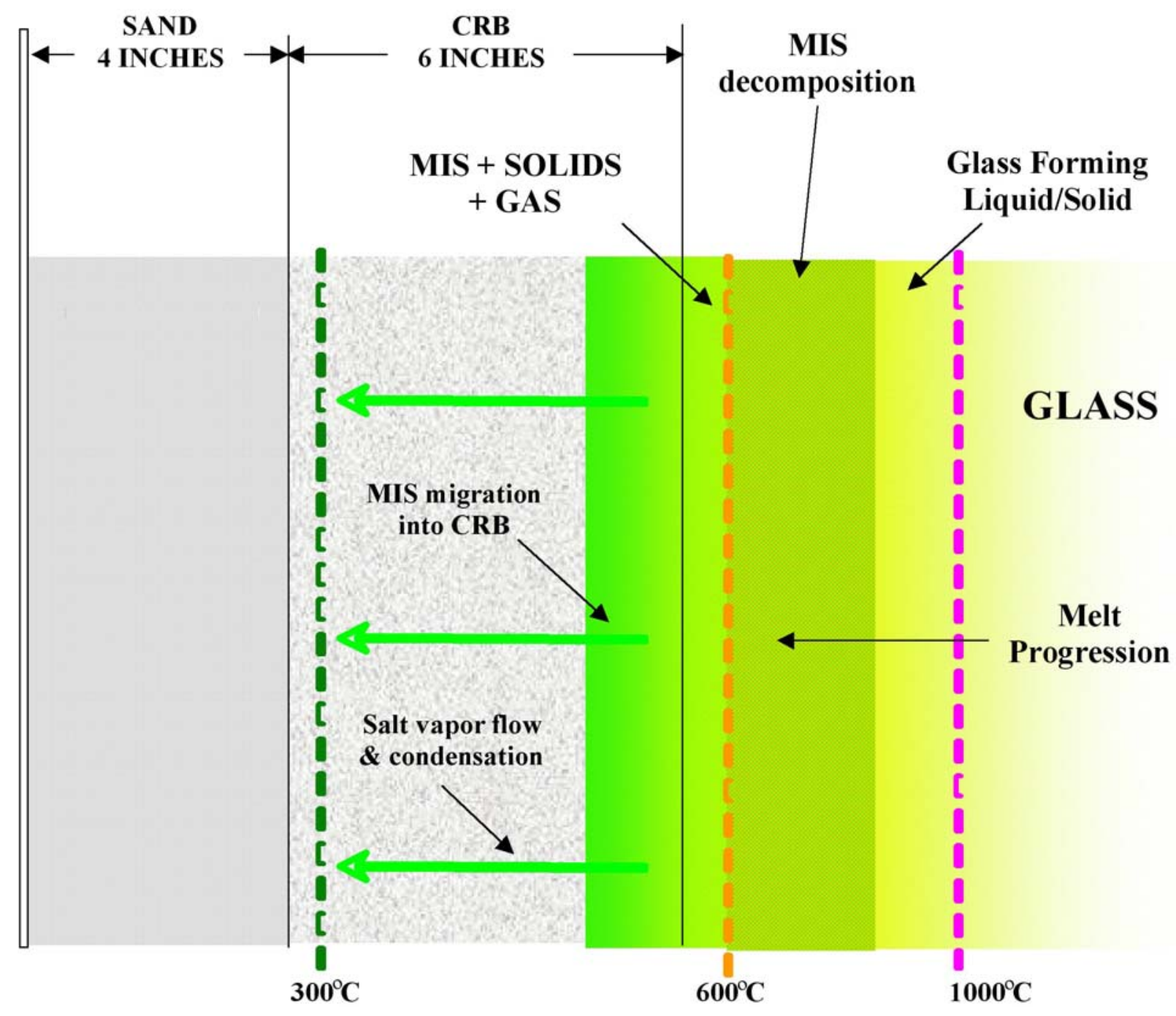

Figure 8.8. Melt Process Concept-Lateral Progression

While there are insufficient data to describe the process very well, the lateral melt progression model is attractive because it provides a clear mechanism for sweeping perrhenate salts outward to concentrate at the wall. It also exposes a large volume of liquid salts to the wall over a large depth that helps explain how the CRB pores could saturate with post-decomposition salt.

However, this model probably represents a limiting condition or special case in Test 38 that cannot exist in production. The TEMPEST simulation used a melting criterion where material at less than $1000^{\circ} \mathrm{C}$ was considered a solid not subject to convection, forcing the colder feed to act as a solid boundary until reaching the specified transition temperature. But the dry, low density $(\sim 1.6 \mathrm{~g} / \mathrm{mL})$ feed powder would have had little or no strength, and the heavier (density $\sim 2.9 \mathrm{~g} / \mathrm{mL}$ ) liquid glass should have pushed it up out of the way and flowed to the wall. At the same time, later feed batches added on top of the higherdensity glass would float with 80 to $90 \%$ of their volume submerged. The floating feed would exist in a "trough" located either in the central part of the melter or as a ring around the periphery. A central trough of feed would tend to keep the molten salt in a pool away from the wall, while a peripheral trough would keep the molten salt in contact with the wall more like the horizontal model of Figure 8.8. 
It is not possible at this time to conclude which of these scenarios, illustrated in Figure 8.9, is most likely. The actual melt process probably lies somewhere between the vertical and horizontal progression models. The method of feeding probably makes a substantial difference in the mode of MIS-CRB interaction.
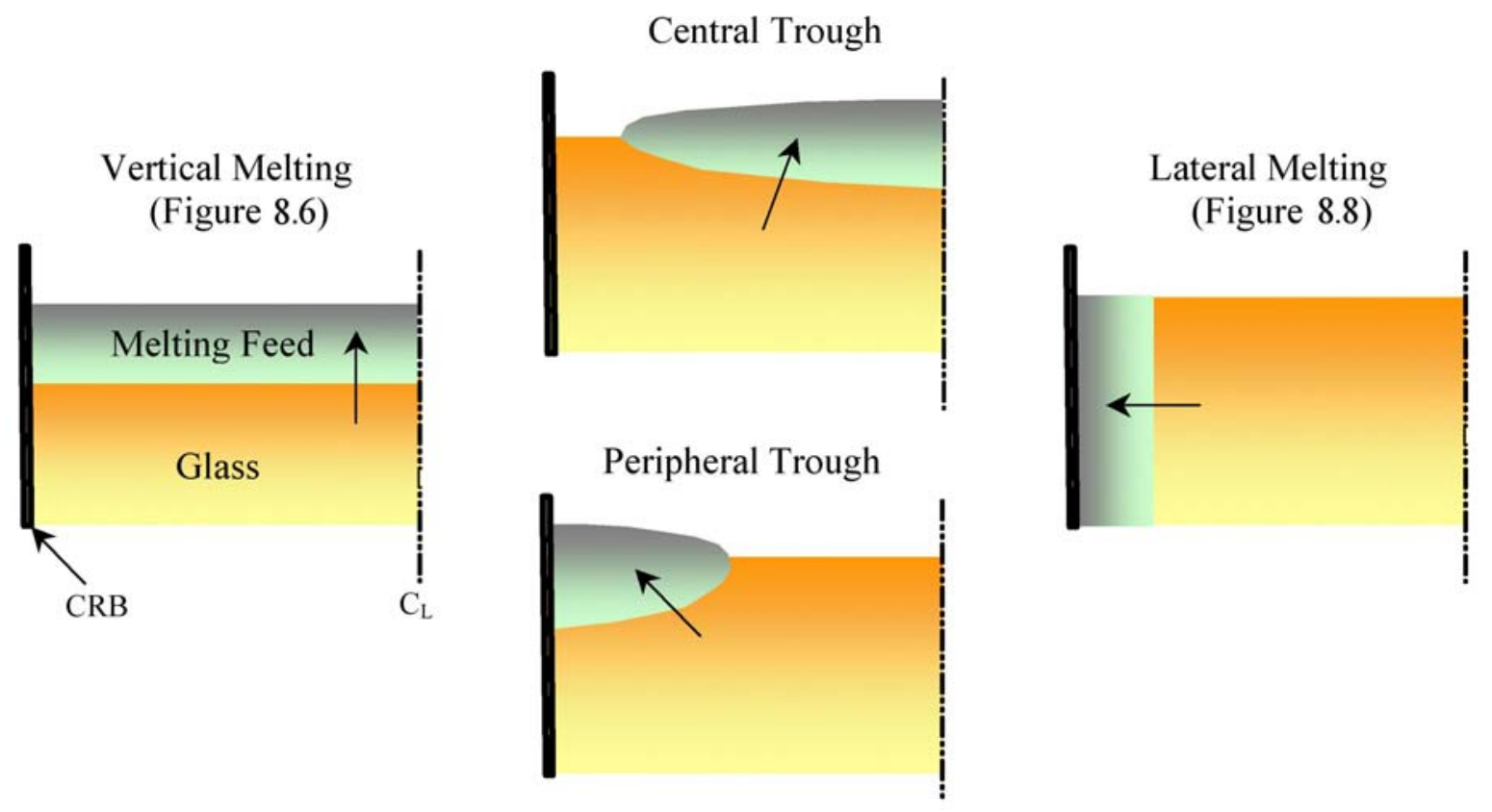

Figure 8.9. Possible Scenarios for the Melt Model

\subsection{Mathematical Model for Molten Salt Migration into the CRB}

This section describes an initial model for molten salt migration into the CRB based on the vertical melt progression conceptual model expressed in Figure 8.6. As a starting point, the model assumes the following:

- A distinct layer of MIS-saturated feed exists next to the CRB below the "dry" unsaturated feed above and a layer below where nitrates and nitrites decompose, and viscosity increases to prevent further penetration.

- There is both gravity- and capillary-driven MIS migration into the CRB.

- The MIS layer is liquid-saturated, completely wetting the CRB and developing a hydrostatic pressure.

- Isothermal conditions exist within the portion of the CRB where the MIS penetrates.

- There is a transient, one-dimensional Darcy flow.

Figure 8.10 shows an idealized model of the physical problem with its nomenclature. The liquid MISsaturated layer progresses upward as feed is added and is incorporated into the glass at a rate dependent on the feed rate and melting rate. Within this moving layer, the MIS penetrates the CRB to a distance s as a function of time, dependent on both the capillarity and gravity head of the MIS. 


\subsubsection{Equations}

The Darcy-flow superficial velocity of MIS migration into the CRB in response to a pressure gradient, $\mathrm{dp} / \mathrm{dx}$, is described by:

$$
\mathrm{u}=-\frac{\mathrm{k}}{\mu} \frac{\mathrm{dp}}{\mathrm{dx}}
$$

where $\mathrm{k}$ is the permeability of the $\mathrm{CRB}$, and $\mu$ is the liquid viscosity. Assuming incompressible, unsteady flow, the pressure gradient is constrained by:

$$
\frac{d^{2} p}{d x^{2}}=0
$$

This requires that $\mathrm{dp} / \mathrm{dx}$ and $\mathrm{u}$ are uniform in $\mathrm{x}$, but they may vary with time.

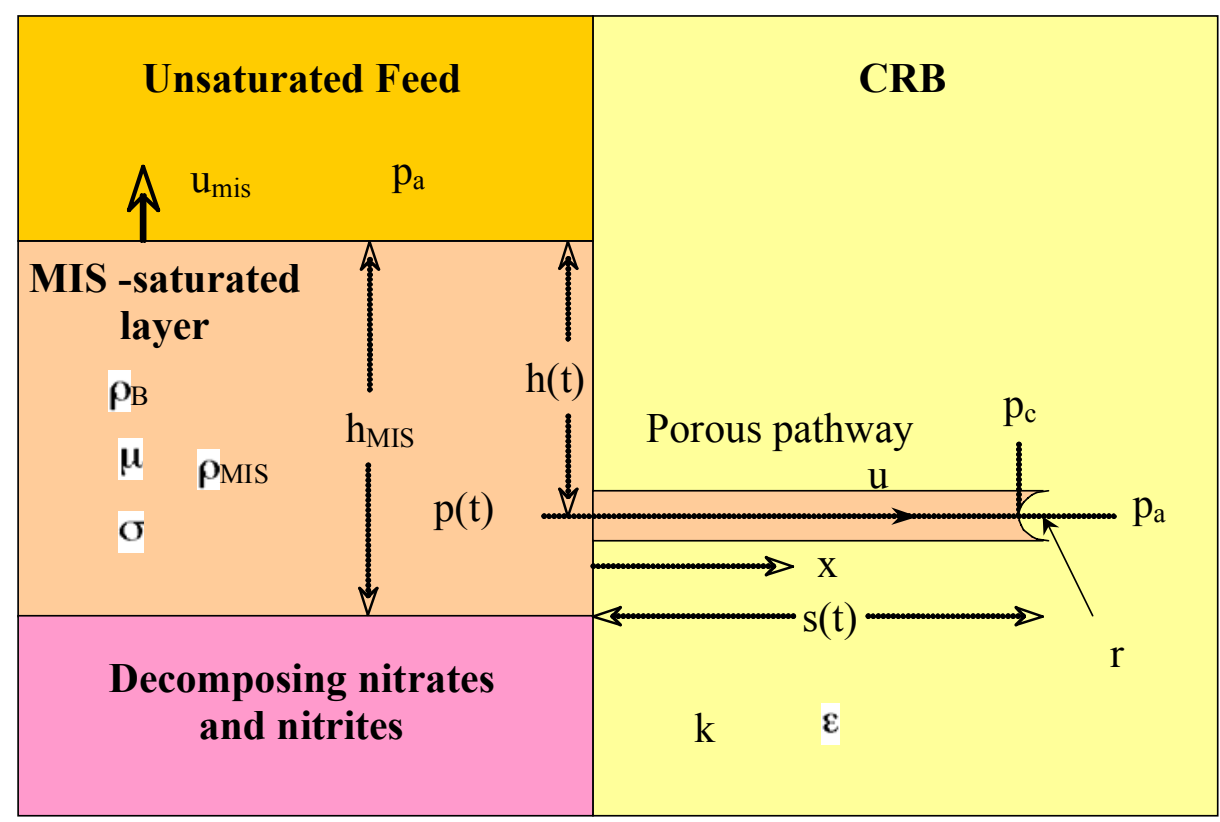

Figure 8.10. Illustrating the MIS Layer and Transport into CRB

The capillary pressure difference across a pore of radius $r$ is given by:

$$
\Delta \mathrm{p}_{\mathrm{c}}=-2 \sigma / \mathrm{r}
$$

where $\sigma$ is the surface tension. The gravity head in MIS at depth, h, of the MIS-saturated layer is computed from the MIS density, $\rho_{\text {MIS }}$, by:

$$
p(t)=p_{a}+\rho_{M I S} g h(t)
$$


The uniform pressure gradient in Equation (8.8) is the total pressure difference driving MIS into the CRB (the sum of the gravity pressure difference and capillary pressure) divided by the distance, $\mathrm{s}(\mathrm{t})$, as follows

$$
\frac{\mathrm{dp}}{\mathrm{dx}}=\frac{\mathrm{p}(\mathrm{t})-\mathrm{p}_{\mathrm{a}}-\Delta \mathrm{p}_{\mathrm{c}}}{\mathrm{s}(\mathrm{t})}=\frac{\rho_{\mathrm{MIS}} \mathrm{gh}(\mathrm{t})+2 \sigma / \mathrm{r}}{\mathrm{s}(\mathrm{t})}
$$

The position, s, of the MIS front as it penetrates the CRB, which is a function of the liquid superficial velocity, $\mathrm{u}$, and porosity, $\varepsilon$, is described by:

$$
\frac{\mathrm{ds}}{\mathrm{dt}}=\mathrm{u} / \varepsilon
$$

Assuming that $\mathrm{h}_{\mathrm{MIS}}$ is effectively constant on the average and that there is minimal mass loss during melting, the depth of the MIS-saturated layer at a fixed elevation can be expressed as a function of the average mass feed rate, $M_{F}$, the box cross-sectional area, $A_{B}$, and the bulk density of the MIS-saturated layer by:

$$
h(t)=\frac{M_{F}}{\rho_{F} A_{B}} t
$$

Combining Equations (8.8), (8.12), and (8.13) and substituting Equation (8.14) for the depth gives

$$
s(t)=\sqrt{\frac{2 k}{\varepsilon \mu}\left(\frac{\rho_{M I S}}{\rho_{F}} \frac{g M_{F}}{2 A_{T}} t^{2}+\frac{2 \sigma}{r} t\right)}
$$

The maximum penetration distance of MIS into the CRB, achieved at the point where the MIS-saturated layer passes, is given by Equation (8.15) at time $t=h_{M I S} \rho_{B} A_{B} / M_{F}$ :

$$
s_{\max }=\rho_{\text {MIS }} h_{M I S} \sqrt{\frac{\rho_{F}}{\rho_{M I S}} \frac{k g A_{T}}{\varepsilon \mu M_{F}}\left(1+F_{\sigma}\right)}
$$

where $\mathrm{F}_{\sigma}=\frac{4 \sigma}{\rho_{\mathrm{MIS}} \mathrm{gh}_{\mathrm{MIS}} \mathrm{r}}$.

Evaluating Equation (8.16) for the conditions and property values listed in Table 8.4, the predicted MIS penetration layer thickness in the CRB for a full-scale operation is $\sim 540 \mathrm{~mm}$. This estimate is far greater than the $\sim 15$-mm penetration implied from the CRB sodium atom fraction analysis in Section 8.2.2. The extremely small pore radius observed in the recent PNNL capillary rise tests (see note in Table 8.4), makes capillary wicking the dominant mechanism of penetration with $\mathrm{F}_{\sigma}=4\left(10^{4}\right)$. This means that any MIS exposed to the inner surface will penetrate the full thickness of the CRB without regard to available gravity head. 
Table 8.4. Values Used for Evaluating MIS Penetration Model

\begin{tabular}{|c|c|c|}
\hline Variable/Symbol/Units & Value & Source \\
\hline permeability, $\mathrm{k}\left(\mathrm{m}^{2}\right)$ & $3\left(10^{-17}\right)$ & Hrma et al. (2005) \\
\hline porosity, $\varepsilon$ & 0.18 & Hrma et al. (2005) \\
\hline viscosity of MIS, $\mu\left(\mathrm{N}-\mathrm{s} / \mathrm{m}^{2}\right)$ & $7\left(10^{-3}\right)$ & Section 5.3 \\
\hline density of MIS, $\rho_{\text {MIS }}\left(\mathrm{kg} / \mathrm{m}^{3}\right)$ & 2,200 & Section 8.1 .4 \\
\hline bulk density of feed, $\rho_{\mathrm{F}}\left(\mathrm{kg} / \mathrm{m}^{3}\right)$ & 1,600 & PNNL measurements ${ }^{(a)}$ \\
\hline surface tension of MIS, $\sigma(\mathrm{N} / \mathrm{m})$ & 0.1 & Hrma et al. (2005) \\
\hline CRB pore radius, $\mathrm{r}(\mathrm{m})$ & $1.7\left(10^{-9}\right)$ & Section 5.3 \\
\hline thickness of MIS-saturated layer, $\mathrm{h}_{\mathrm{MIS}}(\mathrm{m})$ & 0.3 & $\begin{array}{l}\text { Est. from temperature } \\
\text { transients }{ }^{(b)}\end{array}$ \\
\hline mass feed rate, $\mathrm{M}_{\mathrm{F}}(\mathrm{kg} / \mathrm{s})$ & 0.121 & AMEC test instruction ${ }^{(\mathrm{c})}$ \\
\hline box cross-sectional area, $\mathrm{A}_{\mathrm{B}}\left(\mathrm{m}^{2}\right)$ & 120 & Approx. as length $\mathrm{x}$ width \\
\hline \multicolumn{3}{|c|}{$\begin{array}{l}\text { (a) Memo from Renee Russell, PNNL, February 22, 2006, reporting measurements obtained } \\
\text { under Test Instruction AMEC-TI-06-02. } \\
\text { (b) Draft report by Pat Lowery (ARES), February 7, 2006, TEMPEST Simulation of a Bulkvit } \\
\text { Feed-While-Melt ICV Process: Comparison of Computation with Experiment. } \\
\text { (c) Large Scale Test Instruction: Test LS38C, 34006-TI-001, Rev. A (draft), March 2006, } \\
\text { AMEC Earth \& Environmental, Inc., Richland, WA. }\end{array}$} \\
\hline
\end{tabular}

\subsubsection{Scaling}

If we assume simple geometric scaling with the length scale, L, Equation (8.14) identifies the main scalable parameters as:

- Container cross-section $\mathrm{A}_{\mathrm{T}}$ : This scales with the linear dimension squared $\left(\mathrm{L}^{2}\right)$. Hence, all else being equal, $\mathrm{s} \sim \mathrm{L}$.

- Mass feed rate $\mathrm{M}_{\mathrm{F}}$ : This is an operationally controlled parameter for which is difficult to assign a functional dependency. If the feed rate is volumetrically scaled, then the penetration scales with $\mathrm{S} \sim \mathrm{L}^{3 / 2}$. If the operators hold $\mathrm{M}_{\mathrm{F}} / \mathrm{A}_{\mathrm{T}}$ constant by varying the power, the penetration distance is also constant with the scale, $\mathrm{s} \sim \mathrm{L}^{0}$.

- Thickness of MIS layer $\mathrm{h}_{\text {mis }}$ : This term appears twice in Equation (8.14) because it affects capillary and gravity action differently. If the gravity head dominates $\left(\mathrm{F}_{\sigma}<<1\right)$, then $\mathrm{s} \sim \mathrm{h}_{\text {mis. }}$. If capillary action dominates $\left(\mathrm{F}_{\sigma}>>1\right)$, then $\mathrm{s} \sim \mathrm{h}_{\text {mis }}{ }^{1 / 2}$. From above, the latter case appears most probable.

How $\mathrm{h}_{\mathrm{MIS}}$ scales is quite important. On the average, it must scale as a balance of the melt and feed rates. The melt rate would, in turn, be proportional to net power input according to

$$
\mathrm{h}_{\mathrm{MIS}}=\mathrm{C} \frac{\mathrm{P}-\mathrm{P}_{\text {loss }}}{\Delta \mathrm{E}_{\mathrm{MIS}_{\mathrm{F}}} \mathrm{M}_{\mathrm{F}}}
$$


where $\quad \mathrm{P}=$ power to the melter

$\mathrm{P}_{\text {loss }}=$ heat loss rate

$\Delta \mathrm{E}_{\mathrm{MIS}}=$ energy required to convert $1 \mathrm{~kg}$ of bulk feed to the material of the MIS-saturated layer

$\mathrm{C}=\mathrm{a}$ constant.

If the heat loss is minor, the net power to the melter likely scales with $\mathrm{P} \sim \mathrm{L}^{3}$. But $\mathrm{M}_{\mathrm{F}}$ should also scale with $\mathrm{L}^{3}$, and $\Delta \mathrm{E}_{\mathrm{MIS}}$ should be constant. Hence, the MIS thickness must also be a constant, or it depends on other factors. It is also subject to operator intervention, and, since the feed is added in batches, it varies over some significant range. All things considered, it would be logical if the MIS thickness varied directly with $\mathrm{L}$ on the average.

Combining all these factors, the MIS penetration thickness may scale with: $\mathrm{s} \sim \mathrm{L}^{\mathrm{a}}$, where $\mathrm{a}=0$ for capillary-driven MIS migration and $\mathrm{a}=0.5$ for gravity-driven MIS migration. Based on the small pore size of the CRB, the MIS penetration process is completely dominated by capillary action, and neither the MIS layer thickness nor any other scaled parameter has a significant effect.

\subsection{Summary}

The main purpose of the modeling effort described in this section was to check if the modeling can identify additional mechanisms for MIS transport that have not been thought of. The present modeling result supports the conclusion from capillary experiments in Section 5.0 that the MIS penetration process is dominated by capillary action, without any indication of other parameters that have significant effects. 


\subsection{Re Migration Tests}

This subtask extended the previous cold-finger tests (Kim et al. 2005) to investigate specific aspects of early melting reactions and Re volatilization from molten glass. The cold-finger test setup was redesigned to provide data with higher confidence by improving the Re mass balance closure. Unlike the previous study, the present work was performed in a non-radioactive laboratory using only Re, which previous work indicated to be a good surrogate for Tc. Modified cold-finger tests were used to 1) establish the rate of Re release and condensation from pre-melted glass held at temperatures below the $1200^{\circ} \mathrm{C}$ tested earlier, 2) determine the effect of change in the waste and glass composition on the Re release and condensation during feed melting, and 3) perform screening tests to evaluate the effectiveness of alternate feed materials to reduce Re release as discussed in Task 30.

\subsection{Feeds and Pre-Melted Glass Preparation}

The LAW simulant described in Section 4.0 (Table 4.1) was used to prepare the feeds. The feed variations tested in this study were:

- Case 1-Baseline: A baseline feed with a target concentration of $8.1 \mathrm{mg} / \mathrm{kg}$ Re in glass. The target glass was the current baseline composition (Kim et al. 2003) used in a previous study (Kim et al. 2005) as summarized in Table 4.2.

- Case 2-High $\mathrm{Cl} / \mathrm{F}$ : A feed with a simulant modified by chlorine and fluorine spiking to simulate the high- $\mathrm{Cl} / \mathrm{F}$ waste. $\mathrm{NaCl}$ and $\mathrm{NaF}$ were added to the feed to provide target concentrations of $0.37 \mathrm{wt} \%$ $\mathrm{Cl}$ and $0.62 \mathrm{wt} \% \mathrm{~F}$ in glass (compared to $0.18 \mathrm{wt} \% \mathrm{Cl}$ and $0.07 \mathrm{wt} \% \mathrm{~F}$ in the baseline glass supplied from 6-tank composite simulant only), which were expected to be maximum based on a recent study. ${ }^{(p)}$ The target glass composition was basically the same as the baseline case except for $\mathrm{Cl}$ and $\mathrm{F}$ concentrations. This case was to determine the effect of $\mathrm{Cl}$ and $\mathrm{F}$ in the waste on the migration of $\mathrm{Re}$.

- Case 3-High $\mathrm{CaO} / \mathrm{MgO}:$ A feed with the same simulant as in the baseline case but with a modified target glass composition with higher concentrations of $\mathrm{CaO}$ and $\mathrm{MgO}$ that were expected to increase the sulfur loading in LAW glass (Vienna et al. 2004). The concentration of $\mathrm{CaO}$ and $\mathrm{MgO}$ in glass was increased by $\sim 2 \mathrm{wt} \% \mathrm{CaO}$ (from 2.95 to $5.0 \mathrm{wt} \%$ ) and by $\sim 1 \mathrm{wt} \% \mathrm{MgO}$ (from 1.44 to $2.5 \mathrm{wt} \%$ ). This test was to determine the effectiveness of changing the glass composition on sulfur loading and the migration of Re.

- Case 4-Crushed soil: The same baseline feed as Case 1 but with crushed soil. Task 30 identified that crushing the soil to provide a higher surface area is the most promising method to decrease the MIS penetration into the CRB. The soil was ground in a tungsten carbide mill for $2 \mathrm{~min}$. This case was to determine the effect of crushed soil on the migration of Re.

Table 9.1 summarizes the recipe to produce the 800 grams of each feed required for the four test runs necessary for each test case. Table 9.1 also includes oxide loading for each recipe material in terms of mass fraction of oxides and halogens, assuming the glass retains $100 \%$ of all components. Table 9.2 summarizes the target glass composition for each test feed. The modification of waste simulant in Case 2 and of glass composition in Case 3 resulted in a small difference in the amount of simulant per unit mass

(p) LA Mahoney. 2005. Letter Report: Development of Waste Simulants for Series 33 Bulk Vitrification Tests. ST05.013, Pacific Northwest National Laboratory. 
of glass and therefore there were different concentrations for components supplied from the simulant, especially for $\mathrm{S}$ and Re. For Case 2, $\mathrm{Na}_{2} \mathrm{SO}_{4}$ was spiked in addition to $\mathrm{NaCl}$ and $\mathrm{NaF}$ to compensate for the decreased $\mathrm{S}$ because it was found from a previous study (Kim et al. 2005) that the concentration of $\mathrm{S}$ in the feed had a strong effect on the migration of Re. However, no adjustment was made for Re.

Table 9.1. Feed Recipe and Oxide Loading

\begin{tabular}{|c|c|c|c|c|c|c|}
\hline \multirow[b]{2}{*}{ Materials } & \multicolumn{3}{|c|}{ Recipe for $800 \mathrm{~g}$ glass $(\mathrm{g})$} & \multicolumn{3}{|c|}{ Oxide Loading $^{\text {(a) }}$ (mass fraction) } \\
\hline & $\begin{array}{l}\text { Cases } 1 \\
\text { and } 4^{b}\end{array}$ & Case 2 & Case 3 & $\begin{array}{l}\text { Cases } 1 \\
\text { and } 4^{b}\end{array}$ & Case 2 & Case 3 \\
\hline $\begin{array}{l}\text { 6-tank composite simulant } \\
\text { (Liquid simulant volume) }\end{array}$ & $\begin{array}{c}356.7 \\
(938.9 \mathrm{~mL})\end{array}$ & $\begin{array}{l}335.1 \\
(882.1 \mathrm{~mL})\end{array}$ & $\begin{array}{c}358.5 \\
(943.7 \mathrm{~mL})\end{array}$ & 0.2024 & 0.1901 & 0.2034 \\
\hline $\mathrm{NaCl}$ & - & 2.621 & - & - & 0.0037 & - \\
\hline $\mathrm{NaF}$ & - & 9.789 & - & - & 0.0146 & - \\
\hline $\mathrm{Na}_{2} \mathrm{SO}_{4}$ & - & 0.791 & - & - & 0.0010 & - \\
\hline $\mathrm{CaCO}_{3}$ & - & - & 31.34 & - & - & 0.0219 \\
\hline $\mathrm{MgCO}_{3}$ & - & - & 18.88 & - & - & 0.0113 \\
\hline $\mathrm{HRTSO}_{5}$ & 553.8 & 548.1 & 525.8 & 0.6776 & 0.6706 & 0.6434 \\
\hline $\mathrm{ZrO}_{2}$ & 56.00 & 56.00 & 56.00 & 0.0700 & 0.0700 & 0.0700 \\
\hline $\mathrm{B}_{2} \mathrm{O}_{3}$ & 41.95 & 41.95 & 41.95 & 0.0500 & 0.0500 & 0.0500 \\
\hline Total & 1008.4 & 994.3 & 1032.5 & 1.0000 & 1.0000 & 1.0000 \\
\hline
\end{tabular}

Table 9.2. Target Glass Compositions (in mass fraction except for Re metal in $\mathrm{mg} / \mathrm{kg}$ )

\begin{tabular}{||c|c|c|c||}
\hline Component & Cases 1 and 4 & Case 2 & Case 3 \\
\hline $\mathrm{Al}_{2} \mathrm{O}_{3}$ & 0.0878 & 0.0867 & 0.0836 \\
\hline $\mathrm{B}_{2} \mathrm{O}_{3}$ & 0.0500 & 0.0500 & 0.0500 \\
\hline $\mathrm{BaO}$ & 0.0005 & 0.0005 & 0.0005 \\
\hline $\mathrm{CaO}$ & 0.0295 & 0.0292 & 0.0500 \\
\hline $\mathrm{Cl}$ & 0.0018 & 0.0037 & 0.0018 \\
\hline $\mathrm{Cr}_{2} \mathrm{O}_{3}$ & 0.0010 & 0.0010 & 0.0010 \\
\hline $\mathrm{F}$ & 0.0007 & 0.0062 & 0.0007 \\
\hline $\mathrm{Fe}_{2} \mathrm{O}_{3}$ & 0.0462 & 0.0457 & 0.0439 \\
\hline $\mathrm{K}_{2} \mathrm{O}$ & 0.0223 & 0.0220 & 0.0212 \\
\hline $\mathrm{MgO}$ & 0.0144 & 0.0143 & 0.0250 \\
\hline $\mathrm{MnO}_{\mathrm{Na}} \mathrm{O}$ & 0.0007 & 0.0007 & 0.0007 \\
\hline $\mathrm{P}_{2} \mathrm{O}_{5}$ & 0.2000 & 0.2000 & 0.2000 \\
\hline $\mathrm{SiO}_{2}$ & 0.0057 & 0.0054 & 0.0056 \\
\hline $\mathrm{SO}_{3}$ & 0.4531 & 0.4484 & 0.4302 \\
\hline $\mathrm{SrO}_{\mathrm{TiO}}$ & 0.0085 & 0.0085 & 0.0085 \\
\hline $\mathrm{ZrO}_{2}$ & 0.0003 & 0.0003 & 0.0003 \\
\hline $\mathrm{Total}_{2}$ & 0.0700 & 0.0073 & 0.0070 \\
\hline $\mathrm{Re}_{2} \mathrm{mg} / \mathrm{kg}$ & 8.10 & 0.0700 & 0.0700 \\
\hline
\end{tabular}


For each test, the simulant solution was mixed with various additive materials as given in Table 9.1. The slurry feed mix was dried before crucible testing. Initially, the water from the wet feed was evaporated by mechanically stirring the feed contained in a stainless steel beaker placed on hot plate. This process continued until the feed became dry. The resulting dried feed was analyzed for Re via ICP-MS and for major glass components via ICP-AES.

The pre-melted glass was prepared according to the PNNL procedure Glass Development LaboratoryGlass Batching and Melting (GDL-GBM) using raw chemicals that achieve the same baseline glass composition as prepared from the dried feed. The baseline pre-melted glass was fabricated in $\mathrm{Pt}-10 \% \mathrm{Rh}$ crucibles following a two-step melting process: melt raw materials for $1 \mathrm{~h}$ at $1300^{\circ} \mathrm{C}$, quench on a steel plate, grind glass for homogeneity, and re-melt glass for $1 \mathrm{~h}$ at $1300^{\circ} \mathrm{C}$. The glass batch was spiked with twice the Re required for the current target $(8.1 \mathrm{mg} / \mathrm{kg}$ in glass) to compensate for the volatile loss during glass fabrication. The glass was prepared in three separate batches, and all the resulting glass was homogenized before taking three samples for chemical analysis. The glass was analyzed for Re via ICPMS and $\mathrm{Na}$ and $\mathrm{S}$ via ICP-AES in three samples and for major glass components via ICP-AES in one sample.

\subsection{Experimental Methods}

The cold-finger test setup used in a previous study (Kim et al. 2005), shown in Figure 9.1, was very useful to obtain the information on the relative effect of feed variation on the volatilization of $\mathrm{Re}$ and $\mathrm{Tc}$ from melting feed or molten glass.

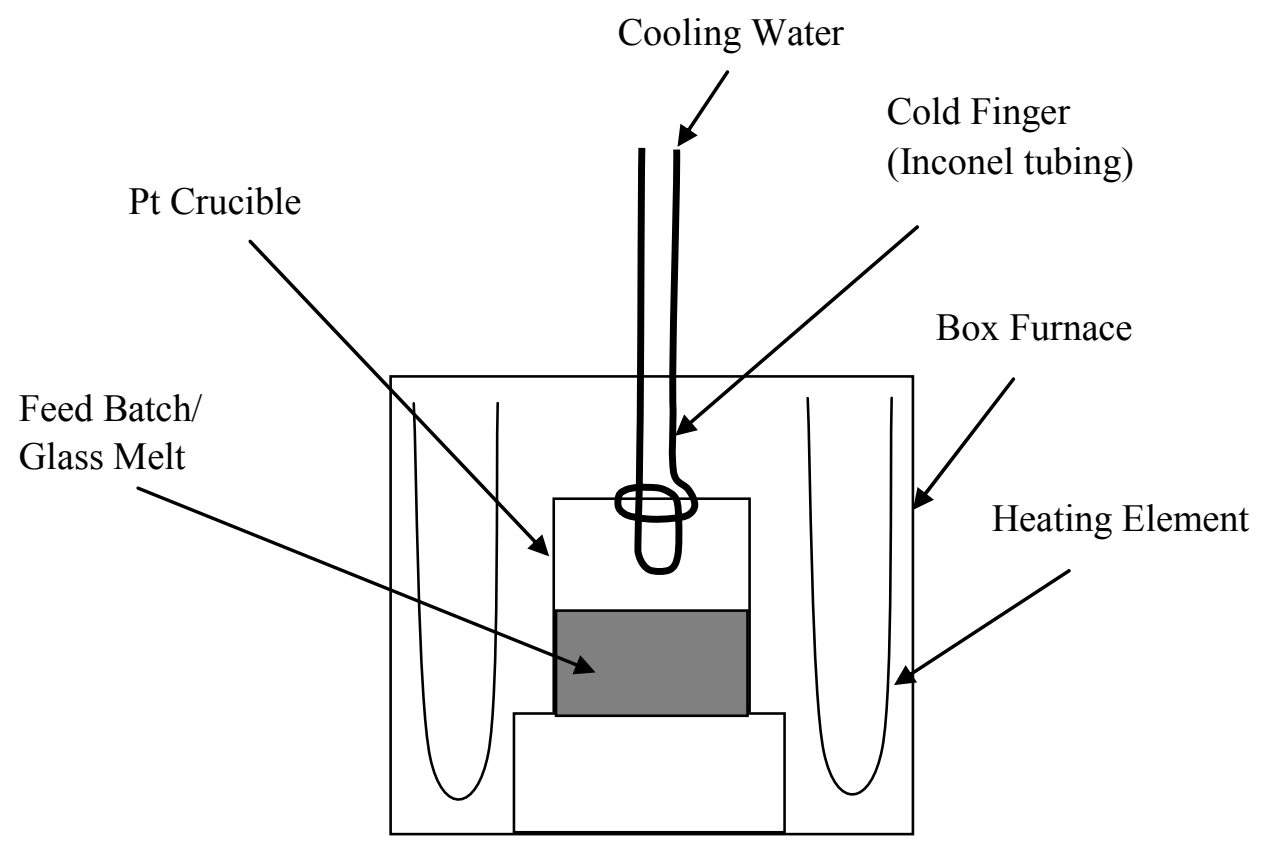

Figure 9.1. Schematic of Experimental Setup for Cold Finger Crucible Tests Used in the Previous Study (Kim et al. 2005) 
The tests conducted using this cold-finger test setup were not intended to supply a full Tc and Re mass balance, mainly because the setup was not designed to capture all the volatiles. In a previous study (Kim et al. 2005), it was assumed that the condensation efficiency (fraction collected on the cold finger to the total volatilized) is roughly constant without a significant variation to test. Although these test methods were good enough to provide information on the major effect of feed variations, the application of these tests is limited because of high data uncertainties caused by the poor mass balance. The total Re or Tc mass accounted for by chemical analyses in crucible rinse, condensate, and residual glass samples was 48 to $71 \%$ for Re and 48 to $77 \%$ for Tc relative to the mass added to the feed. Therefore, a new setup was developed, and preliminary tests were conducted to evaluate the feasibility of mass balance tests and the effectiveness of the setup.

In addition, two other factors that contributed to high data uncertainties in the previous study were modified:

- The sample for glass retention measurement was taken after fully homogenizing the entire remaining glass materials, which was not performed in the previous study because of constraints associated with handling radioactive samples. The glass melt heated to just $1200^{\circ} \mathrm{C}$ (the highest temperature used in a previous study) is expected to be inhomogeneous as collected.

- The Re partition calculation will be based on measured concentrations in the feed instead of target values used in the previous study to minimize errors associated with analytical bias.

Figure 9.2 is a schematic of a new experimental setup developed to improve system mass balance. The new setup was designed to capture all the volatiles by condensing them inside a stainless steel tube or dissolving them in a pair of scrub solutions. The first scrub solution was kept at $10^{\circ} \mathrm{C}$ using a water bath equipped with a chiller to facilitate capturing the volatiles. The container for the second scrub solution was kept at a slightly lower pressure than the ambient pressure to minimize the leakage of volatiles through the gap between the Pt crucible and the lid. After each experiment, the tubes were washed with DIW and mixed with scrub solutions to analyze for total volatilized materials. The initial test of the system included washing the tube with a more aggressive rinse that used a tube brush to check if the DIW wash alone was enough to remove all the condensates. The fritted pipe end was used to reduce the bubble size so the volatiles would dissolve faster into the solution.

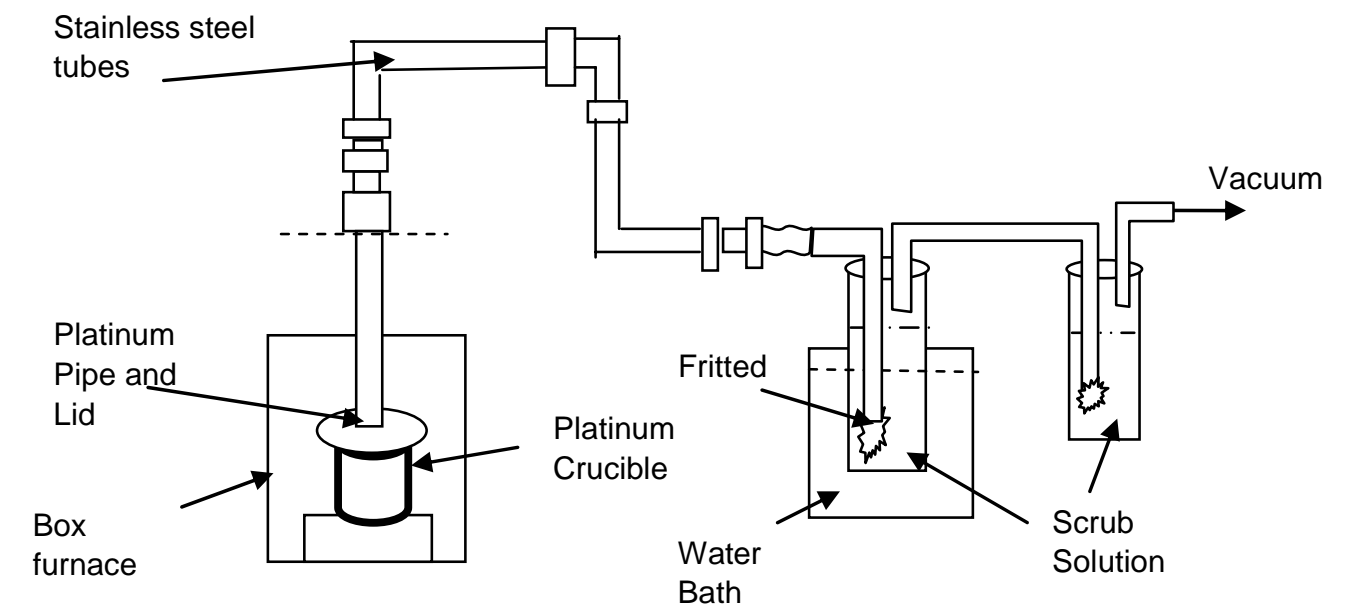

Figure 9.2. Schematic of New Experimental Setup Proposed for Re Migration Tests 
The dried feeds were tested by heating in a Pt- $10 \% \mathrm{Rh}$ crucible at $5^{\circ} \mathrm{C} / \mathrm{min}$ starting from $80^{\circ} \mathrm{C}$ and terminating at the following temperatures right after each temperature is reached: 800, 900, 1000, and $1200^{\circ} \mathrm{C}$ (four test runs per each feed). The pre-melted glass was ramp heated at $5^{\circ} \mathrm{C} / \mathrm{min}$ starting from $500^{\circ} \mathrm{C}$ to three different temperatures of 1000,1100 , and $1200^{\circ} \mathrm{C}$ and held at the final temperature for 1 and $5 \mathrm{~h}$. In addition, the test run at $1100^{\circ} \mathrm{C}$ for $5 \mathrm{~h}$ was repeated for reproducibility.

The test with pre-melted glass used $\sim 200 \mathrm{~g}$ of pre-melted glass. For tests with dried feed, the mass required for $\sim 200 \mathrm{~g}$ glass was used for each run. However, in Case 3, the feed at $1000^{\circ} \mathrm{C}$ foamed more severely than with the previous two feeds and overflowed the crucible. The foam at the center of the crucible touched the lid and clogged the pipe entrance connected to the lid, suggesting that a bigger crucible or a smaller amount of feed is needed. Meanwhile, in the tests with crushed soil performed under Task 30, we discovered that the crushed soil feed foams to more than twice the volume of feed prepared with uncrushed soil. It was decided to reduce the mass of the batches for the remaining Case 3 and Case 4 feeds. Preliminary melting experiments were performed with crushed soil feed to determine the maximum amount of feed that can be used without having the foaming that can clog the pipe. It was found that the batch size should be decreased approximately by a half. Therefore, the subsequent tests, starting from Case $31000^{\circ} \mathrm{C}$ tests, used the feed mass required to make $\sim 100 \mathrm{~g}$ glass. To evaluate the effect of using a smaller batch size, two tests with Case 1 feed at 1000 and $1200^{\circ} \mathrm{C}$ were repeated with half-size feed batches.

The heat-treated samples were air cooled after reaching the preset temperature (for the tests with dried feed) or after the preset time at each test temperature (for tests with pre-melted glass). The following samples were analyzed:

- Crucible rinse samples: All the partly reacted feed and glass materials remaining in the Pt crucible were collected, crushed, and washed with a dilute $(0.001 \mathrm{M})$ nitric acid $\left(\mathrm{HNO}_{3}\right)$. The rinse solutions from the tests with dried feed were filtered and analyzed for Re via ICP-MS, Na, and S via ICP-AES, and for anions via ion chromatography (IC). The rinse solutions from the tests with pre-melted glass were prepared but were not analyzed. The solutions were archived in case it was determined that the analyses were necessary based on the evaluation of other test results. The solid materials collected after the crucible rinse were washed with DIW two or three times to remove any residual soluble components.

- Condensate samples: The condensate materials were collected from the tubes by washing with DIW and mixed with the two scrub solutions. The condensate samples from all tests were analyzed for $\mathrm{Re}$ via ICP-MS, for Na and S via ICP-AES, and for anions via IC.

- Glass samples: The glass samples from $1200^{\circ} \mathrm{C}$ tests performed with dried feed and from all tests with pre-melted glass were analyzed for Re via ICP-MS and for $\mathrm{Na}$ and $\mathrm{S}$ via ICP-AES.

Table 9.3 summarizes the chemical analyses of all the samples collected from the tests described in this section. 
Table 9.3. Summary of Chemical Analyses To Be Performed for Various Samples

\begin{tabular}{||l|c|c|c||}
\hline \multicolumn{1}{|c|}{ Sample } & $\begin{array}{c}\text { ICP-MS } \\
\text { (Re) and ICP- } \\
\text { AES (Na, S) }\end{array}$ & $\begin{array}{c}\text { ICP-AES } \\
(\text { major glass } \\
\text { components })\end{array}$ & $\begin{array}{c}\text { IC } \\
\left(\mathbf{C l}, \mathbf{F}, \mathbf{N O}_{3}, \mathbf{N O}_{2},\right. \\
\left.\mathbf{P O}_{4}, \mathbf{S O}_{4}\right)\end{array}$ \\
\hline Dried feed and pre-melted glass & Yes & Yes & No \\
\hline $\begin{array}{l}\text { Crucible rinse solution from tests with } \\
\text { dried feed }\end{array}$ & Yes & No & Yes \\
\hline $\begin{array}{l}\text { Crucible rinse solution from tests with } \\
\text { pre-melted glass }\end{array}$ & \multicolumn{2}{|c||}{ Archive only } \\
\hline $\begin{array}{l}\text { Condensate rinse solutions from all } \\
\text { tests with dried feed and pre-melted } \\
\text { glass }\end{array}$ & Yes & No & Yes \\
\hline $\begin{array}{l}\text { Glass sample from } 1200^{\circ} \mathrm{C} \text { tests with } \\
\text { dried feed and all tests with pre- } \\
\text { melted glass }\end{array}$ & Yes & No & No \\
\hline \hline
\end{tabular}

The preliminary test was performed with the baseline feed following the procedure described above with an initial setup that was slightly different from Figure 9.2 as discussed below. The final temperature was $1200^{\circ} \mathrm{C}$. Table 9.4 summarizes the Re $\mathrm{wt} \%$ of total found in each sample from the preliminary test. The mass balance closure was $82.4 \mathrm{wt} \%$ compared to $57.2 \mathrm{wt} \%$ for the same baseline feed from a previous study (Kim et al. 2005). This indicated that the initial setup helped to improve the Re mass balance, but in an effort to further improve the Re mass balance, the initial setup was modified in two areas: 1) a taller container was used for scrub solution to provide a longer time for the bubbles to be in contact with the solution, and 2) a second scrub solution was added to the setup as shown in Figure 9.2 to capture the volatiles that escape from the first scrub solution. Table 9.4 also suggests that the contribution of an aggressive pipe rinse is negligible. Therefore, the main tests did not include the aggressive pipe rinse step.

Table 9.4. Summary of Re Mass Balance Closure from Preliminary Tests

\begin{tabular}{|r|c|c|c|c||}
\hline \multicolumn{1}{|c|}{ Sample } & $\begin{array}{c}\text { Concentration } \\
\text { of Re (mg/kg) }\end{array}$ & $\begin{array}{c}\text { Sample } \\
\text { Mass (g) }\end{array}$ & $\begin{array}{c}\text { Re mass } \\
(\mathbf{m g})\end{array}$ & $\begin{array}{c}\text { Wt\% of } \\
\text { Total }\end{array}$ \\
\hline Crucible rinse & 0.239 & 100 & 0.0239 & 1.47 \\
\hline Condensate solution including pipe rinse & 0.684 & 819 & 0.560 & 34.60 \\
\hline Aggressive pipe rinse & 0.024 & 105 & 0.00254 & 0.16 \\
\hline Glass & 3.740 & 200 & 0.748 & 46.17 \\
\hline Total & & & 82.40 \\
\hline
\end{tabular}

\subsection{Results and Discussion}

The tests used two batches of liquid simulant: the second batch was prepared after the first batch was depleted. Table 9.5 summarizes the analyzed composition of 6-tank composite simulant compared with the target composition calculated from Table 4.1. Table 9.5 also includes the RPD between the target and analyzed compositions. Table 9.5 shows that the analyzed simulant composition agrees well with the target composition for major components with at least $1000 \mathrm{mg} / \mathrm{kg}$. The large difference for $\mathrm{K}$ is not of concern considering its low concentration in the simulant and in glass $\left(0.34 \mathrm{wt} \% \mathrm{~K}_{2} \mathrm{O}\right.$ in simulant and 
$0.07 \mathrm{wt} \%$ in glass from simulant at $20.24 \mathrm{wt} \%$ simulant oxide loading). There was no practical difference between the first and second batches of simulant.

Table 9.5. Analyzed Composition of 6-Tank Composite Simulant Compared to Target

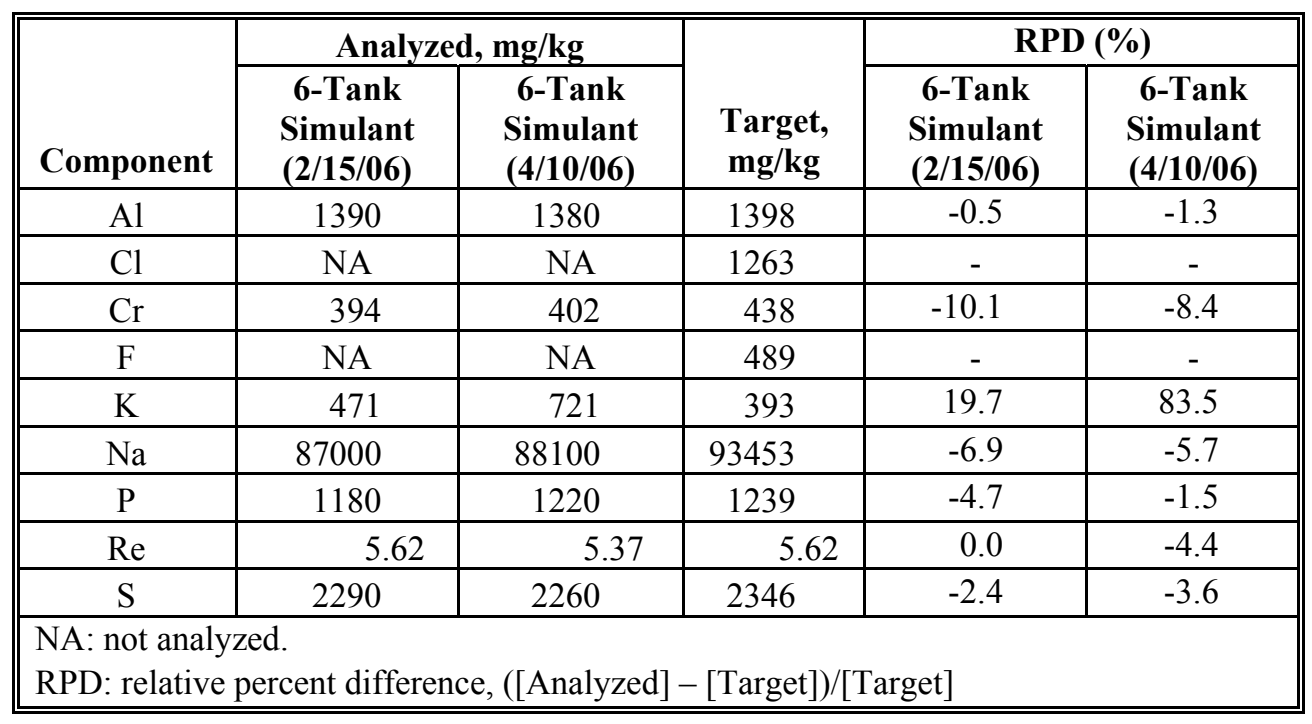

Table 9.6 summarizes the analyzed composition of dried feeds compared with target compositions calculated from Table 9.1. Table 9.7 gives the relative percent difference between target and analyzed concentration. The analyzed compositions agreed well with the target compositions with a relative difference between target and analyzed compositions within $10 \%$ for major components with at least $2 \mathrm{wt} \%$ in the feed. There were two exceptions: $\mathrm{Fe}_{2} \mathrm{O}_{3}$ had a relative difference of $14 \%$ only in the Case 2 feed, and $\mathrm{ZrO}_{2}$ had a relative difference from 11 to $19 \%$, which is a troublesome component for chemical analyses because it is difficult to completely dissolve. The Re showed a good agreement with a relative difference ranging from 3 to 5\%. The analyzed composition is used for Re and S mass balance calculations. 
Table 9.6 Analyzed Composition of Dried Feeds Compared to Target Compositions (in mass fraction for oxides/halogens and $\mathrm{mg} / \mathrm{kg}$ for Re metal)

\begin{tabular}{|c|c|c|c|c|c|c|c|}
\hline \multirow[b]{2}{*}{ Component } & \multicolumn{3}{|c|}{$\begin{array}{c}\text { Case } 1 \text { (Baseline) and Case } 4 \\
\text { (Crushed soil) }\end{array}$} & \multicolumn{2}{|c|}{ Case $2($ High $\mathrm{Cl} / \mathrm{F})$} & \multicolumn{2}{|c|}{ Case 3 (High Ca/Mg) } \\
\hline & $\begin{array}{c}\text { Analyzed, } \\
\text { Case 1 }\end{array}$ & $\begin{array}{l}\text { Analyzed, } \\
\text { Case } 4\end{array}$ & Target & Analyzed & Target & Analyzed & Target \\
\hline $\mathrm{Al}_{2} \mathrm{O}_{3}$ & 0.0693 & 0.0726 & 0.0696 & 0.0712 & 0.0697 & 0.0648 & 0.0647 \\
\hline $\mathrm{B}_{2} \mathrm{O}_{3}$ & 0.0383 & 0.0419 & 0.0397 & 0.0402 & 0.0402 & 0.0386 & 0.0387 \\
\hline $\mathrm{BaO}$ & 0.0005 & 0.0005 & 0.0004 & 0.0005 & 0.0004 & 0.0005 & 0.0004 \\
\hline $\mathrm{CaO}$ & 0.0238 & 0.0238 & 0.0234 & 0.0248 & 0.0235 & 0.0385 & 0.0387 \\
\hline $\mathrm{Cl}$ & NA & NA & 0.0014 & NA & 0.0030 & NA & 0.0014 \\
\hline $\mathrm{Cr}_{2} \mathrm{O}_{3}$ & 0.0008 & 0.0009 & 0.0008 & 0.0009 & 0.0008 & 0.0008 & 0.0008 \\
\hline $\mathrm{F}$ & NA & NA & 0.0006 & NA & 0.0050 & NA & 0.0006 \\
\hline $\mathrm{Fe}_{2} \mathrm{O}_{3}$ & 0.0382 & 0.0380 & 0.0366 & 0.0417 & 0.0368 & 0.0366 & 0.0340 \\
\hline $\mathrm{K}_{2} \mathrm{O}$ & 0.0129 & 0.0133 & 0.0177 & 0.0130 & 0.0177 & 0.0116 & 0.0164 \\
\hline $\mathrm{MgO}$ & 0.0112 & 0.0114 & 0.0115 & 0.0119 & 0.0115 & 0.0179 & 0.0194 \\
\hline $\mathrm{MnO}$ & 0.0006 & 0.0006 & 0.0006 & 0.0007 & 0.0006 & 0.0008 & 0.0005 \\
\hline $\mathrm{Na}_{2} \mathrm{O}$ & 0.1570 & 0.1604 & 0.1587 & 0.1645 & 0.1609 & 0.1631 & 0.1550 \\
\hline $\mathrm{P}_{2} \mathrm{O}_{5}$ & 0.0045 & 0.0042 & 0.0045 & 0.0048 & 0.0044 & 0.0043 & 0.0044 \\
\hline $\mathrm{SiO}_{2}$ & 0.3359 & 0.3337 & 0.3595 & 0.3359 & 0.3608 & 0.3038 & 0.3334 \\
\hline $\mathrm{SO}_{3}$ & 0.0071 & 0.0077 & 0.0067 & 0.0073 & 0.0068 & 0.0069 & 0.0066 \\
\hline $\mathrm{SrO}$ & 0.0002 & 0.0002 & 0.0002 & 0.0002 & 0.0002 & 0.0002 & 0.0002 \\
\hline $\mathrm{TiO}_{2}$ & 0.0068 & 0.0066 & 0.0059 & 0.0073 & 0.0059 & 0.0084 & 0.0054 \\
\hline $\mathrm{ZrO}_{2}$ & 0.0465 & 0.0492 & 0.0555 & 0.0455 & 0.0563 & 0.0442 & 0.0542 \\
\hline LOI & 0.2360 & 0.2310 & 0.2067 & 0.2140 & 0.1954 & 0.2510 & 0.2251 \\
\hline SUM & 0.9897 & 0.9959 & 1.0000 & 0.9844 & 1.0000 & 0.9920 & 1.0000 \\
\hline $\mathrm{Re}, \mathrm{mg} / \mathrm{kg}$ & 6.61 & 6.66 & 6.43 & 6.44 & 6.12 & 6.61 & 6.31 \\
\hline
\end{tabular}


Table 9.7. Relative Percent Difference ${ }^{1)}$ between Target and Analyzed Compositions in Dried Feeds

\begin{tabular}{|c|c|c|c|c||}
\hline Component & Case 1 & Case 2 & Case 3 & Case 4 \\
\hline $\mathrm{Al}_{2} \mathrm{O}_{3}$ & -0.4 & 4.2 & 2.1 & 0.1 \\
\hline $\mathrm{B}_{2} \mathrm{O}_{3}$ & -3.4 & 5.5 & 0.0 & -0.3 \\
\hline $\mathrm{BaO}$ & 9.2 & 15.9 & 14.7 & 28.7 \\
\hline $\mathrm{CaO}$ & 1.5 & 1.5 & 5.3 & -0.7 \\
\hline $\mathrm{Cl}$ & - & - & - & - \\
\hline $\mathrm{Cr}_{2} \mathrm{O}_{3}$ & 0.7 & 6.1 & 12.0 & 5.7 \\
\hline $\mathrm{F}$ & - & - & - & - \\
\hline $\mathrm{Fe}_{2} \mathrm{O}_{3}$ & 4.2 & 3.8 & 13.5 & 7.7 \\
\hline $\mathrm{K}_{2} \mathrm{O}$ & -26.6 & -24.9 & -26.5 & -29.6 \\
\hline $\mathrm{MgO}$ & -1.9 & -0.6 & 3.5 & -7.5 \\
\hline $\mathrm{MnO}$ & 8.2 & 1.4 & 14.3 & 42.4 \\
\hline $\mathrm{Na}_{2} \mathrm{O}$ & -1.0 & 1.1 & 2.2 & 5.2 \\
\hline $\mathrm{P}_{2} \mathrm{O}_{5}$ & -0.7 & -7.5 & 9.8 & -1.2 \\
\hline $\mathrm{SiO}_{2}$ & -6.6 & -7.2 & -6.9 & -8.9 \\
\hline $\mathrm{SO}_{3}$ & 6.2 & 14.6 & 6.9 & 4.6 \\
\hline $\mathrm{SrO}_{\mathrm{TiO}}$ & -0.9 & -0.7 & 0.4 & -3.7 \\
\hline $\mathrm{TrO}_{2}$ & 15.5 & 13.1 & 23.4 & 54.2 \\
\hline $\mathrm{Re}$ & -16.3 & -11.4 & -19.2 & -18.5 \\
\hline 1$) \mathrm{Calculated} \mathrm{as}_{2}([$ Analyzed] $-[$ Target] $) /[$ Target] \\
\hline \hline
\end{tabular}

Table 9.8 summarizes the concentration of $\mathrm{Re}, \mathrm{Na}$, and $\mathrm{S}$ in three samples of pre-melted glass. Table 9.9 compares the analyzed composition of one pre-melted glass (Glass A) with the target composition. There was a good agreement between analyzed and target for all the major components with a target of at least $1 \mathrm{wt} \%$. The Re retention was low at $28.7 \mathrm{wt} \%$ on average (based on $16.2 \mathrm{mg} / \mathrm{kg}$ Re target), and $\mathrm{S}$ retention was relatively high at $84.6 \mathrm{wt} \%$ on average.

Table 9.8. Re, Na, and S Concentration in Pre-melted Glass Samples (in mg/kg)

\begin{tabular}{|c|c|c|c|}
\hline Sample & $\mathbf{R e}$ & $\mathbf{N a}$ & $\mathbf{S}$ \\
\hline Glass A & 4.58 & 154000 & 2865 \\
\hline Glass B & 4.71 & 153000 & 2835 \\
\hline Glass C & 4.66 & 156000 & 2660 \\
\hline Average & 4.65 & 154333 & 2787 \\
\hline \% relative standard deviation & 1.36 & 0.99 & 3.97 \\
\hline
\end{tabular}


Table 9.9. Analyzed Composition of Pre-melted Glass Compared with Target Composition (in mass fraction)

\begin{tabular}{||l|c|c|c||}
\hline Oxide & Analyzed & Target & RPD (\%) \\
\hline $\mathrm{Al}_{2} \mathrm{O}_{3}$ & 0.0895 & 0.0878 & 1.9 \\
\hline $\mathrm{B}_{2} \mathrm{O}_{3}$ & 0.0504 & 0.0500 & 0.8 \\
\hline $\mathrm{BaO}$ & 0.0007 & 0.0005 & 22.4 \\
\hline $\mathrm{CaO}$ & 0.0291 & 0.0295 & -1.5 \\
\hline $\mathrm{Cl}$ & - & 0.0018 & - \\
\hline $\mathrm{Cr}_{2} \mathrm{O}_{3}$ & 0.0011 & 0.0010 & 10.3 \\
\hline $\mathrm{F}$ & - & 0.0007 & - \\
\hline $\mathrm{Fe}_{2} \mathrm{O}_{3}$ & 0.0430 & 0.0462 & -7.0 \\
\hline $\mathrm{K}_{2} \mathrm{O}$ & 0.0230 & 0.0222 & 3.2 \\
\hline $\mathrm{MgO}$ & 0.0132 & 0.0144 & -9.0 \\
\hline $\mathrm{MnO}_{\mathrm{NaO}}$ & 0.0008 & 0.0007 & 11.9 \\
\hline $\mathrm{Na}_{2} \mathrm{O}$ & 0.2076 & 0.2000 & 3.8 \\
\hline $\mathrm{P}_{2} \mathrm{O}_{5}$ & 0.0056 & 0.0057 & -0.9 \\
\hline $\mathrm{SiO}_{2}$ & 0.4567 & 0.4531 & 0.8 \\
\hline $\mathrm{SO}_{3}$ & 0.0072 & 0.0085 & -15.4 \\
\hline $\mathrm{SrO}_{\mathrm{TiO}}$ & 0.0003 & 0.0003 & 0.0 \\
\hline $\mathrm{ZrO}_{2}$ & 0.0081 & 0.0074 & 9.2 \\
\hline $\mathrm{SUM}^{2}$ & 0.0647 & 0.0700 & -7.6 \\
\hline
\end{tabular}

Table 9.10 summarizes the analyses of crucible rinse and condensate solutions. For tests with dried feed, the sample ID denotes Case \#, final temperature, and crucible rinse ("1") or condensate solution (" 2 "). The condensate solution includes all the scrub 1, scrub 2, and pipe wash solutions. The exception was for tests at 800 and $900^{\circ} \mathrm{C}$ with Case 1 feed that had separate samples for the aggressive rinse (denoted as "4") and scrub 2 ("5"). For tests with pre-melted glass, the sample ID starts with "PMG" (for pre-melted glass) and provides information on test temperature, duration at a test temperature, and " 2 " for condensate solution (note that the crucible rinse samples were not analyzed). The additional note " $1 / 2 \mathrm{~B}$ " specifies that the test was performed with a half size batch ( $\sim 100$ g glass instead of $\sim 200$ g glass) and " 2 nd" denotes a repeated run. Table 9.10 shows that the $2^{\text {nd }}$ solution (" 5 ") resulted in a negligibly small concentration or below the reporting limit for Re in both tests. However, for the aggressive pipe wash ("4"), one test resulted in a small but non-negligible Re concentration while another had Re below the reporting limit. The non-negligible Re concentration found in one sample suggests that skipping the aggressive rinsing step can partially contribute to the mass balance closure of less than $100 \%$. 
Table 9.10 Analyzed Concentrations in Crucible Rinse and Condensate Solutions (in mg/L)

\begin{tabular}{|c|c|c|c|c|c|c|c|c|c|}
\hline Sample ID & $\operatorname{Re}$ & $\mathbf{N a}$ & $\mathbf{S}$ & $\mathrm{Cl}^{-}$ & $\mathbf{F}^{-}$ & $\mathrm{NO}_{3}$ & $\mathrm{NO}_{2}^{-}$ & $\mathrm{PO}_{4}{ }^{3-}$ & $\mathrm{SO}_{4}{ }^{2-}$ \\
\hline \multicolumn{10}{|c|}{ Case 1-Baseline } \\
\hline C1-800-1 & 2.02 & 34300 & 1560 & 623 & 181 & 12749 & 2220 & 2318 & 4570 \\
\hline C1-900-1 & 0.294 & 1660 & 444 & 50.9 & 5.34 & 447 & 35.1 & 702 & 1340 \\
\hline C1-1000-1 & 0.803 & 1110 & 630 & 84.8 & 5.21 & 71.5 & 3.88 & 172 & 1940 \\
\hline C1-1000-1-1/2B & 0.347 & 744 & 422 & 39.7 & 3.84 & 46.7 & $<6.57$ & 138 & 1280 \\
\hline C1-1200-1 & 0.112 & 1820 & 1170 & 35.2 & 6.92 & 59.8 & $<6.57$ & 130 & 3600 \\
\hline C1-1200-1-1/2B & 0.0373 & 696 & 437 & 7.33 & 2.75 & 73.9 & 7.00 & 46.9 & 1330 \\
\hline C1-800-2 & 0.0121 & 8.05 & $<0.400$ & 32.5 & $<10.0$ & 27977 & $<32.8$ & $<30.7$ & 25.3 \\
\hline C1-800-4 & $<0.00100$ & $<5.00$ & $<0.400$ & 0.34 & $<0.1$ & 10.9 & $<0.328$ & $<0.307$ & 0.505 \\
\hline C1-800-5 & $<0.00050$ & $<5.00$ & $<0.400$ & 6.45 & $<2$ & 4604 & $<6.57$ & $<6.13$ & 5.48 \\
\hline \begin{tabular}{|l|} 
C1-900-2 \\
\end{tabular} & 0.0761 & 8.06 & $<0.400$ & 40.4 & $<10.0$ & 31297 & $<32.8$ & $<30.7$ & 45.6 \\
\hline C1-900-4 & 0.00395 & $<5.00$ & $<0.400$ & 0.388 & 0.108 & 3.76 & $<0.328$ & $<0.307$ & 0.554 \\
\hline C1-900-5 & 0.00053 & $<5.00$ & $<0.400$ & 10.7 & $<2$ & 7835 & 13.2 & $<6.13$ & 7.7 \\
\hline C1-1000-2 & 0.320 & 14.6 & $<0.400$ & 41.3 & $<10.0$ & 24923 & $<32.8$ & $<30.7$ & 57.3 \\
\hline \begin{tabular}{|l|}
$\mathrm{C} 1-1000-2-1 / 2 \mathrm{~B}$ \\
\end{tabular} & 0.160 & 9.49 & 0.409 & 16.9 & 3.62 & 7747 & $<6.57$ & $<6.13$ & 9.56 \\
\hline C1-1200-2 & 0.537 & 39.1 & 7.61 & 63.7 & 11.6 & 20186 & $<32.8$ & $<30.7$ & 96.7 \\
\hline C1-1200-2-1/2B & 0.272 & 23.0 & 8.42 & 35.6 & 8.15 & 8544 & $<6.57$ & $<6.13$ & 42.8 \\
\hline \multicolumn{10}{|c|}{ Case 2-High $\mathrm{Cl} / \mathrm{F}$} \\
\hline C2-800-1 & 3.02 & 30500 & 1840 & 1830 & 1800 & 25764 & 4401 & 1637 & 5310 \\
\hline C2-900-1 & 1.48 & 1770 & 798 & 348 & 94.0 & 415 & 52.2 & 145 & 2470 \\
\hline C2-1000-1 & 1.53 & 2300 & 1260 & 428 & 88.9 & 96.5 & $<32.8$ & 128 & 3810 \\
\hline C2-1200-1 & 0.0539 & 2110 & 1360 & 106 & 50.0 & 85.0 & $<32.8$ & 69.3 & 4090 \\
\hline C2-800-2 & 0.0119 & $<5.00$ & $<0.400$ & 18.8 & $<10.0$ & 11908 & $<32.8$ & $<30.7$ & 29.2 \\
\hline C2-900-2 & 0.0596 & $<5.00$ & $<0.400$ & 29.9 & 10.2 & 15228 & $<32.8$ & $<30.7$ & 38.3 \\
\hline C2-1000-2 & 0.282 & 30.6 & 5.39 & 58.4 & 16.7 & 14011 & $<32.8$ & $<30.7$ & 76.5 \\
\hline C2-1200-2 & 0.475 & 69.5 & 9.58 & 111 & 44.9 & 13502 & $<32.8$ & $<30.7$ & 93.4 \\
\hline \multicolumn{10}{|c|}{ Case 3-High $\mathrm{CaO} / \mathrm{MgO}$} \\
\hline C3-800-1 & 4.61 & 51800 & 2410 & 1630 & 458 & 72599 & 12251 & 1033 & 7480 \\
\hline C3-900-1 & 0.208 & 596 & 297 & 68.1 & 3.33 & 69.1 & 8.93 & 69.0 & 922 \\
\hline C3-1000-1-1/2B & 0.364 & 673 & 411 & 36.9 & 4.04 & 103 & 6.32 & 25.4 & 1280 \\
\hline C3-1200-1-1/2B & 0.0155 & 532 & 348 & 10.8 & 7.05 & 57.1 & $<3.28$ & 15.05 & 1130 \\
\hline C3-800-2 & 0.00294 & $<5.00$ & $<0.400$ & 5.55 & 2.51 & 4471 & $<6.57$ & $<6.13$ & 6.95 \\
\hline C3-900-2 & 0.0456 & $<5.00$ & $<0.400$ & 34.0 & $<10.0$ & 20894 & $<32.8$ & $<30.7$ & 31.0 \\
\hline \begin{tabular}{|l|}
$\mathrm{C} 3-1000-2-1 / 2 \mathrm{~B}$ \\
\end{tabular} & 0.206 & 63.2 & 1.61 & 37.5 & 80.8 & 10314 & $<32.8$ & $<30.7$ & 44.3 \\
\hline \begin{tabular}{|l|}
$\mathrm{C} 3-1200-2-1 / 2 \mathrm{~B}$ \\
\end{tabular} & 0.238 & 49.4 & 2.25 & 18.2 & 690 & 4307 & $<6.57$ & $<6.13$ & 10.8 \\
\hline \multicolumn{10}{|c|}{ Case 4-Crushed Soil } \\
\hline C4-800-1-1/2B & 0.0293 & 9080 & 450 & 109 & 20.6 & 122 & 14.3 & 1018 & 1380 \\
\hline C4-900-1-1/2B & 0.0860 & 406 & 166 & 27.4 & 1.97 & 113 & 5.06 & 111 & 521 \\
\hline \begin{tabular}{|l|}
$\mathrm{C} 4-1000-1-1 / 2 \mathrm{~B}$ \\
\end{tabular} & 0.239 & 602 & 364 & 29.5 & 2.41 & 49.1 & $<6.57$ & 62.2 & 1090 \\
\hline \begin{tabular}{|l|}
$\mathrm{C} 4-1200-1-1 / 2 \mathrm{~B}$ \\
\end{tabular} & 0.0133 & 684 & 436 & 3.94 & 2.40 & 44.1 & $<6.57$ & 43.8 & 1320 \\
\hline C4-800-2-1/2B & 0.00374 & 7.63 & $<0.400$ & 12.5 & 16.5 & 8455 & $<32.8$ & $<30.7$ & 21.7 \\
\hline C4-900-2-1/2B & 0.0335 & 4.33 & $<0.400$ & 15.8 & 9.41 & 9075 & 28.6 & 13.1 & 20.5 \\
\hline \begin{tabular}{|l|}
$\mathrm{C} 4-1000-2-1 / 2 \mathrm{~B}$ \\
\end{tabular} & 0.180 & 12.9 & $<0.400$ & 24.0 & 5.39 & 5976 & $<6.57$ & $<6.13$ & 6.62 \\
\hline \begin{tabular}{|l|}
$\mathrm{C} 4-1200-2-1 / 2 \mathrm{~B}$ \\
\end{tabular} & 0.346 & 48.2 & 18.2 & 66.0 & 14.5 & 8057 & $<6.57$ & $<6.13$ & 71.1 \\
\hline
\end{tabular}


Table 9.10 (Contd)

\begin{tabular}{|c|c|c|c|c|c|c|c|c|c|}
\hline Sample ID & $\operatorname{Re}$ & $\mathrm{Na}$ & $\mathbf{S}$ & $\mathrm{Cl}^{-}$ & $\mathbf{F}^{-}$ & $\mathrm{NO}_{3}$ & $\mathrm{NO}_{2}^{-}$ & $\mathrm{PO}_{4}{ }^{3-}$ & $\mathrm{SO}_{4}{ }^{2-}$ \\
\hline \multicolumn{10}{|c|}{ Pre-melted Glass } \\
\hline PMG-1000-1-2 & 0.00715 & $<5.00$ & 0.506 & 2.65 & 1.60 & 1.27 & $<0.657$ & $<0.613$ & 0.775 \\
\hline PMG-1000-5-2 & 0.0147 & 10.3 & 2.04 & 6.27 & 4.46 & 1.21 & $<0.657$ & $<0.613$ & 5.54 \\
\hline PMG-1100-1-2 & 0.0287 & 8.25 & 2.39 & 11.6 & 2.58 & 0.978 & $<0.657$ & $<0.613$ & 6.51 \\
\hline PMG-1100-5-2 & 0.129 & 45.7 & 13.9 & 48.3 & 12.5 & 1.09 & $<0.657$ & $<0.613$ & 41.5 \\
\hline PMG-1100-5-2 2nd & 0.179 & 68.5 & 21.6 & 71.0 & 17.0 & 12.0 & $<3.28$ & $<3.07$ & 65.0 \\
\hline PMG-1200-1-2 & 0.214 & 76.2 & 44.6 & 68.1 & 13.7 & 5.67 & $<3.28$ & $<3.07$ & 137 \\
\hline PMG-1200-5-2 & 0.443 & 141 & 88.6 & 123 & 20.2 & $<4.43$ & $<3.28$ & $<3.07$ & 266 \\
\hline
\end{tabular}

Table 9.11 summarizes the $\mathrm{wt} \%$ of the total mass added to the feed (or glass) found in each crucible rinse or condensate solution for all the components analyzed. The concentration of $\mathrm{SO}_{4}$ ion was converted to elemental S. For the tests with feeds, the mass of each component was calculated by multiplying the volume of solution collected by the analyzed concentration. The total mass used in each test was obtained from either analyzed concentrations (for $\mathrm{Re}, \mathrm{Na}, \mathrm{S}$, and $\mathrm{PO}_{4}$ ) for the feeds or target concentrations (for $\mathrm{Cl}$, $\mathrm{F}, \mathrm{NO}_{3}, \mathrm{NO}_{2}$ ) and the mass of feed or glass used in each test.

For pre-melted glass, $\mathrm{NO}_{3}$ and $\mathrm{NO}_{2}$ are not applicable, and $\mathrm{PO}_{4}$ concentration was below reporting limits for all samples. The analyzed concentrations were used for $\mathrm{Re}, \mathrm{Na}$, and $\mathrm{S}$, and target concentrations were used for $\mathrm{Cl}$ and $\mathrm{F}$. The actual $\mathrm{Cl}$ and $\mathrm{F}$ concentrations in the pre-melted glass will be lower than the target value because of volatilization, but this analysis is still valid for a relative comparison between tests.

The S results by ICP-AES showed good agreement with IC results for all crucible rinse solutions; however, there were some cases of discrepancy for condensate samples with a low concentration. The IC results will be used for data evaluation because the IC methods provided lower reporting limits for those samples with a low concentration. The sample results for low concentrations do not make any practical difference in evaluating results.

For $\mathrm{PO}_{4}$ and $\mathrm{NO}_{2}$, the $\mathrm{wt} \%$ of total in the crucible rinse decreases as the temperature increases because of decomposition $\left(\mathrm{NO}_{2}\right)$ and/or reaction into glass-forming melt $\left(\mathrm{PO}_{4}\right)$, but they are not found in the condensate samples in any significant amount. For $\mathrm{NO}_{3}$, similarly to $\mathrm{NO}_{2}$ and $\mathrm{PO}_{4}$, the wt\% of the total analyzed in the crucible rinse decreases as temperature increases; however, $\mathrm{NO}_{3}$ is captured in the condensate. The $\mathrm{NO}_{3}$ results will be used for the main evaluation. For $\mathrm{Cl}$ and $\mathrm{F}, \mathrm{Cl}$ is used for further evaluation to analyze the behavior of halogens because the change of $\mathrm{F}$ is overall similar to $\mathrm{Cl}$. In summary, data are evaluated on $\mathrm{Re}, \mathrm{Na}, \mathrm{S}, \mathrm{Cl}$, and $\mathrm{NO}_{3}$ results. 
Table 9.11. Wt\% of Total Analyzed in Crucible Rinse or Condensate Solution

\begin{tabular}{|c|c|c|c|c|c|c|c|c|c|c|}
\hline Samples & Test Condition & $\mathbf{R e}$ & $\mathrm{Na}$ & $\mathbf{S}$ & $\mathrm{Cl}$ & $\mathbf{F}$ & $\mathrm{NO}_{3}$ & $\mathrm{NO}_{2}$ & $\mathrm{PO}_{4}$ & $\mathbf{S}$ \\
\hline \multirow{6}{*}{$\begin{array}{l}\text { Case 1: Crucible } \\
\text { Rinse }\end{array}$} & $800^{\circ} \mathrm{C}$ & 24.37 & 23.48 & 43.57 & 34.38 & 25.69 & 7.01 & 9.75 & 30.84 & 42.61 \\
\hline & $900^{\circ} \mathrm{C}$ & 3.54 & 1.14 & 12.39 & 2.81 & 0.76 & 0.25 & 0.15 & 9.33 & 12.49 \\
\hline & $1000^{\circ} \mathrm{C}$ & 10.07 & 0.79 & 18.29 & 4.86 & 0.77 & 0.04 & 0.02 & 2.37 & 18.81 \\
\hline & $1000^{\circ} \mathrm{C}-1 / 2 \mathrm{~B}$ & 9.02 & 1.10 & 25.40 & 4.72 & 1.17 & 0.06 & - & 3.95 & 25.74 \\
\hline & $1200^{\circ} \mathrm{C}$ & 1.35 & 1.24 & 32.59 & 1.94 & 0.98 & 0.03 & - & 1.73 & 33.48 \\
\hline & $1200^{\circ} \mathrm{C}-1 / 2 \mathrm{~B}$ & 0.91 & 0.97 & 24.77 & 0.82 & 0.79 & 0.08 & 0.06 & 1.27 & 25.16 \\
\hline \multirow{6}{*}{\begin{tabular}{|l} 
Case 1: \\
Condensate \\
Solution
\end{tabular}} & $800^{\circ} \mathrm{C}$ & 0.72 & 0.03 & - & 9.64 & - & 81.14 & - & - & 1.28 \\
\hline & $900^{\circ} \mathrm{C}$ & 4.68 & 0.03 & - & 12.41 & 0.04 & 94.85 & 0.13 & - & 2.28 \\
\hline & $1000^{\circ} \mathrm{C}$ & 25.86 & 0.07 & - & 15.27 & - & 91.84 & - & - & 3.58 \\
\hline & $1000^{\circ} \mathrm{C}-1 / 2 \mathrm{~B}$ & 27.73 & 0.09 & 0.16 & 13.40 & 7.38 & 61.23 & - & - & 1.28 \\
\hline & $1200^{\circ} \mathrm{C}$ & 52.02 & 0.21 & 1.71 & 28.23 & 13.22 & 89.16 & - & - & 7.24 \\
\hline & $1200^{\circ} \mathrm{C}-1 / 2 \mathrm{~B}$ & 44.23 & 0.21 & 3.17 & 26.48 & 15.59 & 63.35 & - & - & 5.38 \\
\hline \multirow{4}{*}{$\begin{array}{l}\text { Case 2: Crucible } \\
\text { Rinse }\end{array}$} & $800^{\circ} \mathrm{C}$ & 38.40 & 20.47 & 51.42 & 50.35 & 29.54 & 15.27 & 20.82 & 20.92 & 49.53 \\
\hline & $900^{\circ} \mathrm{C}$ & 19.26 & 1.22 & 22.82 & 9.80 & 1.58 & 0.25 & 0.25 & 1.90 & 23.58 \\
\hline & $1000^{\circ} \mathrm{C}$ & 19.48 & 1.55 & 35.25 & 11.79 & 1.46 & 0.06 & - & 1.64 & 35.58 \\
\hline & $1200^{\circ} \mathrm{C}$ & 0.69 & 1.42 & 38.05 & 2.92 & 0.82 & 0.05 & - & 0.89 & 38.19 \\
\hline \multirow{4}{*}{\begin{tabular}{|l} 
Case 2: \\
Condensate \\
Solution
\end{tabular}} & $800^{\circ} \mathrm{C}$ & 1.22 & - & - & 4.15 & - & 56.70 & - & - & 2.19 \\
\hline & $900^{\circ} \mathrm{C}$ & 6.29 & - & - & 6.83 & 1.39 & 74.98 & - & - & 2.97 \\
\hline & $1000^{\circ} \mathrm{C}$ & 32.49 & 0.19 & 1.37 & 14.57 & 2.48 & 75.39 & - & - & 6.48 \\
\hline & $1200^{\circ} \mathrm{C}$ & 58.16 & 0.45 & 2.58 & 29.41 & 7.10 & 77.08 & - & - & 8.39 \\
\hline \multirow{4}{*}{$\begin{array}{l}\text { Case 3: Crucible } \\
\text { Rinse }\end{array}$} & $800^{\circ} \mathrm{C}$ & 58.41 & 35.85 & 73.12 & 96.24 & 69.54 & 42.73 & 57.53 & 15.01 & 75.76 \\
\hline & $900^{\circ} \mathrm{C}$ & 2.51 & 0.39 & 8.57 & 3.82 & 0.48 & 0.04 & 0.04 & 0.95 & 8.88 \\
\hline & $1000^{\circ} \mathrm{C}$ & 7.91 & 0.80 & 21.36 & 3.73 & 1.05 & 0.10 & 0.05 & 0.63 & 22.23 \\
\hline & $1200^{\circ} \mathrm{C}$ & 0.38 & 0.71 & 20.24 & 1.22 & 2.05 & 0.06 & - & 0.42 & 21.94 \\
\hline \multirow{4}{*}{\begin{tabular}{|l} 
Case 3: \\
Condensate \\
Solution
\end{tabular}} & $800^{\circ} \mathrm{C}$ & 0.29 & - & - & 2.55 & 2.97 & 20.47 & - & - & 0.55 \\
\hline & $900^{\circ} \mathrm{C}$ & 4.30 & - & - & 14.93 & - & 91.43 & - & - & 2.33 \\
\hline & $1000^{\circ} \mathrm{C}$ & 33.41 & 0.56 & 0.63 & 28.34 & $157^{(\mathrm{a})}$ & 77.71 & - & - & 5.74 \\
\hline & $1200^{\circ} \mathrm{C}$ & 38.32 & 0.43 & 0.87 & 13.66 & $1331^{(\mathrm{a})}$ & 32.22 & - & - & 1.39 \\
\hline \multirow{4}{*}{$\begin{array}{l}\text { Case 4: Crucible } \\
\text { Rinse }\end{array}$} & $800^{\circ} \mathrm{C}$ & 0.74 & 12.85 & 24.60 & 12.70 & 6.17 & 0.14 & 0.13 & 30.71 & 25.18 \\
\hline & $900^{\circ} \mathrm{C}$ & 2.19 & 0.58 & 9.13 & 3.21 & 0.59 & 0.13 & 0.05 & 3.36 & 9.56 \\
\hline & $1000^{\circ} \mathrm{C}$ & 6.06 & 0.85 & 19.95 & 3.45 & 0.72 & 0.06 & - & 1.88 & 19.94 \\
\hline & $1200^{\circ} \mathrm{C}$ & 0.35 & 1.01 & 24.82 & 0.48 & 0.75 & 0.05 & - & 1.38 & 25.08 \\
\hline \multirow{4}{*}{\begin{tabular}{|l} 
Case 4: \\
Condensate \\
Solution
\end{tabular}} & $800^{\circ} \mathrm{C}$ & 0.70 & 0.08 & - & 10.82 & 36.71 & 72.92 & - & - & 2.94 \\
\hline & $900^{\circ} \mathrm{C}$ & 6.07 & 0.04 & - & 13.19 & 20.20 & 75.52 & 1.90 & 2.83 & 2.68 \\
\hline & $1000^{\circ} \mathrm{C}$ & 31.09 & 0.12 & - & 19.11 & 11.03 & 47.42 & - & - & 0.83 \\
\hline & $1200^{\circ} \mathrm{C}$ & 61.32 & 0.48 & 6.97 & 53.92 & 30.46 & 65.60 & - & - & 9.10 \\
\hline \multirow{7}{*}{$\begin{array}{l}\text { Premelted Glass: } \\
\text { Condensate } \\
\text { Solution }\end{array}$} & $1000^{\circ} \mathrm{C} 1 \mathrm{~h}$ & 1.05 & - & 0.12 & 0.99 & 1.54 & - & - & - & 0.06 \\
\hline & $1000^{\circ} \mathrm{C} 5 \mathrm{~h}$ & 2.01 & 0.04 & 0.47 & 2.19 & 4.02 & - & - & - & 0.42 \\
\hline & $1100^{\circ} \mathrm{C} 1 \mathrm{~h}$ & 4.26 & 0.04 & 0.59 & 4.39 & 2.52 & - & - & - & 0.54 \\
\hline & $1100^{\circ} \mathrm{C} 5 \mathrm{~h}$ & 17.67 & 0.19 & 3.18 & 16.88 & 11.27 & - & - & - & 3.17 \\
\hline & $1100^{\circ} \mathrm{C} 5 \mathrm{~h} 2 \mathrm{nd}$ & 27.35 & 0.32 & 5.51 & 27.67 & 17.09 & - & - & - & 5.53 \\
\hline & $1200^{\circ} \mathrm{C} 1 \mathrm{~h}$ & 30.64 & 0.33 & 10.65 & 24.86 & 12.91 & - & - & - & 10.92 \\
\hline & $1200^{\circ} \mathrm{C} 5 \mathrm{~h}$ & 59.92 & 0.57 & 19.99 & 42.43 & 17.98 & - & - & - & 20.03 \\
\hline
\end{tabular}


Table 9.12. Analyzed Concentration and $\mathrm{Wt} \%$ of Total Retained in Glass for Re, Na, and S

\begin{tabular}{|c|c|c|c|c|c|c|}
\hline \multirow[b]{2}{*}{ Sample } & \multicolumn{3}{|c|}{ Concentration, mg/kg } & \multicolumn{3}{|c|}{ Wt\% of Total Retained in Glass } \\
\hline & $\mathbf{R e}$ & $\mathbf{N a}$ & $\mathbf{S}$ & $\mathbf{R e}$ & $\mathbf{N a}$ & $\mathbf{S}$ \\
\hline \multicolumn{7}{|c|}{ Tests with Dried Feeds at $1200^{\circ} \mathrm{C}$ Final Temperature } \\
\hline Case 1 & 3.40 & 146000 & 2390 & 38.8 & 94.5 & 63.1 \\
\hline Case $1-1 / 2 \mathrm{~B}$ & 3.45 & 142500 & 2375 & 39.3 & 92.2 & 62.7 \\
\hline Case 2 & 2.33 & 147000 & 2100 & 27.9 & 92.8 & 55.2 \\
\hline Case 3 & 3.56 & 149000 & 2710 & 39.9 & 91.2 & 72.8 \\
\hline Case 4 & 3.25 & 142000 & 2180 & 37.3 & 91.3 & 54.1 \\
\hline \multicolumn{7}{|c|}{ Tests with Pre-melted Glass } \\
\hline $1000^{\circ} \mathrm{C} 1 \mathrm{~h}$ & 4.34 & 144000 & 2640 & 93.4 & 93.3 & 94.7 \\
\hline $1000^{\circ} \mathrm{C} 5 \mathrm{~h}$ & 4.16 & 144000 & 2620 & 89.5 & 93.3 & 94.0 \\
\hline $1100^{\circ} \mathrm{C} 1 \mathrm{~h}$ & 3.89 & 142000 & 2470 & 83.7 & 92.0 & 88.6 \\
\hline $1100^{\circ} \mathrm{C} 5 \mathrm{~h}$ & 3.08 & 143000 & 2490 & 66.3 & 92.7 & 89.4 \\
\hline $1100^{\circ} \mathrm{C} 5 \mathrm{~h} 2 \mathrm{nd}$ & 3.10 & 143000 & 2490 & 66.7 & 92.7 & 89.4 \\
\hline $1200^{\circ} \mathrm{C} 1 \mathrm{~h}$ & 3.10 & 140000 & 2360 & 66.7 & 90.7 & 84.7 \\
\hline $1200^{\circ} \mathrm{C} 5 \mathrm{~h}$ & 1.61 & 144000 & 1970 & 34.6 & 93.3 & 70.7 \\
\hline
\end{tabular}

Table 9.13 summarizes the analytical results of $\mathrm{Re}, \mathrm{Na}$, and $\mathrm{S}$ concentrations for those samples with duplicate analyses. Table 9.13 shows that the reproducibility of analyses is good with a RPD of $10 \%$ or smaller for all samples.

There was only one duplicate test that was performed under exactly the same condition (test with premelted glass at $1100^{\circ} \mathrm{C}$ for $5 \mathrm{~h}$ ), and there were two duplicate tests that were performed under the same condition except for the batch size (tests with Case 1 feed at final temperatures of 1000 and $1200^{\circ} \mathrm{C}$ ). Table 9.14 summarizes the results from these duplicate tests. Table 9.14 shows that there was no apparent bias between tests with different batch sizes (i.e., $1 / 2$ batch size was obtained, depending both upon test condition and component) and that the reproducibility of duplicate tests was in general poor with the RPD of up to $43 \%$ for Re. This poor reproducibility, although based on very limited data, suggests that one should be cautious when evaluating the present results. 
Table 9.13. Summary of Duplicate Analytical Results

\begin{tabular}{|c|c|c|c|c|c|c|c|}
\hline \multicolumn{8}{|c|}{ Solution Samples } \\
\hline \multirow[b]{2}{*}{ Sample ID } & \multirow[b]{2}{*}{ Sample Description } & \multicolumn{3}{|c|}{ Analyzed Concentration } & \multicolumn{3}{|c|}{ RPD, \% } \\
\hline & & $\begin{array}{c}\mathbf{R e} \\
(\mathrm{mg} / \mathrm{L})\end{array}$ & $\begin{array}{c}\mathrm{Na} \\
(\mathrm{mg} / \mathrm{L})\end{array}$ & $\begin{array}{c}\mathrm{SO}_{4} \\
(\mathrm{mg} / \mathrm{L})\end{array}$ & $\mathbf{R e}$ & $\mathbf{N a}$ & $\mathrm{SO}_{4}$ \\
\hline C1-1000-1 & \multirow{2}{*}{$\begin{array}{l}\text { Case } 1,1000^{\circ} \mathrm{C} \text { run, } \\
\text { crucible rinse }\end{array}$} & 0.803 & 1110 & 1930 & \multirow{2}{*}{0.1} & \multirow{2}{*}{0.0} & \multirow{2}{*}{1.0} \\
\hline Duplicate & & 0.802 & 1110 & 1950 & & & \\
\hline $\mathrm{C} 2-1000-2$ & \multirow{2}{*}{$\begin{array}{l}\text { Case } 2,1000^{\circ} \mathrm{C} \text { run, } \\
\text { condensate }\end{array}$} & 0.285 & 29.8 & 73.1 & \multirow{2}{*}{2.5} & \multirow{2}{*}{4.9} & \multirow{2}{*}{8.9} \\
\hline Duplicate & & 0.278 & 31.3 & 79.9 & & & \\
\hline C3-1000-1 & \multirow{2}{*}{$\begin{array}{l}\text { Case } 3,1000^{\circ} \mathrm{C} \text { run, } \\
\text { crucible rinse }\end{array}$} & 0.363 & 670 & 1280 & \multirow{2}{*}{0.5} & \multirow{2}{*}{0.7} & \multirow{2}{*}{0.0} \\
\hline Duplicate & & 0.365 & 675 & 1280 & & & \\
\hline C1-1000-1-1/2 BATCH & \multirow{2}{*}{$\begin{array}{c}\text { Case } 1 \text { with } 1 / 2 \text { batch, } \\
1000^{\circ} \mathrm{C} \text { run, crucible } \\
\text { rinse }\end{array}$} & 0.35 & 743 & 1280 & \multirow{2}{*}{2.0} & \multirow{2}{*}{0.1} & \multirow{2}{*}{0.0} \\
\hline Duplicate & & 0.343 & 744 & 1280 & & & \\
\hline \multicolumn{8}{|c|}{ Glass samples } \\
\hline \multirow[b]{2}{*}{ Sample ID } & \multirow[b]{2}{*}{ Sample Description } & \multicolumn{3}{|c|}{ Analyzed concentration } & \multicolumn{3}{|c|}{ RPD, \% } \\
\hline & & $\begin{array}{c}\mathrm{Re} \\
(\mathrm{mg} / \mathrm{kg})\end{array}$ & $\begin{array}{c}\mathrm{Na} \\
(\mathrm{mg} / \mathrm{kg})\end{array}$ & $\begin{array}{c}\mathrm{S} \\
(\mathrm{mg} / \mathrm{kg})\end{array}$ & $\operatorname{Re}$ & $\mathbf{N a}$ & $\mathbf{S}$ \\
\hline Re Glass A & \multirow{2}{*}{$\begin{array}{l}\text { Pre-melted glass, } \\
\text { sample A }\end{array}$} & 4.55 & 155000 & 2850 & \multirow{2}{*}{1.3} & \multirow{2}{*}{1.3} & \multirow{2}{*}{1.0} \\
\hline Duplicate & & 4.61 & 153000 & 2880 & & & \\
\hline Re Glass B & \multirow{2}{*}{$\begin{array}{c}\text { Pre-melted glass, } \\
\text { sample B }\end{array}$} & 4.75 & 153000 & 2830 & \multirow{2}{*}{1.9} & \multirow{2}{*}{0.0} & \multirow{2}{*}{0.4} \\
\hline Duplicate & & 4.66 & 153000 & 2840 & & & \\
\hline $\mathrm{C} 1-1200-3-1 / 2 \mathrm{BATCH}$ & \multirow{2}{*}{$\begin{array}{l}\text { Case } 1 \text { with } 1 / 2 \text { batch, } \\
1200^{\circ} \mathrm{C} \text { run, glass }\end{array}$} & 3.57 & 144000 & 2370 & 70 & 21 & 04 \\
\hline Duplicate & & 3.33 & 141000 & 2380 & & & \\
\hline $\begin{array}{l}\text { The } \mathrm{SO}_{4} \text { concentration in } \\
\text { MS. }\end{array}$ & tion samples was from & and the & ncentrat & in glas & & fro & \\
\hline
\end{tabular}

Table 9.14. Comparison of Results from Duplicate Tests

\begin{tabular}{|c|c|c|c|c|c|c|c|}
\hline \multirow[b]{2}{*}{ Samples } & \multirow[b]{2}{*}{ Test Condition } & \multicolumn{3}{|c|}{$\begin{array}{c}\text { Wt\% of Total Analyzed } \\
\text { in each Sample }\end{array}$} & \multicolumn{3}{|c|}{ RPD, \% } \\
\hline & & $\mathbf{R e}$ & $\mathbf{N a}$ & $\mathbf{S}$ & $\mathbf{R e}$ & $\mathbf{N a}$ & $\mathbf{S}$ \\
\hline \multirow{4}{*}{$\begin{array}{l}\text { Crucible } \\
\text { rinse }\end{array}$} & Case $1,1000^{\circ} \mathrm{C}$ & 10.07 & 0.79 & 18.81 & \multirow{2}{*}{-11.0} & \multirow{2}{*}{32.8} & \multirow{2}{*}{31.1} \\
\hline & Case $1,1000^{\circ} \mathrm{C}-1 / 2 \mathrm{~B}$ & 9.02 & 1.1 & 25.74 & & & \\
\hline & Case $1,1200^{\circ} \mathrm{C}$ & 1.35 & 1.24 & 33.48 & \multirow{2}{*}{-38.9} & \multirow{2}{*}{-24.4} & \multirow{2}{*}{-28.4} \\
\hline & Case $1,1200^{\circ} \mathrm{C}-1 / 2 \mathrm{~B}$ & 0.91 & 0.97 & 25.16 & & & \\
\hline \multirow{6}{*}{$\begin{array}{l}\text { Condensate } \\
\text { solution }\end{array}$} & Case $1,1000^{\circ} \mathrm{C}$ & 25.86 & 0.07 & 3.58 & \multirow{2}{*}{7.0} & \multirow{2}{*}{25.0} & \multirow{2}{*}{-94.7} \\
\hline & Case $1,1000^{\circ} \mathrm{C}-1 / 2 \mathrm{~B}$ & 27.73 & 0.09 & 1.28 & & & \\
\hline & Case $1,1200^{\circ} \mathrm{C}$ & 52.02 & 0.21 & 7.24 & \multirow{2}{*}{-16.2} & \multirow{2}{*}{0.0} & \multirow{2}{*}{-29.5} \\
\hline & Case $1,1200^{\circ} \mathrm{C}-1 / 2 \mathrm{~B}$ & 44.23 & 0.21 & 5.38 & & & \\
\hline & PMG, $1100^{\circ} \mathrm{C} 5 \mathrm{~h}$ & 17.67 & 0.19 & 3.17 & \multirow{2}{*}{43.0} & \multirow{2}{*}{51.0} & \multirow{2}{*}{54.3} \\
\hline & $\mathrm{PMG}, 1100^{\circ} \mathrm{C} 5 \mathrm{~h} 2 \mathrm{nd}$ & 27.35 & 0.32 & 5.53 & & & \\
\hline \multirow{4}{*}{ Glass } & Case $1,1200^{\circ} \mathrm{C}$ & 38.8 & 94.5 & 63.1 & \multirow{2}{*}{1.3} & \multirow{2}{*}{-2.5} & \multirow{2}{*}{-0.6} \\
\hline & Case $1,1200^{\circ} \mathrm{C}-1 / 2 \mathrm{~B}$ & 39.3 & 92.2 & 62.7 & & & \\
\hline & $\mathrm{PMG}, 1100^{\circ} \mathrm{C} 5 \mathrm{~h}$ & 66.3 & 92.7 & 89.4 & \multirow{2}{*}{0.6} & \multirow{2}{*}{0.0} & \multirow{2}{*}{0.0} \\
\hline & PMG, $1100^{\circ} \mathrm{C} 5 \mathrm{~h} 2 \mathrm{nd}$ & 66.7 & 92.7 & 89.4 & & & \\
\hline
\end{tabular}




\subsubsection{Tests with Pre-Melted Glass}

Figure 9.3 displays the $\mathrm{wt} \%$ of total $\mathrm{Re}, \mathrm{S}$, and $\mathrm{Cl}$ analyzed in condensate, and Figure 9.4 shows Re and $\mathrm{S}$ retained in glass from tests with pre-melted glass as a function of temperature. The overall volatilization of $\mathrm{Re}, \mathrm{S}$, and $\mathrm{Cl}$ strongly increased as the temperature increased, starting from a negligible extent at $1000^{\circ} \mathrm{C}$. At $1200^{\circ} \mathrm{C}, \sim 30 \%$ of Re was lost through volatilization after $1 \mathrm{~h}$ and $\sim 60 \%$ after $5 \mathrm{~h}$. As seen in Figure 9.4, retention of $\mathrm{Re}$ and $\mathrm{S}$ in glass is inversely proportional to the observed volatilization. Figure 9.3 shows that Re had the highest volatility among three components whereas $\mathrm{S}$ had the lowest volatility.

Figure 9.5 and Figure 9.6 display the wt\% of total Re (Figure 9.5) and S (Figure 9.6) analyzed in condensate solutions and retained in glass from tests with pre-melted glass, showing the trend of increasing volatilization as the temperature and the time increase. Figure 9.5 and Figure 9.6 show that the modified experimental setup developed in this study successfully achieved a high mass balance closure, which was $\sim 93 \%$ on average for both Re and S, not including the contribution from the crucible rinse. This result is encouraging considering the typical analytical uncertainty of $\pm 10 \%$.

Figure 9.7 and Figure 9.8 (same as Figure 9.7 in log scale) plot the average volatilization rate, $r_{a, \mathrm{i}}$ (in $\mathrm{wt} \% / \mathrm{h}$ obtained as an average rate between 1 and $5 \mathrm{~h}$ ), of $\mathrm{Re}, \mathrm{S}$, and $\mathrm{Cl}$ as a function of temperature. Figure 9.8 is the same as Figure 9.7 but in logarithm of $r_{a, \mathrm{i}}$ versus reciprocal temperature to fit the Arrhenius form

$$
r_{a, \mathrm{i}}=r_{a, \mathrm{i} 0} \exp \left(-E_{a, \mathrm{i}} / R T\right)
$$

where $r_{a, \mathrm{i} 0}=$ a constant

$E_{a, \mathrm{i}}=$ an experimental activation energy for average volatilization

$\mathrm{R}=$ a gas constant $(8.314 \mathrm{~J} / \mathrm{mol} \mathrm{K})$

$T=$ the absolute temperature.

Figure 9.8 shows that the experimental data do not fit the Arrhenius equation well, which is understandable because the $r_{a, \mathrm{i}}$ was based on the initial concentration whereas the volatilization rate should be adjusted as the concentration of volatiles in the melt decreases, especially in the case of the extremely high volatilization rate in this study. The activation energy values directly obtained from Figure 9.8 (simple linear fit) were 270, 254, and $214 \mathrm{~kJ} / \mathrm{mole}$ for Re, S, and $\mathrm{Cl}$, respectively.

A more rigorous analysis was performed for Re to obtain the activation energy based on the volatilization rate adjusted for the concentration of volatiles in the melt. The accumulated $\mathrm{wt} \%$ of Re volatilized, $w$, for the test conditions in this study is given as

$$
w_{\theta, \tau}=\int_{773}^{\frac{\theta-773}{5}} r(1-w) d t+\int_{\frac{\theta-773}{5}}^{\frac{\theta-773}{5}+\tau} r_{T=\theta}(1-w) d t
$$

where $\theta$ is the final temperature $(1273,1373$, or $1473 \mathrm{~K}), \tau$ is the time $(60$ or $300 \mathrm{~min})$ at the final temperature, and $r$ is the volatilization rate of Re, which is defined as: 


$$
r=\frac{d w}{(1-w) d t}
$$

The temperature dependence of $r$ is given as

$$
r=r_{0} \exp (-E / R T)
$$

where $r_{0}$ is a constant. During ramp heating from $500^{\circ} \mathrm{C}$ to the final temperature, $T=773+5 t$, then Equation (9.2) can be rewritten as

$$
w_{\theta, \tau}=\int_{773}^{\frac{\theta-773}{5}} r_{0} \exp \left(-\frac{E}{R(773+5 t)}\right)(1-w) d t+\int_{\frac{\theta-773}{5}}^{\frac{\theta-773}{5}+\tau} r_{T=\theta}(1-w) d t
$$

Because there is no analytical solution to Equation (9.5), a simple numerical calculation was performed to obtain the constants $r_{0}$ and $E$. Using the $w$ (equivalent to the wt $\%$ of total analyzed in condensate) data given in Table 9.11, we obtain $r_{0}=4,998,969 \mathrm{~min}^{-1}$ and $E=258 \mathrm{~kJ} / \mathrm{mole}$. Table 9.15 summarizes the volatilization rate calculated from Equation (9.4). Figure 9.9 shows the measured and calculated values of the accumulated $\mathrm{Re} w \mathrm{t} \%$ volatilized.

Table 9.15. Calculated Re Volatilization Rate

\begin{tabular}{|c|c|}
\hline Temperature $\left({ }^{\circ} \mathbf{C}\right)$ & $\begin{array}{c}\text { Re volatilization rate }(\boldsymbol{r}), \\
\mathbf{w t} \% \mathbf{h} \mathbf{h r}\end{array}$ \\
\hline 1000 & 0.7 \\
\hline 1100 & 4.4 \\
\hline 1200 & 20.4 \\
\hline
\end{tabular}




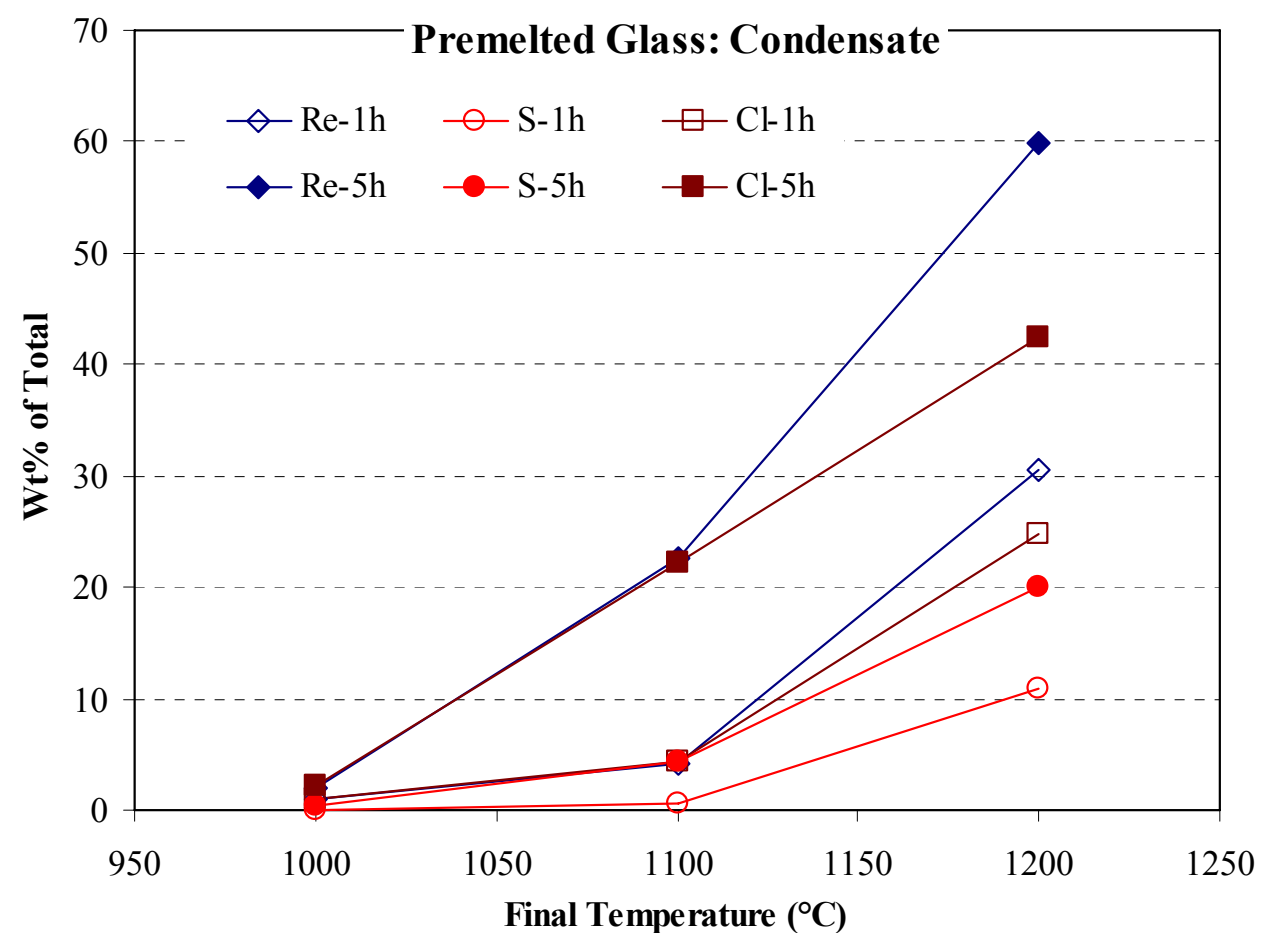

Figure 9.3. Wt\% of Total Analyzed in Condensate Solutions from the Tests with Pre-melted Glass

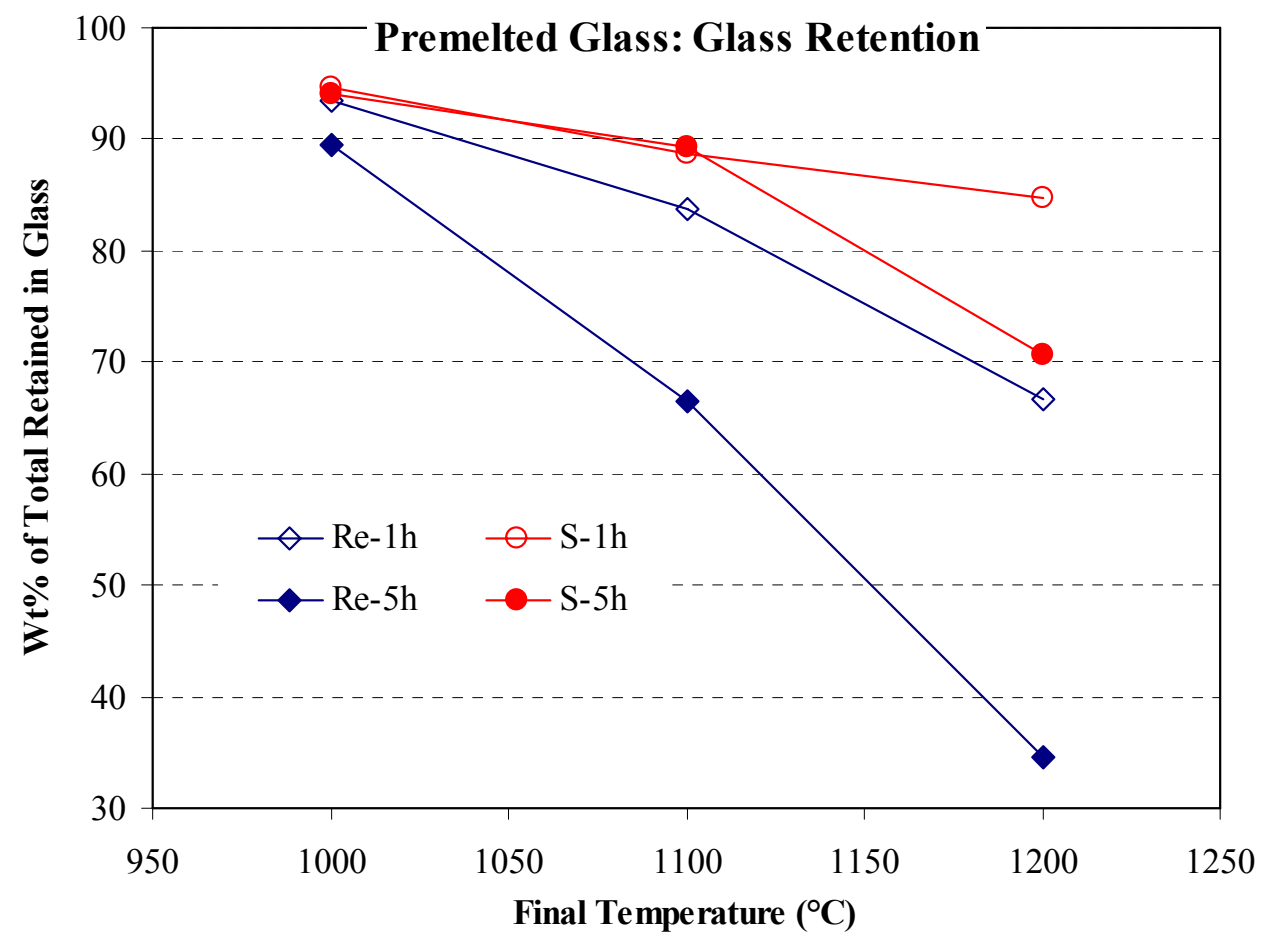

Figure 9.4. Wt\% of Total Retained in Glass from the Tests with Pre-melted Glass 


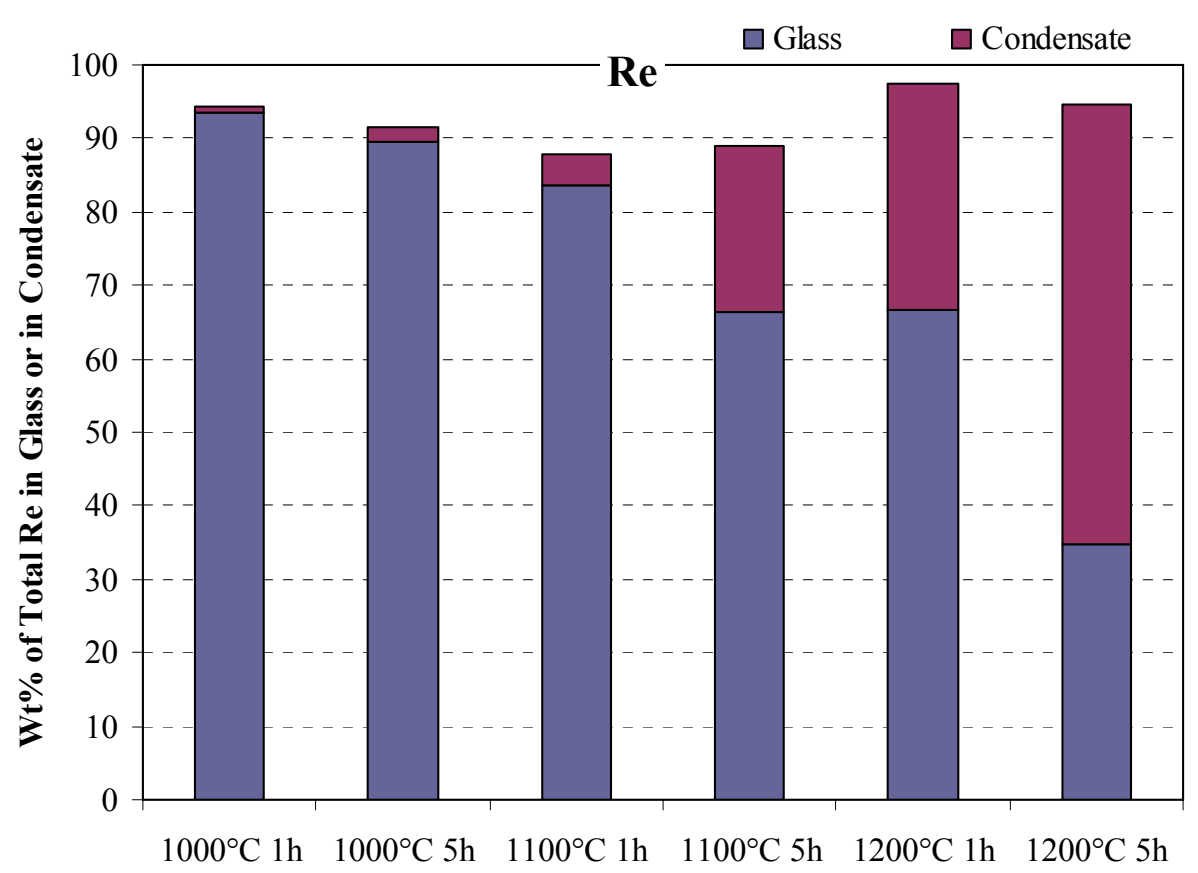

Figure 9.5. Wt\% of Total Re Retained in Glass and Analyzed in Condensate Solutions from the Tests with Pre-melted Glass

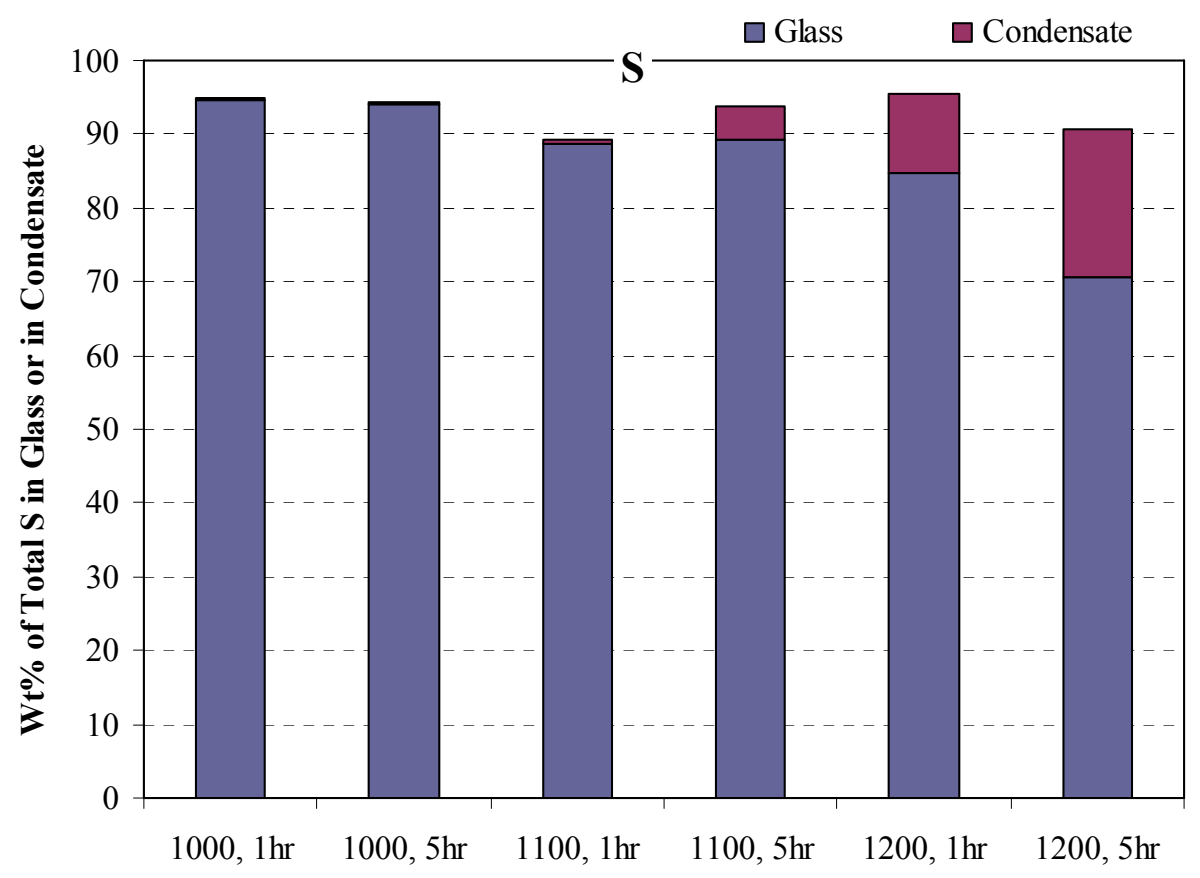

Figure 9.6. Wt\% of Total $\mathrm{S}$ Retained in Glass and Analyzed in Condensate Solutions from the Tests with Pre-melted Glass 


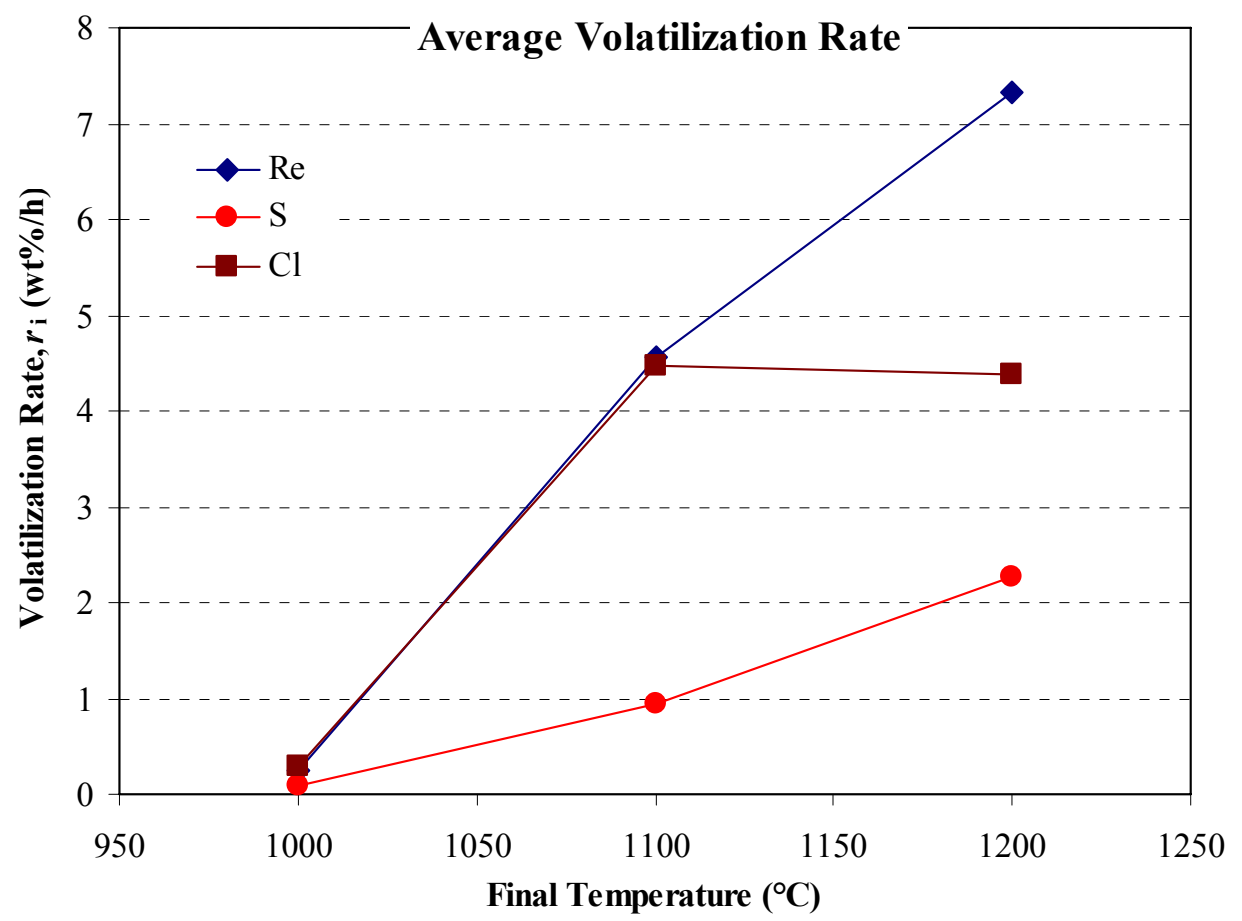

Figure 9.7. Average Volatilization Rate of Re, S, and Cl from Pre-melted Glass

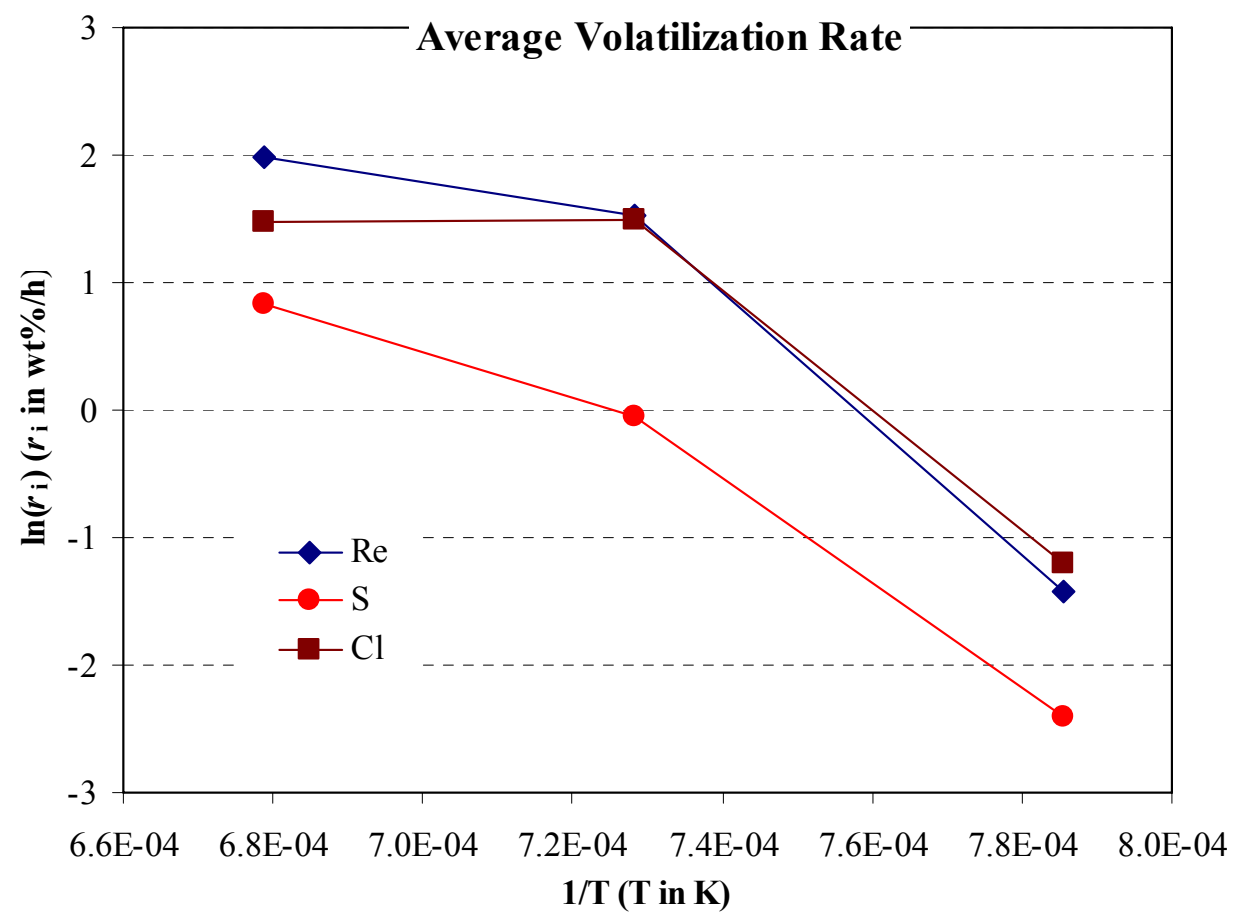

Figure 9.8. Natural Log of Average Volatilization Rate of Re, S, and Cl from Pre-melted Glass 


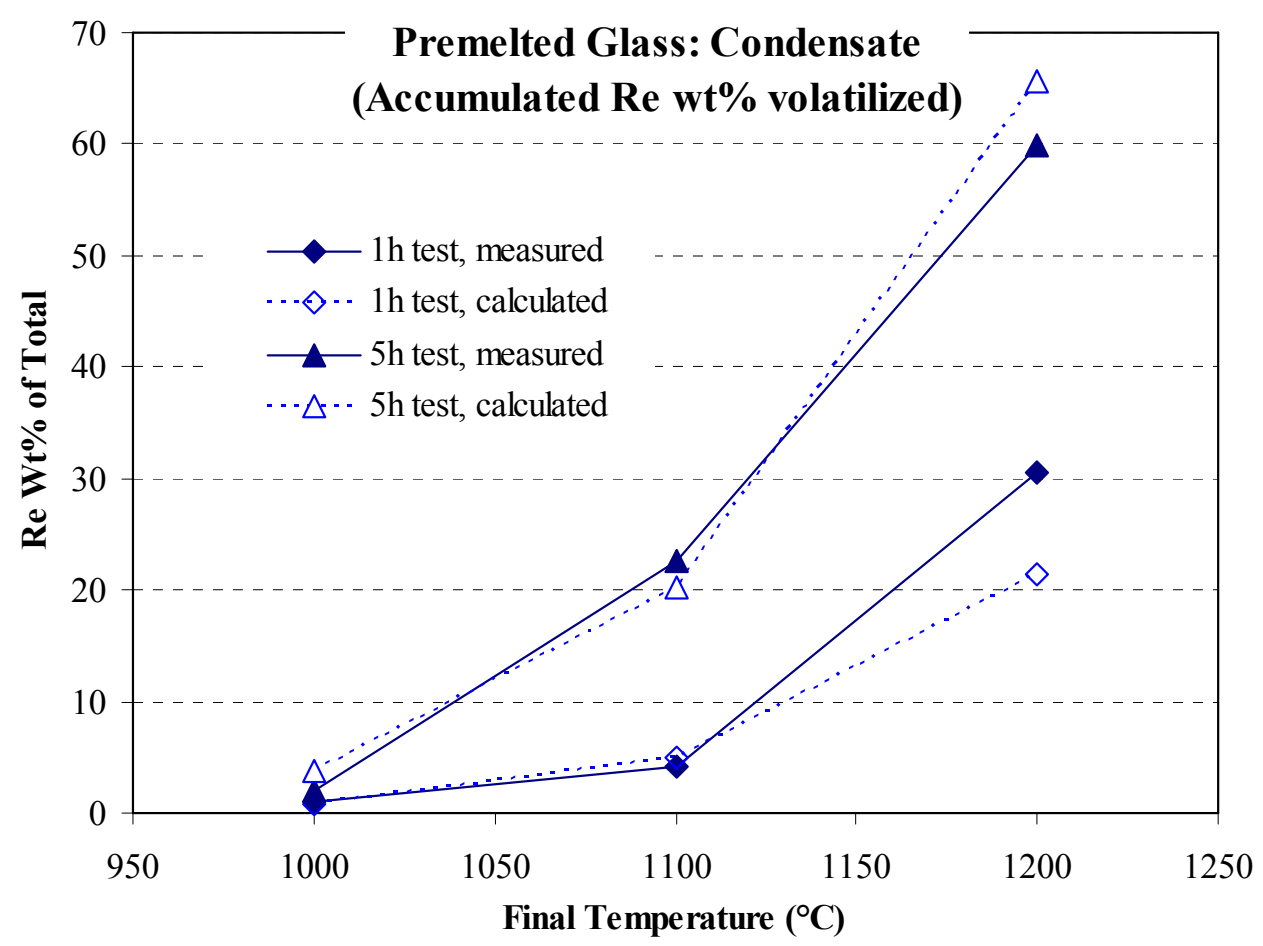

Figure 9.9. Measured Versus Calculated Accumulated Re wt\% Volatilized

\subsubsection{Tests with Dried Feed}

Figure 9.10 and Figure 9.11 display the wt\% of total $\mathrm{Re}, \mathrm{Na}, \mathrm{S}, \mathrm{Cl}$, and $\mathrm{NO}_{3}$ analyzed in the crucible rinse (Figure 9.10) and in the condensate (Figure 9.11) from tests with Case 1 (baseline) feed. The same plots from the tests with Case 2 (high $\mathrm{Cl} / \mathrm{F}$ ) feed are in Figure 9.12 (crucible rinse) and Figure 9.13 (condensate), Case 3 (high $\mathrm{CaO} / \mathrm{MgO}$ ) feed in Figure 9.14 (crucible rinse) and Figure 9.15 (condensate), and Case 4 (crushed soil) feed in Figure 9.16 (crucible rinse) and Figure 9.17 (condensate). The plots of the $\mathrm{wt} \%$ of total $\mathrm{Re}, \mathrm{S}$, and $\mathrm{Cl}$ analyzed in both crucible rinse and condensate for all test cases are in Figure $9.18(\mathrm{Re})$, Figure $9.19(\mathrm{~S})$, and Figure $9.20(\mathrm{Cl})$.

Figure 9.10 shows that $\mathrm{Na}$ and $\mathrm{NO}_{3}$ in the crucible rinse decrease to close to zero at $900^{\circ} \mathrm{C}$. The concentration of $\mathrm{Cl}$ and $\mathrm{Re}$ decreases between 800 and $900^{\circ} \mathrm{C}$, increases between 900 and $1000^{\circ} \mathrm{C}$, and then decreases as the temperature increases from 1000 to $1200^{\circ} \mathrm{C}$, whereas $\mathrm{S}$ decreases between 800 and $900^{\circ} \mathrm{C}$ and then increases between 900 and $1200^{\circ} \mathrm{C}$.

The decrease of $\mathrm{Na}$ and $\mathrm{NO}_{3}$ to close to zero at $900^{\circ} \mathrm{C}$ suggests that most $\mathrm{NaNO}_{3}$ and (other salts) reacted with additives (mainly soil) to form glass-forming melt and generated $\mathrm{NO}_{3}$ by $900^{\circ} \mathrm{C}$. Starting from $\sim 900^{\circ} \mathrm{C}$, the remaining MIS was highly concentrated with sulfate as the nitrate decomposition was completed. It is likely that the salt phase at $900^{\circ} \mathrm{C}$ is distributed as droplets throughout the glass-forming melt. Then a separated salt layer started to form as the temperature increased, transported by rising bubbles (Hrma et al. 2005), which can be inferred from the increase of sulfate between 900 and $1200^{\circ} \mathrm{C}$ shown in Figure 9.10. The method of crucible rinse used in this study did not dissolve the salt phases that were distributed in small closed pores or as small inclusions. The decrease of $\mathrm{Re}$ and $\mathrm{Cl}$ in the crucible 
rinse is explained by the volatilization of $\mathrm{Re}$ and $\mathrm{Cl}$ from this separated sulfate salt. This means that the $\mathrm{Re}$ and $\mathrm{Cl}$ that did not become incorporated into glass-forming melt during initial melting was lost through volatilization below $1200^{\circ} \mathrm{C}$.

Figure 9.11 shows that $\mathrm{NO}_{3}$ in the crucible rinse increased to $\sim 80 \mathrm{wt} \%$ at $800^{\circ} \mathrm{C}$ and was constant-it is likely that the difference measured between 900 and $1200^{\circ} \mathrm{C}$ is within experimental variation. No measurable volatilization was observed for $\mathrm{Na}$. The volatilization of $\mathrm{Re}, \mathrm{S}$, and $\mathrm{Cl}$ increased as the temperature increased with the highest rate for Re.

Figure 9.12 shows that the crucible rinse from the Case 2 feed with spiked $\mathrm{Cl}$ and $\mathrm{F}$ had a general behavior similar to the baseline feed. One noticeable difference was that the crucible rinse from the Case 2 feed had an overall higher wt $\%$ of Re, S, and $\mathrm{Cl}$ rinse at 900 and $1000^{\circ} \mathrm{C}$. Figure 9.13 also shows that the condensate from the Case 2 feed showed a trend similar to the baseline feed, but with significantly lower $\mathrm{NO}_{3}$ at $800^{\circ} \mathrm{C}$ and slightly higher $\mathrm{Re}$ than the baseline feed.

Figure 9.14 shows that the crucible rinse from the Case 3 feed with higher $\mathrm{CaO}$ and $\mathrm{MgO}$ also showed an overall trend similar to that shown by the baseline feed. A noticeable difference was seen in the $800^{\circ} \mathrm{C}$ crucible rinse results where all five components from the Case 3 feed had higher concentrations than the baseline feed. For condensate, Figure 9.15 shows that there was a major decrease in the $\mathrm{NO}_{3}$ for 800 and $1200^{\circ} \mathrm{C}$ tests for Case 3, relative to the baseline feed. Another noticeable difference was that the increase of $\mathrm{Re}$ in the condensate between 1000 and $1200^{\circ} \mathrm{C}$ was smaller for the Case 3 feed than for the baseline feed. The low $\mathrm{NO}_{3}$ level in the Case 3 condensate agrees well with the high $\mathrm{NO}_{3}$ in the crucible rinse at $800^{\circ} \mathrm{C}$. Overall, the high $\mathrm{wt} \%$ of MIS components in the crucible rinse and low $\mathrm{NO}_{3}$ in the condensate at $800^{\circ} \mathrm{C}$ compared to the baseline suggests that the incorporation of MIS into glass-forming melt was delayed in the Case 3 feed. However, the low $\mathrm{NO}_{3}$ at $1200^{\circ} \mathrm{C}$ is not understood.

Figure 9.16 shows that crucible rinses for the Case 4 (crushed soil) feed also behave similarly to the baseline feed. The main difference was that the $800^{\circ} \mathrm{C}$ Case 4 test showed an overall lower concentration of MIS components in the crucible rinse, especially $\mathrm{NO}_{3}$, which was zero at $800^{\circ} \mathrm{C}$. This suggests that nitrate decomposition is complete below $800^{\circ} \mathrm{C}$ for the Case 4 feed, whereas the nitrate decomposition is complete between 800 and $900^{\circ} \mathrm{C}$ for the baseline feed. The finer particle size of crushed soil seemed to accelerate the reaction between MIS and soil. However, this early reaction had no noticeable effect on the volatilization of the MIS components. Figure 9.17 shows that the Case 4 feed condensate had results comparable to the baseline feed. The only difference was that the $\mathrm{NO}_{3} \mathrm{wt} \%$ in the condensate was lower than the baseline, especially at $1000^{\circ} \mathrm{C}$.

Figure 9.21 shows the $\mathrm{wt} \%$ of $\mathrm{Re}$ and $\mathrm{S}$ retained in the glass for the tests with dried feeds at a final temperature of $1200^{\circ} \mathrm{C}$. Figure 9.21 shows that Re retention in the glass is $29 \%$ lower than the baseline for Case 2 feed while Case 3 and 4 feeds had Re retentions within $\pm 5 \%$ of the baseline. The $\mathrm{S}$ retention was higher in Case 3 by $16 \%$ and lower in Case 2 and Case 4 by $12 \%$ and 14\%, respectively. Figure 9.22 and Figure 9.23 show the combined wt\% of Re (Figure 9.22) and S (Figure 9.23) present in the glass, crucible rinse, and condensate samples at a final temperature of $1200^{\circ} \mathrm{C}$. The total mass balance closure ranged from 79 to $99 \mathrm{wt} \%$ with an average of $88 \mathrm{wt} \%$ for Re and 88 to $102 \mathrm{wt} \%$ with an average of $96 \mathrm{wt} \%$ for $\mathrm{S}$. The high variation of mass balance closure for tests with feeds compared to the tests with pre-melted glass is likely caused by larger quantities of gas generated with the feeds. Overall, there was no correlation between the mass balance closures for Re and S-Case 3 feed had lowest mass-balance 
closure of $79 \%$ for Re, but the S mass balance closure was comparable to other feeds, and Case 4 had the highest mass balance closure for Re whereas it had the lowest for S. This may indicate that the case-tocase variation was not simply related to the materials lost through the Pt crucible and lid gap. Overall, the mass balance for Re was significantly better than that obtained in earlier tests (Kim et al. 2005).

However, these tests show that even in well controlled laboratory tests, it is difficult to consistently close the mass balance for Re to better than $90 \%$.

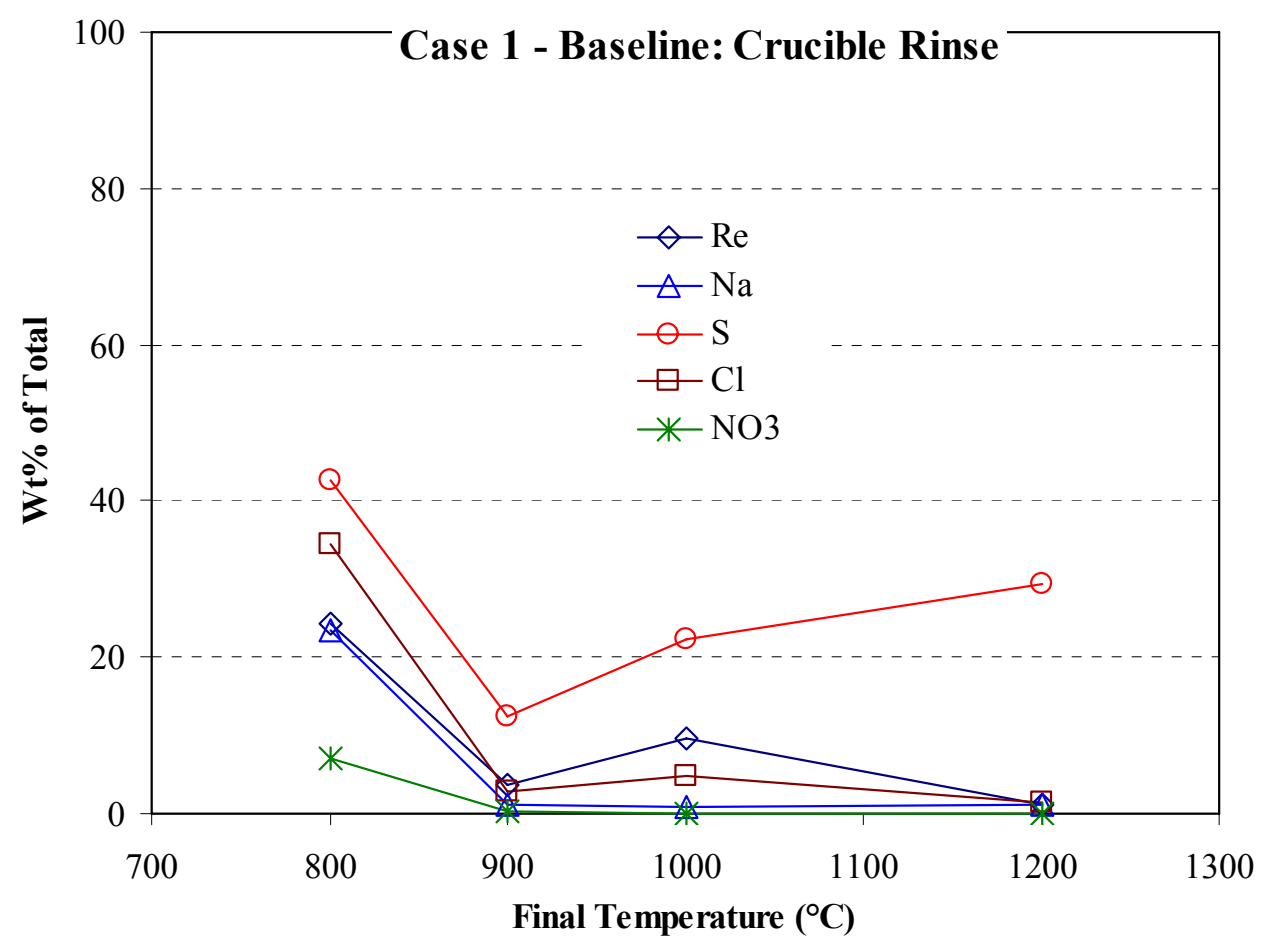

Figure 9.10. Wt\% of Total Analyzed in Crucible Rinse from Case 1 (Baseline Feed) 


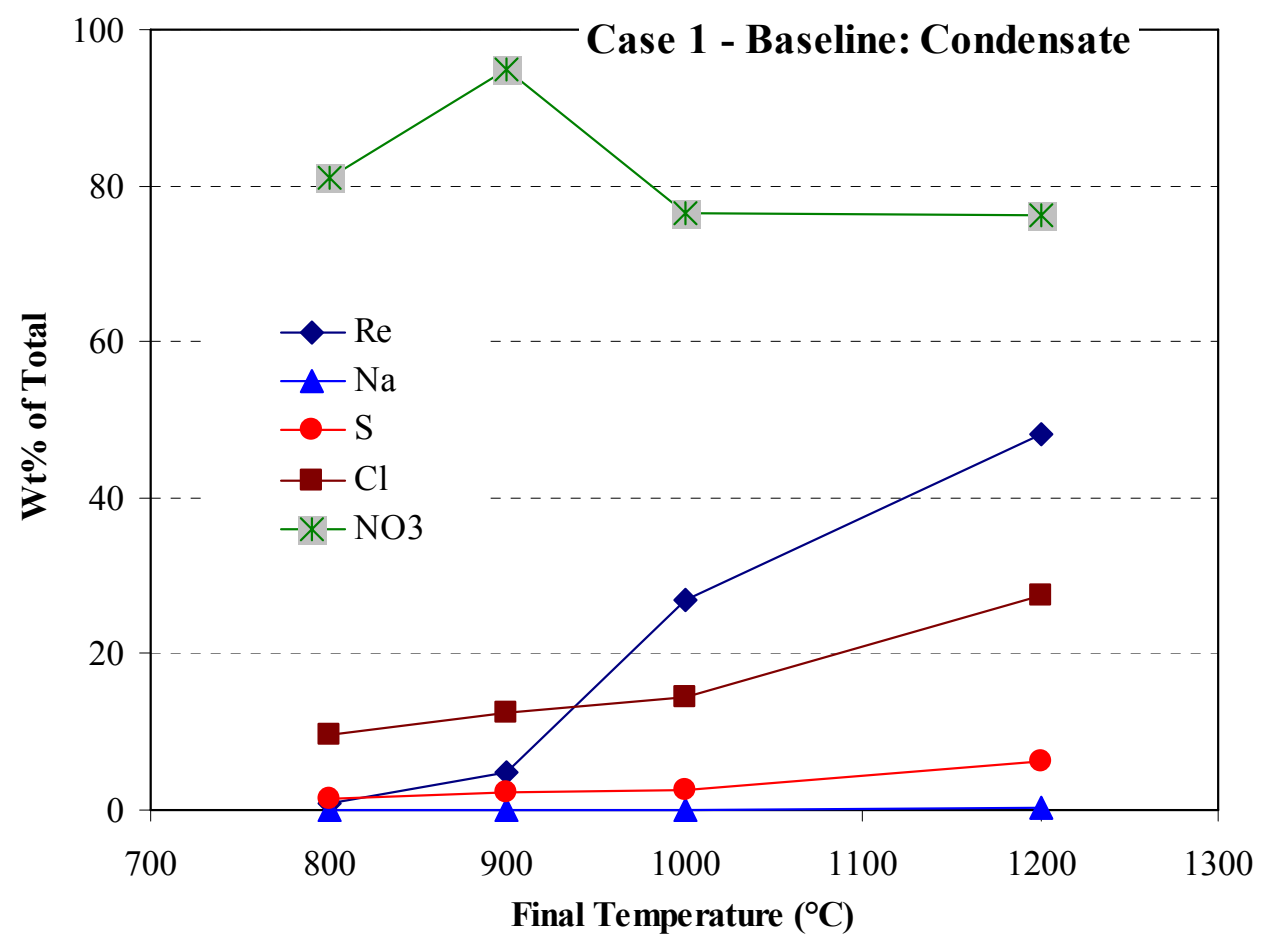

Figure 9.11. Wt\% of Total Analyzed in Condensate Solutions from Case 1 (Baseline Feed)

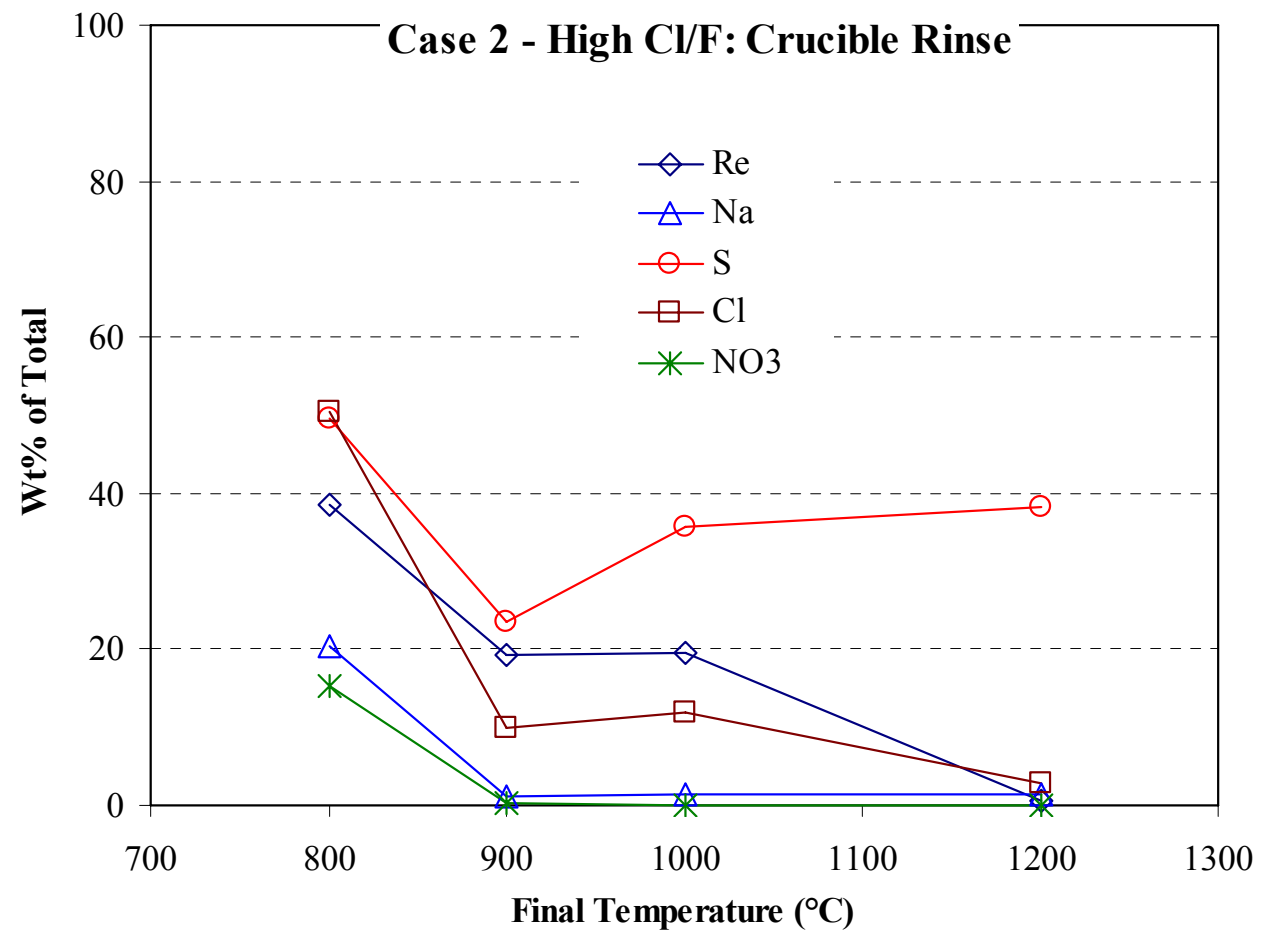

Figure 9.12. Wt\% of Total Analyzed in Crucible Rinse from Case 2 (High Cl/F Feed) 


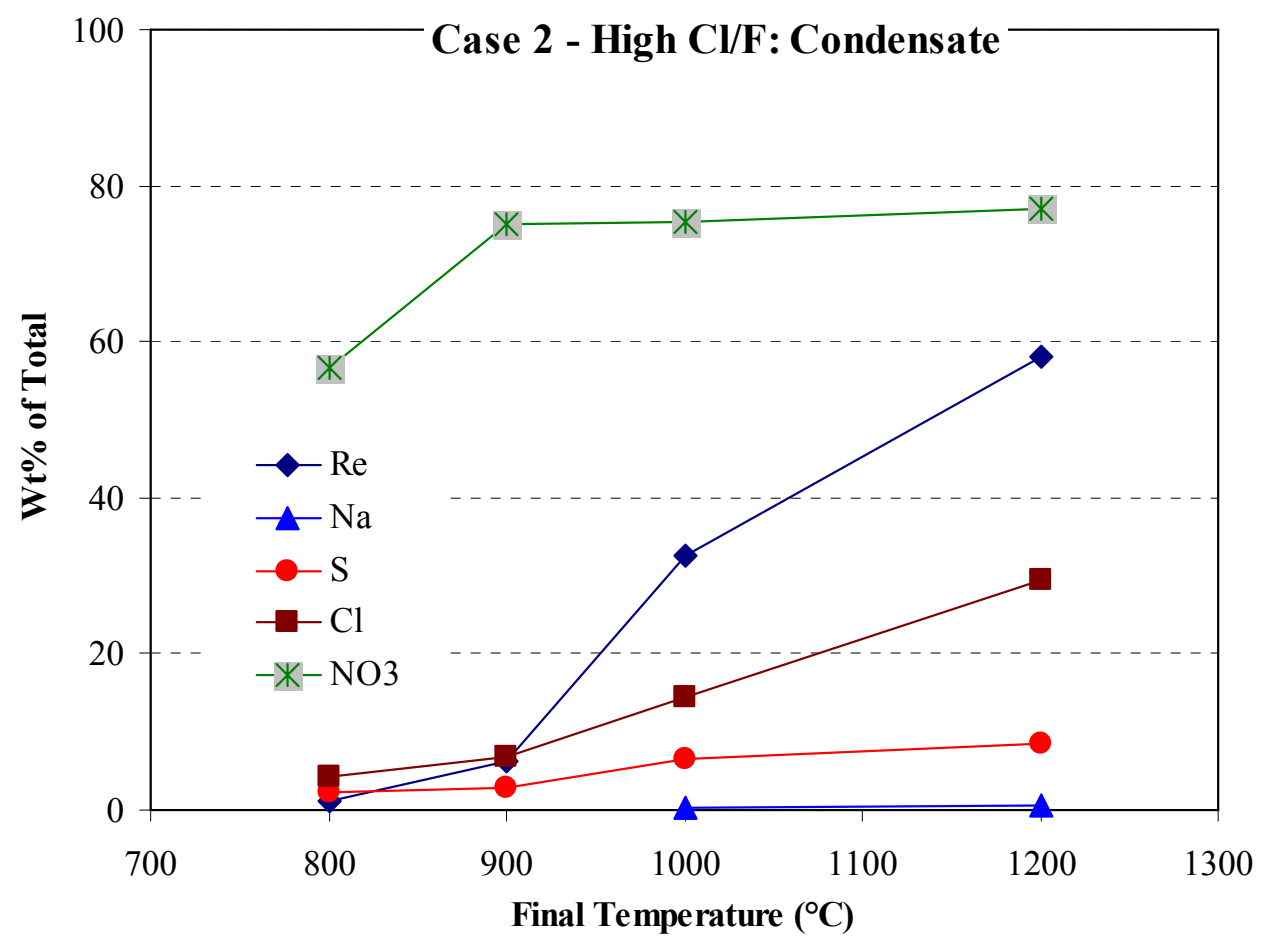

Figure 9.13. Wt\% of Total Analyzed in Condensate Solutions from Case 2 (High $\mathrm{Cl} / \mathrm{F} \mathrm{Feed)}$

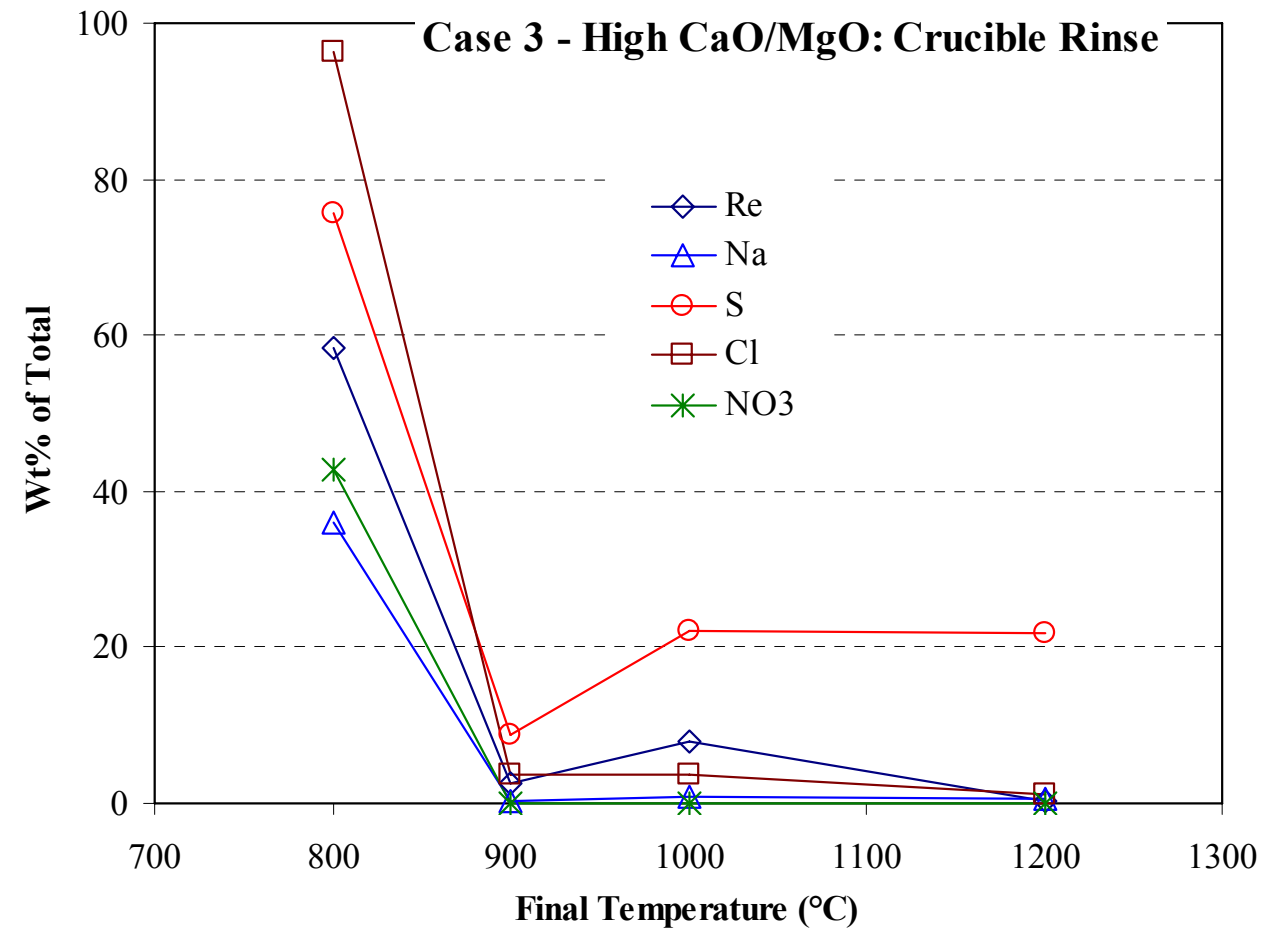

Figure 9.14. Wt\% of Total Analyzed in Crucible Rinse from Case 3 (High CaO/MgO Feed) 


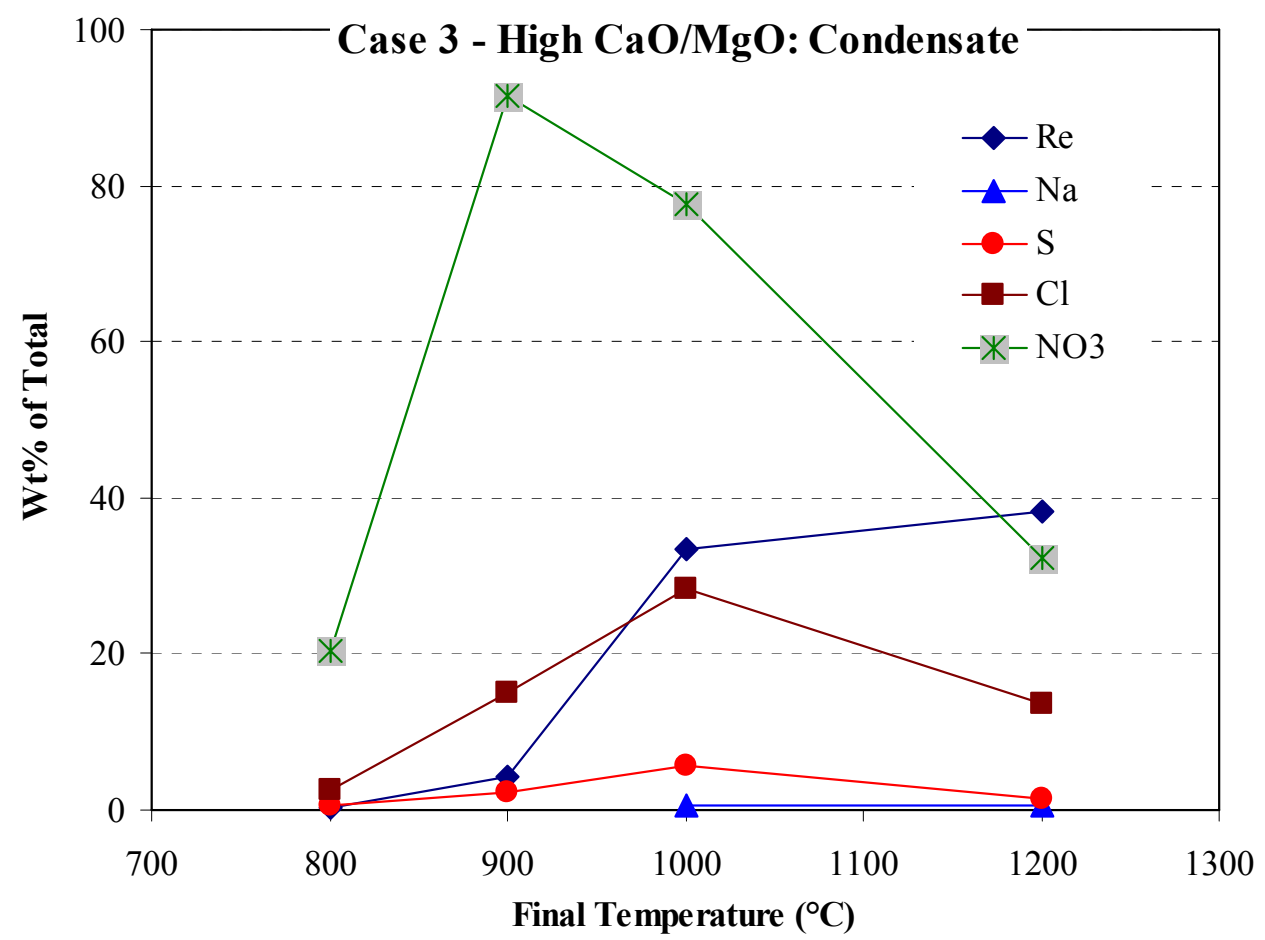

Figure 9.15. Wt\% of Total Analyzed in Condensate Solutions from Case 3 (High CaO/MgO Feed)

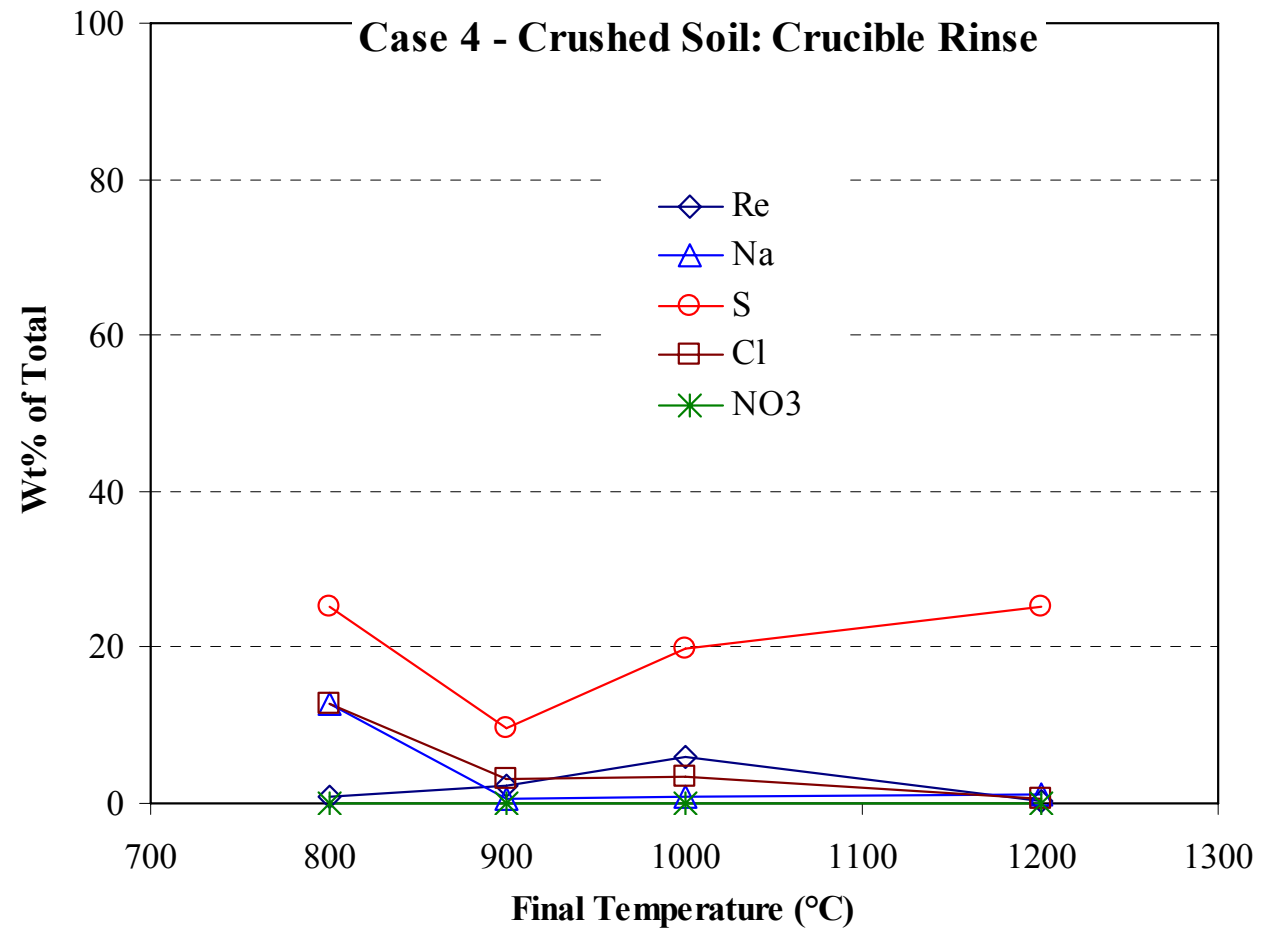

Figure 9.16. Wt\% of Total Analyzed in Crucible Rinse from Case 4 (Crushed Soil Feed) 


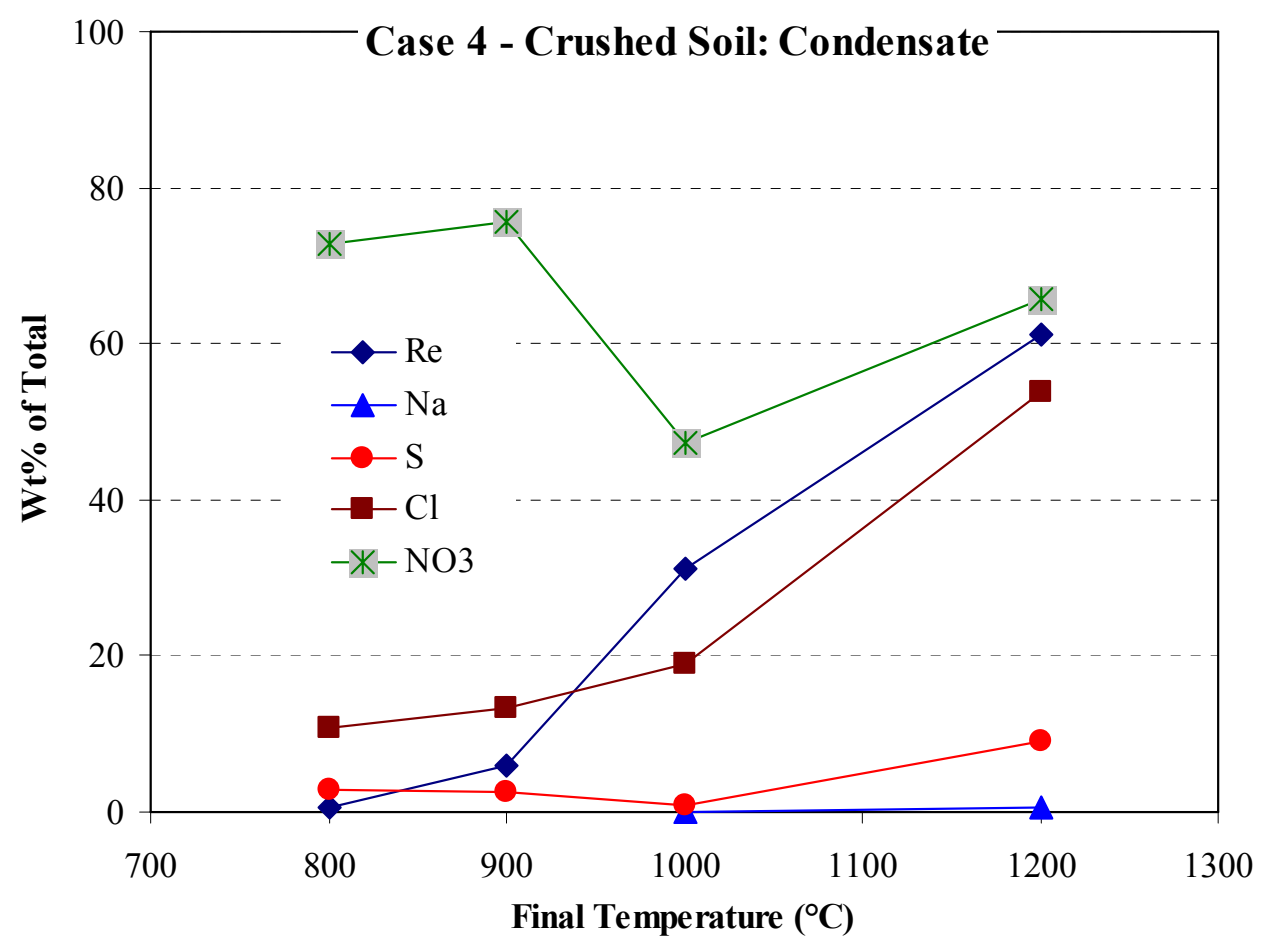

Figure 9.17. Wt\% of Total Analyzed in Condensate Solutions from Case 4 (Crushed Soil Feed)

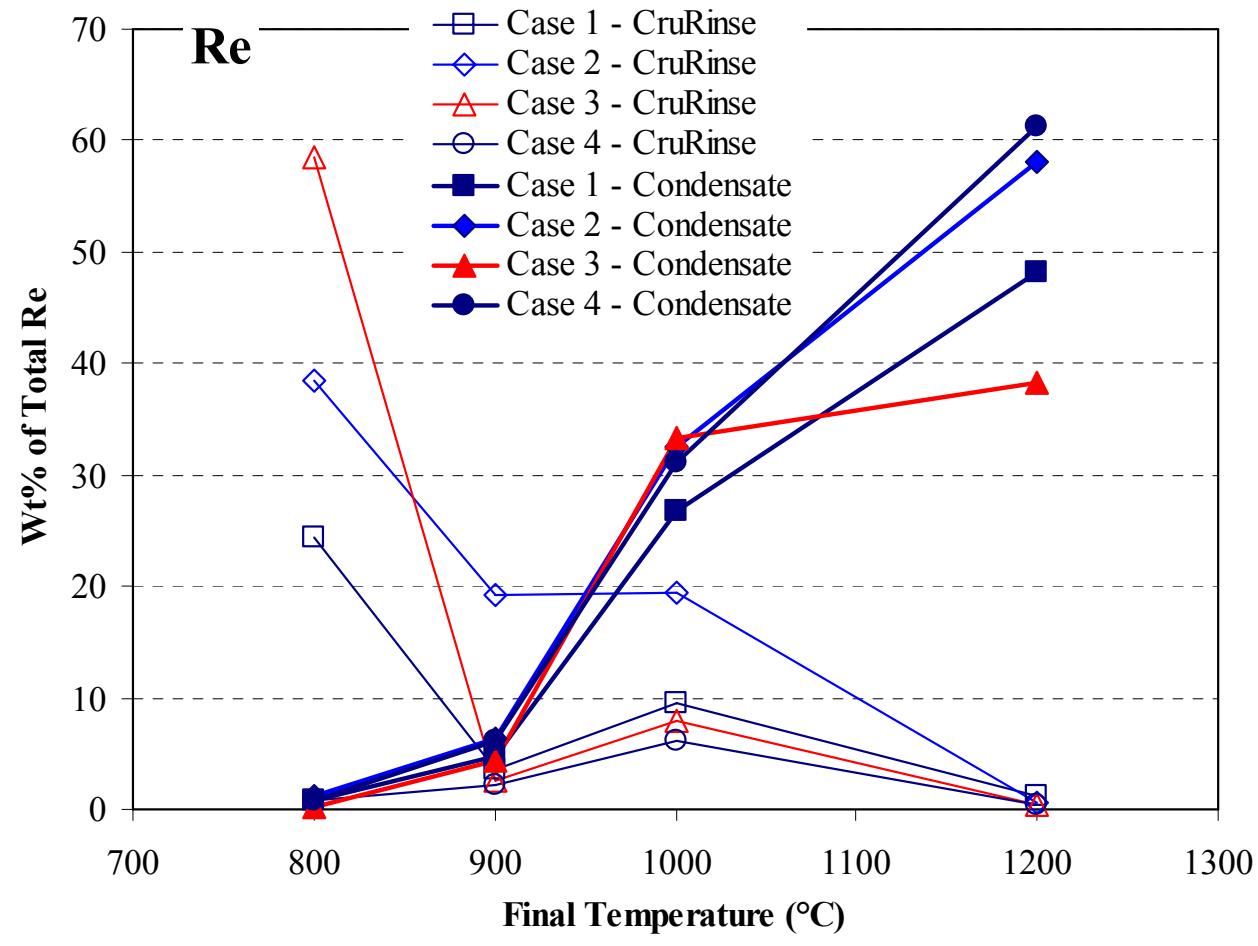

Figure 9.18. Wt\% of Total Re Analyzed in All Crucible Rinses and Condensate Solutions 


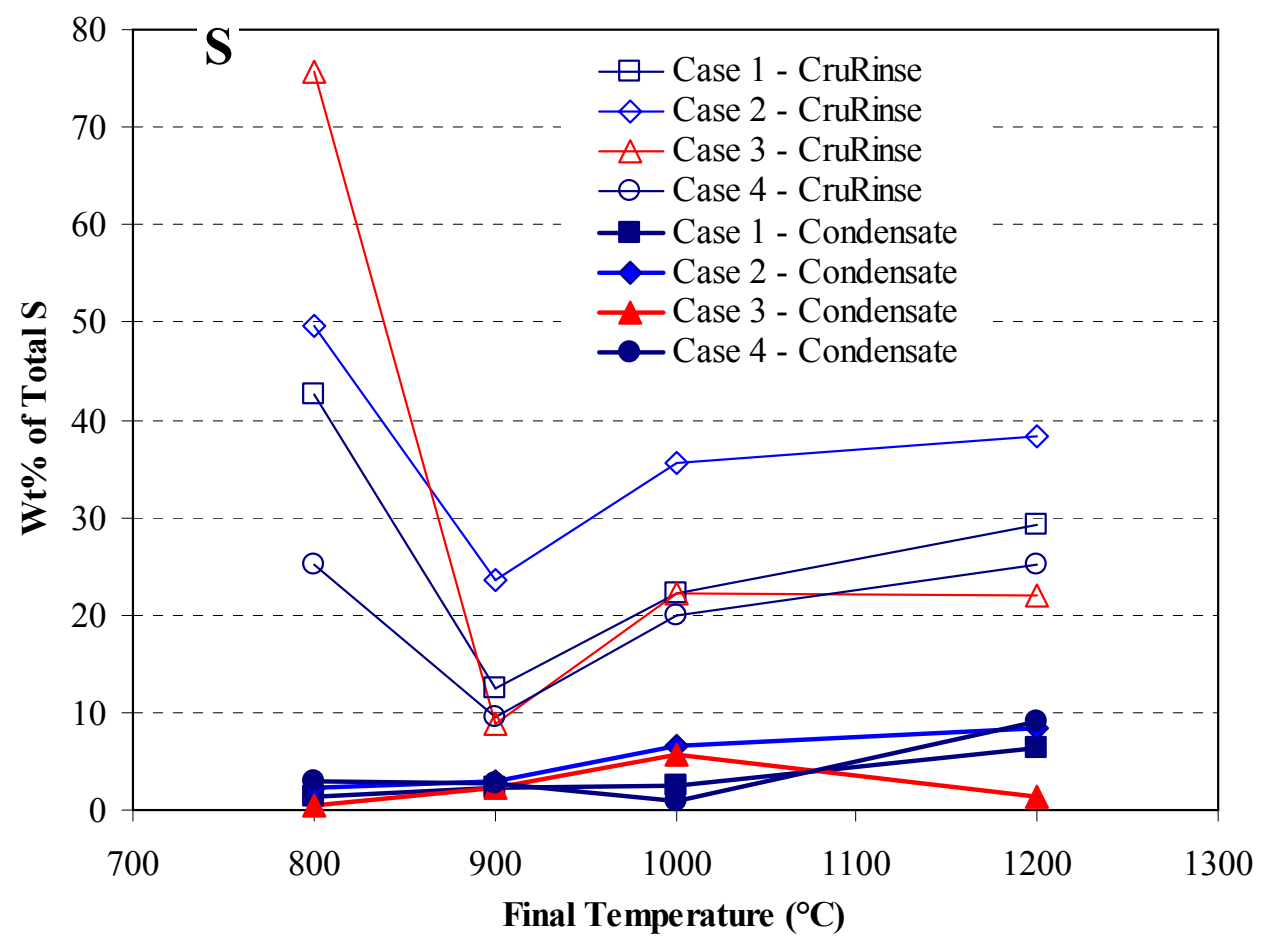

Figure 9.19. Wt\% of Total S Analyzed in All Crucible Rinses and Condensate Solutions

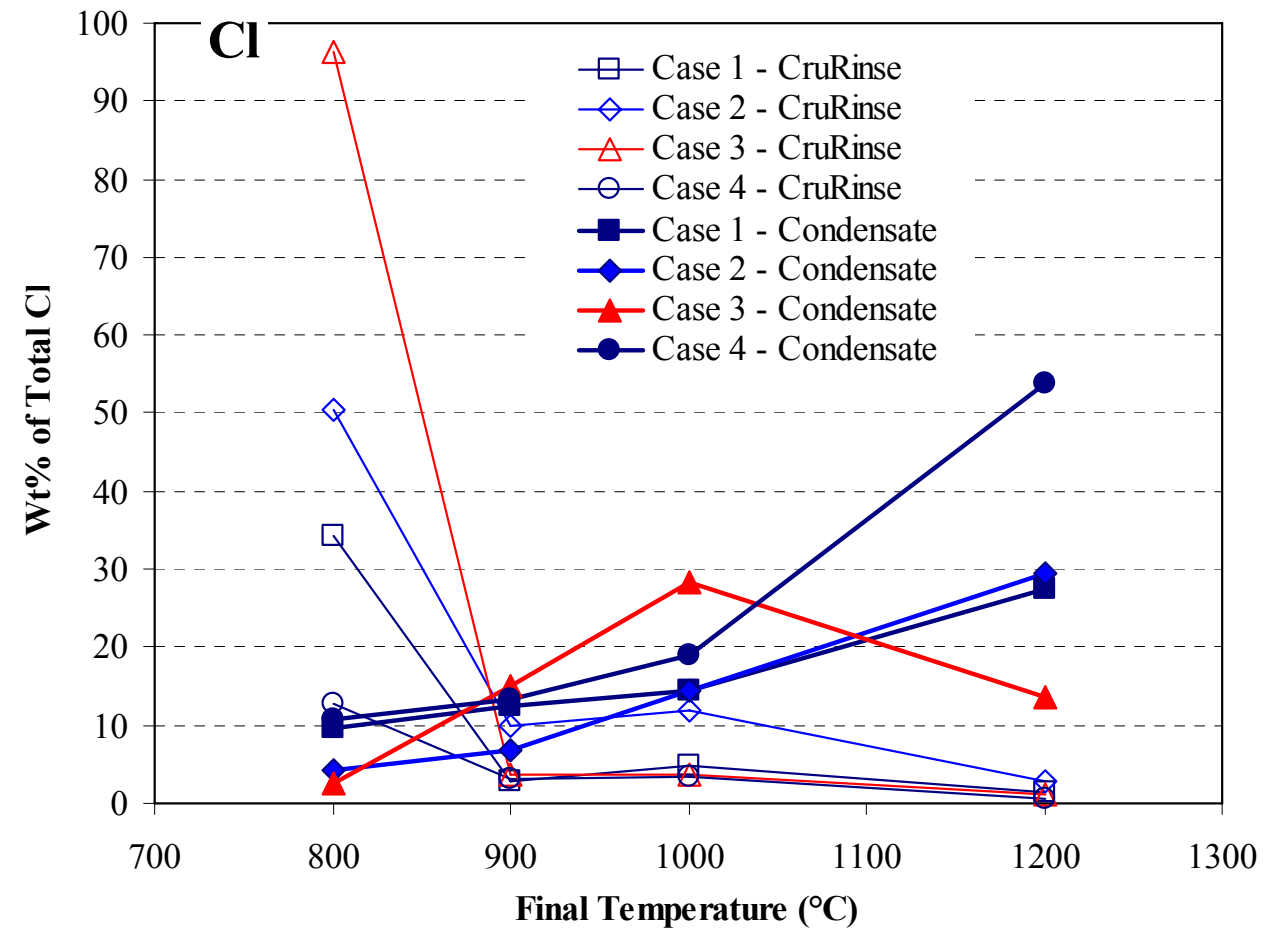

Figure 9.20. Wt\% of Total Cl Analyzed in All Crucible Rinses and Condensate Solutions 


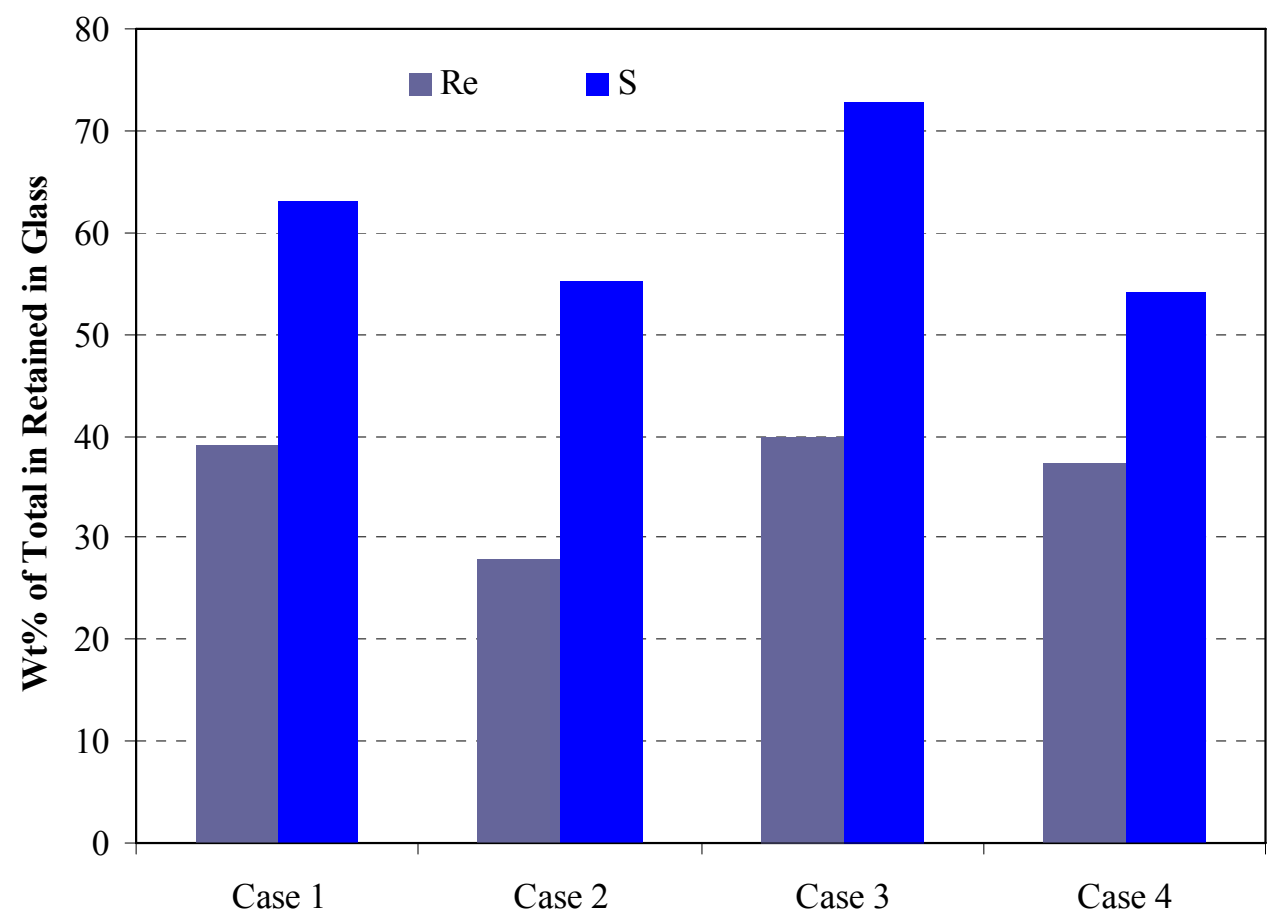

Figure 9.21. Wt\% of Total Re and S Retained in Glass Tested at $1200^{\circ} \mathrm{C}$

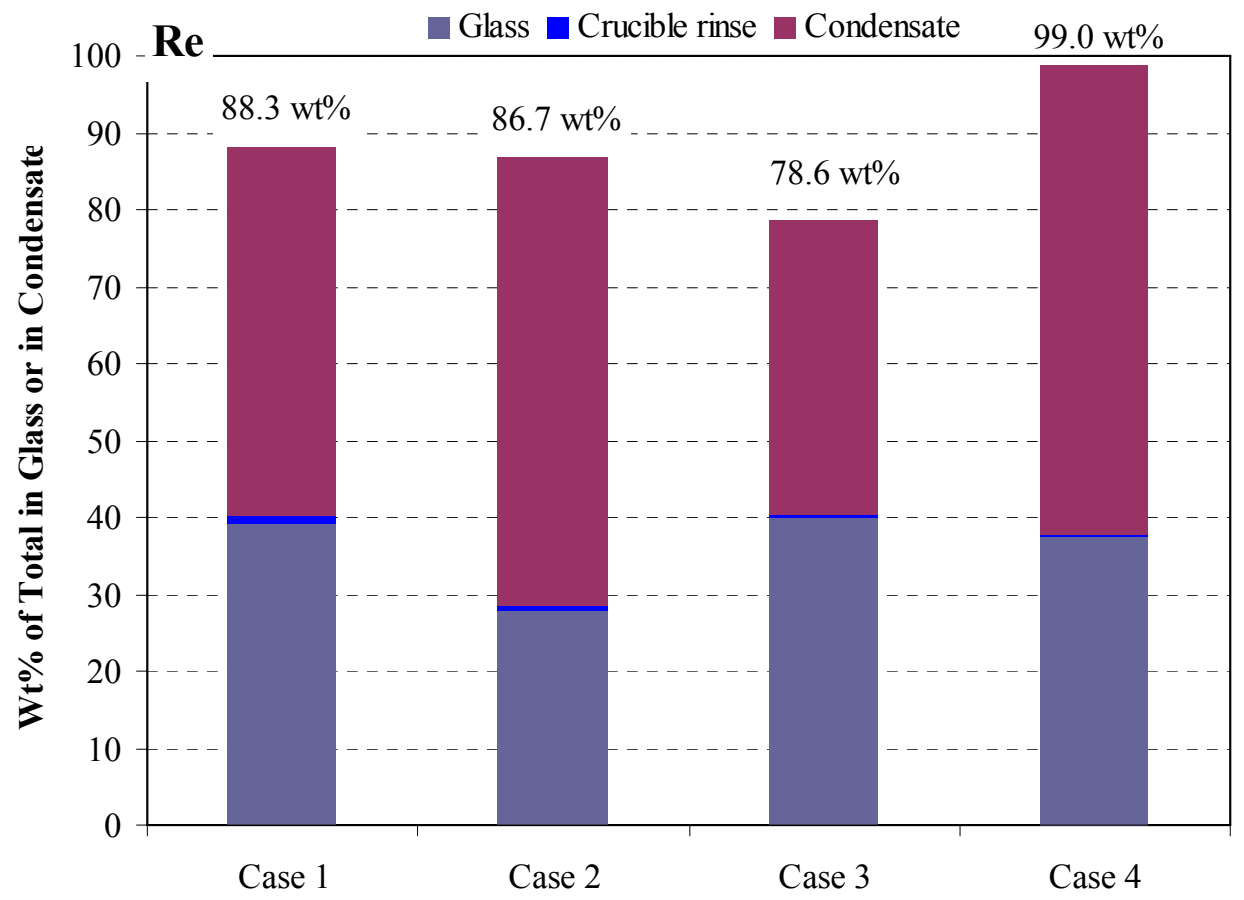

Figure 9.22. Wt\% of Total Re Retained in Glass and Analyzed in Crucible Rinse and Condensate Tested at $1200^{\circ} \mathrm{C}$ 


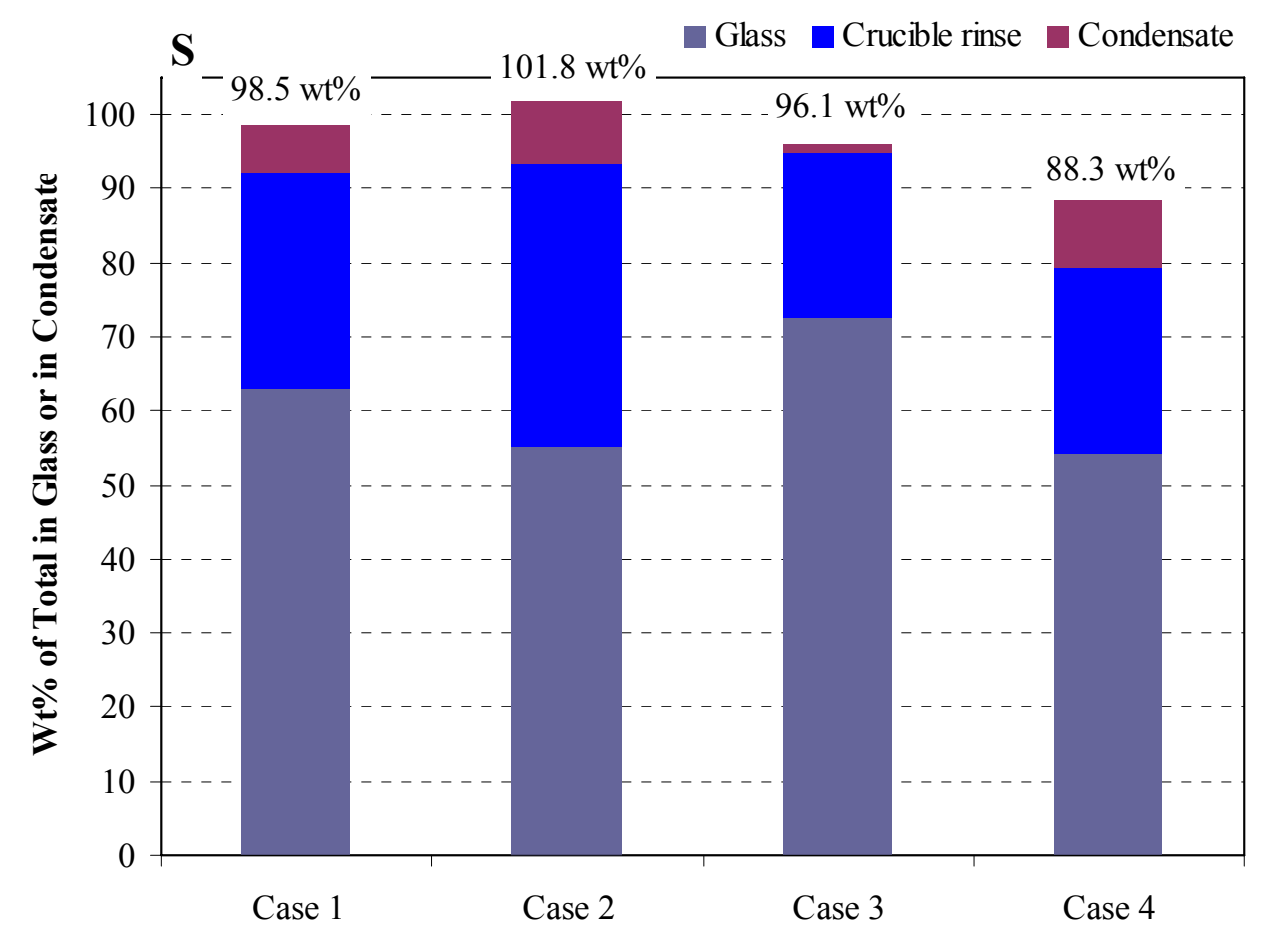

Figure 9.23. Wt\% of Total S Retained in Glass and Analyzed in Crucible Rinse and Condensate Tested at $1200^{\circ} \mathrm{C}$

\subsection{Summary}

The tests with pre-melted glass showed that $\mathrm{Re}$ is more volatile than $\mathrm{S}$ and $\mathrm{Cl}$ with an estimated $r=20.4 \mathrm{wt} \% / \mathrm{h}$ at $1200^{\circ} \mathrm{C}$. The volatilization rate of Re showed a strong dependence on temperature with an activation energy of $258 \mathrm{~J} /$ mole.

The results of dried feed (Cases 2 to 4 ) in relation to the baseline feed (Case 1) are summarized below:

- The feed with high $\mathrm{Cl}$ and $\mathrm{F}$ (Case 2) resulted in higher volatilization of Re during melting and consequently lower Re retention in glass than the baseline feed. The high $\mathrm{Cl}$ and $\mathrm{F}$ concentrations in the feed resulted in more separated salt, which is likely responsible for higher Re volatilization.

- The feed with $\mathrm{CaO}$ and $\mathrm{MgO}$ added (Case 3) resulted in comparable Re retention in glass to the baseline feed. As expected, the $\mathrm{CaO}$ and $\mathrm{MgO}$ increased $\mathrm{S}$ retention in the melt, but this did not lead to the desired increase in Re retention. The results gave some indication of lower Re volatilization, but this result is questionable because of the low Re mass balance for this feed at $1200^{\circ} \mathrm{C}$.

- The feed with crushed soil (Case 4) resulted in a comparable Re retention in the glass to the baseline feed. The crushed soil accelerated the formation of the glass-forming melt to a lower temperature, but that did not improve the Re retention in glass. The results gave some indication of higher Re volatilization, but this result is questionable because of the unusually high Re mass balance for this melt. Severe foaming observed in this melt is consistent with greater Re volatilization. Increased foaming leads to better convection and higher surface areas that might increase Re volatilization rates. 
However, foaming is a phenomenon that is exaggerated in crucible scale melts and, therefore, may not be significant in the full-scale process. 


\subsection{Incorporation of Re into Glassy Phase}

This section documents the results of tests to determine the temperature range at which the Re, initially concentrated in the MIS, incorporates into the glassy phase during the feed-melting process. This information is necessary for better understanding of the factors controlling MIS and Re migration into CRB.

\subsection{Experimental}

The dry baseline feed to make $\sim 200 \mathrm{~g}$ glass was heated from room temperature at $5^{\circ} \mathrm{C} / \mathrm{min}$ to predetermined final temperatures of $400,500,600,700,800,900$, and $1000^{\circ} \mathrm{C}$ (i.e., seven separate test runs) and air quenched. The partially reacted feed was ground into coarse particles and washed with dilute nitric acid solution following the same procedure discussed in Section 9 for preparing crucible wash samples, except that these tests used $\sim 300 \mathrm{~mL}$ instead of $200 \mathrm{~mL}$. The crucible rinse samples were analyzed for $\mathrm{Re}, \mathrm{Na}$, and $\mathrm{S}$. The remaining partially reacted feeds (solids) were ground into fine particles for homogenization, and a sample was taken for the analyses for Re, Na, and S.

\subsection{Results and Discussion}

Table 10.1 summarizes the concentration of $\mathrm{Re}, \mathrm{Na}$, and $\mathrm{S}$ analyzed in the crucible rinse and in the solids from tests with baseline feed. The results at $25^{\circ} \mathrm{C}$ are for the feed before heat treatment. Table 10.2 summarizes the mass of each element found in the crucible rinse and in the solids and total batched. The mass of each element found in the crucible rinse was obtained by multiplying the concentration in Table 10.1 with the mass of DIW used for rinse. The mass of each element found in the solids was obtained by multiplying the concentration in Table 10.1 with target mass of glass calculated from the mass of feed used in each test, based on oxide mass fraction of the feed, 0.7933 . The total batched mass of each element was calculated from the mass of feed used in each test and the target feed composition given in Table 9.6. Table 10.3 summarizes the $\mathrm{wt} \%$ of total $\mathrm{Re}, \mathrm{Na}$, and $\mathrm{S}$ analyzed in the crucible rinse and solid. Table 10.3 also includes the total wt $\%$ recovered in the combined crucible rinse and solid.

Table 10.1. Analyzed Concentration of Re, $\mathrm{Na}$, and $\mathrm{S}$ in Crucible Rinse and Solids

\begin{tabular}{||c|c|c|c|c|c|c||}
\hline \multirow{2}{*}{$\begin{array}{c}\text { Final } \\
\text { Temp }\left({ }^{\circ} \mathbf{C}\right)\end{array}$} & \multicolumn{2}{|c|}{ Crucible rinse, mg/kg } & \multicolumn{3}{c||}{ Solid, mg/kg } \\
\cline { 2 - 7 } & $\mathbf{R e}$ & $\mathbf{N a}$ & $\mathbf{S}$ & $\mathbf{R e}$ & $\mathbf{N a}$ & $\mathbf{S}$ \\
\hline 25 & 2.63 & 44600 & 1290 & 1.15 & 40300 & 579 \\
\hline 400 & 1.98 & 32750 & 942 & 0.784 & 36650 & 283 \\
\hline 500 & 1.61 & 26600 & 756 & 1.85 & 53500 & 815 \\
\hline 600 & 1.93 & 30400 & 914 & 2.09 & 65200 & 715 \\
\hline 700 & 1.85 & 25900 & 918 & 2.90 & 77800 & 906 \\
\hline 800 & 0.517 & 7740 & 384 & 6.58 & 108000 & 1860 \\
\hline 900 & 0.583 & 838 & 369 & 5.40 & 139000 & 2670 \\
\hline 1000 & 0.219 & 647 & 349 & 3.65 & 142000 & 2250 \\
\hline
\end{tabular}


Table 10.2. Mass of Re, Na, and $S$ in Crucible Rinse and Solids and Total Batched

\begin{tabular}{|c|c|c|c|c|c|c|c|c|c||}
\hline \multirow{2}{*}{$\begin{array}{c}\text { Final } \\
\text { Temp }\left({ }^{\circ} \mathbf{C}\right)\end{array}$} & \multicolumn{3}{|c|}{ Crucible Rinse } & \multicolumn{4}{c|}{ Solid } & \multicolumn{3}{c|}{ Total Batched } \\
\cline { 2 - 10 } & $\mathbf{R e}, \mathbf{m g}$ & $\mathbf{N a}, \mathbf{g}$ & $\mathbf{S}, \mathbf{g}$ & $\mathbf{R e}, \mathbf{m g}$ & $\mathbf{N a}, \mathbf{g}$ & $\mathbf{S}, \mathbf{g}$ & $\mathbf{R e}, \mathbf{m g}$ & $\mathbf{N a}, \mathbf{g}$ & $\mathbf{S}, \mathbf{g}$ \\
\hline 25 & 0.789 & 13.4 & 0.387 & 0.226 & 7.93 & 0.114 & 1.59 & 29.2 & 0.666 \\
\hline 400 & 0.594 & 9.83 & 0.283 & 0.154 & 7.20 & 0.056 & 1.59 & 29.2 & 0.665 \\
\hline 500 & 0.483 & 7.98 & 0.227 & 0.364 & 10.5 & 0.160 & 1.59 & 29.2 & 0.667 \\
\hline 600 & 0.579 & 9.12 & 0.274 & 0.411 & 12.8 & 0.141 & 1.59 & 29.2 & 0.666 \\
\hline 700 & 0.555 & 7.77 & 0.275 & 0.576 & 15.4 & 0.180 & 1.61 & 29.5 & 0.672 \\
\hline 800 & 0.155 & 2.32 & 0.115 & 1.31 & 21.4 & 0.369 & 1.61 & 29.4 & 0.672 \\
\hline 900 & 0.175 & 0.251 & 0.111 & 1.08 & 27.9 & 0.536 & 1.63 & 29.8 & 0.679 \\
\hline 1000 & 0.0657 & 0.194 & 0.105 & 0.724 & 28.2 & 0.447 & 1.61 & 29.4 & 0.672 \\
\hline
\end{tabular}

Table 10.3. Wt\% of Total Analyzed in Crucible Rinse and in Solids and Total Recovered

\begin{tabular}{|c|c|c|c|c|c|c|c|c|c||}
\hline \hline \multirow{2}{*}{$\begin{array}{c}\text { Final } \\
\text { Temp }\left({ }^{\circ} \mathbf{C}\right)\end{array}$} & \multicolumn{3}{|c|}{ Crucible rinse } & \multicolumn{3}{c|}{ Solid } & \multicolumn{3}{c|}{ Total recovered } \\
\cline { 2 - 10 } & $\mathbf{R e}$ & $\mathbf{N a}$ & $\mathbf{S}$ & $\mathbf{R e}$ & $\mathbf{N a}$ & $\mathbf{S}$ & $\mathbf{R e}$ & $\mathbf{N a}$ & $\mathbf{S}$ \\
\hline 25 & 49.51 & 45.83 & 58.09 & 14.20 & 27.16 & 17.10 & 63.71 & 73.00 & 75.19 \\
\hline 400 & 37.32 & 33.70 & 42.47 & 9.68 & 24.70 & 8.36 & 47.00 & 58.40 & 50.83 \\
\hline 500 & 30.29 & 27.32 & 34.03 & 22.84 & 36.06 & 24.07 & 53.13 & 63.38 & 58.10 \\
\hline 600 & 36.35 & 31.26 & 41.18 & 25.80 & 43.94 & 21.12 & 62.16 & 75.21 & 62.30 \\
\hline 700 & 34.51 & 26.38 & 40.97 & 35.80 & 52.44 & 26.76 & 70.32 & 78.81 & 67.72 \\
\hline 800 & 9.65 & 7.89 & 17.15 & 81.23 & 72.79 & 54.93 & 90.89 & 80.68 & 72.08 \\
\hline 900 & 10.76 & 0.84 & 16.29 & 66.67 & 93.68 & 78.85 & 77.43 & 94.53 & 95.14 \\
\hline 1000 & 4.09 & 0.66 & 15.58 & 45.06 & 95.71 & 66.45 & 49.15 & 96.36 & 82.03 \\
\hline
\end{tabular}

Figure 10.1 shows the $\mathrm{wt} \%$ of total batched $\mathrm{Re}, \mathrm{Na}$, and $\mathrm{S}$ analyzed in the crucible rinse. Figure 10.1 also includes the results from Section 9.3 for the temperature range from 800 to $1000^{\circ} \mathrm{C}$. Figure 10.2 shows the $\mathrm{wt} \%$ of total batched $\mathrm{Re}, \mathrm{Na}$, and $\mathrm{S}$ analyzed in the solid. Figure 10.3 plots the $\mathrm{wt} \%$ of total batched $\mathrm{Re}, \mathrm{Na}$, and $\mathrm{S}$ recovered in the crucible rinse and solid together.

Because no measurable volatilization is expected below $800^{\circ} \mathrm{C}$ based on the results in Section 9.3, it is expected that the total $\mathrm{wt} \%$ of total batched elements recovered in this series of tests should be close to $100 \%$. However, as seen in Figure 10.3, the total $\mathrm{wt} \%$ recovered is very low, indicating significant loss of materials. One of the likely sources of loss is that the present tests used two or three DIW wash steps after the crucible rinse before analyzing solid samples. These wash steps were performed to prevent the soluble components, which remained in the residual dilute acid leach solution that did not drain from the solid particles, from being included in the solids. However, the DIW wash process could also dissolve additional soluble components that were not captured in the initial dilute nitric acid leach, especially for lower temperature tests. The low total recovery shown in Figure 10.3 suggests that the latter was the case. A better overall mass balance may have been obtained if the leached solids were dried without rinsing, or if rinse solutions were collected and analyzed. Therefore, these tests give a good indication of the extent of $\mathrm{Re}, \mathrm{S}$, and $\mathrm{Cl}$ incorporation into the solid phase, but they provide a poor overall mass balance. Note that similar issues were not discovered in Section 9 because solid samples were analyzed only from $1200^{\circ} \mathrm{C}$ tests that have distinct and fully separated soluble and durable glass phases. 
Figure 10.1 shows that the as-dried feed $\left(25^{\circ} \mathrm{C}\right.$ test $)$ dissolved only $\sim 50 \%$ of the soluble Re during the crucible rinse. The soluble $\mathrm{Re}, \mathrm{Na}$, and $\mathrm{S}$ in general decreased as the temperature increased with a rather sudden change between 700 and $800^{\circ} \mathrm{C}$. They all followed the same general trend up to $800^{\circ} \mathrm{C}$, and $\mathrm{Na}$ disappeared at $900^{\circ} \mathrm{C}$, suggesting that almost complete decomposition of sodium nitrate occurred as discussed in Section 9. There was a significant discrepancy between the two sets of results for the tests from 800 to $1000^{\circ} \mathrm{C}$, although the only experimental difference was in the amount of dilute nitric acid used in the rinsing operation. The source of this discrepancy is not understood. Although there is a quantitative disagreement, the following two qualitative observations hold true: 1) Re is contained in the sulfate salt at temperatures between 800 and $1000^{\circ} \mathrm{C}$, and 2) significant volatilization begins only at $1000^{\circ} \mathrm{C}$ as discussed in Section 9.

Figure 10.2 shows that the wt $\%$ of $\mathrm{Re}, \mathrm{Na}$, and $\mathrm{S}$ retained in the solid phase all increased in parallel up to $700^{\circ} \mathrm{C}$, and then (1) Na increased to reach $>90 \mathrm{wt} \%$ at $900^{\circ} \mathrm{C}$, which agrees well with the crucible rinse results, (2) the Re and S sharply increased as more Re and S was incorporated into the glass-forming melt. However, Re was incorporated into the glass earlier between 700 and $800^{\circ} \mathrm{C}$ while $\mathrm{S}$ increased up to $900^{\circ} \mathrm{C}$. The decrease of Re between 800 and $1000^{\circ} \mathrm{C}$ was likely a result of volatilization enhanced by convection. It is also possible that some salt inclusions embedded in the glassy phase coalesced as a separated salt phase as melting progressed. The present results are inconclusive and suggest that microscopic observations of the partially melted feed by SEM may improve the understanding of the Re volatilization mechanism.

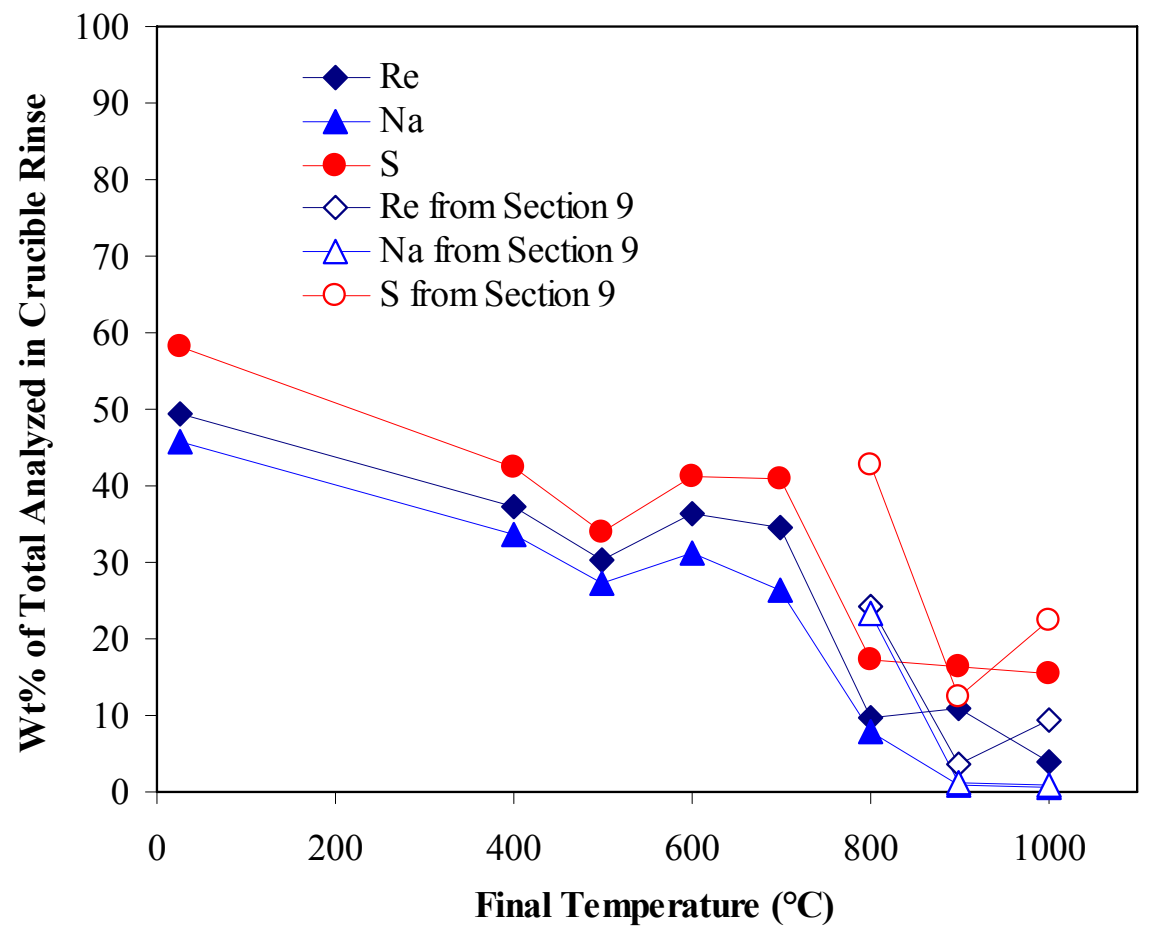

Figure 10.1. Wt\% of Total Batched Re, Na, and $S$ Analyzed in Crucible Rinse 


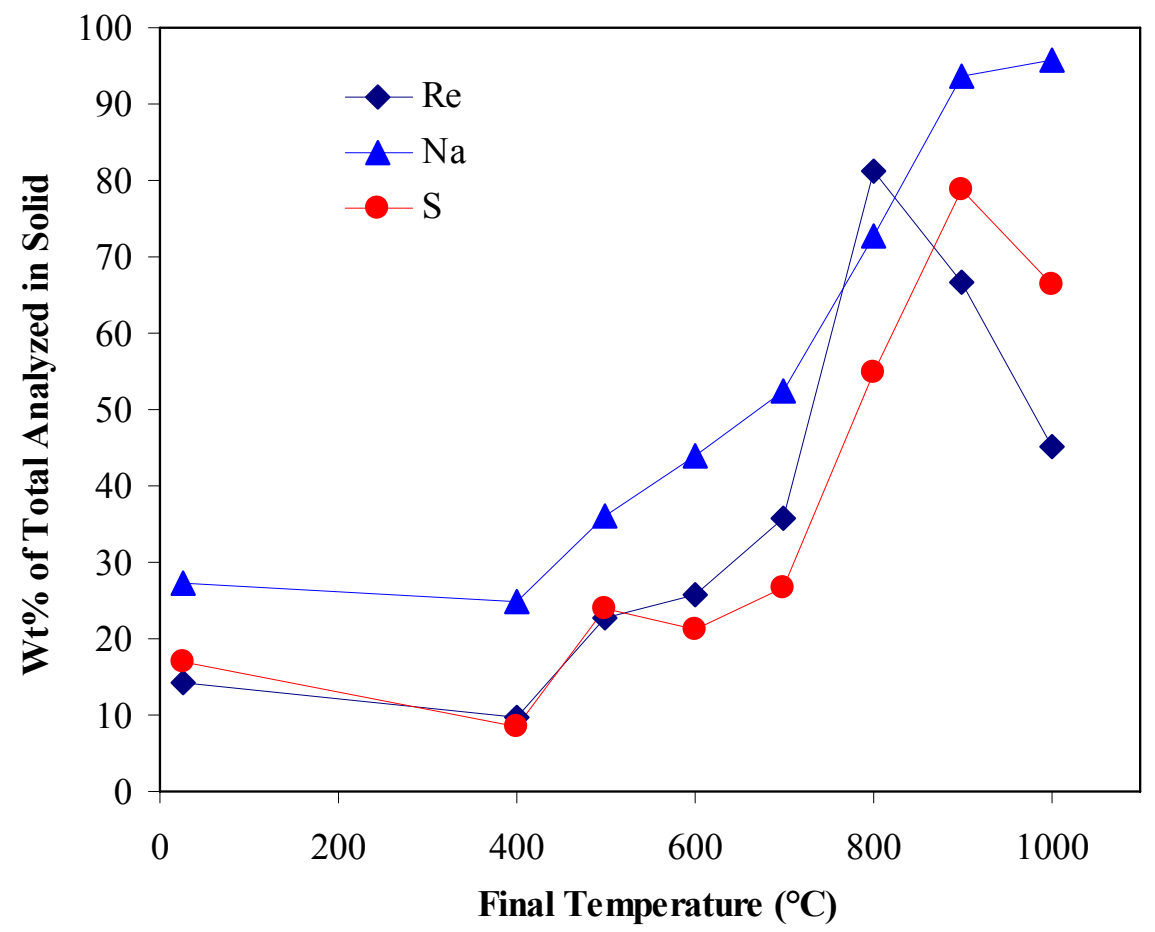

Figure 10.2. Wt\% of Total Batched Re, Na, and S Analyzed in Solid

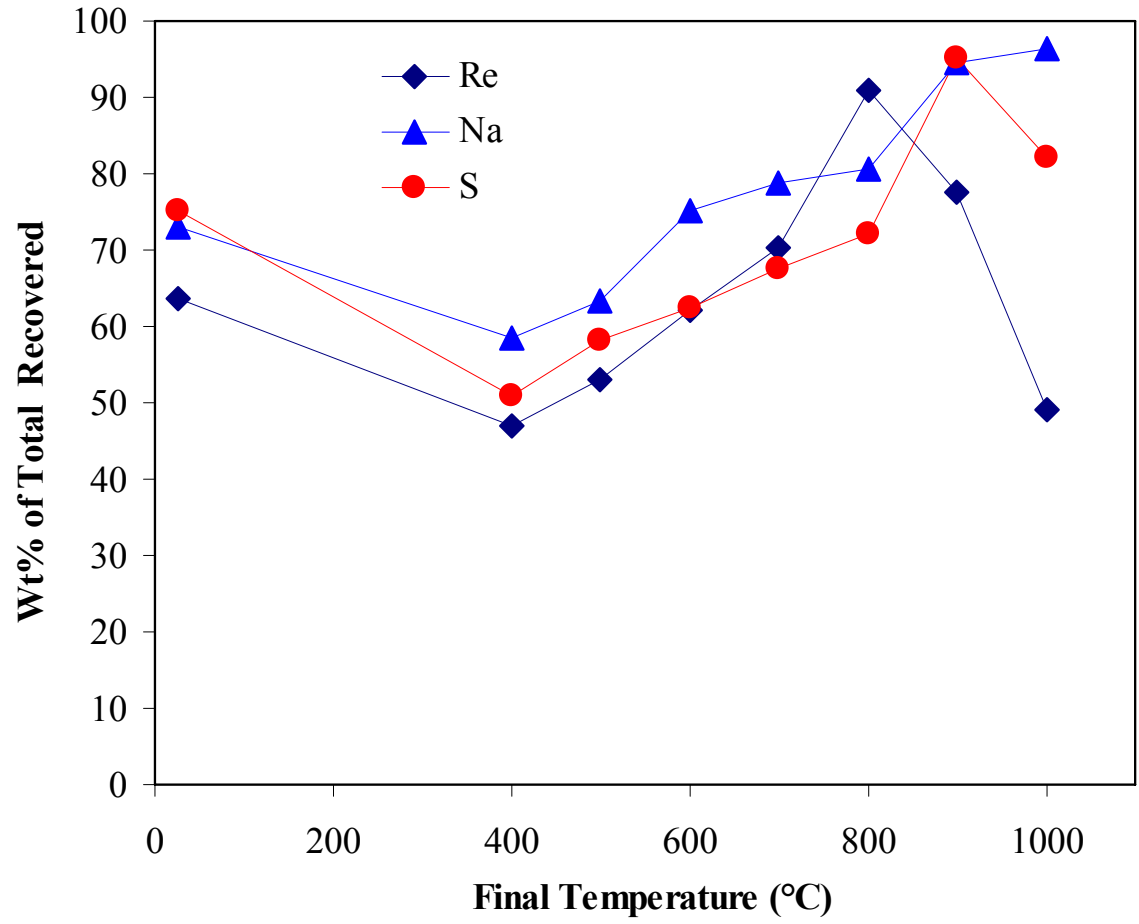

Figure 10.3. Sum of Wt\% of Total Batched Re, Na, and S Recovered in Crucible Rinse and Solid 


\subsection{Summary}

The Re was incorporated into a glass forming melt at approximately $700^{\circ} \mathrm{C}$, and the incorporation of $\operatorname{Re}$ in the glass-forming melt reached a maximum at $\sim 800^{\circ} \mathrm{C}$ and then decreased as the temperature increased up to $1000^{\circ} \mathrm{C}$. The rather sharp decrease of Re present in the glass-forming melt between 800 and $1000^{\circ} \mathrm{C}$ may suggest that the decrease of Re was not solely from volatilization from the glass-forming melt, but may have been partly caused by partitioning to small salt inclusions that coalesced to form a separated salt phase at higher temperatures.

The poor mass balance closure at low temperatures for the present Re incorporation tests was likely caused by multiple steps of DIW washes performed after the crucible rinse, which seemed to dissolve additional soluble components that were not captured in the initial dilute nitric acid wash. A better overall mass balance can be obtained if the washed solids are dried without additional rinsing, or if rinse solutions are collected and analyzed. 


\subsection{Conclusions}

Water and MIS capillary experiments confirmed that suction of MIS into CRB through capillary forces can be a dominant mechanism for MIS penetration. This conclusion was supported by the preliminary modeling results, which suggested that the MIS penetration process is completely dominated by capillary action, and neither the MIS layer thickness nor any other scaled parameter has a significant effect. The effective capillary radius in the castable refractory was estimated as $1.7 \mathrm{~nm}$ from the experiment with water.

Hot-stage microscopy was proven useful for detailed observation of the feed-melting and liquid-formation processes. Hot-stage observations show that the behavior of a dry blended feed and a feed prepared from liquid simulant are significantly different. A dry blended feed seemed to form a higher fraction of liquid than a feed prepared from liquid simulant, which could cause an increase in MIS migration into CRB. This may suggest that the information obtained in the full-scale tests conducted with dry blended feed may need to be verified with drier prepared feed in future operations.

Thin-section profile measurements with FS-38B CRB samples provided new information on how the MIS and Re penetrate as the melt progresses. For the CRB samples above the melt line and at the melt line, soluble Re is present only up to $\sim 2 \mathrm{~cm}$ from the glass interface. For the CRB above the melt line, $\operatorname{Re}$ penetrates into $\mathrm{CRB}$ by a vapor disposition mechanism, i.e., Re deposits when the CRB is cold, becomes molten as temperature increases, and then penetrates further into the CRB by capillary action. The extent of penetration and the concentration of Re above the melt line are small. For the CRB at the melt line, Re penetrates into the CRB through both vapor deposition at the early stages of processing and then liquid MIS formation and penetration at later processing stages. The CRB at the melt line close to the glass interface had the highest soluble Re concentration. For the CRB below the melt line, a relatively low concentration of soluble Re was present on the surface layer whereas a higher concentration of soluble $\mathrm{Re}$ was observed in the outer layer close to the $\mathrm{CRB} /$ sand interface. Insoluble Re at a higher concentration than the blank level was observed only in the first 0- to 1-cm layer of the CRB at the melt line. The below melt line results indicate that regions of the CRB that experienced Re penetration through MIS migration early in the process that were subsequently covered by the progressing melt did not incorporate the Re in an insoluble melt phase, but instead pushed the Re salt outward through evaporation and/or melting and flow of molten salt.

The new experimental setup developed in this study to investigate Re migration during feed processing and glass melting was successful in achieving a high mass balance closure. The new setup was designed to capture all the volatiles by condensing them inside a stainless steel tube or dissolving them in a pair of scrub solutions. The tests with pre-melted glass showed that $\mathrm{Re}$ is more volatile than $\mathrm{S}$ and $\mathrm{Cl}$ with an estimated $r=20.4 \mathrm{wt} \% / \mathrm{h}$ at $1200^{\circ} \mathrm{C}$. The volatilization rate of Re also showed a strong dependence on temperature with an activation energy of $258 \mathrm{~J} /$ mole.

The results of dried feed Cases 2 to 4 in relation to the baseline feed (Case 1) are summarized below:

- The feed with high $\mathrm{Cl}$ and $\mathrm{F}$ (Case 2) resulted in higher volatilization of Re during melting and consequently lower Re retention in glass than the baseline feed. The high $\mathrm{Cl}$ and $\mathrm{F}$ concentrations in the feed resulted in more separated salt, which is likely responsible for higher Re volatilization. 
- The feed with $\mathrm{CaO}$ and $\mathrm{MgO}$ added (Case 3) resulted in comparable Re retention in glass to the baseline feed. As expected, the $\mathrm{CaO}$ and $\mathrm{MgO}$ increased $\mathrm{S}$ retention in the melt, but this did not lead to the desired increase in Re retention. The results gave some indication of lower Re volatilization, but this result is questionable because of the low Re mass balance for this feed at $1200^{\circ} \mathrm{C}$.

- The feed with crushed soil (Case 4) resulted in a comparable Re retention in the glass to the baseline feed. The crushed soil accelerated the formation of the glass-forming melt to a lower temperature, but that did not improve the Re retention in glass. The results gave some indication of higher $\mathrm{Re}$ volatilization, but this result is questionable because of the unusually high Re mass balance for this melt. Severe foaming observed in this melt is consistent with greater Re volatilization. Increased foaming leads to better convection and higher surface areas that might increase Re volatilization rates. However, foaming is a phenomenon that is exaggerated in crucible scale melts and, therefore, may not be significant in the full-scale process.

From the study of Re incorporation, it was found that the Re becomes incorporated into glass-forming melt at approximately $700^{\circ} \mathrm{C}$, reaches a maximum at $\sim 800^{\circ} \mathrm{C}$, and then decreases as the temperature increases up to $1000^{\circ} \mathrm{C}$. The rather sharp decrease of Re present in glass-forming melt between 800 and $1000^{\circ} \mathrm{C}$ may suggest that the decrease of Re is not solely from volatilization from glass-forming melt, but may be partly caused by partitioning to small salt inclusions that coalesce to form a separated salt phase at higher temperatures.

The present study has focused on two routes of Re (used as a surrogate for Tc) transport to the outside of the bulk glass: (1) to the offgas stream through volatilization and (2) to the CRB through MIS penetration by capillary action. The Re is a highly volatile component, and its volatilization will even be enhanced by the presence of other volatile components such as $\mathrm{Cl}$ and F. Due to its inherent nature of high volatility, it seems that there is no simple effective solution except for the application of a cold cap that condenses the volatiles and brings them back to the feed to maximize their retention in glass. The thicker cold cap and lower plenum temperature would help to incorporate more Re into glass.

Using clean glass feed would help to capture the Re volatilized from melting waste-containing feed and incorporate it into the glass at the end of the bulk vitrification process. However, once the clean glass becomes melted and mixed into the main body of the melt, the Re-containing melt will become exposed to the surface. The volatilization of Re also proceeds at a relatively high rate from a melt that has already incorporated the Re. The Re can escape relatively easily from the surface as the temperature increases at the end of the process. Therefore, it is important to find the optimal heating condition at the end of the process to fully melt the clean glass feed to a reasonably durable glassy phase (because the partially melted feed may contain the volatilized Re that is soluble), but not to overheat, which would expose the hot-glass surface to volatilization.

As discussed in Section 7.0, the main mechanism of Tc transport to the CRB is penetration of MIS. The contribution of volatilization and condensation of Re to the total Re migration into CRB seems to be very small compared to MIS penetration. Using a cold cap, although very critical to control Re volatilization, is likely to promote MIS penetration into the CRB by providing the condition to increase the MIS formation: the cold cap helps to keep the feed at the temperatures favored for MIS formation (e.g., 350 to $550^{\circ} \mathrm{C}$ ) for a longer time. A few promising methods to reduce the MIS migration have been identified and are being tested in a crucible scale under Task 30, which will be described in a separate report. Depending on the effectiveness of the methods developed under Task 30, the balance between the 
transport of Re to offgas and to the $\mathrm{CRB}$ can be made by controlling the formation of the cold cap during the bulk vitrification process. 


\subsection{References}

Cooley SK, EM Pierce, LM Bagaasen, and MJ Schweiger. 2006. Analysis of Soluble Rhenium Concentrations in the Refractory from Bulk Vitrification Full-Scale Test 38B. PNNL-15868, Pacific Northwest National Laboratory, Richland, WA.

Gale WF, and TC Totemeier. 2004. Smithells Metals Reference Book ( $8^{\text {th }}$ Edition). Elsevier. Available at: http://www.knovel.com/knovel2/Toc.jsp?BookID=717. Accessed 11-21-2006.

Hrma P, J Matyas, LM Bagaasen, KBC Minister, AE Beck, MJ Schweiger, TM Brouns, DM Strachan, DD Caldwell, BP Tinsley, ML Elliott, and GW Hollenberg. 2005. Bulk Vitrification Castable Refractory Block Protection Study. PNNL-15193, Pacific Northwest National Laboratory, Richland, WA.

Kim D, JD Vienna, P Hrma, MJ Schweiger, J Matyas, JV Crum, DE Smith, WC Buchmiller, JS Tixier, Jr., JD Yeager, and KB Belew. 2003. Development and Testing of ICV Glasses for Hanford LAW. PNNL-14351, Pacific Northwest National Laboratory, Richland, WA.

Kim D-S, CZ Soderquist, JP Icenhower, BP McGrail, RD Scheele, BK McNamara, LM Bagaasen, MJ Schweiger, JV Crum, JD Yeager, J Matyáš, LP Darnell, HT Schaef, AT Owen, AE Kozelisky, LA Snow, and MJ Steele. 2005. Tc Reductant Chemistry and Crucible Melting Studies with Simulated Hanford Low-Activity Waste. PNNL-15131, Pacific Northwest National Laboratory, Richland, WA.

Mann FM, BP McGrail, DH Bacon, RJ Serne, KM Krupka, RJ Puigh, R Khaleel, and S Finfock. 2003. Risk Assessment Supporting the Decision on the Initial Selection of Supplemental ILAW Technologies. RPP-17675, Rev 0, CH2M HILL Hanford Group, Inc., Richland, WA.

Pierce EM, BP McGrail, LM Bagaasen, EA Rodriguez, DM Wellman, KN Geizler, SR Baum, LR Reed, JV Crum, and HT Schaef. 2005. Laboratory Testing of Bulk Vitrified Low-Activity Waste Forms to Support the 2005 Integrated Disposal Facility Performance Assessment. PNNL-15126, Pacific Northwest National Laboratory, Richland, WA.

Rassat SD, LA Mahoney, RL Russell, SA Bryan, and RL Sell. 2003. Cold Dissolved Saltcake Waste Simulant Development, Preparation, and Analysis. PNNL-14194 Rev.1, Pacific Northwest National Laboratory, Richland, WA.

Raymond RE, RW Powell, DW Hamilton, WA Kitchen, BM Mauss, and TM Brouns. 2004. "Initial Selection of Supplemental Treatment Technologies for Hanford's Low-Activity Tank Waste." In: Proceedings of WM'04 Symposia. WM-4524/RPP-19763-FP, CH2M HILL Hanford Group, Inc. Richland, WA.

Vienna JD, P Hrma, WC Buchmiller, and JS Ricklefs. 2004. Prelimianry Investigation of Sulfur Loading in Hanford LAW Glass. PNNL-14649, Pacific Northwest National Laboratory, Richland, WA.

Washburn EW. 1921. “The dynamics of capillary flow.” Physical Review 17(3):273-283. 
Whitehead, JB and EW Greenfield. 1932. "Capillary action in impregnated paper insulation.” Physics 3:324-330. 


\subsection{Technical Procedure}

GDL-GBM, Rev. 3. 2002. Glass Batching and Melting. Pacific Northwest National Laboratory, Technical Procedure. 